\title{
A case study of the expatriate boundary spanning role
}

By

Karen L. Johnson, M.M.S.

A thesis submitted to

the Faculty of Graduate Studies and Research

in partial fulfilment of

the requirements for the degree of

Doctor of Philosophy, Management

Sprott School of Business

Carleton University

Ottawa Ontario

(C) copyright Karen L. Johnson, 2007 


$\begin{array}{ll}\begin{array}{l}\text { Library and } \\ \text { Archives Canada }\end{array} & \begin{array}{l}\text { Bibliothèque et } \\ \text { Archives Canada }\end{array} \\ \begin{array}{l}\text { Published Heritage } \\ \text { Branch }\end{array} & \begin{array}{l}\text { Direction du } \\ \text { Patrimoine de l'édition }\end{array} \\ \begin{array}{l}\text { 395 Wellington Street } \\ \text { Ottawa ON K1A ON4 }\end{array} & \begin{array}{l}\text { 395, rue Wellington } \\ \text { Ottawa ON K1A ON4 } \\ \text { Canada }\end{array}\end{array}$

Your file Votre référence ISBN: 978-0-494-33494-2 Our file Notre référence ISBN: 978-0-494-33494-2

NOTICE:

The author has granted a nonexclusive license allowing Library and Archives Canada to reproduce, publish, archive, preserve, conserve, communicate to the public by telecommunication or on the Internet, loan, distribute and sell theses worldwide, for commercial or noncommercial purposes, in microform, paper, electronic and/or any other formats.

The author retains copyright ownership and moral rights in this thesis. Neither the thesis nor substantial extracts from it may be printed or otherwise reproduced without the author's permission.
AVIS:

L'auteur a accordé une licence non exclusive permettant à la Bibliothèque et Archives Canada de reproduire, publier, archiver, sauvegarder, conserver, transmettre au public par télécommunication ou par l'Internet, prêter, distribuer et vendre des thèses partout dans le monde, à des fins commerciales ou autres, sur support microforme, papier, électronique et/ou autres formats.

L'auteur conserve la propriété du droit d'auteur et des droits moraux qui protège cette thèse. $\mathrm{Ni}$ la thèse ni des extraits substantiels de celle-ci ne doivent être imprimés ou autrement reproduits sans son autorisation.
In compliance with the Canadian

Privacy Act some supporting forms may have been removed from this thesis.

While these forms may be included in the document page count, their removal does not represent any loss of content from the thesis.
Conformément à la loi canadienne sur la protection de la vie privée, quelques formulaires secondaires ont été enlevés de cette thèse.

Bien que ces formulaires aient inclus dans la pagination, il n'y aura aucun contenu manquant.

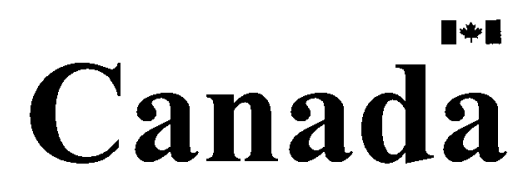




\begin{abstract}
Organizations managing international operations face the challenge of adapting to dispersed and often uncertain task environments. Macro-level theory maintains that under conditions of uncertainty organizations adapt by increasing their linkages with the external environment to exert control over external players and exchange resources needed to ensure viability in shifting environments. Conceptually, these "linkages" occur at inter-organizational boundaries, where cross-boundary exchanges are transacted by individual "boundary spanning" employees. However, in spite of over 40 years of theoretical interest, the dimensions of the individual boundary spanning role have not been empirically established. Conceptual development seems warranted at this juncture, given emerging research interest in the boundary spanning role played by expatriates in supporting organizational learning and adaptation in international settings.

This exploratory case study applies qualitative methodology to describe the nature of the expatriate boundary role and to explore the conditions for individual effectiveness in the role. The host organization was Canada's Department of Foreign Affairs and International Trade. Semi-structured interviews were conducted with 84 executive, mid-management and non-management employees on assignment in 56 missions abroad. Interviews explored the nature of boundary spanners' interactions with local external agents and the nature of their interactions with members of the home organization. Findings suggested that interpersonal working relationships comprised a central dimension of the expatriate boundary spanning role and were the cornerstones and enablers of other resource exchanges. Familiarity with the local context, clarity on organizational expectations for the boundary role, and regular access to the home organization's strategic and relational context over the duration of the assignment were central conditions for effectiveness in the role.

The study concludes with the development of: (1) a nine-dimension typology of the expatriate boundary spanning role; (2) a five-component model identifying the conditions for individual effectiveness in the role; (3) an emergent model identifying the potential constraints on effectiveness posed by geographic distance from the home organization (intra-organizational distance) and perceived distance from the local culture (interface distance); and (4) a series of propositions for future quantitative testing.
\end{abstract}




\section{ACKNOWLEDGEMENTS}

This research could not have been completed without the support and encouragement of a large number of individuals. First, I would like to express my deep gratitude to the 84 heads of mission, managers, and political officers who took time from their work to share with me a "day in the life" of the diplomat. I can only hope that my account of their experiences abroad can do at least partial justice to this most fascinating and complex work.

I express my sincere thanks to my thesis supervisor, Dr. Linda Duxbury, for her enthusiasm, energy, and insightful guidance throughout this project. I am grateful also to the internal members of my doctoral dissertation committee, Dr. David Cray, who introduced me to some of the classic readings in my subject domain, and Dr. Lorraine Dyke, on whom I could always count to keep asking the "tough questions". Thank you to my external examiner, Dr. Sharon Leiba O'Sullivan for her thorough comments on the review of the expatriate management literature. And a very special thank you to Mr. David Mulroney, Associate Deputy Minister, Department of Foreign Affairs and International Trade Canada (DFAIT), who both championed this research and generated lively discussion as an examiner at my thesis defense.

I am indebted also to a number of individuals at DFAIT, who assisted and supported me throughout the data collection process and provided insightful comments on the research findings. Thanks to Adam Blackwell, Todd Kuiack, and Andrew Stirling of the Strategy and Operations Bureau, and to Jim Fox, Lynne Thomson, and Avril O'Neill, who championed the study in the true spirit of "e3".

Thank you to graduate administrator, Janice Walker, for her flare for coordination (and, more often than not, technical support!)

Finally, this thesis could not have been completed without the support (and patience!) of my family and friends. Thanks to my daughter and son, Laine and Mack Johnson, (may we never again see pizza for Sunday dinner!) Thanks to their dad, Curtis Johnson, for his many patient hours spent listening to the finer points of designing a coding scheme. Thank you to my friends and colleagues, Dr. Mary Tivy and Donna Coghill, who were always there to brainstorm or just listen. And, as always, I extend my gratitude and love to my mother, Eleanor Graham, to whom I dedicate this thesis. 


\section{TABLE OF CONTENTS}

ABSTRACT

\section{PART ONE: INTRODUCTION}

1. Introduction

$1.1 \quad$ Research objectives $\quad$....................................................................

1.2 Research approach $\quad$........................................................................ 5

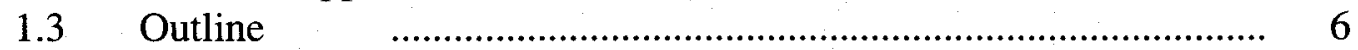

$1.4 \quad$ A note on terminology

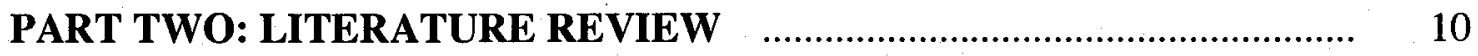

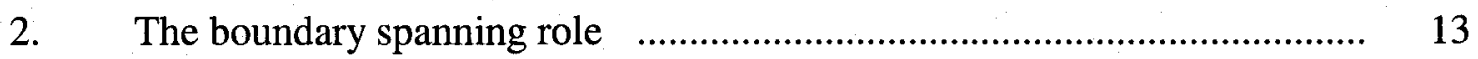

2.1 Theoretical origins of the concept $\quad$................................................ 13

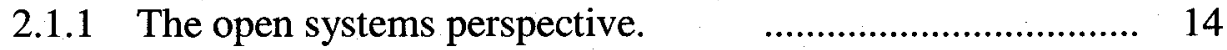

2.1.2 The role theory perspective …………………................. 19

2.2 Empirical efforts to conceptualize boundary transactions at the micro level

2.3 Summary and implications for further conceptual development $\quad 30$

3. Effectiveness in the boundary spanning role ............................................... 34

3.1 Intra-organizational context ………………….......................... 36

3.1.1 Organizational communication of role expectations .......... 36

3.1.2 Boundary spanner ability to influence strategic decision making

3.1.2.1 Theoretical origins of the strategic influence literature

3.1.2.2 Empirical studies of boundary spanner influence

3.1.2.3 A related literature: The strategic influence of mid-managers

3.1.2.4 Summary

3.2 Interface context: Reconciling the expectations of internal and external constituents

3.2.1 Theoretical origins of the interface experience:

Role stress theory

3.2.2 Empirical literature related to the interface experience 


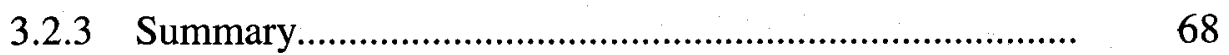

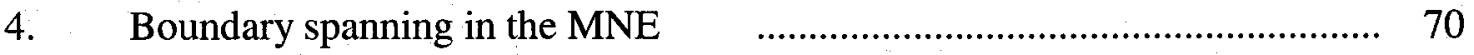

4.1 The boundary spanning role in the MNE _................................... 73

4.1.1 Thomas' conceptual model of MNE boundary

spanning ……............................................................ 73

4.1.2 Au and Fukuda's empirical study of MNE

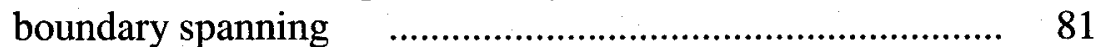

4.2 Effectiveness in the MNE boundary spanning role …………….... 85

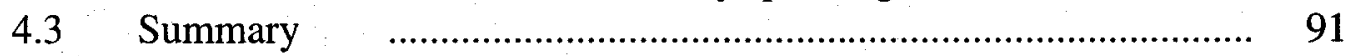

5. Perceived organizational support for boundary spanners $\quad$....................... 94

PART THREE: PRELIMINARY CONCEPTUAL DEVELOPMENT AND RESEARCH QUESTIONS $\quad$.................................. 97

6. Conceptual development and research questions. …............................... 98

6.1 Conceptualizing the boundary spanning role .................................... 98

6.2 Conceptualizing the conditions for effectiveness in the role. ......... 102

$6.3 \quad$ Research questions …............................................................... 110

PART FOUR: METHOD

7. Host organization ……….......................................................... 115

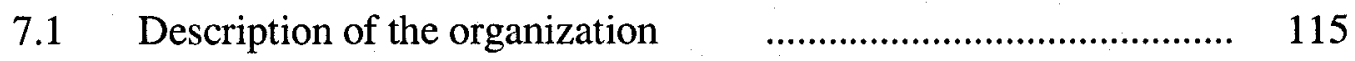

7.2 Impetus for this research _...................................................... 116

7.3 Suitability of this organization for the case study approach $\ldots . . . . . . \quad 116$

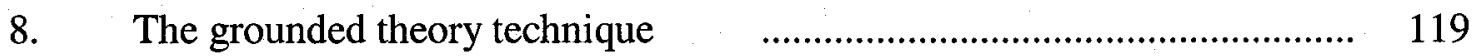

8.1 The application of grounded theory in case study research $\quad \ldots . . . . . \quad 119$

8.2 Overview of Eisenhardt's model ……………...................... 120

8.3 Strengths and weaknesses of the approach ………...................... 124

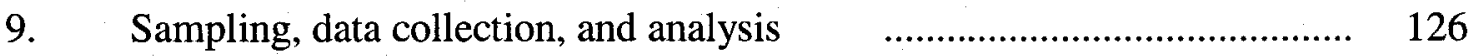

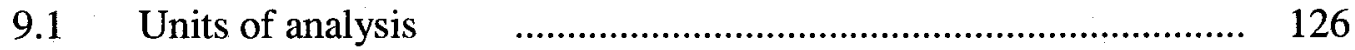

9.2 Sampling ......................................................................... 127

9.2.1 Sample selection protocol …………………….............. 130

9.2.2 Participant recruitment ………………………........ 133

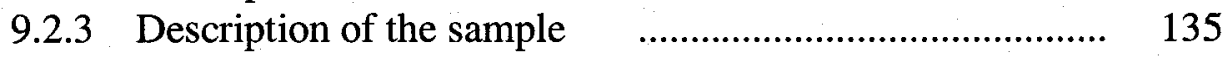

iv 
9.3 Data collection _............................................................... 138

9.3.1 Qualitative data _.......................................................... 139

9.3.1.1 The interview protocol $\quad$................................... 139

9.3.1.1 Pilot interviews and adjustments to interview protocol ................................................ 144

9.3.1.2 Administration and recording of interviews

9.3.2 Quantitative data ............................................................ 146

9.3.2.1 Description of the questionnaire $\quad$....................... 147

9.3.2.2 Pilot and adjustments to the questionnaire ............ 151

9.3.2.3 Administration of the questionnaire ..................... 152

$9.4 \quad$ Data analysis ....................................................................... 152

9.4.1 Coding .................................................................. 153

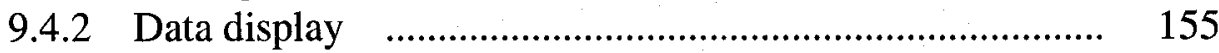

9.4.3 Enfolding the quantitative data …………………..... 156

9.5 Data interpretation …………............................................... 160

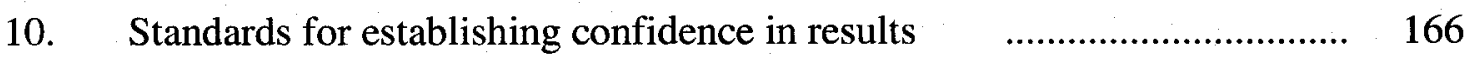

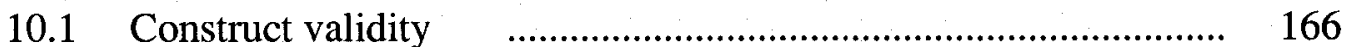

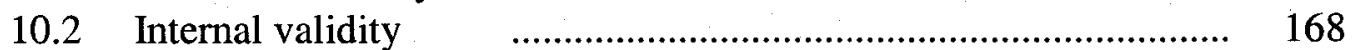

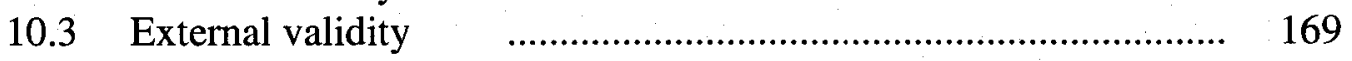

10.4 Reliability ………........................................................... 170

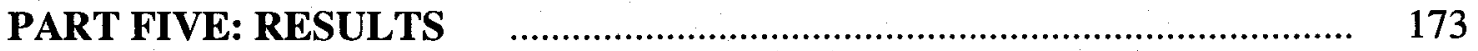

11. Boundary spanner interaction within the organization: Perceptions of organizational expectations for performance

11.1 Reporting structure and respondents' perceived expectations for their work abroad

11.2 Sources of role cues within the organization .................................. 183

11.3 Perceived effectiveness of role cues in communicating expectations

11.3.1 Perceived effectiveness of formal cues $\quad$..................... 187

11.3.2 Perceived effectiveness of cues from individuals

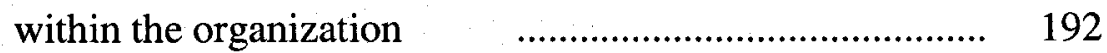

11.3.2.1 Manager effectiveness $\quad$...................... 192

11.3.2.2 HQ effectiveness $\quad$................................... 197

11.3.2.3 Boundary spanners' "key person" for direction and guidance................................. 201

11.4. Cues from the job and other sources ........................................... 205

11.5 Summary ………........................................................... 210 
12. Boundary spanner interaction with local constituents: The interface

12.1 Sources of role cues in the local environment............................. 216

12.2 The boundary role construct ...................................................... 221

12.2.1 Overview of boundary episodes $\quad$.............................. 222

12.2.2 A typology of the dimensions of the boundary role $\ldots . . . . . . .225$

12.2.3 Enfolding the quantitative data $\quad$............................... 245

12.2.4 Patterns observed within boundary episodes .................. 250

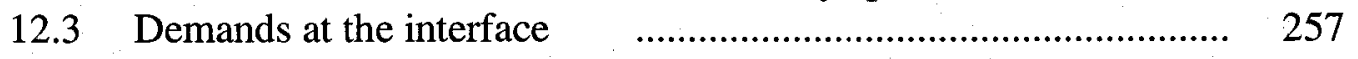

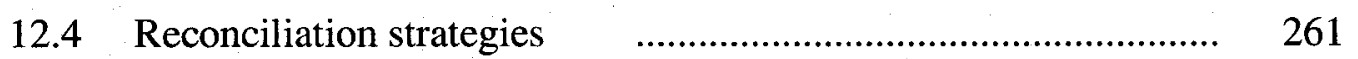

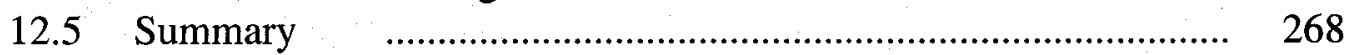

12.5.1 Dimensions of the boundary role construct $\ldots \ldots \ldots \ldots \ldots \ldots . . . . .269$

12.5.1.1 Limitations of the emergent dimensions $\quad \ldots \ldots \ldots . .271$

12.5.2 Conditions for effectiveness at the interface ................. 275

13. The translation of organizational and local expectations to individual work objectives

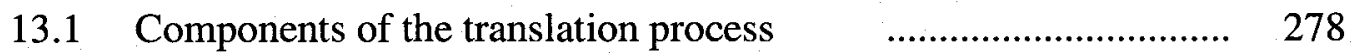

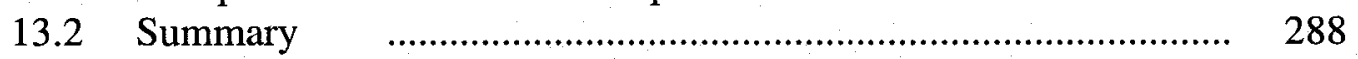

14. Boundary spanner efforts to influence strategy: "Issue selling" . ........ 290

14.1 Responses to the screening question: Have boundary spanners tried to advance an issue from post? ........................................... 291

14.2 The nature of the issues advanced ........................................ 295

14.3 Issue-selling "moves" $\quad$...................................................... 298

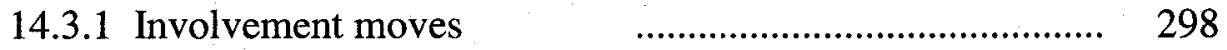

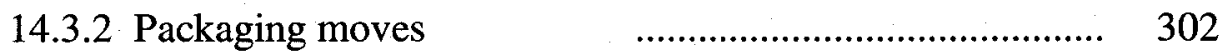

14.3.3 Process moves $\quad$................................................... 307

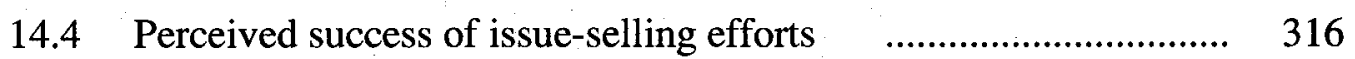

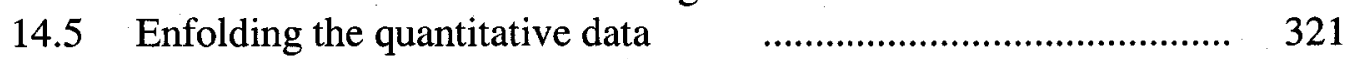

14.5.1 Job autonomy ............................................................. 322

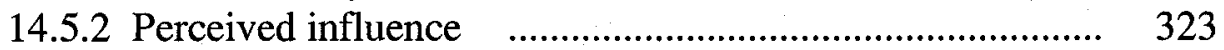

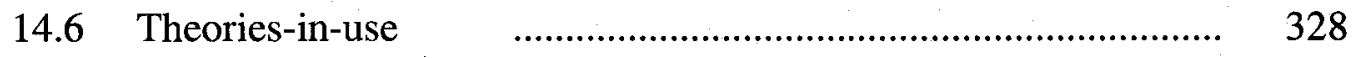

14.7 Summary (................................................................... 331

15. Boundary spanner perceptions of organizational support

for the boundary role

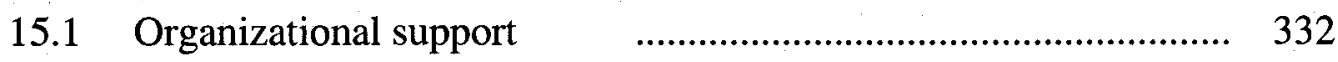

15.2 Manager support …...................................................... 342

15.3 Summary.................................................................. 347

vi 
16. Discussion and conceptual refinement

16.1 An expanded conceptual framework of the dimensions of the boundary role

16.2 An expanded conceptual framework of the conditions for individual effectiveness in the boundary role

16.3 An emergent conceptual framework of the effects of intra-organizational and interface distance on the conditions for effectiveness in the boundary role

PART SEVEN: CONCLUSIONS

17. Conclusions

17.1 Conclusions and contributions of this research $\quad \ldots \ldots \ldots \ldots \ldots \ldots . . . . . . .384$

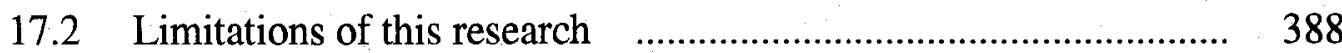

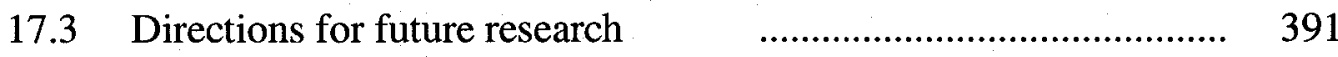

17.4 Implications for practice $\quad$....................................................... 393

REFERENCES

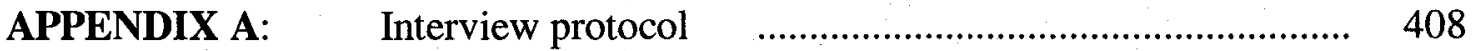

APPENDIX B: ～Questionnaire ....................................................... 418

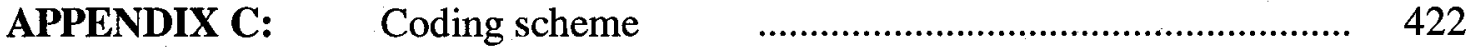

\section{LIST OF TABLES}

Table 2-1 Adaptive boundary spanning functions, as identified in macro-level literature.

Table 2-2 Job activity items loading on the boundary spanning factor (Miles, 1976)....

Table 2-3 Classification of boundary behaviours of R\&D teams (Ancona and Caldwell, 1988.

Table 2-4 A typology of boundary spanning activities in the R\&D team (Ancona and Caldwell, 1992).

Table 9-1 Preliminary sampling frame by geography, mission size, and sex of head of mission

Table 9-2 Preliminary sampling frame by job level

Table 9-3 Respondents by geography and mission size

Table 9-4 Respondents by geography and mission priority status... 
Table 9-5 Respondents by job level and sex.

Table 9-6

Characteristics of sample by age and work characteristics

Table 9-7

Distribution of sample by work outcomes measures.........

Table 11-1

Respondent's perceived reporting hierarchy.

181

Table 11-2

Perceived organizational expectations.

183

Table 11-3

Overview of primary sources of role cues at post.

184

Table 11-4

Perceived effectiveness of formal role cues in communicating expectations.

Table 11-5

Perceived effectiveness of manager in communicating

expectations.

Table 11-6

Perceived effectiveness of HQ in communicating

expectations.

Table 11-7 Role ambiguity and perceived effectiveness of interaction with HQ.

Table 11-8 Respondent's "key person" $n$ terms of communicating expectations.....

Table 11-9 Respondent's "take-away" from exchanges with key person.

Table 11-10 Cues from the job and from persons outside the organization. 207

Table 12-1 Gaining knowledge of local expectations: Approaches to developing contacts.

Table 12-2 Gaining knowledge of local expectations: Sources of role cues in the external environment.

Table 12-3

Target person identified in boundary episodes..

222

Table 12-5

Dimensions of the boundary spanning role. 229

Table 12-6

Quantitative support for selected dimensions of the boundary role.

Table 12-7 Dimensions of the boundary spanning role by target person 252

Table 12-8 Evidence of the multidimensionality of the boundary role 254

Table 12-9 Pairings of boundary dimensions with the relationship function

Table 12-10

Perceived demands of the external agent. 258

Table 12-12

Reconciliation strategies

Table 13-1

Components of the translation process..

280

Table 14-1

Influence effort: Overview of response categories for analysis.

Table 14-2

Sample selection process for analysis of influence moves

Table 14-3

Nature of issue advanced.

Table 14-4

Influence efforts: Overview of moves mentioned

in issue-selling accounts.

Table 14-5

Involvement moves.

Table 14-6

Packaging moves

Table 14-7

Process moves. 
Table 14-8 Perceived success of influence effort................................... 317

Table 14-9 Perceived success factors in moving issues........................ $\quad 319$

Table 14-10 Perceived influence and choice of strategic approach to issue-selling................................................................... 325

Table 14-11 Theories-in-use............................................................... 328

Table 15-1 Perceptions of support from the organization..................... 335

Table 15-2 Preferred organizational support............................................ 338

Table 15-3 Perceptions of support from the manager............................. 342

Table 15-4 Preferred support from the manager..................................... 346

Table 16-1 Aspects of intra-organizational distance:

"The intra-organizational divides"..................................... $\quad 375$

Table 16-2 Aspects of interface distance: "The interface divides"........ 376

\section{LIST OF APPENDIX TABLES}

Table A-1 Mapping of selected interview items to rationale and supporting literature.

Table B-1 Mapping of preliminary classification of boundary role questionnaire items to revised classification as used in analysis.

\section{LIST OF EXHIBITS}

Exhibit 10-1 Quality procedures for case study research applied in this study

Exhibit 12-1 Typology of the dimensions of the expatriate boundary spanning role.

Exhibit 12-2 Typology of reconciliation strategies used in boundary interactions.

Exhibit 16-1 Typology of the dimensions of the expatriate boundary spanning role...

\section{LIST OF FIGURES}

Figure 4.1 Thomas' conceptual model of expatriate boundary spanning.

Figure 6.1 Preliminary conceptual framework of the dimensions of the boundary spanning role.

Figure 6.2 Preliminary conceptual framework of the conditions for individual effectiveness in the boundary spanning role........ 109

Figure 16.1 Expanded conceptual framework of the conditions for individual effectiveness in the boundary spanning role.

Figure 16.1.1 Individual elements of the expanded conceptual framework 366 
Figure 16.2 Emergent conceptual framework of the potential effects of intra-organizational and interface distance on the conditions for individual effectiveness in the boundary spanning role 


\section{INTRODUCTION}

In today's global economy, more and more organizations are establishing an international presence. Private sector firms are locating operations outside of their home countries in search of competitive advantage. Government and non-governmental organizations are increasing in size and scope to regulate and integrate corporate expansion, or to pursue their social, economic and humanitarian agendas (Brewster, 2002). Many of these organizations rely on expatriate staff to manage or transfer skills to their international operations, and data indicate that three quarters of Canadian and U.S. firms anticipate further growth in the number of employees on international assignment (Mercer Human Resource Consulting, 2003; Peppas, 2004). Research suggests that many of these enterprises, both public and private, encounter challenges operating in unfamiliar environments, including difficulties in dealing with foreign governments and local partners, managing local staff, or in tailoring products and services to local tastes cultures, and business systems (Lord and Ranft, 2000). The need to adapt to their dispersed and uncertain task environments thus seems a challenge faced by virtually all multinational enterprises (MNEs).

Open systems theory indicates that under conditions of uncertainty, organizations adapt by increasing their linkages with the external environment to support the inward flow of information and to exert outward control over clients, suppliers, partners, and other organizations in their task environment (Katz and Kahn, 1966; Thompson, 1967). 
Conceptually, these "linkages" occur at inter-organizational boundaries. Linkages take the form of transactions between individuals who operate at these boundaries and external agents. Employees whose jobs require interaction with agents outside the organization's boundary are thus said to perform a "boundary spanning" role (Adams, 1976; Kahn, Wolfe, Quinn, Snoek, and Rosenthal, 1964; Organ, 1971).

It is argued that, since boundary spanners are in effect the organization's only points of contact with the external environment, it is by virtue of their transactions with external agents that the organization adapts- or fails to adapt- to a changing environment (Leifer and Delbecq, 1976; Organ, 1971). Whether their transactions are relatively routine (e.g., sales), or complex (e.g., R\&D), whether they are executive or front line, boundary spanners' location on the organization's periphery places them in a position to perform activities of strategic value (Jemison, 1984). It is through the agency of its boundary spanners that the organization is able to gather local intelligence or exert influence over external agents in pursuit of organizational objectives (Adams, 1976; Thompson, 1967).

Given the strategic importance to the MNE of scanning the local environment and forging relationships with local constituents, it would seem that the boundary spanning role would be the focus of a good deal of attention in the international management literature. The work of the expatriate, however, has seldom been framed from the theoretical perspective of the boundary spanning role (for exceptions, see $\mathrm{Au}$ and Fukuda, 2002; Thomas, 1994). Research in the international context has been further limited by the fact that the vast majority of expatriate literature has focussed on 
the experience of executives and senior managers. This has been noted as a shortcoming of the literature (Hechanova, Beehr and Christiansen, 2003), since it would seem that the MNE in particular would want to maximize its learning from all organizational members so as to adapt to new or shifting environments as readily as possible.

We therefore know little about the nature of the boundary spanning role in international settings or what individual employees might need in order to be effective in the role. Macro level theory discussed above suggests that organizational effectiveness is a function of the organization's ability to manage its boundary exchanges so as to keep the organizational system viable in the face of a changing environment (Thompson, 1967). This suggests that individual effectiveness in the boundary role would be a function of the ability of the individual's boundary transactions to contribute to organizational performance and adaptation over the long run. Boundary spanning effectiveness at the level of the individual employee, however, has not been conceptualized. Further, to date, there exists no conceptual framework to guide managers in creating the organizational context needed to support employees in their boundary roles. This research is intended to fill these gaps.

\subsection{Research objectives}

This research has four objectives:

1. To describe the dimensions of the boundary spanning role in an international setting

2. To explore the conditions for individual effectiveness in the boundary 
spanning role

3. To examine job level differences in the conditions associated with effective performance in the boundary spanning role

4. To identify boundary spanners' perceptions of, and preferences for, organizational support for the boundary role

Objective 1 is descriptive. It attempts to map out the dimensions of the boundary spanning role in the MNE context. It thus seeks to observe at the micro level the transactions that constitute the intra-organizational "linkages" observed at the macro level (Adams, 1976; Katz and Kahn, 1966; Thompson, 1967). Objective 1 seeks to answer the questions: what do boundary spanners do over the course of their activities with external agents? What is the content and purpose of these interface activities in terms of their contribution to organizational performance and adaptation?

Objective 2 is also descriptive. It is aimed at generating a conceptual model of the potential conditions for individual effectiveness in the boundary role. It seeks to explore, in an international setting, the following questions: how would you define boundary spanner effectiveness at the individual level? What would boundary spanners need in order to be effective in their boundary roles? What conditions would have to be met- - both within the organization and at the interface- - to enable boundary spanners to perform effectively in their roles?

Objective 3 looks to expand the international management literature by examining the boundary role at both management and non-management levels. This objective is aimed at redressing the current imbalance in the expatriate literature, which 
has tended to neglect the experience of the many clerical, blue-collar, technical and professional employees for whom international assignments are also a reality (Bonache, 2005).

Objective 4 seeks a practical application of the learning obtained through the first three objectives. It examines boundary spanners' perceptions of organizational support for employees in the boundary role. It seeks to answer the questions: what do boundary spanners perceive to be supportive of them in their roles as boundary spanners? What would they like from their organizations in the way of support? This objective is directed at tapping the management implications of an enhanced understanding of the expatriate boundary spanning role.

\subsection{Research approach}

Since the boundary spanning role has seldom been investigated in international settings, this research is exploratory. In order to obtain the richest data possible, the research strategy is case study. Because the area of interest is relatively unexplored, the study relies primarily on qualitative methods, complemented by quantitative methods to encourage converging lines of inquiry in a corroborative mode (Yin, 2003). The case study strategy is appropriate in instances where the purpose is to study a phenomenon in depth, the phenomenon is one that has seldom been investigated or is difficult to access, and where the contextual conditions surrounding the phenomenon are believed to be highly pertinent to understanding it (Eisenhardt, 1998; Yin, 2003). Cases are often chosen so as to represent the "extreme" in the phenomenon of interest. 
All of the above conditions apply in the current research. First, the host organization for the study is the federal Department of Foreign Affairs and International Trade Canada (DFAIT). DFAIT's political-economic staff abroad clearly represent the "extreme" in boundary spanning. DFAIT has extensive international presence, and a long tradition of boundary spanning. Indeed, boundary spanning is the core technology for a foreign ministry, thus offering a unique opportunity to explore boundary interactions with a vast number of external agents and at all levels of the organization. Second, DFAIT management was willing to grant the researcher interview time with nearly 90 political officers and managers posted on four continents, presenting a rare opportunity to speak with boundary spanners in the field and to explore in depth the boundary spanning role in a truly international context. DFAIT and the research methodology will be discussed further in Chapter 7 .

\subsection{Outline}

As the research objectives suggest, the ultimate goal of this research is to explore the boundary spanning role in the international context. However, since the boundary role had not been conceptualized at the individual level in any employee population, it was first necessary to construct a general exploratory model. The approach was as follows. First, the management literature was reviewed to identify the general elements needed to conceptualize the boundary spanning role and to conceptualize the conditions for individual effectiveness in the role. Then, the international management literature with potential relevance to boundary spanning was reviewed. This served to bring into 
relief some of the elements of the more "generic" model that required special attention in the international context. This two-step approach is consistent with O'Donnell (2000), who recommends that the first step in building theory in international management research is to apply existing management theories in the unique context of the MNE so as to identify similarities, limitations and points of departure.

The thesis is thus structured to support this two-step approach to conceptual development. Part Two reviews the literature. The first two chapters of the review (Chapters 2 and 3 ) examine the boundary spanning and related literatures in order to identify the potential elements to include in a preliminary conceptualization of the boundary spanning role and a conceptualization of the conditions for effectiveness in the role. Chapter 3 also examines the very limited literature on the potential effect of job level on the boundary spanning role. Chapter 4 then turns to the international management literature to examine literature with potential relevance to conceptualization of the boundary role in the special context of the MNE. Part Three of the thesis develops from these literatures preliminary conceptual frameworks and a set of research questions to guide data collection and analysis. Part Four describes the host organization and the methodology used to answer the research questions developed in Part Three. Part Five presents the findings. Part Six discusses the findings and refines and expands the preliminary conceptual models in light of the findings. The research concludes in Part Seven with a discussion of the contributions of this research, limitations of the study, and directions for future research and management practice. 


\subsection{A note on terminology}

As more and more organizations establish international presence, we see proliferation in the terminology used to refer to them. Terms such as "global", "international", "transnational", "multinational", and "multildomestic" are often used interchangeably, and have contributed to debate, if not confusion, among management scholars seeking a common language (for a discussion, see Yip, 2003).

For the purpose of this research, the term, "multinational enterprise" is used in a neutral sense to denote any organization that owns or controls operations situated outside of the home country, and does not imply any particular configuration of ownership or control. This definition is consistent with that given by Brewster (2002). The definition favours the term "enterprise" over "corporation" because it is sufficiently broad to capture the full range of organizations that have established an international presence and is not restricted to the private sector, where most extant research has been concentrated. As argued by Brewster, the term "multinational enterprise" is sufficiently generic to include not only private corporations, but also the large and growing number of government bodies, inter-governmental organizations (e.g., World Bank, OECD, United Nations), and non-government organizations (e.g., churches, trade union federations, and international standards and scientific associations) that now operate in virtually every country in the world and have responsibility for managing large numbers of employees on a truly "multinational" scale. Since it is the premise of this research that a better understanding of the boundary spanning role may be of advantage to any organization with responsibility for managing employees in international settings, 
Brewster's definition of the "multinational enterprise" is adopted here. 


\section{PART TWO: LITERATURE REVIEW}

Since boundary spanning in the international context is a largely unexplored area, it was necessary to assemble the literature review from a number of related bodies of research. To date, boundary spanning research has resided in a number of publication "silos", including such diverse literatures as macro-level organizational theory, international human resource management, strategic decision making, communications, marketing, and psychology. In order to develop the preliminary conceptual frameworks needed to guide a qualitative study (Eisenhardt, 1989), it was necessary to integrate these literatures.

As indicated in the introduction, conceptualization was needed in two areas. First, there was a need to characterize the role itself (what are the "dimensions" of the boundary spanning role: what do employees do at the intra-organizational boundary, and why?) Second, there was a need to conceptualize at the individual level the conditions for effectiveness in the boundary role (what would boundary spanners need in order to perform their roles effectively?) This review is structured around these two conceptual tasks.

Chapter 2 examines literature that has concerned itself directly with defining the boundary spanning concept (Research Objective 1). This literature includes seminal work from the fields of macro-organization theory and social psychology in which the boundary concept originated, as well as a very small branch of empirical literature that 
has attempted to conceptualize the dimensions of boundary interactions at the micro level. The conceptual literature is valuable to this study since it provides guidance in identifying the critical elements to include in a conceptualization of the boundary spanning role at the level of the individual.

Chapter 3 turns to literature that can provide insights around the potential conditions for individual effectiveness in the boundary spanning role (Research Objective 2). It is divided into two sections. The first section looks at the boundary spanner's experiences within the organization. It examines various features of the boundary spanner's organizational context (intra-organizational context) that might enhance or constrain the individual's effectiveness in the boundary role. It draws first on role theory to identify the various work context and job design features that serve to communicate to boundary spanning employees what is expected of them in their roles. It then turns to social network theory to investigate the extent to which boundary spanning employees, in turn, might be able to communicate boundary information to the organization through their ability to exert influence over organizational decision makers. The influence literature will be reviewed with special attention to the potential effect of job level on the conditions for effectiveness (Research Objective 3).

The second section of Chapter 3 looks at the boundary spanner's experiences at the interface between his or her organization and the external environment (interface context). It examines aspects of the boundary spanner's interactions with external agents that may enhance or constrain the individual's effectiveness in the role. This section returns to the role stress literature to explore the various demands that external 
constituents may impose on boundary spanners and to identify a number of strategies that boundary spanners may invoke to deal with these demands.

Chapter 4 then turns to research that has dealt with boundary spanning specifically within the multinational context. This literature is very small, but helps to identify some of the special conditions that may prevail for boundary spanners in international settings. This literature has relevance both in terms of what boundary spanners actually do at the interface in an MNE setting (Research Objective 1) and in terms of the conditions for individual effectiveness in this special context (Research Objective 2).

Finally, Chapter 5 examines literature addressing organizational support for boundary spanners (Research Objective 4). 


\section{THE BOUNDARY SPANNING ROLE}

This chapter reviews the origins of the boundary spanning concept in order to lay the foundation for development of the boundary spanning construct at the individual level. The first section introduces the theoretical origins of the boundary spanning concept from its roots in macro-organization theory and the social psychology of organizations. From these literatures, it abstracts the elements with relevance to conceptual development of the role at the level of the individual. The second section reviews the few existing empirical efforts at exploring the dimensions of the boundary spanning role at the micro level. The chapter concludes by synthesizing the conceptual work in order to identify its contributions and establish the requirements for further conceptual development of the role at the level of the individual.

\subsection{Theoretical origins of the concept}

Research interest in boundary spanning emerged during the mid 1960s, with the publication of three highly influential books. In 1967, James Thompson released his seminal work, "Organizations in Action", presenting a macro-level perspective on organizations as open systems, and identifying the organization's structural boundary as the critical locus for adaptive transactions between the organization and its environment (open systems theory). At roughly the same time, Kahn and colleagues (Kahn et al., 1964; Katz and Kahn, 1966) released their equally influential works on the social psychology of organizations. This body of work also assumed the open systems 
perspective, but from the vantage of the organization's social system. Kahn and colleagues linked survival and adaptation at the organizational level to the structured pattern of social interactions within the organization and the pattern of social interaction at its boundaries. The two perspectives are described below.

\subsubsection{The open systems perspective}

Classical management theory of the early 1900 s viewed an organization's recurring cycles of input-transformation-output as largely determinate (Thompson, 1967). According to these perspectives, organizations were closed systems where organizational goals were established by management, and organizational effectiveness defined in terms of the efficiency achieved in attaining these goals. Scientific management (Taylor, 1911), for example, focussed on maximizing efficiency through the logical sequencing and control of production activities. Administrative management (Fayol,1937) focussed on the structuring and coordination of relationships among production, supply, human resources, and other functional units of the organization. What these perspectives shared was a view of the organization as a closed system: analysis was restricted to phenomena internal to the organization. In a closed system, goals were known, tasks were predictable, resources were "automatically available" and the outputs of production "somehow disappeared" (Thompson, 1967). The closed system model enabled managers to attend to principles of internal functioning as if they were independent of any external environment.

Toward the second half of the century, an alternative conceptualization of 
organizations emerged that emphasized the interdependence of the organization with elements of its external environment. Following in the tradition of von Bertalanffy's (1950) exploration of systems in the biological and physical sciences, management theorists began to study organizations as open systems. Open systems theory, as advanced by Thompson (1967) and Katz and Kahn (1966), positioned the organization's input-transformation-output cycle within its broader environmental context. These perspectives recognized that organizations relied on other systems in their task environments to supply the human, material, and financial inputs to their internal productive system and to absorb its outputs. Central to the open system model was the concept of homeostasis, or self-stabilization (Thompson, 1967). In order to survive, organizations needed to both maintain the stable functioning of their internal productive system (a maintenance function), and detect and respond to any fluctuations in the external environment that might pose a threat to the system (an adaptive function; Katz and Kahn, 1966). The open systems model thus defined organizational effectiveness, not in terms of internal efficiency, but in terms of the organization's adaptability to its environment (Thompson, 1967).

Although open systems theory assumes a macro perspective that is beyond the scope of this thesis, it is responsible for laying the theoretical foundation on which has been based much of the ensuing conceptual research on boundary spanning. Open systems theory introduced a number of conceptual elements that can be seen to be precursors to current operationalizations of boundary spanning at both the macro and micro level. 
First, open systems theory gave us the concepts of "boundary" and "boundary spanning" and identified boundaries as the site of the organization's adaptive function (Katz and Kahn, 1966). "Boundaries" were defined as the lines of demarcation identifying an individual or an activity as belonging to one system or another (Katz and Kahn, 1966). Boundaries were both internal (i.e., between interdependent units of the organization) and external (between the organization and its broader environment). The adaptive function was performed by "boundary spanning" subsystems or units which performed transactions that controlled the movement of inputs and outputs across external boundaries. Boundary spanning units buffered, controlled and predicted environmental disturbances to protect the organization's core technology from uncertainty (Ibid.). Even during times of relative stability, boundary spanning units performed an adaptive function by developing the environmental niche in a manner conducive to effective performance (Ibid.).

Second, open systems theory specified that the adaptive function involved bidirectional movement. In the event of environmental fluctuation, the adaptive function could flow in one of two directions (Katz and Kahn, 1966). It could exert outward influence to attain control over external forces, or it could exert inward influence to modify the organization's own structures or processes in response to the needs of a changing world. For example, advertising units exert outward control by attempting to create the need for the organization's outputs (products or services; Ibid.). Conversely, a research or marketing unit might exert inward control by bringing into the organization technical or market information that leads to a decision to adapt new technologies or to 
create an internal structure dedicated to a new product line.

Finally, open systems theory enriched and expanded the notion of "inputs" and "outputs". As opposed to the rational view of organizations as performing a mechanistic input-transformation-output function, the open systems view saw organizations as dynamic systems that relied not only on the acquisition and disposal of material goods and services, but also on their ability to gather intelligence and to gain legitimacy among the total system of players in their task environments (Katz and Kahn, 1966). An organization's task environment comprised all those external agents on whom the organization depended in order to continue its cycles of input- transformation-output, including not only suppliers and customers, but also competitors, regulatory agencies, unions, and various experts, consultants and service providers (Thompson, 1967). Viewed in this light, "inputs" assumed a very broad definition, including all of the raw materials, capital, personnel, technology, information, institutional support, and “goodwill" needed to fulfill the organization's productive activities (Adams, 1976). Similarly, "outputs" comprised not only the immediate goods and services resulting from the organization's productive activities, but also more abstract "products" needed to sustain the organization's viability in a changing environment, such as activities aimed at enhancing the organization's reputation or public image, or exerting direct control over suppliers, customers, or others in the task environment. Boundary spanning units, therefore, were seen to play critical roles as mediators (Thompson, 1967) between the organization and the external bodies on whom the organization depended for survival. Combined, these three conceptual contributions laid the groundwork for 
subsequent formulations of the adaptive functions served by boundary spanning subsystems. In contrast with the somewhat lean depiction of input and output given by the closed system model (an activity-based perspective), open systems theory added to the mix the adaptive purpose of input and output processes in terms of organizational effectiveness and survival (a function perspective). Open systems theory maintained that transactions across organizational boundaries did not merely feed the organization's productive core and dispose of its outputs: they served an adaptive purpose for the organization in protecting it from environmental fluctuations and uncertainty. This conceptualization led macro researchers to begin to specify what was crossing the boundary over the course of a transaction (e.g., technical information vs. resources vs. "goodwill"), and to begin to characterize the adaptive purpose served by transactions. The distinction between activity and purpose- - and the recognition of the multidimensionality of boundary spanning interactions- - will be seen to be important underpinnings of the conceptualization of boundary spanning at the micro level. Table 2-1 summarizes the boundary spanning functions described in the early macro literature.

Table 2-1: Adaptive boundary spanning functions, as identified in macro-level literature

\begin{tabular}{|l|c|c|c|c|c|}
\hline & $\begin{array}{l}\text { Acquisition/ } \\
\text { Disposal }\end{array}$ & $\begin{array}{l}\text { Information } \\
\text { gathering }\end{array}$ & $\begin{array}{l}\text { Information } \\
\text { analysis and } \\
\text { filtering }\end{array}$ & $\begin{array}{l}\text { Institutional } \\
\text { relations/ } \\
\text { Representation }\end{array}$ & $\begin{array}{l}\text { Controlling } \\
\text { others in the } \\
\text { task } \\
\text { environment }\end{array}$ \\
\hline Adams, 1976 & $\mathrm{X}$ & $\mathrm{X}$ & $\mathrm{X}$ & $\mathrm{X}$ & $\mathrm{X}$ \\
\hline Leifer \& Delbecq, 1976 & $\mathrm{X}$ & $\mathrm{X}$ & $\mathrm{X}$ & & \\
\hline Leifer \& Huber, 1977 & $\mathrm{X}$ & $\mathrm{X}$ & $\mathrm{X}$ & & \\
\hline Katz \& Kahn, 1966 & $\mathrm{X}$ & $\mathrm{X}$ & $\mathrm{X}$ & $\mathrm{X}$ & $\mathrm{X}$ \\
\hline Thompson, 1967 & $\mathrm{X}$ & $\mathrm{X}$ & $\mathrm{X}$ & $\mathrm{X}$ & $\mathrm{X}$ \\
\hline Aldrich \& Herker, 1977 & $\mathrm{X}$ & $\mathrm{X}$ & $\mathrm{X}$ & $\mathrm{X}$ & $\mathrm{X}$ \\
\hline
\end{tabular}




\subsubsection{The role theory perspective}

Like Thompson's theory, role theory (Katz and Kahn, 1966; Kahn et al., 1964) also assumed an open systems perspective, but cast organizations expressly as social systems. Role theorists maintained that the biological metaphor on which open systems theory was based was a useful, but limited, heuristic for studying social systems. They argued that a social system differed qualitatively from a system in the biological and physical sciences, since it was lacking in physical structure. As expressed by Katz and Kahn, (p. 31):

"A social system is a structuring of events or happenings rather than of physical parts and it therefore has no structure apart from its functioning. Physical or biological systems such as automobiles or organisms have anatomical structures which can be identified even when they are not functioning. In other words, these systems have both an anatomy and a physiology. There is no anatomy to a social system in this sense.... When a social system ceases to function, there is no longer an identifiable structure.... The biological metaphor...ignores the essential difference between the socially contrived nature of social systems and the physical structure of the machine or human organism"

According to role theory, the "cement" that holds social systems together is psychological, not biological (Katz and Kahn, 1966. p. 33). The social system is defined, not by physical boundaries, but by the interwoven pattern of social relationships among system members. An individual's behaviour within an organization is constrained and directed by the expectations of the various constituents with whom the individual interacts in the performance of his or her job. The expected pattern of behaviour for an individual occupying a given position is said to comprise his or her role. The salient constituents with whom the individual interacts comprise his or her role set. 
Role set membership is established by proximity to the role incumbent in terms of work flow or hierarchy. It includes, for example, supervisors, subordinates, or members of other departments or organizations on whom the individual depends to do his or her job. These individuals also depend on the role incumbent so that they may perform their own work. Since they have a stake in the incumbent's performance, they develop beliefs and attitudes about what the incumbent should and should not do as part of his or her role. The prescriptions held by members of a role set are said to comprise role expectations. Role set members communicate their expectations to the incumbent over the course of their interactions. Role set members are thus role senders, and their expectations, once communicated to the incumbent, represent the sent role.

Kahn et al. argue that, collectively, this network of roles and relationships moves individual behaviour in a direction which is system relevant. Role theory thus provides a bridge for linking the properties of an organization (the macro level) to the behaviours of individuals within that organization (the micro level; Aldrich and Herker, 1977). As expressed by Katz and Kahn (1966), the role concept:

“... is the major means for linking the individual and organizational levels of research and theory: it is at once the building block of social systems and the summation of the requirements with which such systems confront their members as individuals." (p. 197)

Role theory thus conceptually "replaces" the organization's structural boundaries by the boundaries on individual behaviour imposed by social structures. The organization is defined, and its boundaries determined, by the human relationships and underlying patterns of behaviour that support the observed cycles of "input-transformation-output" (Kahn et al., 1964).

Role theory, therefore, adds the important social dimension to the concept of 
boundary spanning. By viewing organizations in terms of social systems, role theory defines a boundary position as any position for which some members of the role set are located in a different organizational system (Kahn et al., 1964). Given this rather broad definition of the boundary role, Kahn et al. are careful to note that boundary incumbents vary in the intensity of boundary spanning activity demanded by their jobs. It would be difficult to locate an organizational member who does not need to have at least occasional contact with someone outside of the organization in order to perform his or her work. They thus introduce the term, "boundary relevance" to capture this variation within jobs in terms of the extent of external contact required. They define boundary relevance as varying across two dimensions: (1) the proportion of total work time devoted to contact with externals; and (2) the importance of interaction with externals to the effective performance of the job (Kahn et al., 1964; Katz and Kahn, 1966).

The concept of boundary relevance is an important theoretical contribution, since it places individuals on a continuum in terms of the intensity and importance of boundary spanning activity to their job performance. Whereas macro level theory identified "boundary units" as the sites of adaptive transactions with the environment, the notion of boundary relevance suggests that adaptive transactions can occur wherever individuals connect with outside agents in order to do their jobs, and are not restricted to specific structural units or functional areas traditionally associated with boundary spanning "responsibility" (e.g., marketing, purchasing, R\&D). If boundary transactions are no longer conceived of as functionally limited, it is also easier to detect instances where a given interaction serves multiple adaptive functions. For example, a sales person 
(performing a "traditional" disposal function), over the course of a sale, might also acquire information about a changing competitive environment (an informational function) and enhance the organization's image (a representational function) through his or her conduct during the interaction. The sales person, therefore, has executed three functional transactions over the course of a given boundary interaction.

Role theory also reminds us that all boundary transactions are executed by individuals, and therefore, are inherently social in nature. Over the course of a transaction, roles are being "sent" both from the incumbent to the external agent and from the agent to the incumbent. According to Kahn et al., every episode of role sending contains both information regarding the expected behaviour and an attempt to influence the role incumbent in the direction of that behaviour (Kahn et al., 1964). Role theory thus provides a direct analogue to the macro perspective in its contention that boundary spanning has both an activity and function component. It suggests that in order to fully characterize a boundary transaction at the individual level, it is necessary to know both the content of the transaction (the activity) and the intended purpose of the transaction (the function).

Unfortunately, subsequent theoretical and empirical work inspired by role theory did not move in the direction of further specifying the nature of the boundary role. Instead, researchers in the micro domain pursued a line of inquiry focussing on boundary spanners' psychological response to the role. Kahn et al.'s work sparked forty years of research on the stress and adverse work outcomes experienced by boundary spanners due to their exposure to ambiguous or conflicting demands from role senders both within and 
outside of the organization. Although the role stress literature has elements of value to this research and will be discussed in the next chapter, the preoccupation with the stress construct means that there have been very few attempts to actually characterize the dimensions of the boundary spanning construct (i.e., just what is it that boundary spanners $d o$ at the intra-organizational boundary, and how might their transactions contribute to organizational effectiveness?) The following section reviews the few studies that have explored boundary transactions at the micro level, with particular attention to their treatment of "activity versus function".

\subsection{Empirical efforts to conceptualize boundary transactions at the micro level}

To date, only two studies have empirically examined boundary spanning interactions at the micro level. The first was an early quantitative study by Miles (1976). Although Miles' work, like most of the micro-level research on boundary spanning, was aimed at linking boundary spanning to stress outcomes, his approach differed in that it included an effort to tap the actual interface activities that comprised the boundary spanning role.

Using a survey of 200 supervisory and non-supervisory R\&D professionals employed in nine government laboratories, Miles asked respondents to rate, from a predetermined list of 50 job activities, the extent to which each activity comprised a significant part of the respondent's job. The 50 items were selected to represent both boundary spanning activities and various other facets of R\&D work, such as the substantive components of scientific research activity and supervisory duties. 
Unfortunately, the author did not identify the rationale or method underlying the construction of the items, mentioning only that the items were based on his own experience within R\&D labs.

Factor analysis of the 50 job activity items yielded eleven with loadings on the boundary spanning factor. These items are given in Table 2-2.

Table 2.2: Job activity items loading on the boundary spanning factor (Miles, 1976)

1. Represent directorate/laboratory to outsiders

2. Review plans with outside agencies

3. Travel at least 30 days per year as representative of your organization

4. Inspect or review projects under contract

5. Integrate or coordinate interdependent activities of others

6. Prepare reports for governmental agencies outside the laboratory

7. Request performance obligations from persons outside your immediate unit

8. Prepare and give several briefings per month

9. Write or dictate at least 10 letters per week

10. Prepare contracts for approval by a superior

11. Act as a liaison with other units of the organization

The items listed in Table 2-2 are an interesting mix. Although Miles refers to the items as "activities comprising the boundary spanning role", the items appear to conflate activity with function. For example, items 1 and 3 ("representing the laboratory to outsiders", and "travelling as representative of the organization") tap the boundary role function of "representation" as suggested in the macro literature in Table 2-1. But these items do not describe the actual activities that might be involved in "representation". Items 5 and 11 suggest an additional integrative or coordinating function not covered in the macro literature ("integrating or coordinating interdependent activities of others", and "liaising with other units"), but again do not describe the activity (i.e. what would "liaising" look like?) On the other hand, items 2, 6, 8 and 9 ("reviewing plans with 
outside agencies", "preparing reports for governmental agencies", "giving briefings" and "writing letters") describe activities alone. Although they suggest the informational function given in the macro literature, it is not clear from the description of activities alone what the purpose of these activities might be.

Miles' work represents an important first step at refining the boundary spanning concept from the rather abstract picture given in the macro literature. However, it also reinforces the need to distinguish between activity and function in its conceptualization. The items on information dissemination (e.g., letter writing) were instructive in this regard. These items reflect activities that are consistent with a boundary spanning role, but seem rather meaningless when divorced from their purpose. From a role theory perspective, these activities lack a referent system. According to role theory (Kahn et al., 1964), a defining feature of role behaviour is system relevance. A behaviour is "in role" if it is performed by a member of the system and is consistent with the general set of behaviours expected of the role incumbent by other system members (Ibid.). However, an in-role behaviour is not necessarily an effective behaviour. To use an example from Kahn et al., a line worker who operates a machine badly on a given day is still behaving in role, since machine operation is among the set of behaviours expected of someone holding the line worker job- - even if the in-role behaviour that day is unsatisfactory to coworkers. This suggests that in-role (i.e., system relevant) behaviour may be either effective or ineffective, depending on the extent to which it supports the needs of the system.

Role theory, therefore, suggests that it is not possible to fully characterize a 
boundary behaviour without reference to the organizational system of which it is a part. The notion of system relevance appears to be missing throughout Miles' work. It seems, however, a necessary basis for judging effectiveness. Indeed, Ancona and Caldwell's research, described next, provides an example in which an in-role activity that was out of step with the productive work of the system resulted in ineffective performance in the boundary spanning role.

Ancona and Caldwell $(1988 ; 1992)$ provide the only comprehensive empirical examination of boundary transactions at the micro level. In a series of two studies of product development teams in seven microelectronics firms, they used qualitative and quantitative methods to characterize the content and purpose of the teams' contacts with organizational members outside of the team. Although their research used a group level of analysis (the team), and examined the crossing of internal boundaries only, it provides insights that are very useful to the conceptualization of boundary spanning at the individual level.

The first study (Ancona and Caldwell, 1988) applied qualitative methods to obtain an initial description and classification of the teams' external transactions during a target (ongoing or recent) research project. Interviews were conducted with 38 team managers, asking them to describe activities that they and their team members carried out with people outside the team boundaries. Interviews were semi structured, allowing the researchers to probe for details surrounding each transaction, including rationale for the various transactions. Additionally, logs were obtained from 15 team members of two of the teams, in which were recorded all interactions with people outside the team. 
Interview and log data were combined and content analyzed to yield the classification of boundary behaviours given in Table $2-3$.

\begin{tabular}{|c|c|}
\hline \multicolumn{2}{|c|}{$\begin{array}{l}\text { Classification of boundary behaviours of R\&D teams (Ancona and Caldwell, } \\
\text { 1988) }\end{array}$} \\
\hline Behaviour & Description \\
\hline Modelling & $\begin{array}{l}\text { Talking with people internal and external to the group to map the external } \\
\text { environment and to identify potential allies and trouble spots }\end{array}$ \\
\hline Gathering information/resources & $\begin{array}{l}\text { Focussed search for information and resources, flowing from the task demands, } \\
\text { "shopping list" }\end{array}$ \\
\hline Scanning & $\begin{array}{l}\text { Less focussed search, monitoring of external environment for potential threats } \\
\text { or opportunities, not necessarily relevant to immediate task demands }\end{array}$ \\
\hline Feedback seeking & $\begin{array}{l}\text { Talking with externals to collect their perceptions of team's progress or } \\
\text { functioning }\end{array}$ \\
\hline Opening communication channels & $\begin{array}{l}\text { Introduce someone from the team to externals for the purpose of establishing a } \\
\text { relationship, precursor to anticipated transactions }\end{array}$ \\
\hline Informing & Keeping other groups apprised of team's progress \\
\hline Coordinating/Negotiating & $\begin{array}{l}\text { Communicating with externals where there is a workflow or other } \\
\text { interdependency, often schedule related }\end{array}$ \\
\hline Molding & $\begin{array}{l}\text { Deliberate efforts to influence externals to support the work of the team and to } \\
\text { suit the team's agenda, "profile/image management" }\end{array}$ \\
\hline Allowing entry & $\begin{array}{l}\text { Inviting externals to provide input/participate to secure information or } \\
\text { resources }\end{array}$ \\
\hline Translating & $\begin{array}{l}\text { Bridging differences in language or worldview between team and externals by } \\
\text { "translating" jargon or "interpreting" respective needs }\end{array}$ \\
\hline Filtering & $\begin{array}{l}\text { Taking information from outsiders and delivering smaller amount to the group } \\
\text { (often keeping political or troubling information from the team) }\end{array}$ \\
\hline Classifying & $\begin{array}{l}\text { Delaying response to an external request for information or resources while } \\
\text { analyzing implication for team }\end{array}$ \\
\hline Delivering & Provision of information or resources to externals \\
\hline Protecting & Refusal to provide information or resource to externals \\
\hline
\end{tabular}

Ancona and Caldwell's classification can be seen to provide a much richer conceptualization of the boundary spanning role than did Miles' early attempt. First, it provides a more comprehensive exploration of the multidimensionality of the boundary spanning role at the individual level. Second, the directionality of the adaptive function is clearly specified for each activity (e.g., "provision of information to externals" 
specifies outward flow, whereas "inviting externals to provide input" specifies inward flow). Third, all of the behaviours incorporate both an activity and the purpose of that activity. The classification even identifies two categories in which the absence of activity serves an adaptive function (i.e., protecting the work of the system by delaying response to outsiders, and refusing to provide information and resources). Finally, consistent with Kahn et al.'s definition of a role behaviour, purpose is defined in terms of system relevance. If the team is considered the referent system, all of the activities can be seen to relate to providing support or protection for the core work of this system. In this sense, Ancona and Caldwell's classification provides clear parallels with the macro notion of organizational "adaptability". Their classification suggests how individual boundary transactions might translate to adjustments at the broader system level (ie., it bridges behaviour at the micro level to adaptive behaviour at the macro level). For example, many of the behaviours they observed at the micro level (e.g., molding, classifying, filtering) align directly with the macro functions of representation and control given in Table 2-1.

The adaptive function served by boundary activities is further refined in Ancona and Caldwell's second study. In this study, they used quantitative techniques to identify the factors underlying the initial list of behaviours. From the original classification, they developed a 24-item questionnaire and administered it to 400 members of 45 product development teams located in a subsample of the original firms. Respondents were asked to rate on a Likert format the extent to which each activity was part of their responsibility in dealing with people outside the team. Factor analysis yielded a typology 
of four functional categories of boundary spanning behaviour. The four factors split or recombined many of the activities that had been identified in the qualitative study. The final four functional categories are given in Table 2-4.

\begin{tabular}{|l|l|l|}
\hline Table 2-4: & \multicolumn{2}{|l|}{$\begin{array}{l}\text { A typology of boundary spanning activities in the R\&D team (Ancona and } \\
\text { Caldwell, 1992) }\end{array}$} \\
\hline $\begin{array}{l}\text { Functional } \\
\text { activity }\end{array}$ & Purpose of activity & Sample items \\
\hline Ambassador & $\begin{array}{l}\text { Protect and represent: } \\
\text { buffer team from outside } \\
\text { pressures, persuade others to } \\
\text { support the team, lobby for } \\
\text { resources }\end{array}$ & $\begin{array}{l}\text { "Prevent outsiders from overloading the team with too much } \\
\text { information or too many requests" } \\
\text { "Finding out whether others in the company support or oppose your } \\
\text { team's activities" } \\
\text { "Scan the environment inside the organization for threats" } \\
\text { "Talk up the team to outsiders" }\end{array}$ \\
\hline Scout & $\begin{array}{l}\text { General scanning for ideas and } \\
\text { information about the } \\
\text { competition, the market, or the } \\
\text { technology }\end{array}$ & $\begin{array}{l}\text { "Find out what competing firms or groups are doing on similar } \\
\text { projects" } \\
\text { "Collect technical information from individuals outside the team" }\end{array}$ \\
\hline Task coordinator & $\begin{array}{l}\text { Specific interactions aimed at } \\
\text { coordinating technical or design } \\
\text { issues }\end{array}$ & $\begin{array}{l}\text { "Resolve design problems with external groups" } \\
\text { "Negotiate with others for delivery deadlines" } \\
\text { "Procure things the team needs from other groups" }\end{array}$ \\
\hline Guard & $\begin{array}{l}\text { Controlling external demands for } \\
\text { information/resources }\end{array}$ & $\begin{array}{l}\text { "Keep news about the team secret from others in the company until } \\
\text { the appropriate time" } \\
\text { "Control the retease of information from the team in an effort to } \\
\text { present the profile we want to show" }\end{array}$ \\
\hline
\end{tabular}

This typology can be seen to be cast entirely from a functional perspective.

Discrete activities (e.g., collecting technical information, negotiating) are no longer the basis for classification and have no meaning when removed from the function they serve. For example, "finding out whether others support the team" and "finding out what competing groups are doing on similar projects" would both be classified as "information collection" from a broad macro perspective, but within this functional typology, would fall within separate categories. Although similar in face value, they serve different adaptive purposes. The first is an ambassadorial activity, a political move aimed at identifying potential allies and adversaries. The second is a scout activity, a search for 
task-related information.

Although not shown in the table, Ancona and Caldwell concluded their study by correlating the four activity categories with team performance as rated by superiors. Interestingly, higher levels of boundary spanning activity were not always associated with high performance ratings. Teams high in ambassador and task coordinating activities were rated as high performers. Teams high in scout activity were rated less favourably. The authors attribute this finding to the possibility that scouting (i.e., environmental scanning for ideas and information) serves an adaptive function only in the early stages of a project. In the later stages, continued scouting may reflect an inability to take a decision and commit to a plan of action. This finding provides some empirical evidence of the distinction between engaging in an in-role behaviour and performing effectively in the role. Whereas scouting is a behaviour consistent with the boundary spanning role (i.e., is an appropriate in-role behaviour), it leads to effective performance only where it is aligned with the productive work of the system.

\subsection{Summary and implications for further conceptual development}

The literature reviewed above lays the groundwork both for characterizing the boundary spanning role and for beginning to identify the potential conditions for individual effectiveness in the role. Open systems theory is responsible for giving us the term "boundary spanning". It defines organizational effectiveness in terms of adaptation to the environment and identifies the organization's boundaries as the sites of this adaptive function. According to systems theory, a boundary position is one that places 
the incumbent at the organization's periphery in order to effect a transaction with the environment. The transaction is effective to the extent that it serves an adaptive purpose for the organization.

Role theory provides the conceptual link between boundary spanning at the organizational level and boundary spanning at the level of individual behaviour. It suggests that when studying "organizational adaptation", the place to begin is, not with the organization as a whole, but with the impact of the environment on incumbents of boundary positions in the immediate vicinity of the environment-organization relationship (Aldrich and Herker, 1977). Role theory bridges to intra-organizational processes by defining boundary positions in terms of the incumbent's role within a social system. According to role theory, a boundary position is any position for which some members of the social system (role set) are located in a different organizational system. An individual in a boundary spanning role is effective to the extent that his or her transactions contribute to the productive work of the system.

Combined, the theoretical perspectives suggest that in order to characterize the role at the individual level (i.e., the dimensions of the boundary spanning role; Research Objective 1), it is necessary to include both a description of the boundary activities associated with the role and the adaptive purpose of these activities. The importance of distinguishing between activity and purpose was echoed in the empirical literature. Ancona and Caldwell's functional typology provides a much more meaningful depiction of boundary spanning than the picture provided by Miles' somewhat "mixed" classification. It illustrates at the micro level the wide range of "inputs" and "outputs" 
mediated by boundary incumbents (i.e., it specifies the exchange as involving information, material resources, legitimacy, political support, etc.). It identifies the direction of the adaptive exchange (e.g., a "molding" effort flows outward to shape the attitudes or behaviours of outsiders, whereas a "filtering" effort flows inward to distill information to a form useable by organization members). Most importantly, by being cast from a functional perspective, Ancona and Caldwell's typology suggests the means by which the boundary transactions of organizational members might ultimately translate to adaptive behaviour at the macro level. Their work reinforces the notion that the effectiveness of a boundary activity can be determined only by identifying its contribution to the system of which it is a part.

However, this literature provides little information on how the individual's boundary activities might link to the productive work of the system. This means that conceptual work to date is of limited use in identifying the conditions for individual effectiveness in the boundary role (Research Objective 2). Both literatures would suggest that effectiveness at the individual level would be a function of the boundary spanner's ability to carry out boundary transactions that contribute to the work of the system. But, in turn, the boundary spanner's ability to identify transactions of potential value to the system- - and to successfully carry them out- - would likely depend on a number of conditions, including, for example, the boundary spanner's ability to determine what the organization expects in the boundary role, and the ability of the boundary spanner to act on these expectations at the point of contact with external agents. To date, empirical work at the micro level has been silent on the broader intra-organizational and inter- 
organizational contexts in which boundary transactions are embedded. Even Ancona and Caldwell, who make a substantial contribution to defining the boundary role at the micro level, use the team as the referent system, thus decontextualizing the work of the team from the work of the broader organizational system.

The literature is thus lacking in empirical exploration of the psychological "cement" (Katz and Kahn, 1966, p. 33) that binds the boundary spanner to his or her organizational and inter-organizational systems. How would individuals in boundary positions know what is of value to the organization? If they did, how would they apply this knowledge in their interactions with external constituents? In turn, how might the nature of interaction at the boundary affect individuals' willingness or ability to execute transactions at the local level?

The next chapter examines literature that can shed light on the intraorganizational and interface context in which the boundary spanner is situated. This literature contributes to a better understanding of the boundary spanner's actual experience within the organization and with external constituents. An understanding of this context helps to establish the conditions that might have to be met before an individual might be expected to perform effectively in the boundary role. 
As discussed in the previous chapter, a central contribution of the macro literature was to define organizational effectiveness in terms of environmental adaptability, and to identify the organization's boundaries as the site of the adaptive function. Role theory then provided a conceptual bridge for linking organizational effectiveness to individual performance. Role theory maintained that individual employees were moved toward system relevant behaviour by means of the expectations conveyed to them by their social systems. Given the social system as the structuring framework, boundary spanner effectiveness might be expected to be affected by contextual factors that fall into two broad categories.

The first category would consist of factors emanating from the individual's membership within the organizational system (intra-organizational context). If an individual's behaviour is shaped by the expectations of others in his or her role system, it follows that the individual cannot perform effectively within that system without an understanding of the organization's expectations for performance. Organizations may be expected to vary in their propensity or ability to communicate role requirements and performance expectations. The boundary spanner's access to role cues within the work environment may thus be an important condition for individual effectiveness in the role.

However, the ability to identify and act on the expectations of the organization would in itself not be sufficient for effective performance in the boundary spanning role. The macro framework also indicates that an important part of the adaptive function is to ensure that the organization is able to detect environmental changes, and where 
necessary, make internal adjustments accordingly. At the micro level, this suggests that a key part of the boundary role is not only to act in accordance with the organization's expectations, but also to identify instances where these expectations may be misaligned with changing environmental contingencies. A further condition for effective performance in the boundary role arising from the intra-organizational context may be the boundary spanner's ability to convey to organizational decision makers environmental information with implications for the organization's performance.

The second category of contextual factors related to individual effectiveness would be those emanating from the boundary spanner's membership within extraorganizational systems (interface context). Boundary spanning is by definition an interface construct. Boundary spanners are defined by their membership in two or more social systems: their own organizational system and the systems of their external constituents. What happens at the interface of these domains, including the dynamics of exchanges with external constituents and the strategies boundary spanners use to manage these exchanges, might also be expected to affect individual effectiveness.

This chapter examines studies from both the boundary spanning literature and related literatures that can help to shed light on the boundary spanner's intraorganizational and interface context. These literatures provide the foundation for identifying the conditions for effectiveness at the individual level. The first section looks at intra-organizational context, including the various features of the work context that might convey role expectations to boundary incumbents, and factors related to boundary incumbents' ability to convey environmental information back into the organization. The 
second section looks at the interface context to explore the dynamics of boundary exchanges and the strategies boundary spanners might employ to manage these exchanges. The chapter concludes with a summary of the implications of this literature for conceptualizing the conditions for individual effectiveness in the boundary spanning role.

\subsection{Intra-organizational context}

\subsubsection{Organizational communication of role expectations: Work context and job design features}

Again, it is Kahn et al.'s role theory (Kahn et al., 1964; Katz and Kahn, 1966) that provides the theoretical basis for studying the ways in which organizations communicate to employees what is expected of them in their work roles. To this point, the discussion of role theory has centred on the expectations that are communicated to boundary spanners by members of their role set. Supervisors, of course, are very salient members of this set, so are critical sources of information regarding role expectations and performance feedback. Kahn and colleagues, however, argue that work role expectations also tend to become formalized in the broader organizational system. In addition to the explicit or implicit role sending involved in day-to-day interactions with other system members, role cues also tend to become "hardwired" in a variety of features of the work context and the job itself.

Generally, the theoretical and empirical literature addressing role cues emanating from the work context has been framed from the perspective of role stress (for review and discussion, see Jackson and Schuler, 1985; Ilgen and Hollenbeck, 1991). In 
particular, the role stress literature has concerned itself with identifying specific aspects of job design and supervision that might be modified so as to ameliorate role ambiguity. Although the role stress literature, again, is beyond the scope of this research, it is useful in identifying the work context features that are associated with the communication of performance expectations. Work context features that reduce role ambiguity (defined as a lack of clarity around what is expected and rewarded in the work role; Schuler, Aldag and Brief, 1977) are typically features that communicate role expectations.

In a meta-analysis on role stress, Jackson and Schuler (1985) identify five work context and job design features that are associated with reduced ambiguity and which are of potential interest to this research: leader initiating structure, formalization, job autonomy, feedback from the task, and task identity. Each of these features has its own extensive literature (see Hackman and Oldham, 1976; Ilgen and Hollenbeck, 1991), so will be discussed only briefly here.

Initiating structure is defined as the degree to which the supervisor initiates psychological structure for employees through the assignment of tasks, procedural specification, scheduling of work, and articulation of work expectations (House, 1971). Supervisor initiating structure has been associated with significant reductions in role ambiguity (Jackson and Schuler, 1985). A supervisor who exercises a high degree of initiating structure can act on ambiguity at its source by providing direct information regarding work goals and how to attain them. Supervisor role cues might be expected to be especially powerful within an individual's role set, due to the supervisor's legitimate authority within the organizational system. 
Formalization can be defined as the extent to which procedures, guidelines, work objectives and responsibilities in an organization are documented in writing (Podsakoff and MacKenzie, 1994; Pugh, Hickson, Hinings, and Turner, 1968). Like leader initiating structure, written products, such as job descriptions and work procedures, can provide direct information regarding role requirements, so tend to be associated with significant reductions in ambiguity (Schuler and Jackson, 1985). Also as might be expected, however, the positive effect of formalization tends to be limited to employees in fairly routine jobs, such as administrative, clerical or production workers, where tasks are predictable and can be specified in advance (Ibid.). For employees working in more complex jobs, such as managers and professionals, jobs become less amenable to formalization, and the relationship between formalization and role ambiguity attenuates (Ibid.). Work by Sawyer (1992), however, distinguishes between ambiguity surrounding the goals to be attained and ambiguity surrounding the process needed to achieve them. This suggests that in complex jobs or complex work environments, formalization may still provide a means of clarifying role expectations by communicating broad goals to employees, while allowing them the autonomy to determine the means to achieve them (Ibid.).

Job autonomy is defined as the degree to which the job provides freedom, independence, and discretion to the incumbent in terms of scheduling the work and determining the procedures for carrying it out (Hackman and Oldham, 1975). Autonomy has been found to be negatively related to role ambiguity (Schuler and Jackson, 1985), although the reason for the relationship is not clear (Ibid.). Discretion alone would seem 
to carry no particular information regarding role requirements. One explanation might be that the effect of autonomy on ambiguity is confounded by job level. For example, intuitively, it would seem that jobs that are high in autonomy might also be jobs that are higher within the organization. Ambiguity might then be reduced because those higher in the organization are closer to decision makers who can articulate clear goals. In this case, the favourable effect on ambiguity would be attributable, not to autonomy, but to access to other organizational cues for performance (e.g., role sending from others in the work environment). Role ambiguity, however, has been shown to be unrelated to hierarchical level (Ibid.) Singh (1993) argues that job autonomy reduces ambiguity, not because it provides any clarity regarding role expectations, but because it acts as an "across the board" buffer (i.e., it is a coping mechanism that diminishes perceptions of ambiguity irrespective of the ambiguity inherent in the work context). An alternative, and as yet unexplored, explanation is that autonomy provides greater clarity around roles because, in the absence of clearly defined expectations, incumbents define their own roles and work toward their own objectives. This hypothesis would be consistent with the observation that ambiguity is reduced among employees with a strong internal locus of control (Jackson and Schuler, 1985).

Task feedback is defined as the degree to which carrying out the work activities required by the job provides the individual with direct and clear information about the effectiveness of his or her performance (Hackman and Oldham, 1975). Ambiguity is reduced in situations where the nature of work tasks enables the incumbent to obtain direct knowledge about the results of his or her work, thereby facilitating learning of the 
expected role (Singh, 1993).

Task identity refers to the extent to which a person is able to see the impact of his or her efforts in the form of a visible and complete product or service (Jackson and Schuler, 1985). Like task feedback, task identity shows a moderate to strong negative correlation with ambiguity (Ibid.). Employees who are able to see the "total" job are more likely to know what is expected of them, since they can see their fit in the larger organizational scheme, especially in terms of their interdependence with others in their role set (Ibid.).

Although this discussion of work context has been rather cursory, it serves to map out the various components of the work environment that can serve to transmit important role requirements to organizational members. Clear articulation of what the organization expects in the way of job responsibilities and performance would seem to be a fundamental condition for effective performance in any work role. What is of interest in the case of boundary spanning, however, is the degree to which it would be possible- - or, indeed, desirable- - for an organization to attempt to specify in advance the full requirements for the role.

The literature reviewed here identified two important aspects of the communication of role expectations: the communication of goals or objectives for the role and communication of the activities (procedures) required to attain them. In the case of the boundary role, it would seem that procedural specification would be either impossible or deleterious to performance, since the nature of specific activities with external agents would be highly unpredictable and outside of the organization's control. 
Much of the seminal work on work context features was conducted over thirty years ago, and was based largely on samples drawn from manufacturing firms (e.g., Rizzo, House and Lirtzman, 1970; House and Rizzo, 1972), where procedural specification was feasible. The nature of the boundary role in the contemporary organization, however, is such that a more appropriate approach might be to specify broad objectives, while allowing incumbents the discretion to determine how to attain them. It is conceivable that work features might be modified in such a way that they specify organizationallyvalued objectives for the boundary role, rather than procedures. Such an approach would be consistent with Sawyer's (1992) recognition of the distinction between goal clarity and process clarity. Unfortunately, there exists no empirical work that has examined the relationship between work context features and effectiveness in the boundary role.

\subsubsection{Boundary spanner ability to influence strategic decision making}

A second intra-organizational factor with relevance to effectiveness in the boundary role is the boundary spanner's ability to influence strategic decision making. Influence has been defined as the ability of an individual to affect the outcome of a strategic decision (Jemison, 1984). A strategic decision has been defined in a number of ways, but most definitions tend to emphasize a decision related to the organizationenvironment interface. Strategic decisions are normally cast as decisions that are externally focussed, distinguishing them from routine decisions that are internally focussed and concerned with the organization's daily functioning (Ansoff, 1965). 
Examples of definitions include:

... a decision with intentions of alignment between the organizational external environment and the organizational internal processes and structure (Miles and Snow, 1978)

... an important decision that helps the organization survive and adapt to a changing environment (Pinfield, 1986)

... a decision that profoundly affects the future success and destiny of the organization by assuring that it is adequately responsive to environmental requirements (Jemison, 1984)

These definitions suggest that, whereas the scope of a strategic decision may vary (i.e., decisions ranging from those having a "profound" effect on future success to those involving more minor adjustments of internal process or structure), strategic decisions are generally aimed at increasing the organization's alignment with the external environment.

Given that the defining feature of a strategic decision is its focus on organizationenvironment alignment, the link to the individual boundary spanner is apparent. If an organization's only points of contact with its external environment are its boundary spanning agents (Organ, 1971), then the ability of organizational decision makers to avail themselves of the specialized knowledge of these agents would seem critical to their ability to make environmentally responsive decisions (Ashill, Meadows and Stewart, 2001; Jemison, 1984). This suggests that, in order for individual boundary spanners to perform this function, they would need either to have access to organizational mechanisms that gather relevant information from the boundary or they must themselves have sufficient influence in the organization to get their boundary information "on the screen" of decision makers.

At the time of this writing, there existed no empirical literature on boundary spanner access to organizational structures or processes designed to gather relevant 
information from the boundary. Indeed, one of the primary objectives of this research was to identify ways that organizations might support their boundary spanners in their role, one of which might be expected to be the development of such mechanisms. There was, however, a very interesting body of literature addressing the influence aspect. This section reviews literature related to the potential influence of boundary spanners on internal agents. The influence literature sheds light on a number of factors internal to the organization that may enhance or constrain boundary spanners' ability to perform effectively in their boundary roles.

Prior to reviewing this literature, it is necessary to develop a definition of "strategic influence". As will be discussed later in the chapter, much of the influence literature has been based on the study of managers. Accordingly, strategic influence has tended to be defined as the ability of managers to directly engage and influence top decision-makers (e.g., Watson and Wooldridge, 2005). This definition seemed insufficient, however, to capture the potential influence of boundary spanners lower in the hierarchy; most of whom would not have opportunity to partake in sush stralsgis discussions. It was conceivable, however, that non-management employees might have the potential to influence strategy if they could, directly or indirectly, report changing contingencies or otherwise convey their learning upward through the hierarchy. For the purpose of this research, therefore, we define "strategic influence" as the ability of the boundary incumbent to either participate directly in the strategic decision making process or to transmit boundary information to internal agents with strategic decision authority. This more inclusive definition recognizes that proximity to the strategic 
decision making process is a function of hierarchical level, and allows an examination of influence efforts at both management and non-management ranks.

The first part of this section presents the theoretical foundations of the strategic influence literature. The second presents empirical work that has examined influence in the context of boundary spanners. Since influence literature dealing specifically with boundary spanners is sparse, the third section looks at the broader literature on strategic influence in order to obtain a fuller understanding of the intra-organizational contextual. factors associated with influence. The concluding section summarizes the influence literature in terms of its implications for the conceptualization of the conditions for individual effectiveness in the boundary spanning role.

\subsubsection{Theoretical origins of the strategic influence literature}

The influence literature is rooted in social network theory (Tichy, Tushman and Fombrun, 1979). A social network can be defined as a set of linkages among a defined set of persons where the characteristics of the linkages as a whole may be used to interpret the social behaviour of the persons in the set (Mitchell, 1969). Whereas role theory looked at first-order social linkages only (i.e., a role set comprised only those with whom the focal person had direct contact), social network theory extends the social system to include all of the direct and indirect linkages within the focal person's system (Tichy et al., 1979).

According to social network theory, the location of members within a network can emerge informally through social interactions or can be bureaucratically specified 
through the chain of command or division of labour (Tushman and Romanelli, 1983). Linkages between members are established and maintained through social transactions. Individuals achieve influence over other network members via these transactions. Transactions involve content of four types: exchanges of goods or services; exchanges of information; exchanges of power; or exchanges of affect (Tichy et al., 1979).

Examples of these four exchanges are given by Brass (1984). An exchange of power is normally associated with hierarchical position (i.e, a network member is influential because she is "the boss" and has legitimate authority over other members). The other three transaction types are typically associated with resource dependence: a given network member has influence over others because he controls a resource on which other members depend. Control of resources by one actor implies that others in the social relationship have few alternative sources, so the actor is said to "mediate" access to the valued resource (Thompson, 1967). In the case of an exchange of goods or services, the valued resource is something needed to support the workflow (e.g., an ability to supply needed materials or to dispose of workflow outputs). In an exchange of information, the relevant resource is access to the information itself. In an exchange of affect, the valued resource is friendship. Friendship resources are normally not of themselves related to influence, but are instrumental in obtaining resources that are, such as information or resources needed to support the workflow.

Management researchers who have examined boundary spanning from the social network perspective maintain that boundary spanners achieve influence via resource control (Manev and Stevenson, 2001a). As compared to employees whose networks 
consist entirely of other organizational members, boundary spanners' networks, by definition, include outsiders. Their unique external networks place them in a position to mediate critical environmental contingencies (dependencies) between internal and external constituents (Thompson, 1967). For example, their external network might afford them access to information resources (e.g., market information), workflow resources (e.g., an ability to obtain low-cost supplies) or affect resources (e.g., external contacts and relationships) that are valued by other organizational members. According to social network theory, boundary spanners would gain influence over organizational decision makers to the extent that they mediated access to these resources and the resources were perceived as critical to organizational functioning.

Social network theory is of value to this research since it suggests that boundary spanner effectiveness may be as much a function of the ability to influence internal agents as it is a function of the ability to influence external agents. If boundary transactions are to be of strategic value to the organization, the boundary spanner must be able to influence internal agents so as to reach decision makers who are in a position to take action (Organ, 1971). By including in the analytic framework all of the direct and indirect linkages in the boundary spanner's network, it calls attention to the fact that, typically, most of the boundary spanner's network is indeed internal (Manev and Stevenson, 2001a). Whereas role theory focussed largely on the outward influence of a boundary agent in effecting organizationally valued transactions (e.g., making a sale, negotiating a price, making a presentation to stakeholders), social network theory serves as a reminder that boundary spanner effectiveness is also a function of inward influence. 


\subsubsection{Empirical studies of boundary spanner influence}

This section describes empirical studies of the boundary spanning role that have been taken from the social network perspective. First, it presents studies that have examined the relationship between boundary spanner influence and control over information resources. It then presents research that has looked at influence as a function of control over workflow and friendship resources. Since the conclusions that can be drawn from this literature tend to be limited by the homogeneity of the samples used (comprising either exclusively managers or exclusively non-managers), the section concludes with a discussion of the implications of job level for boundary spanner influence.

\subsection{Control over information resources}

The majority of studies on boundary spanner influence have focussed on transactions involving information exchanges. Work by Tushman and colleagues (Tushman and Romanelli, 1983; Tushman and Scanlan, 1981a; 1981b) provides a nice illustration of the importance of inward influence in the boundary spanning role. In a series of studies of R\&D professionals in a U.S. medical instrument firm, they divided employees into three categories: those who were well integrated in the internal communications network but not were not in boundary positions ("internal communication stars"); those who were highly linked externally, but not well integrated in the internal network ("external communication stars") and those who were strongly linked both internally and externally ("dual spanners"). 
Using a measure involving peer nominations of individuals with perceived influence, they found that the individuals perceived to be most influential were those who were either internal stars or dual spanners. External stars who were strongly connected to outside constituents but not integrated in the internal network were not seen as influential (they were social "isolates"; Tichy et al., 1979). The authors noted that external stars were primary sources of external information and new ideas, but were unable to transmit this information due to lack of access to the intra-organizational network. They concluded that informational boundary spanning was a two-step process: (1) searching out and finding timely and organizationally relevant information; and (2) disseminating this information in organizationally meaningful terms. Both steps require extensive internal knowledge of the organizational context and information needs. Combined, these findings imply that, in order to be effective, informational boundary spanners must be aware of contextual information on both sides of the boundary. They need to have sufficient knowledge of their external environment to source and obtain their information, and they need sufficient knowledge of the organizational context to know what information is needed and how to best "translate" it for internal use.

Other studies of information exchanges support the idea that influential boundary spanners are those who know "both sides of their boundary". Manev and Stevenson (2001a), in a study of informational networks among managers in a U.S. urban transit authority, found a curvilinear relationship between boundary spanning and individual influence. Internal influence rose with the extent of external contacts, and then decreased for network members with extremely high external orientations. Similarly, 
using a measure of peer-rated influence in a study of non-supervisory boundary spanners in a newspaper publishing firm, Brass (1984) found influence to be greatest for those with greatest access to the department's internal communications network.

\subsection{Control over workflow and friendship resources}

Research examining the relationship between influence and other potential sources of resource control is rare. Only Brass (1984) has examined control over friendship resources. His work with newspaper publishing employees indicated that access to friendship networks did not explain significant amounts of variance in influence after controlling for access to internal informational networks. He interpreted this result as providing support for Tichy et al.'s (1979) assertion that friendship is not, of itself, an organizationally valued resource, but is valued for its instrumentality in gaining access to other resources. In this case, it was the information, rather than the friendship, that was the important factor in acquiring influence (i.e., friendship provided the basis for exchange of information).

Two studies have looked at control over workflow resources. The first is, again, Brass (1984). Brass found no difference in influence between boundary spanners (those with direct workflow contacts outside the organization) and technical core employees (those whose workflow connections were entirely inside the organization). He noted that this finding was likely a function of the occupation of boundary spanners in his sample. All of his boundary spanners were personnel responsible for classified ad sales. These employees had many direct links to external agents (customers), but the organization 
employed many persons in the sales capacity, the job of taking classified ads was highly routinized, and the task environment was perceived as relatively predictable. Thus, although the boundary positions were the only points of contact to customers, individuals were perceived as highly interchangeable, and they were rated as having little influence. Brass' non-finding on the influence measure therefore supports the social network perspective. According to social network theory, influence would stem from boundary spanners' perceived ability to mediate crucial environmental contingencies for the organization (Thompson, 1967). In this case, it appeared that the organization-customer interface was not perceived to be a crucial contingency. The organization apparently did not perceive the market to be uncertain, and believed that sales could be performed by many people. No individual was perceived as influential, since there were many "transaction alternatives" (i.e., others who could be substituted to perform the transaction).

In contrast, Jemison (1984) provides an example where boundary spanners were perceived to mediate an important workflow contingency and, in turn, were rated by peers as highly influential. In this case, the boundary spanning sample involved department heads in a general hospital setting whose transactions entailed the acquisition of a variety of key workflow resources: supplies, funding, and personnel. Jemison attributes these employees' influence to the importance hospitals place on containing costs while providing quality care. Employees in these boundary positions were perceived to deal with a critical contingency due to hospitals' combined need for low cost (i.e., government-regulated fee schedules) and quality inputs (i.e., high quality equipment 
and staff). According to social network theory, such employees would be perceived as influential since there would be no ready transaction alternative to the boundary relationships controlled by these individuals.

Both studies on workflow, therefore, suggest that boundary spanners are influential to the extent that they mediate a key organization-environment contingency. However, it is difficult to compare Jemison's findings to Brass' due to the large occupational difference in samples. The sales personnel in Brass' study appeared to be somewhat low-skilled employees who were perceived as "replaceable". In contrast, the hospital personnel in Jemison's study were relatively high-ranking managers with control over highly visible functional areas that, of themselves, may have been a source of internal influence (i.e., irrespective of the managers' boundary spanning roles). In fact, sample differences in job level create an interpretation problem for most of the studies discussed in this section. These studies can tell us little about the relationship between job level and boundary spanner influence, since all involve homogeneous samples consisting exclusively of either managers or non-managers.

\subsection{Job level and influence}

To date, there exists no empirical research that has compared the influence of boundary spanners in management positions to the influence of boundary spanners in non-management positions. Of the above studies, only Manev and Stevenson directly investigated the relationship between hierarchical level and influence. Their results indicated that boundary spanning was strongly related to influence, over and above the 
effect of job level. However, all of their study groups were managers of some type (i.e., categorized as top, middle, or lower management). Moreover, it is not possible to generalize from the findings of a single study to the population of boundary spanning managers in general, or especially, to boundary spanners in non-managerial positions.

Studies of exclusively non-managerial employees offer few additional insights.

One of the problems in comparing these studies to the studies of managers is the difference in the measures employed. Studies of managers tend to operationalize influence as self- or peer-rated influence over specific organizational decisions (e.g., influence over goal setting, policies and procedures; Manev and Stevenson, 2001a; influence over specific decisions identified by top management; Jemison, 1984). Since these measures use relatively clear referents, it is reasonable to conclude that influence extends over at least somewhat important decision areas. Conversely, studies of nonmanagers tend to operationalize influence through peer nominations, often using vague nomination criteria (e.g., "who are the most influential people in the laboratory"; Tushman and Romanelli, 1983; "list the names of persons whom you consider to be influential at the newspaper"; Brass, 1984). In the case of non-managers, therefore, it is not possible to determine whether influence is in any way "strategic influence". Whether the boundary transactions of lower-level employees are "on the screen" of either their own managers or higher-level decision makers remains unexplored.

This differential approach to measuring influence among managers vs. nonmanagers is a shortcoming of the empirical literature on boundary spanner influence. The measures used for non-management employees have simply never tapped influence 
on strategic issues. By measuring strategic influence only among managers, the empirical literature seems to be limited by an assumption that only managers are in positions to influence strategy. This assumption would not be consistent with the theoretical perspectives discussed in this chapter. Open systems theory would suggest that all boundary transactions are of potential strategic value. Social network theory in particular would maintain that even boundary spanners performing purportedly "routine" tasks (such as Brass' classified ad sales force) might perform multiple transactions over the course of a given interaction (such as an exchange of market information over and above the "routine" service exchange). This environmental information might be conveyed to those above them in the hierarchy via their indirect network linkages. It is at least conceivable that any boundary employee might achieve indirect influence over strategic decision making via the influence he or she is able to exert at the local level (e.g., influencing one's own manager). However, this possibility has not been investigated. We know little about strategic influence among non-managers.

In the absence of research on the relationship between strategic influence and job level among boundary spanners, the next section looks outside the boundary spanning literature. It asks the question: what are the factors associated with strategic influence in general? This body of research has generally been limited to the study of upward strategic influence at the mid-management level. However, it is of value to this research, since there is no a priori reason to believe that the factors associated with upward influence at the mid-management level would not also prevail at other levels. The midmanagement literature may provide insight around some of the intra-organizational 
contextual variables that may be associated with boundary spanner effectiveness at any level.

\subsubsection{A related literature: The strategic influence of mid-managers}

Interest in mid-manager influence on strategy has arisen in conjunction with interest in models of "emergent" strategy processes (Burgelman, 1983a; Wooldridge and Floyd, 1989). The notion of emergence is based on the observation that important strategic initiatives arise not only from the structured deliberations of the top management team, but also from the ideas and actions of the organization's managerial grassroots. Andersen (2004) suggests that emergence can occur in one of two ways. First, strategic issues can gain formal recognition as managers at lower hierarchical levels promote their ideas to top management until their ideas become part of formal strategy. Second, decision power can be dispersed throughout the organization so that lower level managers have sufficient autonomy to take their own initiatives in response to changing environmental conditions. In this case, emergence occurs when independent actions taken by mid-managers later become essential elements of the organization's official strategy.

Mid-managers are at the centre of emergent strategy models due to their unique intermediary positions in the organization (Wooldridge and Floyd, 1989). Since they are connected to both the operational and top management levels, mid managers are perceived as critical links in supporting initiatives from operating levels while ensuring that strategic decisions "from above" are being considered in a realistic context 
(Wooldridge and Floyd, 1990). In this sense, they can be viewed as "vertical boundary spanners", bridging the worldviews of upper and lower levels of the organization. However, they also have traditionally been viewed as key external boundary spanners, with formal responsibility for liaising between the organization and its customers, suppliers, and other critical stakeholders (Mintzberg, 1973; Floyd and Wooldridge, 1997). Mid-managers are thus strategic "linking pins" (Organ, 1971) on two planes. Through their external linkages, they mediate, negotiate, and interpret connections between the organization and the environment (Floyd and Wooldridge, 1997). Through their vertical linkages, they can exert upward and downward influence to align the organization with that environment (Ibid.). Not surprisingly, research looking at the outcomes of mid-manager strategic involvement indicates that better decisions are made when top management avails itself of the contributions of its mid-management cadre (Burgelman, 1983a; Collier, Fishwick and Floyd, 2004; Hart, 1992; Wooldridge and Floyd, 1990).

The subset of the mid-manager literature of relevance to this research is recent qualitative work on "issue selling" by Dutton and colleagues (Dutton and Ashford, 1993; Dutton et al., 2001) . Dutton et al. define issue selling as the "process by which individuals affect others' attention to, and understanding of, the events, developments, and trends that have implications for organizational performance" (Dutton et al., 2001, p. 716). According to Dutton et al., organizations are "pluralistic marketplaces of ideas" (Ibid., p. 716) in which issues are "sold" via the persuasive efforts of managers and selectively "bought" by top managers who set the strategic direction. They thus cast issue 
selling as a primary micro level link to organizational adaptation at the macro level.

Of central interest in the Dutton et al. studies were the contextual and psychological factors underlying mid-managers' selling attempts. They believed that, if a primary means of adaptation was to harness mid-managers' ideas, it was important for organizations to understand managers' motivations to sell and the factors associated with their success. Their objective was to identify managers" perceptions of "what works" in their organizations: their implicit theories-in-use (Agyris and Schon, 1982) surrounding the organizational context of norms, values, and routines that shaped their behaviour.

Through structured interviews with 42 mid-level managers in a large U.S. teaching hospital, the researchers asked respondents to recount specific incidents in which they had tried to direct the attention of the top management team to a particular issue. Respondents were prompted to recount both a successful and unsuccessful attempt. Content analysis identified three categories of issue selling "moves".

The first category was labelled "packaging" moves. Packaging generally reflected how an issue was framed, the way it was presented, and the way its relevance was established. The most common packaging tactic was to control the issue's presentation: to use the logic of a business plan (e.g., to present the issue as a bottom line issue and "run the numbers"; to make continuous proposals (e.g., repeatedly selling over time, "readying the receiver"); or to package the issue as incremental (i.e., chunking it into what appeared to be small wins to make it more "palatable"). The second packaging tactic was to bundle the issue with other ideas that held currency in the organization (e.g., tying the issue to current organizational goals, such as profitability, 
market-related issues, or the concerns of key constituents).

The second category was labelled "involvement" moves. This tactic pertained to the decision to "go solo" or to involve others in the issue selling effort. The involvement of others normally represented a deliberate effort to make an issue more visible, to grow a coalition, or to ensure broader and sustained attention or acceptance. Going solo was perceived in some instances as risky to personal reputation or credibility. Engaging others was perceived to reduce that risk. The most common tactic was to involve others at a higher level. Involving one's own manager was a more frequent tactic when midmanagers perceived their managers to be supportive and open. Respondents also variously involved those at the same level, those outside the organization (e.g., a consultant), or those at a lower level (a manager's own employees). Involvement was both formal (e.g., committees) or informal (e.g., casual discussions).

The final category of issue selling involved "process" moves. The most common tactic mentioned in this category was preparation- - "doing one's homework" (e.g., collecting information, meeting with key people to be affected). The second most common tactic was to control the timing (opportunism, a sense of "now's the time", knowing who to involve at what stage).

Overall, successful efforts appeared to be those that were tied to the business plan, involved those at higher levels, and, as expected, were well prepared and timed appropriately. However, the choice of move and its ultimate success seemed contingent on the specific setting and circumstance. Dutton et al. concluded that issue selling was a complex process, deeply embedded in the organization's political and strategic context. 
They argued that, in order to sell an issue successfully, managers needed contextual knowledge in three areas.

First, they needed relational knowledge: knowledge of the relevant actors, their intentions, stakes, private goals, and territories. This need was illustrated in issue sellers' accounts of involvement and timing moves (e.g., knowing who needs to be involved, who is going to feel slighted, knowing where your own manager will stand on the issue). Second, they needed normative knowledge: knowledge of their organization's idiosyncratic ways of doing things, knowledge of what is accepted behaviour and what is not. This need was also evident in accounts of the ways in which they involved others or timed that involvement (e.g., knowing when to persist or when to quit; knowing that a formal mechanism was the "way to get things done around here"). Finally, they needed strategic knowledge: an understanding of the organization's goals, plans and priorities. This need was most evident in packaging moves, knowing how to frame the issue within existing priorities, and how to bundle it with existing issues. Without strategic knowledge, players could not tailor their selling efforts to what mattered in the organization.

Although quite removed from the boundary spanning literature, Dutton et al.'s work provides a useful framework for studying the individual and organizational factors that might be associated with boundary spanning effectiveness. A problem with existing empirical work on boundary spanning was its tendency to remove boundary spanners from their organizational context (e.g., Ancona and Caldwell's work with R\&D teams). This left the unanswered questions: how would boundary spanners know what they 
needed to pursue in order to support organizational objectives, and if they did, how would they go about conveying their knowledge to decision makers? Dutton et al.'s work calls attention to the contextual knowledge required by organizational members if they are to contribute to organizational strategy and enable decision makers to make environmentally responsive decisions. Dutton et al. argue that individuals who are attuned to the strategic context will be better equipped to selectively attend to their environments so as to identify issues of strategic relevance. Those who are attuned to the organization's relational and normative contexts will be better equipped to navigate those contexts in advancing their issues. It would seem that access to these forms of knowledge would be no less valuable to boundary spanners. As expressed by Dutton et al., "By failing to make sure that people are equipped with the knowledge to achieve effective selling from below, organizations rob themselves of this vital source of internal change initiatives" (Dutton et al., 2001, p. 731). One might equally argue that where organizations fail to equip their boundary spanners with the knowledge needed to sell their "issues" internally, they rob themselves of a vital source of environmental information.

\subsubsection{Summary}

The literature on intra-organizational context suggests two conditions for individual effectiveness in the boundary role. At the most basic level, the boundary spanner needs to know what the organization expects of him or her in the boundary role. The literature suggests it may not be feasible, or in all cases, desirable, to specify detailed 
procedures for boundary transactions. However, if boundary spanners are to perform transactions that support the core work of the organization, it would seem that they would need to be equipped with either an understanding of the organization's strategic direction or, at least, an understanding of some set of objectives at the local level. The literature indicates that role expectations are communicated through a wide variety of work context features, such as the design of the job, the level of autonomy afforded by the job, and the supervisor's ability to articulate performance objectives. It would seem that a necessary condition for effectiveness in the boundary role would be access to an intraorganizational environment that effectively communicates the expectations for the boundary role.

The literature also suggests that, in order to perform effectively in the boundary role, it is not enough to be able to identify and act in accordance with the organization's expectations. A key part of the boundary role is to detect instances where these expectations may be misaligned with changing environmental contingencies. A further condition for effective performance, therefore, may be the boundary spanner's ability to convey to organizational decision makers environmental information with implications for the organization's performance. Social network theory suggests that boundary spanners need to be sufficiently connected internally to become part of the "strategic conversation" (Westley, 1990). The literature on boundary spanner influence by Brass (1984), Manev and Stevenson (2001a), and Tushman and colleagues (Tushman and Romanelli, 1983) identifies the potential threat to effectiveness posed by lack of connectedness to internal networks. Boundary spanners who achieve greatest influence 
appear to be those who are internal communication "stars". As expressed by Tushman, effective boundary spanning is a "two-step process" of searching out key information and disseminating it. This process would appear to demand a high level of knowledge of the organizational context, knowledge that is accessible only through strong internal networks.

The literature on mid-management influence adds to our understanding of internal influence by providing insight into the forms this contextual knowledge might take. Dutton et al.'s work suggests that influence requires substantial knowledge of the organization's strategic, relational, and normative contexts. Their work also suggests that this contextual knowledge shapes boundary spanners' motivations and their influence efforts.

\subsection{Interface context: Reconciling the expectations of internal and external constituents}

The previous section identified the boundary spanner's intra-organizational context as a potentially important determinant of effectiveness in the boundary role. However, boundary spanners are "dual citizens". They are defined by their membership in two or more social systems: their own organizational system and the systems of their external constituents. What happens at the interface of these domains might also be expected to affect boundary spanner effectiveness. The nature of boundary spanners' interactions with external agents may affect the degree to which boundary spanners are able and willing to work with these agents to effect organizational strategy at the local level. 
There exists virtually no literature that has examined individual experiences at the boundary. We, therefore, know little about the types of demands external agents might impose on boundary spanners or the rewards and challenges boundary spanners face in their dealings with external agents. We also know little about what strategies they might use to reconcile any differences in perspective that might arise over the course of their transactions.

This section of the review again turns to "nearest neighbour" literature to help identify some of the interface considerations that might need to be taken into account in developing a model of the conditions for effectiveness. We return to role theory, introduced in Section 2.1.2. As indicated in that discussion, Kahn et al.'s role theory triggered an enormous body of research on the role stress associated with participation in multiple social systems. Most of the role stress literature is beyond the scope of this thesis (for meta-analyses, see Tubre and Collins, 2000; Jackson and Schuler, 1985). What is of interest is Kahn et al.'s observations around the characteristics of the boundary position that made incumbents particularly susceptible to role stress. According to Kahn et al.'s original formulation, boundary role stress was a function of boundary spanners' perceived inability to exert control over their various constituencies. Boundary spanners were seen to engage in a number of tactics to acquire this control or to cope in its absence. Some of these tactics apparently enabled boundary spanners to reconcile the potentially competing demands of multiple constituents. Indeed, many of the boundary spanners in Kahn et al.'s study fared rather well, scoring low on tension measures in spite of reporting high demands. However, these interesting aspects of the 
boundary experience did not seem to attract subsequent research attention. As was the case with the boundary spanning construct itself (Section 2.1), conceptual work around the reconciliation of competing demands appears to have been abandoned in favour of empirical work around role stress.

This section of the review revisits Kahn et al.'s role stress literature with an eye to re-introducing these interface elements to the boundary spanning framework. The first subsection briefly reviews role theory to identify the "neglected" aspects of the boundary experience that were evident in Kahn et al.'s original formulation. Since empirical research has not subsequently addressed these phenomena, the second subsection reviews empirical literature peripherally related to interface experiences among boundary spanners. The concluding subsection summarizes implications for this research.

\subsubsection{Theoretical origins of the interface experience: Role stress theory}

As indicated in Section 2.1 .2 , role theory defines a boundary position as a position for which some members of the focal person's role set are located in a different organizational system (Kahn et al., 1964). Kahn et al. maintain that people in boundary positions are particularly susceptible to stress because they are the targets of role sending efforts originating in two or more systems: their employing organization and the systems of their external contacts. Since every episode of role sending involves an attempt to influence, the boundary spanner is often "caught in the cross fire" (Organ, 1971) between people who have differing expectations for his or her performance. To the extent that these expectations are mutually exclusive, the boundary spanner experiences role 
conflict. To the extent that expectations are unclear, the boundary spanner experiences role ambiguity. To the extent that expectations are too numerous, the boundary spanner experiences role overload. Collectively, Kahn et al. refer to these three responses as role stress.

Like other contemporary models of work stress (e.g., Karasek and Theorell, 1990), Kahn et al.'s model depicts stress as a function of two conditions: high job demands and low control. In the case of the boundary spanner, demands come in the form of the performance expectations emanating from the two constituencies. Stress is experienced to the extent that the boundary spanner is unable to exert control over these expectations. According to Kahn et al., the boundary spanner's structural position limits control over both constituencies. Due to her boundary position, the boundary spanner may be psychologically, and often, physically, distant from other members of her organization. Consistent with what would be predicted from social network theory, structural distance weakens the boundary spanner's ability to exert the inward influence necessary to align organizational expectations with external demands. However, the boundary spanner also may lack the ability to influence external agents, since he lacks legitimate authority over members of another organizational system. Stress thus results from the combination of competing and/or ambiguous performance demands and lack of control over the sources of these demands.

Kahn et al. posit that, in the absence of the legitimate authority needed to sway external agents, boundary spanners may resort to other sources of influence to achieve organizationally desired ends. Organ (1971) and Adams (1976) provide anecdotal 
examples of these more subtle forms of influence. In some instances, expertise provides a source of influence, as in the case of an industrial salesperson who has encyclopaedic technical knowledge of customers' needs and of the constraints imposed by their production methods. In many instances, however, the only source of influence available to the boundary spanner is friendship or ingratiation. These tactics may take the form of projecting oneself as an ally of outside agents, making concessions to their beliefs and values, "talking their language" (Organ, 1971, p. 75), or deriding one's own organization to show support for their perspectives. It has been speculated that, over time, the relationships established with external constituents may lead to "dual allegiances" for boundary spanners, who remain caught in the middle between the needs and wishes of their employers and those of their external contacts (Adams, 1976; Aldrich and Herker, 1977; Ancona and Caldwell, 1988; Organ, 1971).

Kahn et al.'s development of the notion of "dual allegiance" is of interest to the conceptualization of boundary spanner effectiveness. The idea that external constituents may be more salient role senders than the employing organization has implications for boundary spanner performance in the role. It suggests that, even where boundary spanners are clear on organizational direction, they may be less willing to implement this direction at the local level if it poses a threat to relationships with local constituents or is otherwise perceived as incompatible with local realities. The nature of demands at the boundary and the ways in which boundary spanners manage these demands is of empirical interest. However, empirical research to date has not examined these issues. The following section turns to related research to explore these interface phenomena. 


\subsubsection{Empirical literature related to the interface experience}

Two studies were identified with potential relevance to the interface experience of boundary spanners. The first is taken from the sales and marketing literature on role stress. As part of the development of a multidimensional measure of role ambiguity, Singh and colleagues (Rhoads, Singh and Goodell, 1994; Singh, 1993) attempted to specify the types of demands customers imposed on marketing personnel. Focus groups were conducted in order to categorize stressors as those emanating from the company, from the supervisor, from other managers, and from customers. Of interest is the customer subscale, which included 14 items tapping the nature of customer demands, and in some cases, the nature of the boundary spanner's response. Subscale items asked boundary spanners the degree to which they were uncertain about the following aspects of customer interactions: how much service they should provide the customer, how to handle customer objections, how to handle unusual problems or criticism, whether they were expected to "lie a little" to win customer confidence, whether they were expected to "hide the company's foul ups from customers", how to handle ethical issues, and what to do if they found others behaving unethically. These items are of interest to this research since they are suggestive of the specific types of pressures that might emanate from interactions at the interface and leave boundary spanners feeling "caught in the cross fire". Some of the items (e.g.,"lie a little", attempt to win confidence) are reminiscent of the anecdotal observations made by Organ (1971) and Adams (1976) surrounding boundary spanners' tendency to use ingratiating or defensive responses in dealing with 
externals (e.g., project oneself as an ally, make concessions to their beliefs and values, “talk their language”). Like other researchers, Singh et al.'s objective was to quantify role stress. However, the qualitative work they used to construct their measures represents the only known effort (since Kahn et al.'s original work) to characterize the specific challenges faced by boundary spanners at the interface and the strategies they might choose to deal with them.

Turning outside the boundary spanning literature, a second study relating to the nature of the interface experience is a study by Tsui, Ashford, St. Clair, and Xin (1995). In a study of 400 private and public sector managers, Tsui et al. examined the strategies managers used to deal with discrepant expectations arising from a variety of internal constituents, including peers, subordinates, and supervisors. Managers' strategies were identified through survey of the constituents themselves. Results suggested that, when confronted with expectations for behaviour that differed from their own expectations, managers tended to invoke response strategies falling into one of two broad categories: constituency-oriented strategies or self-oriented strategies. Constituency-oriented strategies were strategies that were directed at actual behaviour or attitude change to achieve greater alignment with the constituent's expectations. For example, the manager might alter her own behaviour by exerting greater effort to conform with the expectations, attempt to influence the constituent to change his expectations, or simply explain her position to the constituent to increase understanding and show responsiveness to the constituent's needs. Self-oriented strategies were strategies that did not aim to reduce the discrepancy, but protected the manager from discomfort. These strategies 
included disengaging from the discrepancy, either by physically avoiding the constituent or avoiding talking about the problem. The most frequently used strategies were explaining and exerting effort to change one's own behaviour. Attempts to influence the expectations of the constituent and disengagement/avoidance strategies were reported to be very infrequent. Although Tsui et al.'s study involved interactions with internal agents only, intuitively, it would seem that the strategies employed by these managers might be similar to those employed by boundary spanners in their dealings with external agents.

\subsubsection{Summary}

Kahn et al.'s notion of "dual allegiance" has both theoretical support and intuitive appeal. However, empirical support for the notion has been limited to anecdotal claims (Adams, 1976; Organ, 1971) or isolated attempts to quantify external role pressures (Singh and colleagues, 1993; 1994). Indeed, it was a bit of a reach to find empirical work that had explored the interface experiences of boundary spanners even peripherally.

The lack of research interest in interface phenomena is remarkable, given that the nature of boundary experiences figured prominently in Kahn et al.'s original work. Subsequent preoccupation with the role stress construct seems to have distracted researchers from exploring other events at the interface, events that might be expected to have considerable bearing on boundary spanner effectiveness. The empirical work reviewed above suggests that the nature of external role demands and the strategies boundary spanners use to reconcile these demands may be key determinants of 
effectiveness in the boundary role. It would seem that boundary spanners might perform work of value to the organizational system only to the extent that they are able to successfully manage their boundary transactions at the individual level. 


\section{BOUNDARY SPANNING IN THE MULTINATIONAL ENTERPRISE (MNE)}

To this point in the review, the focus has been on identifying the general elements needed to construct an exploratory model of the conditions for boundary spanner effectiveness. This preliminary work was done in order to support a deeper investigation of boundary spanning in the multinational context. This chapter turns to the international management literature as a guide to further conceptual development specifically in the multinational context.

In today's global world, MNEs comprise a diverse and growing body of organizations faced with the challenge of operating in multiple and often uncertain environments. Research suggests that MNEs encounter sizable challenges in establishing and maintaining their foreign operations, including difficulties in dealing with local governments and partners, finding and managing local staff, adapting operations to local infrastructure, and tailoring products and services to diverse local tastes and cultures (Lord and Ranft, 2000). The extent of these challenges has led observers to describe internationalization as a rich and complex process of organizational learning (Andersen, 1993; Barkema et al., 1996; Lord and Ranft, 2000). The literature reviewed to this point suggests that an organization's boundary spanners would be critical agents in initiating this learning process (Organ, 1971), performing vital roles in linking the organization to its environment. Empirical work presented in Chapter 2 identified a host of adaptive functions performed by an organization's boundary spanners, including scouting the external environment for information and ideas, collecting intelligence on the competitive environment, representing the organization to outside agents, and negotiating 
with outsiders for the procurement of financial, technical, or human resources. It would seem that these functions would be invaluable to the MNE, whose success in a host country depends not only on local market knowledge, but also on its ability to adjust to the local language, culture, politics, society, and economy.

Given the strategic importance to the MNE of scanning the local environment and forging relationships with local constituents, it would seem that the boundary spanning role would be the focus of a good deal of attention in the international management literature. However, boundary spanning has seldom been examined in the international context. This is consistent with the literature's comparatively low level of interest in micro-level phenomena in general. Whereas the literature has been extensive on such macro topics as market entry decisions (e.g., Porter, 1986), and strategy-structure alignment (e.g., Bartlett and Ghoshal, 1991; Galbraith, 2000), micro level phenomena have received little research attention. Werner (2002), in a review of 271 international management articles published in top tier journals between 1996 and 2000, identified only 16 that had used the individual expatriate as the unit of analysis. Of these, the majority focussed on cultural adjustment and withdrawal intentions. Studies addressing other work-related behaviours, particularly the expatriate's performance while on assignment, were rare.

Moreover, the few studies that have explored performance and other work behaviours in international settings have tended to position these outcomes within the prevailing cultural adjustment frameworks (e.g., Ayree and Stone, 1996; Caligiuri, 1997; Harrison and Shaffer, 2005; Kraimer and Wayne, 2004; Shay and Baack, 2004). In 
terms of performance, the underlying assumption has been that maladjustment results in psychological withdrawal from the assignment, "spilling over" to deleteriously affect performance (Harrison and Shaffer, 2005; Hechanova et al., 2003). However, studies of the relationship between performance and adjustment have yielded inconsistent results. This equivocal evidence has encouraged some observers to suggest that expatriate adjustment and performance may be related, but conceptually orthogonal (Caliguiri, 1997; Harrison and Shaffer, 2005). They call for closer examination of the expatriate's actual work context in order to identify other potential determinants of performance in international settings (Harrison and Shaffer, 2005). In other words, adjustment may be a necessary, but not sufficient, condition to support performance in the international context.

The majority of the international management literature at the level of the individual thus focuses on helping expatriates to cope with their new environments and reducing the potential loss to the organization when they fail to do so (Au and Fukuda, 2002). Given this focus, the important question of how expatriates actually do their jobs while on assignment has not been given adequate attention (Au and Fukuda; 2002; Caliguiri, 1997; Gupta, Govindaraja and Maholtra, 1999). It would seem that existing models of cultural and personal adjustment, while a useful starting point, may be insufficient to capture the dimensions of the expatriate's work abroad and the organizational context in which it is situated. Further development of the boundary spanning concept in international settings would seem instructive in this regard.

This chapter brings together several literatures with implications for model 
development in the international context. It follows the logic of Chapters 2 and 3. First, it explores the construct by examining literature that has specifically addressed the boundary spanning role in MNE settings. Second, it invokes related bodies of the international management literature with potential relevance to effectiveness in the boundary role in MNE settings. The chapter concludes with a summary of the international management literature and implications for this research.

\subsection{The boundary spanning role in the MNE}

Only two studies have expressly looked at the boundary spanning role in the MNE context. The first (Thomas, 1994) is theoretical. The second (Au and Fukuda, 2002) is empirical. These studies are described in detail below.

\subsubsection{Thomas' conceptual model of MNE boundary spanning}

Thomas (1994) applies existing literature to propose an integrated model of expatriate boundary spanning in the MNE. His stated objective is to bring together existing theories to identify the "environmental, structural, and individual antecedents of expatriate boundary spanning behaviour and the effect of this behaviour on their performance and job related attitudes" (Thomas, 1994, p. 145). Thomas' objective is quoted verbatim here, since its wording suggests a somewhat different interpretation of boundary spanning than has been advanced in this thesis, and a somewhat ambitious effort to link individual boundary spanning behaviour to macro-level antecedents.

To explore this difference in interpretation, Thomas' model is given in Figure 4.1. At the centre of the model is the boundary spanning behaviour of the expatriate. Thomas 
Figure 4.1 Thomas' conceptual model of expatriate boundary spanning

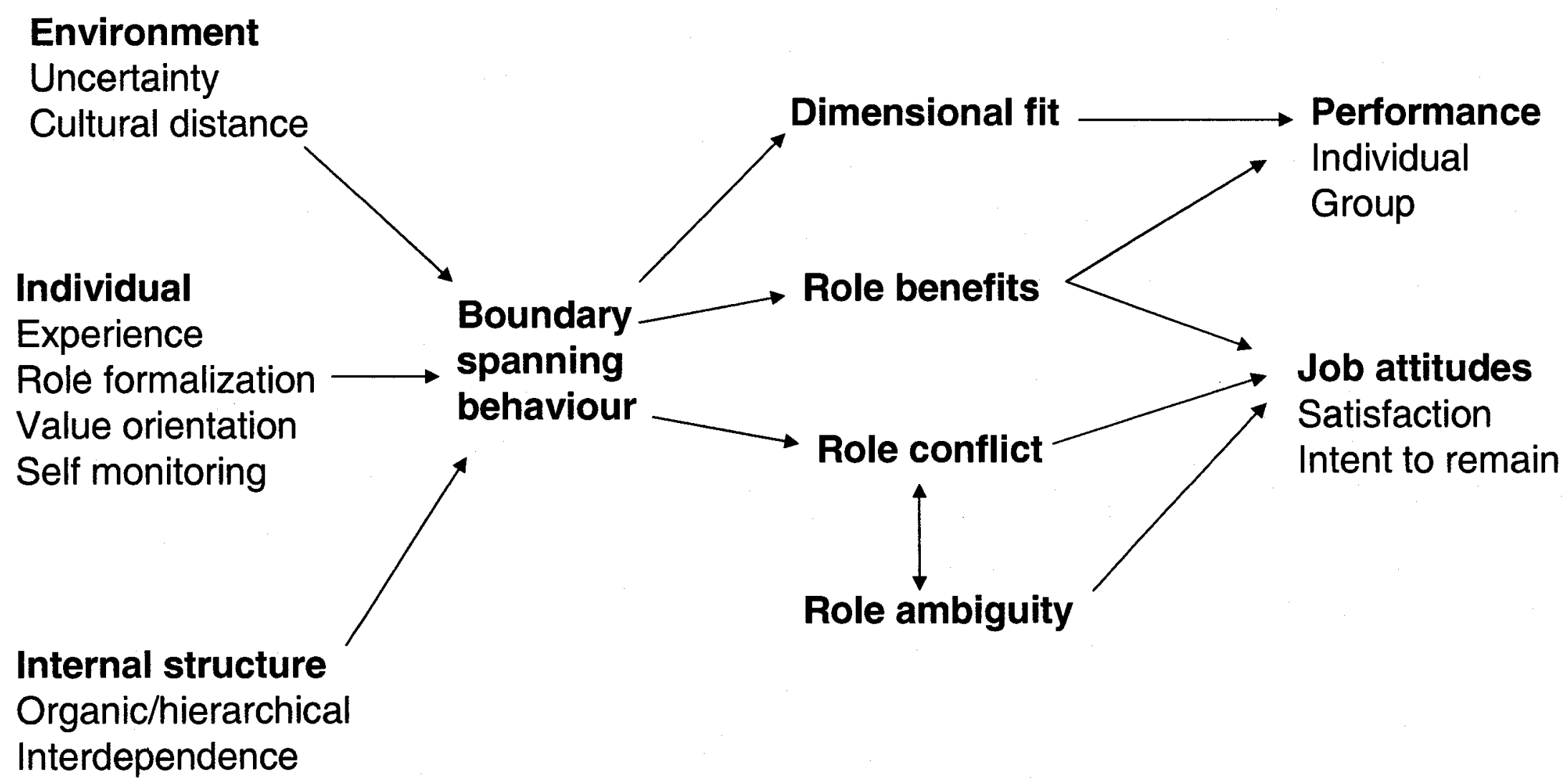

Source: Thomas (1994) 
offers no conceptual development, but invokes Ancona and Caldwell's (1988; 1992) typology to suggest that boundary spanning is "multidimensional" and, thus, boundary spanning behaviours would be of a variety of "types" as described by Ancona and Caldwell. He then suggests that boundary spanning might be operationalized as "the (aggregate) amount of across-boundary information exchange engaged in" (p. 154).

To the left of the model are the proposed antecedents of boundary spanning. The first set of antecedents relates to the environment. Expatriates are proposed to increase their boundary spanning behaviour under conditions of greater environmental uncertainty and greater distance between the culture of the host country and the expatriate's home country. The second set of antecedents relates to individual variables. The model suggests that the expatriate's prior overseas experience, personal values, and ability to self monitor (i.e., adjust behaviour in response to experience) also affect the level of individual boundary spanning. A final set of antecedents pertains to what he labels "internal structural" variables. Where the organization is more organic, or subunits highly interdependent, individuals are proposed to engage in "more boundary spanning".

To the right of the model are "outcomes" of boundary spanning activity. These are categorized as individual and group-level performance outcomes and job attitudes (job satisfaction and intent to remain). Slightly to the left of the outcomes are the moderators, including role stress, role benefits, and an interesting construct labelled "dimensional fit". Dimensional fit is defined very loosely, but seems to relate to the congruence between some "ideal type of boundary spanning behaviour" in the organization vs. "actual expatriate boundary spanning behaviour" (p. 157). This construct is interesting because it seems to reflect a definition of boundary spanning that 
is closer to the conceptualization envisioned for this research: an alignment between some organizational need or goal and the nature of the individual's boundary spanning activity. However, Thomas does not make this connection, saying only that the "ideal" behaviour would be defined as the "organization's relative acceptance of different dimensions... (of boundary spanning, such) as the representative vs. informational approaches" (p.157).

Although Thomas' work represents the only known effort to develop a conceptual model of boundary spanning in the MNE context, it suffers from several limitations. The most serious appears to be the lack of conceptual development of the boundary spanning role at the individual level. Although Thomas cites Ancona and Caldwell as support for the notion that boundary spanning is "multidimensional", and indeed, lists Ancona and Caldwell's 15 boundary spanning “activities" (see Section 2.1.2), his surrounding discussion does not demonstrate an understanding of these activities, and especially, does not show an appreciation for the adaptive function of these activities. For example, his operationalization of boundary spanning as "the (aggregate) amount of across-boundary information exchange engaged in" (p. 154) implies that: (1) all boundary spanning activity is informational, and (2) one would be justified in aggregating across activities. However, Ancona and Caldwell would contend that information exchange is only one of many boundary spanning activities, and not very meaningful when divorced from the purpose of the exchange. Although it may be the case that, ultimately, all boundary activities involve messaging of some kind (i.e., role sending, consistent with Kahn's idea of every episode comprising content plus influence), such messaging is quite a bit richer 
than "information exchange", often involving the transmission of normative or valueladen content. Moreover, Ancona and Caldwell's work suggests that boundary spanners also serve an important adaptive function when they exchange no information at all. This is illustrated best in their observed "guard" function, where boundary spanners protect the core technology from outside interference by choosing not to share information across boundaries.

Thomas' model also seems to suffer from an "analytic levels" gap. In his effort to integrate macro and micro level theory, he makes a bit of an inferential leap to apply relationships that might pertain at the macro level to relationships that might pertain at the micro level. For example, Thomas claims that where the environment is uncertain, the organization experiences an increased need for boundary spanning. This is consistent with macro level theory as given by Thompson (1967). But Thomas then makes a leap to claim that where the environment is uncertain, the expatriate will "increase" his or her boundary spanning activity. The interpretation seems to be that individual employees can choose to "span or not to span", depending on antecedent conditions (e.g., degree of environmental uncertainty). This suggests an inappropriate application of macro-level concepts to the micro level. At the macro level, it is the organizational decision maker, not the boundary spanner, who, to use Thomas' phrase, "increases" boundary spanning (Thompson, 1967; Katz and Kahn, 1966; Mintzberg, 1973). This may be achieved by increasing the number of boundary positions. The number of positions may be increased either directly, by creating positions in formal boundary units (e.g., marketing), or indirectly, by assigning boundary roles to positions throughout the organization that had 
not previously entailed this role (thus effectively "moving" a greater number of positions to the boundary).

However, at the micro level, there is no choice to span or not to span. Boundary spanning is an organizational location. At the micro level, an individual is a boundary spanner by virtue of his or her position on the boundary (Thompson, 1967), by virtue of holding a job that requires interaction with outside agents (Kahn et al., 1964). This does not change unless the individual changes jobs or the job itself changes. What is variable is the type of boundary spanning activity in which the individual engages (e.g., as would be observed in a deliberate shift from "scout" to "guard" functions), and the intensity of boundary spanning activity within that dimension (e.g., an increase in the number of public appearances, or a more vigorous search for information). A change in the focus or intensity of boundary activity would be variables within the individual's control. A change in the focus or intensity of boundary activity at the individual level would suggest a change in what Kahn et al. (1964) labelled the "boundary relevance" of the job (i.e., the proportion of work time devoted to contact with externals and the importance of this contact to the effective performance of the job; see Section 2.1.1.2). Viewed through the lens of boundary relevance, the requirements of the job might indeed change in response to a changing environment (i.e, an existing boundary function might become more important to effectiveness in that job, or the need for a new function might present itself). It might be expected that under these circumstances, the incumbent might adjust boundary spanning activity accordingly (i.e., spend more work time in boundary activity or shift from one boundary function to another). These phenomena would be of 
theoretical interest at the micro level, with implications for the effectiveness of the boundary spanner in any given transaction (why did the boundary spanner engage in the boundary behaviour observed, why did the individual "change gears", and to what effect?)

Boundary relevance, therefore, is an example of the type of mid-level conceptual link missing from Thomas' efforts to integrate macro and micro perspectives. Rather than saying simply that the individual would "increase boundary spanning" in response to increasing environmental uncertainty (a macro-level phenomenon), Thomas might more appropriately have applied the boundary concept at the micro level by hypothesizing that the individual might adapt his or her boundary spanning behaviour in response to perceived changes in contingencies at the interface.

A third limitation of Thomas' model is its failure to employ outcome measures with relevance to the boundary spanning role. In the narrative, Thomas refers the reader to a previous paper (Feldman and Thomas, 1992) for examples of the types of instruments that might be used to measure the attitude and performance outcomes given in his model. Examination of the 1992 paper suggests few conceptual linkages between these outcomes and boundary spanning effectiveness. For example, the intent to remain measure recommended is the same type of measure that has been used in association with overseas assignments in the expatriate adjustment literature- - the measure taps the boundary spanner's intent to remain for the duration of the assignment. There may be many determinants of an expatriate's intent to remain, not the least of which is family and spousal issues, language issues, or other cultural barriers (Mendenhall et al., 2002). 
Intent to remain is thus a seemingly suitable measure of adjustment, but conceptually is not an outcome measure of any aspect of the boundary spanning role. Similarly, the measure of individual performance recommended is a self-rating scale (Feldman and Thomas, 1992). All items are not given for this scale, but those that are appear to involve subjective comparisons of performance while on assignment to previous performance (e.g., "My performance reviews as an expatriate have been lower than before I came overseas"). Again, there appears to be little linkage between getting good performance reviews and performing well in the boundary spanning role, and if there is a link, it is not explicated here.

Finally, Thomas' model is weakened by the lack of development of the "dimensional fit" variable. This is the notion of the boundary spanner's performance being a function of the organization's "relative acceptance of different dimensions of boundary spanning". This wording suggests some organizational expectation for specific boundary spanning behaviour, so is of potential relevance to a model of boundary spanner effectiveness. Presumably, organizational "acceptance" of various dimensions (e.g., informational vs. representational functions) would be based on the extent to which those particular dimensions contributed to organizational effectiveness at a given point in time. Again, however, this interpretation is not advanced by Thomas and no attempt is made to operationalize the notion of "acceptance". Fuller development of the dimensional fit construct might have enabled Thomas to posit clearer linkages between the organization's boundary spanning requirements and the activities of its boundary spanners. This construct then might have been positioned as central to the model, rather 
than as one of many "nodes".

In sum, Thomas' paper is useful in bringing together the many theoretical paradigms in which boundary spanning research has resided to date. However, his model appears to be more of a structuring framework than a conceptual integration. Working from the left of the model, we can see elements of open systems theory (environmental conditions and organizational structure), human psychology (personal experience and values), social psychology (role conflict and enhancement), and organizational behaviour (work attitudes and outcomes). Integration of such disparate literatures requires clear articulation of the relationships that pertain at the interface of each level of theory. Failure to identify such linking mechanisms between levels of analysis leads to theoretical linkages that are lacking in what Simon (1973) refers to as "bond strength". Bond strength is weak where characteristics or processes on one level have only remote influence on the characteristics and processes of interest at another level (Kozlowzki and Klein, 2000). Thomas' model is lacking in bond strength at several junctures (e.g., how would the level of uncertainty in an industry's task environment affect the behaviour of an individual employee; what is it specifically about the boundary spanning role of the expatriate that might affect his or her willingness to complete an assignment?) Thomas' model calls attention to the need for deeper conceptual development at the individual level, and specifically, in the MNE context.

\subsubsection{Au and Fukuda's empirical study of MNE boundary spanning}

Empirical work by Au and Fukuda (2002) begins to bridge some of the inter- 
theory gaps evident in Thomas' model. These authors use Thomas' model as a “springboard" (Ibid., p. 285) to develop hypotheses framed specifically at the individual level. They then test these hypotheses in a survey of 230 executive expatriates working in a variety of service industries in Hong Kong.

First, Au and Fukuda clarify the idea of "dimensional fit" by operationalizing boundary spanning in terms of three of Ancona and Caldwell's functional categories. They develop separate sets of items to tap the "ambassador" function (e.g., "talking up the importance of the work unit to outsiders"; "preventing outsiders from overloading the company with information or requests"); the "task coordinator" function (e.g., "resolving business problems with people outside of my company"; "procuring things that my company requires from outside"); and the "scout" function (e.g., "finding out what competing firms are doing"; "collecting technical information/ideas from outsiders"). Rather than aggregating these scores across dimensions to yield an overall "level" of boundary spanning activity, they retain separate scores on each dimension for analysis. This generates a measure sensitive to the different purposes served by different boundary spanning behaviours. In their words, “... such measurement emphasize(s) the role perceptions of expatriates with regard to boundary spanning activities, rather than its level as emphasized in Thomas" (Ibid., p. 289).

$\mathrm{Au}$ and Fukuda then test the relationship between these dimensions and several of the antecedents (perceived environmental uncertainty, previous overseas experience), moderators (role ambiguity, role benefits), and outcomes (job satisfaction) given in Thomas' model. They also enrich Thomas' model by drawing on social network theory to 
introduce two additional moderating variables to the model: influence (e.g., "I have a lot of influence in determining the work for my unit"); and the use of local resources (e.g., "my current job allows me to tap into information and resources located within groups of different cultural backgrounds in Hong Kong"; "my job requires me to use the knowledge and personal ties of a diverse group of people"). From these, they propose a relationship between strong external connections and internal influence and job satisfaction (i.e., boundary spanners with high use of local resources are predicted to have higher levels of influence in the organization and higher job satisfaction).

Results suggest no relationship between any of the boundary spanning dimensions and the antecedents drawn from Thomson (environmental uncertainty and previous overseas experience). The authors do not comment on these findings. However, the failure to observe relationships is not unexpected, given that conceptual development of these linkages were weak in Thomas' model, and, thus, there were no a priori reasons to anticipate relationships.

In terms of moderators, role ambiguity was reduced and role benefits enhanced for boundary spanners acting in the ambassador and task coordinator functions. The authors speculate that the act of representing the firm to outsiders (ambassador) and negotiating and resolving business problems with outsiders (task coordinator) requires boundary spanners to reconcile the image of the company with outsiders' evaluations. Rather than generate role stress, this activity apparently helped boundary spanners "bridge the gap between different expectations" (p. 292). This finding is consistent with the role enhancement perspective (Section $2 . .2 .2 .3$ ) which suggested that boundary 
relationships may yield favourable outcomes for boundary incumbents. Finally, the scout function was significantly associated with the use of local resources. The authors explain this finding in terms of the need for scouts to continually scan the environment, helping them to locate and use a greater diversity of local contacts. The scout role was also associated with greater perceived internal influence. This finding is consistent with social network accounts of boundary spanning (e.g., Tushman and Romanelli, 1983), which would predict that scouts would wield greater influence in the organization due to their mediation of organizationally valued information resources.

Job satisfaction, the only outcome tested, was significantly associated only with the moderator variables (i.e, negatively associated with role ambiguity and positively associated with role benefits and internal influence). Job satisfaction was unrelated to any of the boundary spanning dimensions over and above the effect of these moderators. Unfortunately, Au and Fukuda did not measure performance as an outcome. Individual performance might be a variable more closely related to the concept of boundary spanner effectiveness as it has been advanced in this thesis.

In terms of its contribution to the conceptualization of boundary spanning, Au and Fukuda's work provides some empirical support for the multidimensionality of boundary spanning as given in Ancona and Caldwell's typology. Their findings suggest that the dimensions of boundary spanning which were identified by Ancona and Caldwell at the team level may prevail also at the level of the individual.

$\mathrm{Au}$ and Fukuda's study also provides support for some of the potential determinants of boundary spanning effectiveness identified in the broader management 
literature. The social network perspective was reinforced in the finding that influence within the organization was enhanced for boundary spanners who controlled information resources (i.e., scouts). Role enhancement theory was reinforced in the finding that ambassador and task coordinator functions were associated, not with role stress, but with role benefits. Therefore, Au and Fukuda provide some justification for consideration of both the boundary spanner's intra-organizational experience (based on their findings on influence) and interface experience (their findings on role benefits) in building a conceptual model of the conditions for effectiveness in the MNE boundary spanning role. Unfortunately, however, Au and Fukuda's study is quantitative only, so can provide no insight as to how these boundary spanners achieved influence or how their interactions with locals contributed to perceived role benefits. The next subsection turns to related literature to explore these elements more closely in the MNE context.

\subsection{Effectiveness in the MNE boundary spanning role}

Section 2.2 identified the boundary spanner's intra-organizational context (in terms of performance expectations and strategic influence) and interface context (in terms of boundary interactions, "dual allegiances") as potentially important determinants of boundary spanner effectiveness. As compared to other complex organizations, the central distinguishing feature of the MNE is the geographic and cultural distance between the home and host country and between organizational units (Govindarajan and Gupta, 2001). The questions of relevance to effectiveness in an international setting are, therefore, "How might geographic and cultural distance affect the boundary spanner's 
ability to understand what the organization expects of the boundary role? How might it affect the boundary spanner's ability to influence internal decision makers? How might it affect the nature of local relationships and interactions with local constituents?"

In terms of conditions emanating from the intra-organizational context, it would seem that the boundary spanner's physical distance from the home organization might limit his or her access to role cues for performance in the boundary role. Although it is conceivable that this limitation could be overcome by organizational attention to articulating concrete goals for the assignment and providing mechanisms for regular performance feedback, research on international management suggests that planning for the overseas assignment and performance management during the assignment are much neglected aspects of the expatriate experience (McNulty and Tharenou, 2005).

Geographic distance also may have implications for the boundary spanner's ability to communicate knowledge about the local environment to organizational decision makers. Social network theory would yield two contradictory predictions about the effect of distance on the boundary spanner's ability to influence decision makers. On the one hand, it would predict that boundary spanners in the MNE would be highly influential since, by virtue of their assignments, they hold a high level of specialized local information that headquarters does not have (i.e., they mediate access to key information resources). They also might be solely responsible for procurement of resources in the host country or disposal of outputs (thereby mediating key workflow resources).

On the other hand, social network theory would predict that boundary spanners' physical distance from headquarters might limit their ability to access the critical internal 
networks needed to build relationships and to obtain the broader contextual knowledge (Dutton et al., 2001) needed to perform their roles effectively. This hypothesis would be supported by communications research that suggests that frequency of communication decreases as physical distance increases (Hinds and Kiesler, 1995). Communications research also suggests that the remote technologies on which MNEs rely (e.g., email, teleconferencing) are poor substitutes for face-to-face contact in conveying relational and normative information (Montoya-Weiss, Massey, and Song, 2001), and in developing and maintaining social relationships (Hinds and Kiesler, 1995; Maznevski and Chudoba, 2000; Tiegland and Wasko, 2003). We might expect, then, that boundary spanners in international settings may well become external communication "stars", but may risk becoming "social isolates" (Tushman and Romanelli, 1983) within their own organizations. The risk of isolation is supported by research that indicates that expatriate executives often report a sense of being "out of sight, out of mind" (Hedlund, 1980; Mendenhall et al., 2002). This perception is reinforced by the observed high turnover rate among expatriates upon return from assignment (McNulty and Tharenou, 2005). In terms of relationships with local constituents (i.e., interface context), social network theory might again yield competing predictions. On the one hand, physical proximity to external constituents may provide boundary spanners with greater sensitivity to local needs and the ability to forge strong relationships in pursuit of organizational objectives. On the other hand, the effect of cultural distance on local relationships is unknown. Any advantage gained by physical proximity may be outweighed by problems associated with language and other cultural barriers. This would be consistent with the 
expatriate adjustment literature which indicates that social adjustment decreases as cultural distance between the home and host country increases (Feldman and Thomas, 1992; Mendenhall et al., 2002). Expatriate adjustment studies, however, are based largely on personal and family adjustment. Research is lacking on the degree to which cultural distance poses barriers to the formation of working relationships in international settings (Manev and Stevenson, 2001b).

The international management literature offers few insights from which to reconcile these competing predictions. As mentioned in the introduction to this chapter, few studies have assumed a micro level of analysis, and even fewer have looked expressly at the expatriate's work context (Werner, 2002). An exception is a small body of literature that has begun to explore HQ-subsidiary interactions at the micro level. This body of research explores the tensions between HQ managers and subsidiary managers as they seek the appropriate balance between centralized control and local autonomy. This literature originates from one of the central macro-level themes of the international management literature: the "global versus local" dilemma (Bartlett and Ghoshal, 1991; Doz and Prahalad, 1984; 1991; Galbraith, 2000). At the macro level, this literature has traditionally focussed on ways in which the MNE can structure or control so as to balance the often conflicting priorities between headquarters' need to obtain efficiencies and coordination across subunits (typically subsidiaries) and subunits' need for local responsiveness in the face of diverse task environments (Doz and Prahalad, 1984; 1991). Recognizing, however, that global vs. local "balance" is the result of strategic decisions taken by individual actors, studies of HQ-subsidiary interactions are now beginning to 
look more closely at the one-on-one dynamics underlying these decisions.

Empirical research in this stream (Birkinshaw, 1997; Gupta, Govindarajan and Malhotra, 1999; McGraw, 2004) suggests that geographic distance poses substantial barriers to the communication of strategic information and the ability to exert influence. Barriers apply in both directions- - in HQ's attempts to communicate expectations to, and exert influence over, subsidiary managers and in subsidiary managers' attempts to influence $\mathrm{HQ}$.

McGraw (2004) and Birkinshaw (1997) studied influence from subsidiary to HQ. Using interviews with subsidiary managers located in Australia and Canada, respectively, they collected accounts of managers' efforts to sell HQ on initiatives of perceived local importance. These studies suggest that, in spite of the existence of formal structures and coordinating processes to facilitate communication across distances, subsidiary influence appeared to be mediated by social networks and informal personal relationships. McGraw (2004) noted a high level of political behaviour in his accounts, with an observed tendency for some subsidiary managers to wield power "out of all proportion to their size" (p. 540). Birkinshaw (1997) reported a number of interesting "selling" behaviours that can be seen to be closely aligned with Dutton et al.'s issue selling categories, including involvement moves (e.g., engaging horizontally, then selling upward to HQ) and process moves (timing the sharing of information with HQ so that initiatives could be sufficiently developed to "sell"). Although these observations might also be interpreted to suggest that distance is no barrier to influence (i.e,. managers in the MNE appear to be using their connections to social networks, much like managers in any 
organization), both authors are careful to note that "effective" lobbying did not always translate to value for the MNE. In some instances, lobbying yielded solutions that were radically asymmetrical and usually unstable (McGraw, 2004). The more important issue from an adaptive standpoint was the implicit loss of strategic input from subsidiary managers who may not have been as adept at selling. As expressed by Birkinshaw (1997), the challenge in managing across distances is in creating the supportive and "entrepreneurial culture" needed to engage all managers in the strategic conversation. In terms of HQ's ability to communicate expectations to subsidiary managers, no studies were identified that looked directly at HQ management behaviours at the micro level. However, an interesting study of subsidiary managers by Gupta et al. (1999) suggests why the efforts of top management to influence subsidiary behaviour in the direction of organizational goals may be limited in the MNE setting. Gupta et al. surveyed presidents of 375 subsidiaries belonging to 75 major MNEs headquartered in the U.S., Japan, and Europe to examine the factors associated with the propensity to seek HQ performance feedback. Gupta et al. argued that the ability to seek performance feedback was critical to managers' ability to align their performance with organizational goals, but that in MNE settings, geographic and cultural distance created barriers to feedback seeking behaviour. In MNE settings, subsidiary managers would be at a disadvantage both in terms of feedback available from the work environment (cues from the organizational context) and in terms of feedback available from other organizational members (feedback obtained by direct inquiry). Results identified a positive relationship between feedback seeking behaviour and the level of social connectedness to HQ. 
Feedback seeking behaviours were observed to increase with increases in the frequency of HQ-subsidiary communication, and with increases in participation in various socialization mechanisms (e.g., mentoring, rotational assignments, or executive development programs).

\subsection{Summary}

In spite of recent calls for greater attention to the behaviour of individuals within international work settings (e.g., Au and Fukuda, 2002; Bartlett and Ghoshal, 1995; Birkinshaw, 1997; Werner, 2002), theoretical or empirical work at the level of the individual employee remains rare. It was especially surprising to find only two studies that had looked specifically at the boundary spanning role, given that the central themes driving the macro level research (e.g., the challenges inherent in controlling and adapting to multiple and widely dispersed operating environments; the "global vs. local" issue) are classic boundary themes. Indeed, it would seem that the expatriate's responsibility for linking the organization to the host country is so central a part of the job that researchers have taken its boundary spanning component as given, and like Thomas, are now starting to explore causal models in the MNE context without adequate development of the boundary spanning construct itself. This may create the same situation as was observed in the broader boundary spanning literature where preoccupation with the role stress aspects of boundary spanning appeared to distract researchers from conceptual work around other aspects of the boundary spanning role. It is the premise of this thesis that a boundary spanning framework can provide the conceptual tool needed to examine the 
conditions for effective performance in the MNE work setting, and help move the expatriate management literature toward more meaningful performance measures than cultural adjustment or intent to remain.

Although the literature needed to inform conceptual development was scant, the empirical studies reviewed here have several implications for examining the boundary spanning role in the MNE context. In terms of the boundary role construct, Au and Fukuda's study suggests that the dimensions of team boundary spanning developed by Ancona and Caldwell may well apply at the individual level. In terms of effectiveness in the role, their work also identified role benefits as a potential interface factor that may enhance effectiveness in the MNE setting. This finding provides some support for the potentially favourable outcomes in the MNE setting predicted by social network theory. It suggests that a potential source of influence for boundary spanners in the MNE may be their control over local knowledge and contacts that otherwise would be impossible for the home office to access. However, the "selling" studies by McGraw, Birkinshaw, and Gupta et al. suggested that MNE boundary spanners might achieve this inward influence only where they were able to overcome the barriers of distance. Their work suggested that managers in the MNE relied on the same sources of social influence as they would in any organization, and that their ability to exert influence over HQ would thus be a function of their ability to remain connected with the social network while on assignment. Gupta et al.'s study of feedback seeking behaviours suggested that the ability of HQ to communicate boundary role expectations and to exert influence over geographically dispersed boundary spanners might be limited by distance as well. 
Finally, it is important to note that the large majority of the international management literature cited here is based on the study of expatriate managers, typically executives at rather high organizational levels. This is an important shortcoming in the literature. As international expansion continues, we see relocations of entire work units as organizations seek to establish operations in foreign sites. This seems especially to be the case in small and medium sized firms (Brewster, 2002) or in professions such as construction, architecture or engineering, where a critical mass of technical or professional people may be required at the working level to oversee local programs and projects (Bonache, 2005). As noted by Caliguiri (1997), many jobs that are nonmanagerial in domestic settings take on managerial aspects in the host country, particularly in terms of developing local working relationships, training local colleagues, or representing the organization to customers or the public. This suggests that the "boundary relevance" (Kahn et al., 1964) of non-managerial jobs may increase in international settings, making expatriates at all job levels a potential source of organizational learning. The international management literature, therefore, may also benefit through a conceptualization of the boundary role that pertains at both management and non-management levels. 


\section{PERCEIVED ORGANIZATIONAL SUPPORT FOR BOUNDARY SPANNERS}

One of the primary benefits of conceptualizing boundary spanning at the individual level would be the identification of features within the organization that contribute to effective performance, and hence, might be modified to support employees in this important role. Measures of employees' perceptions of organizational support are useful in this regard since they identify the various aspects of the organizational context that are perceived salient by the employee. However, given the overall low level of research on boundary spanning at the individual level, it is not surprising to find that there has been very little that has expressly investigated perceptions of organizational support for the boundary role.

Again, research on sales and marketing personnel (Johlke, Stamper, and Shoemaker, 2001; Stamper and Johlke, 2003) provides the only source of information on boundary spanner perceptions of organizational support. Stamper and colleagues applied Eisenberger et al.'s support measure (Eisenberger, Huntington, Hutchison and Sowa, 1986) to determine the antecedents of perceived support among sales and marketing employees, and whether perceived support was related to boundary spanner work outcomes. Results suggested that boundary spanners were more likely to perceive their organization as supportive when they had a history of pay raises, promotions, and good training opportunities. Employees who perceived their organizations as supportive reported lower role stress, and higher job satisfaction and intent to remain. No relationship was found between perceived support and performance (as measured by a 
self-report measure of salesperson task performance).

It appears that these studies have limited applicability to the current research. First, these studies took into account no unique features of the boundary spanning role. Like most of the boundary spanner research in the marketing stream, a sample of sales and marketing personnel was drawn, a measure administered to them, and findings attributed to their (assumed) boundary role responsibilities. The failure to link findings to any distinguishing features of the boundary role is particularly apparent in the generic nature of the antecedents of perceived support identified in this research. Presumably, any employee who saw themselves as well paid, well trained, and on a promotional track might see their organizations as "supportive"- - independent of the jobs they performed or the roles that they played in the organization. Such broad-brush findings offer little to managers who may want to adjust specific aspects of the work context (e.g., formalization of the boundary role, modifications to job design features, or improvements to supervision) to create conditions more conducive to performance in the boundary spanning role.

Second, the Eisenberger et al. scale used in the studies is a global measure that accesses the extent to which employees believe the organization values their contributions and cares about their well-being (e.g., "management shows concern for me", "management cares about my opinions"). Such a tool might be useful in trying to develop a more welcoming workplace. However, the research outlined for this proposal suggests that boundary spanners may face unique challenges in performing their jobs, including lack of connectedness to the organization, communication challenges 
associated with distance, and the need to cope with conflicting or ambiguous

performance expectations. A sense that management cares about the boundary spanner's well-being may be the source of some comfort, but does little to remove these obstacles. Not surprisingly, the above studies found a positive relationship between perceived support and work attitudes (job satisfaction, intent to remain), but no relationship between perceived support and task performance. In other words, employees who sensed their employer had good feelings about them had good feelings about their employer. There was no indication that good feelings translated to any performance increment. Again, these findings offer little to guide managers who may want to support boundary spanners in actually carrying out their roles. Like most of the boundary spanning literature in the sales and marketing domain, findings are more incidental to the boundary spanning role than associated with it. It would seem that an exploration of sources of organizational support specific to the needs of the boundary spanner would enable organizations to diagnose and intervene, rather than merely support boundary spanners in the absence of intervention. 


\section{PART THREE: PRELIMINARY CONCEPTUAL DEVELOPMENT AND RESEARCH QUESTIONS}

This part of the thesis comprises a single chapter. It applies the literature reviewed in Part Two to develop the preliminary conceptual frameworks for the research. In exploratory work, a preliminary framework offers the researcher a set of initial orienting constructs to focus the research and to set the boundaries for observation and data collection (Miles and Huberman, 1994). From the preliminary framework, research questions can be extracted and decisions taken as to how to align the questions with the appropriate sampling frame and methodology (Ibid.). The approach to conceptual development and the identification of research questions for this research is described in Chapter 6. 
There are two conceptual tasks in this research. The first is to develop a conceptual model of the dimensions of the boundary spanning role at the individual level (Research Objective 1). The second is to develop a model of the conditions for individual effectiveness in the role (Research Objective 2). These two tasks are addressed in Sections 6.1 and 6.2 respectively. These two models also provide the basic orienting frameworks for exploring job level differences (Research Objective 3) and perceptions of organizational support for the boundary role (Research Objective 4).

Section 6.3 develops from these models a set of research questions to guide data collection and analysis. The methodology used to address research questions is the topic of Part Four.

\subsection{Conceptualizing the boundary spanning role}

As outlined in Part One, Research Objective 1 is descriptive. Description seeks to identify the features or qualities of individual concepts (i.e,. things, acts, or events; Bacharach, 1989). This distinguishes it from theory, which is a statement of the relations among individual concepts within a set of boundary assumptions (Ibid.). Given the descriptive nature of the task, what is needed in the conceptualization of the boundary role is a basic orienting framework that can serve as a guide to mapping out the dimensions of the boundary role.

Open systems theory was reviewed in Chapter 2 in order to provide the macro level conceptual basis for characterizing the dimensions of the boundary role at the level 
of the individual. By defining organizational effectiveness in terms of adaptability to the environment (Thompson, 1967), macro theory makes three contributions to conceptual development at the micro level. It identifies the organization's boundaries as the site of the "adaptive function" (Katz and Kahn, 1966). It posits that the adaptive function flows in two directions (it exerts outward control to modify the environment, or exerts inward control to modify organizational structures or processes in response to the environment; Ibid.). Finally, macro theory maintains that boundary interactions are multidimensional, both in terms of content (e.g., a flow of information resources versus financial resources) and in terms of the adaptive functions served by the interaction (i.e., in that any given interaction may involve a number of transactions, serving a number of adaptive functions).

It has been a premise of this thesis that a conceptualization of the boundary role at the individual level should be aligned with conceptualization of the adaptive function at the macro level. Previous conceptualizations of the dimensions of the boundary role (e.g., Miles, 1976; Thomas, 1997) have neglected to indicate how individual boundary transactions might connect to the productive work of the organizational system. The conceptualization for this research, therefore, should be designed to suggest ways in which the boundary activities of individual employees might ultimately translate to adaptation at the organizational level. To do this, conceptualization at the micro level should respect the three central features of the macro conceptualization given above.

First, conceptualization should focus on activities that occur at the interface- - the site of the "adaptive function". This allows examination of the boundary spanner's 
activities at the site of intra-organizational "linkages" (Section1.1). This focus respects Aldrich and Herker's (1977) contention that the place to begin in studying "organizational adaptation" is, not with the organization as a whole, but with the impact of the environment on incumbents of boundary positions in the immediate vicinity of the environment-organization interface (Section 2.3). Second, the conceptualization should respect the bidirectional "flow" of the adaptive function (Katz and Kahn, 1966), allowing for classification of cross-boundary exchanges in both directions, and not be restricted to exchanges in one direction only (e.g., as was the case in Thomas' emphasis on the inward flow of information). Third, the conceptualization should capture the multidimensionality of boundary activities in terms of both content and the adaptive purpose served by these activities when viewed in perspective of the broader organizational system.

The conceptual work reviewed in Part Two indicated that the typology of boundary spanning activities given by Ancona and Caldwell (1988; 1992) was relatively successful in respecting these three features of the macro literature. Although their research linked boundary activities to the work of the team, and stopped short of linking activities to the work of the broader organizational system, their typology captured the central elements of the macro perspective.

First, the focal point for their conceptualization was the interface (i.e., the typology was derived by examining respondent interactions with organizational members outside of the team). Second, their typology captured adaptive flow in both directions (as illustrated in the dimensions of "scout", which enabled inward flow to bring information 
into the organization vs. "ambassador", which exerted outward flow to persuade and lobby). Finally, all boundary role behaviours in the typology respected the multidimensionality of the role in terms of both activity and purpose (i.e., by identifying four boundary spanning functions, each defined in terms of the potential purposes it served for the team).

This two-component conceptualization of "activity plus purpose" is consistent with other empirical efforts to define specific role behaviours. For example, Mintzberg (1973) in his classic qualitative study, "The Nature of Managerial Work" defined the managerial role as comprising both an identifiable set of activities and the purpose behind these activities. The observation that Ancona and Caldwell's conceptualization of the boundary role construct is consistent with the conceptualization of role constructs in other domains provides some assurance around this approach.

Ancona and Caldwell's typology, therefore, will be used as the preliminary conceptual framework for data collection and analysis in this research. For reference, Figure 6.1 repeats the dimensions of Ancona and Caldwell's typology from Table 2-4. The methodology used to apply this framework to the collection and analysis of data is described further in Part Four. 
Figure 6.1 Preliminary conceptual framework of the dimensions of the boundary spanning role

Functional activity
Ambassador
protecting, persuading, lobbying
Scout
general scanning for ideas, trends
Task coordinator
technical coordination and negotiation
Guard
controlling external demands for
information/resources

Based on Ancona and Caldwell, 1992

\subsection{Conceptualizing the conditions for effectiveness in the role}

Although Ancona and Caldwell's work provides a useful framework for conceptualizing the dimensions of the boundary role, there is no pre-existing framework for conceptualizing the conditions for effectiveness in the role. The literature reviewed in Part Two, however, offers "pockets" of theory that might aid in the development of such a framework.

Returning to open systems theory, we have defined organizational effectiveness in terms of the ability of the organization to adapt to its environment. Central to the notion of adaptability was the concept of homeostasis, or self-stabilization (Thompson, 1967). According to open systems theory, organizations needed to both maintain the stable functioning of their internal productive system, and detect and respond to any 
fluctuations in the external environment that might pose a threat to the system (Katz and Kahn, 1966). This adaptive function was performed through transactions which occurred at the organization's boundaries.

If it is assumed that boundary spanners are the agents through whom boundary transactions occur, then individual effectiveness in the boundary role would be determined by the extent to which the individual's transactions contributed to the ability of the organization to adapt to its environment. Further, if it is accepted that "adaptability" is, at least in part, a function of the strategic decisions taken by organizational decision makers (Jemison, 1984), then, individual effectiveness might be defined more specifically as the ability of the boundary spanner to carry out boundary transactions aligned with the organization's strategic direction, and to inform and influence the strategic direction in response to a changing environment.

The literature examined in Part Two identified a number of intra-organizational and interface contextual factors that might enhance or constrain the boundary spanner's ability to carry out boundary transactions or to exert influence over the organization's strategic direction. Integration of these factors allows us to infer the following five conditions for effective performance in the boundary role:

1. Knowledge of the organization's expectations for the role. By definition, the boundary spanner is connected to external agents. However, in order to perform effectively, the boundary spanner needs to be connected to those agents who are important to the attainment of the organization's goals. He or she also needs to 
determine what agenda to pursue with each. This requires some level of awareness either of the organization's overall strategy or of a set of organizational objectives at the local level. We posit, therefore, that the most basic condition for effective performance in the boundary role is the individual's knowledge of the organization's expectations for the role. The literature indicated that role expectations were communicated through a variety of work context features, such as the design of the job, the level of autonomy afforded by the job, and the supervisor's ability to provide direction. Access to such role cues in the work context might be expected to be a fundamental condition for effectiveness in the boundary role. The boundary spanner's knowledge of organizational expectations is of particular interest in the international setting, given that the balance of the literature reviewed here suggested that geographic distance may pose a threat to access to intraorganizational role cues and access to performance feedback.

2. The ability to influence the organization's strategic direction The literature suggests that, in order to perform effectively in the boundary role, it is not enough to be able to identify and act in accordance with the organization's expectations. A key part of the boundary role is to detect and act on instances where these expectations may be misaligned with changing environmental contingencies. A further condition for effective performance, therefore, may be the boundary spanner's ability to achieve some level of influence over the strategic direction of the organization. For the purpose of this study, we have defined "strategic influence" broadly as the ability of an individual to either participate directly in the strategic decision making process or to transmit boundary information to internal agents who have strategic decision authority (Section 3.1.2). We 
posit, therefore, that in order to perform effectively, boundary spanners would need to have sufficient influence within the organization to directly or indirectly become part of the organization's "strategic conversation" (Westley, 1990). Social network theory suggested that becoming part of the "conversation" was largely a function of the boundary spanner's knowledge of the organization's normative, relational, and strategic context and access to internal networks.

3. Knowledge of the expectations of local constituents. The literature also suggested that in order to perform effectively, the boundary spanner needed to know "both sides" of the boundary. One of these "sides" is populated by the external agents with whom the boundary spanner must interact in order to do his or her job. Social network theory suggested that the boundary spanner needed to be sufficiently connected externally to know who would be of value in achieving organizational objectives (i.e., where to obtain resources, which stakeholders to approach). In addition, social network theory suggested that the boundary spanner's mediation of the valuable information and workflow resources provided through their external networks was a potential source of influence within the organization. A further condition for effective performance in the boundary role, therefore, may be the boundary spanner's ability to connect with, and identify the needs and expectations of, local constituents who are important to the attainment of organizational objectives. Again, this is an important consideration in the international context, where the effects of cultural and language issues on local relationships is unknown.

4. Reconciliation of organizational expectations with local expectations. Role stress 
theory (Kahn et al., 1964) called attention to the potential conflict and ambiguity encountered by boundary spanners due to their exposure to potentially conflicting demands from constituents inside and outside of the organization. The idea of "dual allegiance" (Adams, 1976; Organ, 1971) provided insight to this interface phenomenon. It suggested that boundary spanners may lack influence over those inside the organization, since they are removed from the organization's core and may be disconnected from internal networks. However, they also may lack influence over external contacts since they hold no legitimate authority over those outside the organization (Organ, 1971). This situation sometimes led boundary spanners to use friendships and various discrepancy-reduction strategies to reconcile competing expectations and to obtain some degree of influence over constituents. This literature suggests that the nature of external demands and the strategies boundary spanners use to reconcile these demands may be key determinants of effectiveness. It would seem that boundary spanners might perform work of value to the organization only to the extent that they are able to successfully manage their boundary transactions at the individual level. A further condition for effective performance in the boundary spanning role, therefore, may be the successful reconciliation of internal and external expectations for performance.

5. Translation of expectations to viable work objectives. Having reconciled organizational and local demands, a final condition for effective performance in the boundary role might be the boundary spanner's ability to integrate perspectives from "both sides" of the boundary to enact a strategy that is meaningful in terms of their own 
jobs. Although this idea has not been explored in the literature, intuitively, it would seem to be a necessary intermediate step in terms of individual performance outcomes. For example, a boundary spanner in a senior position might be responsible for developing the local business plan. A more junior officer might be responsible for developing a client outreach strategy. Presumably, the success of these efforts would depend on the boundary spanner's ability to take decisions as to whether and how to incorporate the organizational direction into everyday work, given his or her specialized knowledge of the local context.

In summary, the literature suggests that in order to perform effectively, the boundary spanner would need to: (1) be connected with the organization's strategic direction (knowledge of organizational expectations); (2) be connected with the local environment (knowledge of external expectations); (3) be willing and able to reconcile the organization's direction with local demands (reconciliation of internal/external expectations); (4) enact the strategic direction locally (translation to work objectives); and (5) feed back local knowledge to inform and further develop organizational strategy (ability to influence).

These elements are suggested to comprise the conditions for individual effectiveness in the boundary role and are illustrated conceptually in Figure 6.2. In keeping with the central theme of this proposal that individual effectiveness should be defined in terms of contribution to organizational effectiveness, the figure incorporates both micro and macro elements. Micro concepts are denoted by shaded elements. The model nests these elements within a higher-order framework of macro concepts, denoted 
by unshaded elements (organizational strategy, organizational effectiveness, and environmental conditions). The model thus captures the assumed relationship between effectiveness at the individual level and effectiveness at the organizational level. Although the relationship between individual performance and organizational performance is complex and indirect, most observers would agree that performance at the level of the organization is in large part a function of the contributions of individual organizational members (Klein and Kozlowski, 2000). Including macro level concepts in the model makes this assumption explicit.

Lettered elements A-F represent the proposed conditions for boundary spanner effectiveness and are the topics of primary research interest. The goal of the research was to develop an expanded conceptual model that specified the intra-organizational and interface factors underlying each of these elements. The methods used to develop, refine and expand the model are discussed in Part Four. 
Figure 6.2 Preliminary conceptual framework of the conditions for individual effectiveness in the boundary spanning role

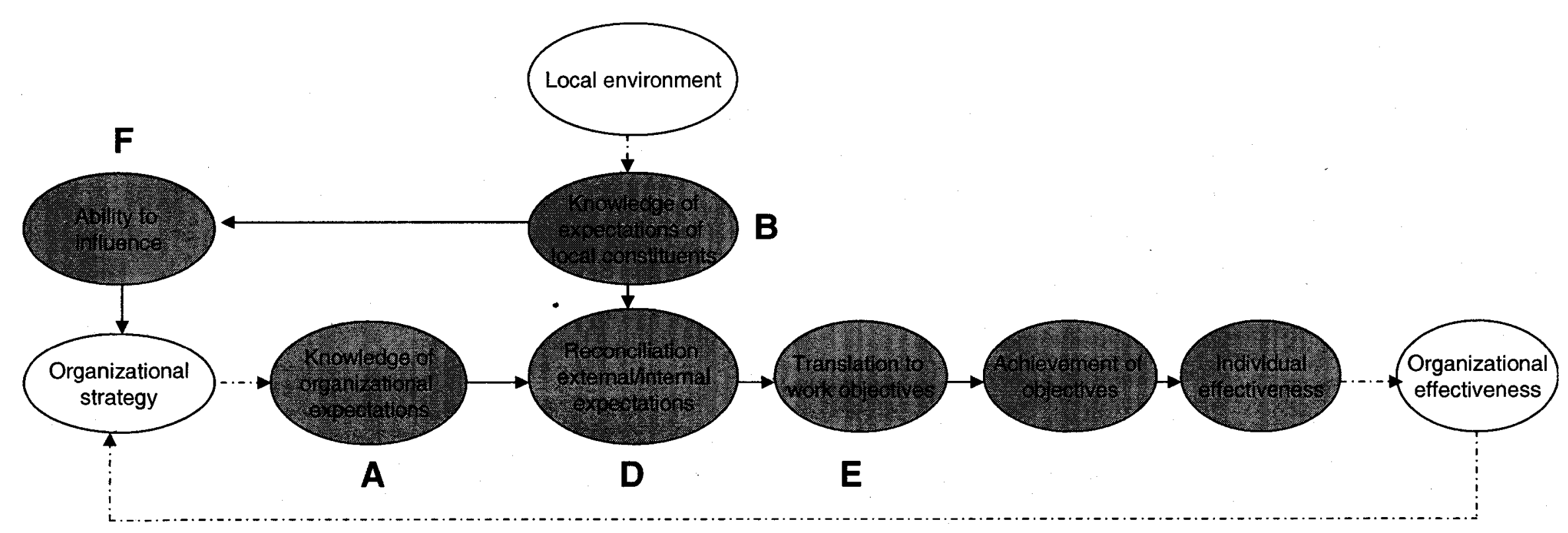

Notes: $\quad$ 1. Lettered elements reference corresponding sections of the interview protocol and are the concepts of primary interest

2. Dashed lines indicate complex and indirect relationships that are beyond the scope of the study

3. Arrows imply logical ordering, not causal relationships 


\subsection{Research questions}

In exploratory research, an initial set of research questions helps to focus data collection and constrain observations from what is a potentially unlimited universe (Miles and Huberman, 1994). The literature review and conceptual development given in the previous section were used to generate the following research questions. Questions are organized by research objective as given in Section 1.1.

\section{Objective 1 (Nature of the boundary spanning role in the MNE)}

The overarching objective of this research is to describe the dimensions of the boundary role at the individual level. Consistent with earlier macro-level (e.g., Aldrich and Herker, 1977; Katz and Kahn, 1996; Thompson, 1967) and micro-level (e.g., Ancona and Caldwell, 1988; 1992) conceptualizations, this research explores the boundary role by targeting the site of individual boundary transactions (Section 6.1). This approach enables the researcher to examine the activities in which the boundary spanner engages at the interface and the potential purposes served by these activities in terms of their contribution to the work of the broader organizational system. From descriptions of individual boundary transactions, the researcher is also able to map out both the direction and content of the exchanges. The first research question, therefore, is:

1. What is the nature of the boundary spanning role in the MNE? (The dimensions of the construct: activity plus purpose)

- In what activities does the boundary spanner engage with external agents?

- What is the content of these activities (i.e., what is exchanged over the course of these activities)?

- What is the direction of the adaptive "flow" (i.e., inward vs. outward movement 
of resources)?

- What does the boundary spanner identify as the purpose of these activities?

Objective 2 (Conditions for individual effectiveness in the boundary spanning role)

The second objective for the research is to explore the conditions for effectiveness in the boundary role. Whereas the first objective targets the interface to map the dimensions of the boundary role, this objective recognizes that effectiveness in the boundary role entails interactions on "both sides of the boundary". Effective performance in the boundary role is a function not only of the interface context, but also of the intra-organizational context in which the role is embedded (Section 6.2). Research Questions 2 though 6, therefore, explore both intra-organizational and interface factors that might affect effectiveness in the boundary role:

2. How does the boundary spanner know what the organization expects of him or her in the boundary role (Organizational expectations)?

- What are the sources of role cues in the boundary spanner's internal organizational environment (e.g., features of the work context/ job design)?

- How are expectations communicated to the boundary spanner by salient individuals internal to the organization?

3. How does the boundary spanner know what local constituents expect of him or her in the boundary role? (Expectations of local constituents)

- What are the sources of role cues in the boundary spanner's external environment?

- How are expectations communicated to the boundary spanner by salient individuals outside of the organization?

- What sorts of demands do these individuals place on the boundary spanner?

4. How does the boundary spanner reconcile organizational expectations with local expectations? (Reconciliation) 
- What strategies does the boundary spanner use to deal with constituent expectations when they are perceived to conflict with the expectations of the organization?

5. How does the boundary spanner translate organizational expectations to individual work objectives? (Translation)

- What factors does the boundary spanner take into account in setting work priorities?

6. How does the boundary spanner influence management on issues of perceived strategic importance? (Ability to influence)

- Has the boundary spanner ever tried to direct the attention of management to a local strategic issue?

- What issue-selling "moves" (Dutton et al., 2001) did the boundary spanner use?

- What do these "moves" say about the boundary spanner's normative, relational, or strategic knowledge?

\section{Objective 3 (Job level differences)}

The third objective of the research is to examine job level differences in the conditions

for effectiveness in the boundary role. Research Question 7 is thus:

7. Do boundary spanners in senior management, mid-level management and front line positions differ in terms of the conditions associated with effectiveness in the boundary role?

\section{Objective 4 (Organizational support)}

The last objective of the research is to identify boundary spanners' perceptions of, and preferences for, organizational support for their boundary roles. Research Question 8 is:

8. What are the perceived sources of organizational support for the boundary spanning role?

- $\quad$ Current and preferred support from the organization?

- Current and preferred support from the boundary spanner's manager? 


\section{PART FOUR: METHOD}

The research strategy for this thesis is case study. A case is defined as a phenomenon occurring in a bounded context (Miles and Huberman, 1994). A case study is a comprehensive empirical inquiry that investigates this phenomenon within its context (Yin, 2003). Emphasis on context is the case study's defining feature. This distinguishes it from other strategies, such as a survey or experiment, which are designed to isolate variables from their context so as to test prescribed relationships (Ibid.). Case study is the strategy of choice when the researcher believes that contextual conditions are highly pertinent to the phenomenon of interest and the objective is to explore this context in depth (Ibid.) .

Features of the boundary spanner's work context were of central interest in this research. A key theme of this thesis has been that the effectiveness of a boundary activity can be determined only by identifying the value of the activity to the system of which it is a part. To date, boundary spanning research has tended to study boundary activities divorced from their purpose (e.g., Miles' early conceptualization of boundary spanning activity), or to include purpose, but divorced from the broader organizational context (e.g., Ancona and Caldwell's study of teams). A case study strategy enables a deeper exploration of both the boundary role and the important intra-organizational and interface context in which it is situated. Context is expected to be particularly pertinent to effectiveness in international settings, where local conditions may be highly variable and where geographic and cultural distance may pose sizable challenges to both local and 
intra-organizational interactions.

A case study can serve a number of research objectives. It can be used to test an existing theory within a "real-life" context (a confirmatory use) or to define and describe a previously unexamined phenomenon (an exploratory use; Patton, 2002). The use of the case study in this research is exploratory. In instances where the primary objective is exploratory, a qualitative method is recommended (Patton, 2002; Yin, 2003).

The overarching methodology chosen for this research is, therefore, qualitative, and the primary data collection instrument is telephone interview. An advantage of case study research, however, is the ability to integrate qualitative and quantitative data in a corroborative mode (Yin, 2003). This research thus complements the interview data with quantitative data collected from interview respondents by means of pencil and paper survey.

This part of the thesis describes the case study methodology used to conduct this research. The first chapter (Chapter 7) introduces the host organization, with emphasis on how this particular organization satisfies criteria for a single-organization research design. Chapter 8 describes the grounded theory technique that comprises the methodological framework for the study. Chapter 9 describes the procedures used for sampling, data collection, data analysis, and interpretation as given by the grounded theory approach. The methodology concludes in Chapter 10 with a discussion of the standards used in this research to establish confidence in the results, including approaches to assessing validity and reliability. 


\section{THE HOST ORGANIZATION}

The organization chosen for this research was the Department of Foreign Affairs and International Trade Canada (DFAIT). This chapter briefly describes the organization and the organizational context in which the research was situated. The chapter also identifies the ways in which this organization meets the criteria for the singleorganization case study approach taken in this research.

\subsection{Description of the organization}

DFAIT employs roughly 10,000 employees, located at its Ottawa headquarters (HQ) and approximately 150 missions worldwide. Of these, roughly 3,000 employees are rotational and non-rotational staff stationed at $\mathrm{HQ}$, and 1,000 are rotational staff abroad, including heads of mission (HOMs), program managers, political-economic and trade officers, management-consular staff, and employees providing administrative and technical support. The remaining 6,000 employees comprise locally engaged staff (LES) who work in DFAIT's missions abroad in a variety of professional and support roles.

At the time of this study, DFAIT was structured into two large geographic branches: a North American Branch responsible for missions in the United States and Mexico, and a Bilateral Relations Branch responsible for missions in the rest of the world. At the sub-branch level, the reporting structure was such that missions reported to one of several geographic divisions at HQ responsible for that mission's geographic region. Missions range in size from "micro-missions" with fewer than 20 employees on 
site (including locally engaged staff), to large embassies with over 300 employees. Many missions also house staff from partner federal departments and provincial governments who have shared policy interest in Canada's international agenda. The HOM is accountable for all mission staff, including those from co-located partner departments and those who are locally engaged.

\subsection{Impetus for this research}

This study was initiated in the summer of 2005 , prompted by interest in a new strategic planning model under development in DFAIT's Bilateral Relations Branch. The Assistant Deputy Minister of the Branch invited the researcher to collect some data that might help the Branch find ways to maximize mission engagement in the new planning process. Specifically, the researcher was asked to conduct telephone interviews with HOMs, program managers, and political-economic staff abroad whose involvement in the process was believed to be central to its success. Given that the Bilateral Relations Branch operated over 140 missions on four continents, this research presented a rare opportunity to study the boundary spanning role in a "truly" global setting ${ }^{1}$.

\subsection{Suitability of this organization for the case study approach}

The study of a single organization is appropriate in instances where the case represents an extreme of the phenomenon of interest or in instances where an observer

\footnotetext{
${ }^{1}$ The researcher was granted access to the Bilateral Relations Branch; therefore, N. American missions were not available for study.
} 
has access to a rarely accessible phenomenon (Eisenhardt, 1989). Given the phenomenon of interest in this research was the expatriate boundary role, DFAIT met both of these criteria.

First, a foreign service ministry represents the "extreme" in boundary spanning in the international context. Foreign service jobs are extremely high in what Kahn et al. (1964) refer to as "boundary relevance" (Section 2.1.2). Political staff at post do not engage in boundary spanning as part of their jobs- - boundary spanning is the job (i.e., it comprises the core technology; Aldrich and Herker, 1977; Thompson, 1967). In order to do their jobs, political staff come into contact with a wide range of external contacts in virtually all sectors, including other orders of government, private industry, community representatives, NGOs and academics. A foreign ministry also has extensive international presence (in this case, representation at 140 missions abroad), so might be considered "extreme" by geographic scope as well. DFAIT's foreign service cadre, therefore, represented a rich source of information on the boundary spanning role. In an exploratory study, it is desirable to have participants who are highly conversant on the subject of research interest and who can readily identify research-relevant situations as referents for discussion and inquiry (Miles and Huberman, 1994; Patton, 2002).

Second, DFAIT met the criterion of "access" to a rare event. At the time of this research, the department was undergoing a major change in its strategic planning process, including the development of a new international policy framework and the introduction of a suite of accountability and alignment measures aimed at supporting the enactment of the department's strategic direction at the mission level. Alignment tools had been 
prepared by geographic divisions at HQ. Geographic managers and desk officers at HQ were in the process of rolling these tools out to missions in consultation with HOMS and foreign officers abroad. The centrepiece of the alignment suite was a "country strategy" template that outlined for missions Canada's key areas of international policy interest. HOMs were requested to complete the template showing how they would meet international interests at the local level. The template was complemented by, and aligned with: a HOM mandate letter; a local reporting agreement between HQ and HOMs; a HOM performance management agreement; and messaging from HQ that the mission's resource allocation for the next fiscal year would be based on the quality of the country strategy received and the fit of the strategy in terms of DFAIT's overall international policy agenda. Management of the Bilateral Relations Branch had granted the researcher interview time with nearly 90 staff abroad, including HOMs, mid-level managers and front line officers, located in seven geographic regions (Asia/South Pacific, China/East Asia, the Middle-East/ North Africa, Africa, Latin America/Caribbean, Northern and Western Europe, Central and Southern Europe). This case thus presented a rare opportunity to conduct an exploration of the expatriate boundary spanning role under conditions of intense strategic discussions between the organization and its boundary spanning personnel. 


\section{THE GROUNDED THEORY TECHNIQUE}

The methodological framework adopted for this research is an approach to building theory from case study given by Eisenhardt (1989). Eisenhardt's model provides a rigorous approach to qualitative research, adapted specifically for application to the study of management. Central to her method is the grounded theory technique, an inductive approach to building theory from empirical observation. Since grounded theory entails an iterative approach to theory building, it drives all steps in the research process, including procedures for sampling, data collection and data analysis. This chapter presents an overview of the technique to provide the logic for the sampling and data collection procedures discussed in Chapter 9.

\subsection{The application of grounded theory in case study research}

Grounded theory is an inductive approach to conceptual development based on the abstraction of concepts and theory from empirical observation (Patton, 2002). It can be applied to define and develop constructs, to propose relationships, or both. The product of grounded theory may be the concepts themselves, a general conceptual framework, or a fully articulated theory capable of suggesting propositions and testable hypotheses (Bacharach,1989; Eisenhardt, 1989).

The method was originally formulated by Glaser and Strauss (1967). In its "purest" form, researchers began theory-building research as close as possible to the ideal of "no theory under consideration" (Eisenhardt, 1989, p.536) so as to allow concepts and 
relationships to "emerge" from the raw data. However, as the approach gained popularity, particularly in the field of management studies (e.g., Eisenhardt and Bourgeois, 1988; Bouty, 2000; Dutton et al., 2001), emphasis shifted to a priori specification of concepts, more fully developed research questions, and greater codification and standardization in data collection and analysis (Miles and Huberman, 1994; Yin, 2003).

Eisenhardt's (1989) model incorporates all of these advances in the application of grounded theory to management research. She combines Glaser and Strauss' grounded theory technique with quantitative case study techniques given by Yin (2003) and qualitative data analysis techniques given by Miles and Huberman (1994) to develop a comprehensive approach to building theory from empirical observation. An overview of her approach follows.

\subsection{Overview of Eisenhardt's model}

Following is a summary of "steps" to building theory from case study research, as given by Eisenhardt (1989), and as adopted for this research.

1. Specification of constructs and research questions An initial orienting framework and a set of research questions are developed to focus empirical observations and sensitize the researcher to variables of interest. The preliminary identification of constructs also helps researchers identify any elements that are amenable to quantitative measurement and which can be explicitly addressed through questionnaires or other quantitative methods. Should these constructs then emerge through interview or 
observation, strong, triangulated measures are available to further ground the emerging theory. The conceptual models and research questions for this research were formulated in the previous chapter and will be revisited in Chapter 9 as the basis for data collection and analysis.

2. Sampling Grounded theory relies on purposive or theoretical sampling. Cases are chosen for theoretical, not statistical, reasons. The goal is to inform, replicate or extend an emerging concept or theory (to infer from case to theory), rather than to obtain accurate statistical representation of a population parameter (to infer from sample to population). Cases are chosen to represent extreme situations or polar types in which the process of interest is readily accessible and transparently observable. The purposive sampling procedure employed in this research is described in Section 9.2.

3. Crafting instruments and protocols The combined application of quantitative and qualitative data within the case study strengthens theory building through the triangulation of evidence. Questions addressed in data collection instruments flow directly from the conceptual frameworks and research questions. Data collection instruments designed for this research are described in Section 9.3.

\section{Iteration of data collection and data analysis in the field Whereas quantitative} methods tend to specify data collection, analysis, and "conclusion drawing" as discrete and sequential steps, a central feature of grounded theory is the intentional overlapping of data collection, data analysis, and interpretation in the field. Overlap is necessary because the essence of grounded theory is the identification of themes and patterns within the raw data that begin to emerge in the first few cases and, over time, accumulate to 
converge on a construct or theory. Grounded theory begins with basic description of a single case, moves to conceptual ordering (organizing data into discrete categories according to their properties or dimensions) and then to theorizing (conceiving or intuiting ideas, such as concepts or relationships, and formulating them into a logical scheme; Patton, 2002). The analytic process thus begins with the first case observed (basic description) and continues through a process of constant comparison as additional cases are examined.

5. The constant comparison technique The technique of constant comparison lies at the heart of grounded theory. The technique moves the researcher through the three levels of abstraction described above (i.e., description, conceptual ordering, theorizing). First is the within-case analysis. The within-case analysis yields description: what do I see happening in this instance? Typically, description takes the form of transcription or recording of an interview or a write-up of an observed event. Within-case analysis allows the unique patterns of each case to emerge before the researcher pushes to generalize patterns across cases.

The description of the first few cases lay the foundation for the first set of comparisons: the cross-case analysis. Cross-case comparisons yield the conceptual ordering. The researcher selects a category or dimension of interest and begins to search for similarities and differences on this dimension in the descriptions of each case. The category or dimension can be driven by the research questions or can emerge from the cases themselves. The product of the cross-case analysis is a coding scheme, which is developed iteratively as categories surface. 
From the within- and cross-case analyses, patterns begin to surface that suggest tentative constructs or relationships between constructs. The emergence of cross-case patterns is the beginning of the theorizing stage of grounded theory. At this point, the researcher begins a second set of comparisons: case-to-theory. New cases are examined- or old cases reexamined- - in light of the emerging concepts or relationships. The idea is to test the fit of the theory to the case data (i.e., to empirically "ground" the theory). Through case-to-theory comparisons, the researcher either builds support for the emerging theory, revises it, or discards the theory for lack of evidence. The use of the constant comparison method in development of the coding scheme and data analysis for this research is described in Section 9.4.1.

\section{Enfolding the literature in the final shaping of properties, constructs, or theory} Through the iterative process of constant comparison, the researcher shapes and sharpens emerging descriptions, constructs or theory. At this point, the researcher is encouraged to return to the literature to check findings against related research and to identify any consistencies or points of departure. Contradictions with the literature present a further opportunity to return to the data, and to again challenge the emerging theory. This introduces a further level of iteration, that between the literature and the emerging theory, and contributes to construct validity. The literature for this research was reviewed in advance of data collection in order to develop the conceptual framework, and was revisited during data analysis and interpretation.

7. Closure Depending on the research questions or the limits of the data, theory building can stop at any of the three levels of abstraction (description of the properties of 
a thing or event, a well-defined construct, or a fully-articulated theory). Closure is reached when the researcher is no longer observing concepts or relationships not seen before, and when the iteration between theory, data, and literature yields little incremental improvement to constructs or theory (i.e., the point of "theoretical saturation" has been reached.) In the case of this research, objectives were descriptive (to map the dimensions of the boundary spanning role construct, and to elaborate the various conditions for effectiveness in the role). However, relationships and higher-order concepts did suggest themselves, and are discussed progressively as results are reported in Part Five.

\subsection{Strengths and weaknesses of the approach}

Eisenhardt's approach reflects a highly iterative process, with "back and forward" movement between the data and emerging theory. She discusses several strengths and weaknesses of the flexibility inherent in grounded theory. The major strength is its ability to generate novel ideas that would not be available from deduction from existing literature alone. A second strength is that the resultant theory is likely to be empirically testable. Testability is high because the theory-building process is so intimately tied with evidence.

In terms of weaknesses, Eisenhardt indicates that grounded theory's intensive use of empirical evidence can yield theory that is narrow and idiosyncratic. Theory building is "bottom up", such that the specifics of the data produce the generalizations of theory. The risk is that the theorist is unable to raise the generality of the theory, leading to 
modest theory that is applicable only to specific phenomena.

The major weakness cited by Eisenhardt is the potential for bias. There is a risk that the investigator's preconceptions will drive the empirical "search", limiting what is seen, and tempting the investigator to close the iterative process once the "hoped for" patterns are detected. Eisenhardt counters, however, that the continuous juxtaposition of conflicting realities through constant comparison tends instead to unfreeze thinking, so that the process has the potential to generate theory with less researcher bias than theory built from existing literature or "armchair" deduction. Further, Eisenhardt's technique has important differences from Glaser and Strauss' original technique. Eisenhardt's application of grounded theory has a decidedly positivist orientation, including a priori specification of questions, flexible instrumentation, multiple lines of evidence, and several uses of literature. It thus offers a combination of deductive frames (through the initial orienting framework and emerging theory) and inductive frames (through repeated empirical observation in the field), much like hypothesis testing in quantitative methods. In addition, it might equally be argued that researcher bias remains a possibility in any research setting. It would seem that the subjectivity inherent in grounded theory is no greater than that of quantitative research, where investigators may also "return to the data" to run new models when initial hypotheses are found to lack support. 


\section{SAMPLING, DATA COLLECTION, AND ANALYSIS}

This chapter describes the application of the grounded theory technique to sampling, data collection and data analysis for this research.

\subsection{Units of analysis}

The first task in data collection and analysis in case study research is to define the units of analysis for investigation (Miles and Huberman, 1994; Patton, 2002; Yin, 2003). The unique feature of a case study is that the unit of analysis can shift within any given study, depending on the research question asked and what it is the researcher wants to describe and make claims about (Miles and Huberman, 1994).

Examination of the research questions given in Chapter 6 indicates that the primary unit of analysis for this research is the individual (e.g., How does the individual boundary spanner know what is expected of him or her? How does the boundary spanner translate these expectations into work objectives?) Further, although the individual is the primary unit of analysis, two of the research questions have an additional unit of analysis embedded within them. Research Question 1 asks what is the nature and purpose of the boundary spanning role in the MNE. In this instance, the unit of analysis is the role, not the individual. Research Question 6 asks about the boundary spanner's previous efforts to influence management on strategic issues. This question is oriented toward the description of an issue-selling "episode". In this instance, the unit of analysis is the episode, not the individual. 
This design is what Yin (2003) has termed "embedded case". Embedded denotes the nesting of units of analysis (essentially, a nesting of "cases"). It is important to specify the units of analysis prior to data collection, since they drive sampling and coding procedures, and form the foundation for the display of results.

\section{$9.2 \quad$ Sampling}

Unlike sampling in quantitative research, sampling for the purpose of grounded theory is not governed by criteria for sample size (Yin, 2003). The goal is to generalize from the observations at hand to an underlying theory (analytic generalization), not to a broader population (statistical generalization; Yin, 2003). Decisions regarding sample size thus focus on obtaining sufficient observations to provide confidence around the analytic generalizations made (Ibid., p. 29).

The specific approach to sampling for this research was maximum variation sampling. This procedure involves purposefully choosing a wide range of cases so as to maximize variation on the construct of interest (Miles and Huberman, 1994; Patton, 2002). This strategy is recommended for exploratory research, since it exposes the researcher to as variable a set of responses as possible and allows fuller mapping of focal constructs.

There are no hard and fast rules regarding the number of cases required to obtain "maximum variation". Where the unit of analysis is the individual, a starting sample of 30 cases has been recommended as a rule of thumb for obtaining sufficient individual variation in responses to observe patterns in the data (Mertens, 1998). Of course, were 
all 30 cases selected from the same site, doing the same job, under the same conditions, little variation might be expected, except that owing to individual differences. Yin (2003) recommends that the sample be selected by articulating the various conditions that might affect the phenomenon of interest, and then selecting a number of cases across these conditions.

Given these recommendations, the sampling strategy for this research was as follows. First, based on the research objectives, there were three primary conditions of interest. These were given by job level: it was of interest to observe variations in the boundary role between senior managers, mid-level managers, and employees at the officer level. Therefore, a target sample size was established at 90 individuals, 30 to be drawn from each of the job levels. Further, in order to tap into the large number of contexts in which boundary spanning is situated in the MNE, it was of interest to increase the variability within each of these job categories. Therefore, four additional conditions were identified that were deemed likely to affect the nature of the boundary role and the local context in which it was situated:

1. Mission size Mission size was of interest because communication or influence patterns might be expected to vary with mission size. Work by Watson and Wooldridge (2005), for example, suggests that upward influence on corporate strategy is enhanced for managers of business units with a large number of employees, as compared to managers of smaller units. To increase variability in the nature of responses, sampling was structured to ensure representation of respondents from missions across the "size" 
spectrum.

2. Geography In an MNE context, different geographies imply different physical and cultural distances, and differential access to local infrastructure (e.g., limited internet bandwidth). These may be important contextual elements both in terms of intraorganizational communication patterns and local interactions. Sampling was structured to obtain participants assigned to all seven of the Branch's geographies.

3. "Priority" status Like any multinational organization, DFAIT has some missions that are deemed to be more central than others in achieving its strategic objectives. It might be expected that boundary spanners in high-priority countries would find it somewhat easier to become part of the "strategic conversation". At the time of this research, DFAIT's policy framework had identified relationships with four countries as priority relationships: Brazil, Russia, India, and China ${ }^{2}$. Both high- and low-priority countries were sampled.

4. Gender Gender has not been a factor of interest in the boundary spanning literature. However, research on women in management suggests that women and men have different communication, leadership, and interpersonal styles (Rosner, 1990) and that women often occupy positions of lower influence in the organization, with reduced access to the social networks they need to gain important contextual information (Dutton, Ashford, Lawrence, Miner-Rubino, 2002.). These differences may have implications for the boundary activities women perform, the nature of their boundary interactions, or their ability to connect to intra- or extra-organizational networks. Again, to ensure the

\footnotetext{
${ }^{2} \mathrm{~N}$. American missions were also of high priority, but were not available for study.
} 
broadest variability in responses, both women and men were sampled.

\subsubsection{Sample selection protocol}

DFAIT's management supplied the researcher with a position detail report that provided a complete sampling frame of the 108 bilateral missions ${ }^{3}$ within the Bilateral Relations Branch, including DFAIT employees, employees co-located from other government departments, and locally engaged staff. Using the above sampling criteria and a set of decision rules for selection, a preliminary sample of 61 missions was drawn. Following is an outline of the logic of the sampling strategy.

Step 1: Define job level The first task was to identify job level within the position reports to support sampling within the three job level categories. The reports identified HOMs by a special flag, so HOMs were easily classified. However, in some larger missions, there were several levels below the HOM, some also holding executive job classifications, implying more than one level of "mid-management". In addition, many at the officer level also appeared to have some supervisory responsibility, due to the need to manage various local research and support staff.

Decision rules were therefore formulated to identify the mid-management and officer levels. Given the objectives of this research, the central interest in job level was not to explore the nature of management responsibility per se. It was to explore whether job level- - particularly the proximity to decision-makers- - might affect the boundary

\footnotetext{
${ }^{3}$ Management requested that the researcher restrict her interviews to bilateral missions who had been involved in the country strategy process. This requirement excluded 32 missions who dealt primarily with multilateral issues and reduced the potential sampling frame from 140 to 108 .
} 
role or effectiveness in the role. It was decided, therefore, that the relevant classification criterion was the number of levels above the employee. This approach is similar to an approach by Ireland, Hitt, Bettis, and de Porras (1987), who used a senior manager classification scheme based on the number of levels between the manager and the CEO. The decision rule taken for selecting mid-managers in the current study, therefore, was that: (1) the individual had responsibility for supervision of DFAIT political officers (which would distinguish the individual from officers, who typically supervised only local staff); and (2) the individual reported directly to the HOM. Similarly, the decision rule for classifying an employee as front line officer was: (1) the individual may or may not have had supervisory responsibility; but (2) there was at least one reporting level between the individual and the HOM. The appropriateness of these decision rules to sample selection was verified by a member of DFAIT's Post Support Unit.

This step yielded 40 mid- to large-sized missions with sufficiently tall structures to have a mid-level management position. This created a sampling frame of $40 \mathrm{HOMs}$, one from each of the 40 missions. Forty mid-managers and 40 front line officers were then selected from the same missions.

Step 2: Verify adequate sampling across mission sizes By locating missions with sufficiently tall structures to have a mid-management level, Step 1 had also generated the sample of mid- to large-sized missions. Inspection of the 40 missions obtained in Step 1 suggested that an adequate range of sizes had been sampled (ranging in size from roughly 30 employees to nearly 350 , with high variation between these endpoints). This left the task of identifying micro missions. We, therefore, returned to the original sampling 
frame and selected 16 micro missions with fewer than 20 employees. The only selection criterion was to sample across the 7 geographies (note that there are no micro missions in China/East Asia, so this region is not represented in the sampling frame).

Step 3. Ensure that high priority missions had been included Inspection of the original 40 mid- to large missions indicated that Brazil, Russia, India, and China had been included in the sample, so all priority countries were represented.

Step 4. Ensure reasonable representation of women Inspection of the officer sample indicated that women and men were roughly equally represented. At the HOM and midmanagement level, however, men outnumbered women by a ratio of roughly 4 to 1 . This imbalance was not an artifact of the sampling procedure, but reflected a long-standing gender imbalance in the proportion of women in senior positions in the Department. We, therefore, returned to the original frame to search for additional missions headed by women, and randomly added five to the original 40 .

The above series of steps yielded a total of 45 mid-large missions, and 16 micro missions. The total number of women HOMs was 15 . Table 9-1 provides a summary of the preliminary sampling frame by mission size, geography, and sex of HOM. The number of women HOMs is given in brackets. Table 9-2 provides a summary of the sampling frame by job level. 


\begin{tabular}{|l|c|c|c|}
\hline \multicolumn{1}{|c|}{$\begin{array}{c}\text { Preliminary sampling frame by geography, mission size, and sex of head of } \\
\text { mission }\end{array}$} & Mid-large missions & Micro missions & Total \\
\hline Geography & 9 & 4 & 13 \\
\hline Asia/South Pacific & 5 & - & 5 \\
\hline China/East Asia & 3 & 3 & 6 \\
\hline Central and Southern Europe & 7 & 2 & 9 \\
\hline Northern and Western Europe & 5 & 4 & 9 \\
\hline Africa & 8 & 1 & 9 \\
\hline Middle-East/ North Africa & 8 & 2 & 10 \\
\hline Latin America/Caribbean & $\mathbf{4 5}(\mathbf{1 0})$ & $\mathbf{1 6}$ & $(\mathbf{5})$ \\
\hline Total & & $\mathbf{6 1}$ & $(\mathbf{1 5})$ \\
\hline
\end{tabular}

Note: Numbers in brackets indicate the number of women HOMs

\begin{tabular}{|l|c|}
\hline Table 9-2 Preliminary sampling frame by job level \\
\hline HOM & 61 \\
\hline Mid-management & 45 \\
\hline Front line & 45 \\
\hline Total & $\mathbf{1 5 1}$ \\
\hline
\end{tabular}

\subsubsection{Participant recruitment}

In order to maximize respondent willingness to participate, and to enhance the quality of data collected, recruitment procedures followed guidelines for contexting qualitative management research given by Balogun, Huff and Johnson (2003). First, Balogun et al. recommend establishing credibility by having the research sanctioned by a high level of the organization. Invitations to participate were issued to mission personnel via email from the Director General of DFAIT's Strategy and Services Bureau, 
explaining the value of the research to the organization, and encouraging participation. This individual was the executive responsible for the design and coordination of the country strategies, so was of fairly high rank in the organization and was well known to missions.

Second, Balogun et al. recommend that organizational research be positioned as professionally and organizationally relevant, and sufficiently enjoyable to sustain respondent interest. In terms of professional relevance, invitations indicated that DFAIT had been chosen for this study because its mission personnel were experts in the phenomenon of interest, and their expertise was of interest to researchers in the area of international management. Organizational relevance was maximized by indicating that the study addressed immediate organizational needs surrounding the strategy alignment process and would support monitoring and adjustments around this process.

Invitations were issued in two waves. The first wave comprised a general information note issued to all 108 mission heads to maintain transparency and to request that they encourage their staff to participate, should their staff be contacted. The information note was then followed by invitations to the samples for each of the three job categories. Interested respondents contacted the researcher directly to ensure anonymity.

Twenty-five of the 151 emails generated out-of-office replies, reducing the sampling frame to 126 . Seventy-nine mission staff agreed to participate, representing an effective response rate of $63 \%$. Since probabilistic sampling was not applied in this research, it is not appropriate to comment on the adequacy of the response rate. It is offered here as evidence of the relatively high rate of interest in the study, and as an 
indication that the invitations had been adequately framed to establish relevance and generate motivation to participate, as recommended by Balogun et al. (2003). Further, five heads of mission not in the original frame volunteered to participate in the research in response to the general information note they received prior to the study. This yielded a total of 85 participants: 35 heads of mission, 21 mid-level managers, and 28 front-line officers, representing 56 missions in total.

\subsubsection{Description of the sample}

The final sample by job level, sex, mission and geography are given in Tables 9-3 to 9-5. Since the sample obtained reasonable coverage of all of the purposive sampling criteria established for this research, no follow up effort was made to increase sample size. 


\begin{tabular}{|l|r|r|r|r|r|r|}
\hline Table 9-3 Respondents by geography and mission size \\
\hline & \multicolumn{7}{|c|}{ Mission size } \\
\hline & $1-20$ & $21-50$ & $51-100$ & $101-150$ & $>150$ & Total \\
\hline Geography & \multicolumn{7}{|c|}{ Number of respondents (\%) } \\
\hline China/E. Asia & 1 & - & 6 & 4 & 4 & $\mathbf{1 5}(\mathbf{1 8})$ \\
\hline Asia/ S. Pacific & 1 & 4 & 4 & 2 & 3 & $\mathbf{1 4}(\mathbf{1 7})$ \\
\hline Latin America/ Carribean & 1 & 5 & 9 & - & - & $\mathbf{1 5}(\mathbf{1 8})$ \\
\hline C/E/S Europe & 2 & - & 2 & 3 & - & $\mathbf{7}(\mathbf{8})$ \\
\hline N/W Europe & - & 5 & 5 & - & 2 & $\mathbf{1 2}(\mathbf{1 4})$ \\
\hline Mid East./ N. Africa & - & 4 & 6 & - & - & $\mathbf{1 0}(\mathbf{1 2})$ \\
\hline Africa & 4 & 1 & 4 & 2 & - & $\mathbf{1 1}(\mathbf{1 3})$ \\
\hline Total & $\mathbf{9}(\mathbf{1 1})$ & $\mathbf{1 9}(\mathbf{2 3})$ & $\mathbf{3 6}(\mathbf{4 3})$ & $\mathbf{1 1}(\mathbf{1 3})$ & $\mathbf{9 ( 1 1 )}$ & $\mathbf{8 4}(\mathbf{1 0 0})$ \\
\hline
\end{tabular}

4 Tables 9-3 to 9-5 provide frequencies for each cell, with marginal percentages appearing in brackets. For example, in Table 9-3, there are a total of 84 respondents, thus representing $100 \%$ of the sample. Column 1 indicates that, of the total 84 respondents, 9 were from missions with 1-20 employees. This represents $11 \%$ of the total, so this number follows in brackets. Similarly, Row 1 indicates that, of the total 84 respondents, 15 were from China/E. Asia. This represents $18 \%$ of the total, so follows in brackets. 


\begin{tabular}{|c|c|c|c|c|c|c|}
\hline \multirow[b]{3}{*}{ Geography } & \multicolumn{3}{|c|}{ Missions } & \multicolumn{3}{|c|}{ Respondents } \\
\hline & \multicolumn{3}{|c|}{ Mission priority status } & \multicolumn{3}{|c|}{ Mission priority status } \\
\hline & Yes & No & Total & Yes & No & Total \\
\hline & \multicolumn{6}{|c|}{ Number $(\%)$} \\
\hline China/ E. Asia & 2 & 4 & $6(11)$ & 7 & 8 & $15(18)$ \\
\hline Asia/ S. Pacific & 2 & 7 & $9(16)$ & 2 & 12 & $14(17)$ \\
\hline $\begin{array}{l}\text { Latin America/ } \\
\text { Caribbean }\end{array}$ & 2 & 11 & $13(23)$ & 3 & 12 & $15(18)$ \\
\hline $\mathrm{C} / \mathrm{E} / \mathrm{S}$ Europe & 1 & 4 & $5(9)$ & 3 & 4 & $7(8)$ \\
\hline N/W Europe & 3 & 4 & $7(13)$ & 4 & 8 & $12(14)$ \\
\hline Mid East/ N. Africa & 2 & 5 & $7(13)$ & 4 & 6 & $10(12)$ \\
\hline Africa & 2 & 7 & $9(16)$ & 3 & 8 & $11(13)$ \\
\hline Total & $14(25)$ & $42(75)$ & $56(100)$ & $26(31)$ & $58(69)$ & $84(100)$ \\
\hline
\end{tabular}

\begin{tabular}{|c|c|c|c|c|}
\hline \multicolumn{5}{|c|}{ Table 9-5 Respondents by job level and sex } \\
\hline & Head of mission & Mid-manager & Officer & Total \\
\hline & \multicolumn{4}{|c|}{ Number $(\%)$} \\
\hline Men & 25 & 15 & 16 & $56(67)$ \\
\hline Women & 10 & 6 & 12 & $28(33)$ \\
\hline Total & $35(42)$ & $21(25)$ & $28(33)$ & $84(100)$ \\
\hline
\end{tabular}

Further, given the maximum variability sampling technique, one would also hope to obtain heterogeneity within the sample in terms of personal and work-related profiles.

Table 9-6 provides a description of the sample by age and selected work characteristics, and suggests this heterogeneity was achieved. As expected, HOMs represented a very experienced cadre of professionals, averaging 23 years with the department, and four 
previous postings to countries other than the one to which they were posted at the time of interview. In contrast, a very large proportion of respondents at the officer level were on their first assignment (75\%). This heterogeneity allowed for interesting job level differences to emerge in response to the research questions and will be revisited in interpreting the findings (Part Five).

\begin{tabular}{|l|c|c|c|}
\hline \multicolumn{1}{|c|}{ Table 9-6 Characteristics of sample by age and work characteristics } \\
\hline & $\begin{array}{c}\text { Head of mission } \\
(\mathbf{N}=\mathbf{3 5})\end{array}$ & $\begin{array}{c}\text { Mid-manager } \\
(\mathbf{N}=\mathbf{2 1})\end{array}$ & $\begin{array}{c}\text { Officer } \\
(\mathbf{N}=\mathbf{2 8})\end{array}$ \\
\hline Age (mean) & 53 & 45 & 35 \\
\hline Years with DFAIT (mean) & 23 & 13 & 6 \\
\hline Months at this post (mean) & 19 & 26 & 21 \\
\hline Number of countries prior to this & 3.7 & 1.5 & .32 \\
post (mean) & & & 75 \\
\hline First posting? (percent yes) & 6 & 14 & \\
\hline
\end{tabular}

\subsection{Data collection}

As indicated in the overview of Eisenhardt's model, a major strength of the case study approach to theory-building is its flexibility in terms of the triangulation of qualitative and quantitative data. Any finding of a study is likely to be more convincing if it is based on several sources of data used in a corroborative mode (Yin, 2003.). This section describes the approach to qualitative and quantitative data collection taken in this research. 


\subsubsection{Qualitative data}

\subsubsection{The interview protocol}

The instrument used in collecting the qualitative data was a semi-structured interview. The semi-structured interview format specifies the core wording of each question in advance, while allowing flexibility in delivery and follow-up probes (Patton, 2002). The format ensures that all questions are delivered to respondents so that no important data are neglected, and ensures that the precise instrument used in the study is available for inspection by those who might want to use the findings (Patton, 2002). However, it remains sufficiently flexible to allow the researcher to add or reword questions and present probes as needed. This flexibility is important to theory-building research, where unanticipated responses may generate the need for additional questions or clarification.

In respect of respondents' time demands, the interview was designed to last roughly one hour. A copy of the interview protocol is provided in Appendix A. An overview of the protocol, ordered by research question, is given below.

Research Question 1 (Section C: The nature of the boundary spaning role in the MNE) This section was aimed at eliciting an account of a specific boundary interaction to compare and contrast to the dimensions given by Ancona and Caldwell's framework (Section 6.1; Figure 6.1). This section asks the respondent to identify a recent interaction with an important external constituent, and walks the respondent through the nature of this interaction. The identification of specific targets for discussion ("let's discuss your 
interaction with X"), rather than abstract generalizations ("what do you usually want to achieve when you interact with people outside of the organization?") leads to responses that are grounded in experience, rather than shaped by opinion or social desirability (Patton, 2002). The approach is consistent with that taken by Ancona and Caldwell $(1988 ; 1992)$, who also used target boundary interactions to map the dimensions of the boundary role. For each of the interactions described, the researcher is able to note the content of the transaction (i.e., what is exchanged across the boundary), the direction of the exchange (e.g., an inward vs. outward flow of resources), and the purpose of the exchange in terms of the work of the organization. Section $\mathrm{C}$, therefore, comprised the basis for conceptualizing the boundary role.

Research Question 2 (Section A: How does the boundary spanner know what the organization expects in the role?) This section was aimed at exploring the first posited condition for effectiveness in the boundary role: the respondent's perception of the organization's expectations for the boundary role. It was intended to elicit from the respondent a listing of the salient intra-organizational role cues identified in the literature reviewed in Section 3.1.1 (e.g., documents, supervisory direction). The open-ended nature of this question allowed for the emergence of new categories of cues not anticipated.

Research Question 3 (Section B: How does the boundary spanner know what external constituents expect?) This section investigates the second posited condition for effectiveness in the boundary role: the respondent's perceptions of the expectations of local constituents. It was intended to elicit from the respondent a listing of the salient 
external cues for the boundary role (i.e., various constituent behaviours or other sources of information that might contribute to the boundary spanner's sent role). Unlike Research Question 1 (the boundary role construct), this series of questions does not target a particular interaction for investigation. It asks, "in general", how the boundary spanner might know what outsiders expect of him or her. The decision to phrase this question in the abstract was taken in the belief that boundary spanners' attributions regarding the expectations of various external constituents might be a function not only of roles sent during a given interaction, but also of a more global sense of what a member of that constituency might want. Since the sources of role cues in the external environment had not been previously investigated empirically, this section of the interview allowed for the broadest range of responses so as not to restrict the respondent to a preconceived range of answers.

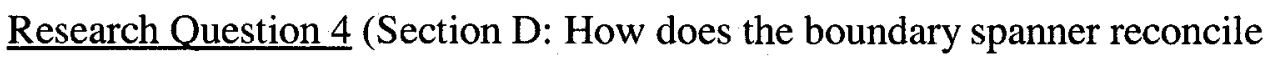
external/internal expectations?) This section investigates the third condition for effectiveness in the boundary role: the boundary spanner's strategies for reconciling conflicting demands. It was designed to elicit the various interpersonal strategies boundary spanners might invoke to avoid or reduce discrepancies (e.g., the use of friendship, expertise). This series of questions involved a skip sequence. Where respondents cited a discrepancy over the course of the focal boundary episode described in Section C, the researcher was able to code the reconciliation strategy from the episode, and skip to Section E. Where respondents did not cite a discrepancy in the focal boundary episode, they were asked to think of another example. This approach enabled the 
researcher to obtain a larger number of episodes for exploration. The use of specific episodes grounded the theory in the boundary spanner's actual experience and reduced the likelihood of social desirability response bias.

Research Question 5 (Section E: How does the boundary spanner translate organizational and local expectations to work objectives?) This section was aimed at exploring the fourth condition for effectiveness: the translation of expectations to work objectives. It attempts to identify the factors that boundary spanners might take into account in determining what they should be doing in their jobs. The questions were very difficult to word. There was no literature from which to speculate how boundary spanners might incorporate multiple perspectives in designing their work goals or in carrying out their tasks. However, translation was believed to be critical to individual effectiveness in the boundary role, especially in international settings, where local contacts may be more salient sources of role cues than the home organization.

Research Question 6 (Section F: How does the boundary spanner influence management on important issues?) This section was aimed at exploring the last condition for effectiveness in the boundary role: the respondent's perceived ability to influence management. The questions are modelled after Dutton et al. (2001)'s investigation of issue-selling efforts. Respondents are asked to recount a specific episode where an attempt was made to "get management attention" on a strategic issue. This item was intended to elicit a description of the episode in terms of the salient intra-organizational factors believed to have contributed to success or failure in the attempt. The section thus enabled the researcher to explore the various issue-selling strategies used by boundary 
spanners in this international setting, with particular attention to the potential effects of geographic distance on the choice of strategy and its perceived success. The decision to gauge perceived influence by targeting a separate influence effort (i.e., rather than to attempt to code influence from the boundary transaction given in Section C) was made in anticipation of the possibility that not all boundary episodes would entail an attempt to influence management. The structuring framework used to explore the boundary role in this research (Ancona and Caldwell, 1992) suggested a wide range of purposes served by boundary transactions, only some of which might be expected to include an effort to influence management (i.e., an effort to modify the internal organizational environment). Indeed, most dimensions in the framework reflected efforts to modify the external environment (e.g., ambassador), or to prevent outside pressures from impinging on the work of the organization (e.g., guard). By targeting a separate influence effort, the researcher was able to ensure that data on perceived influence were obtained from all respondents. More importantly, the targeted approach provided a more complete picture of boundary spanners' overall sense of influence and perceived connectedness with the organization's strategic, normative, and relational context (Section 6.2).

Research Question 7 (Section G: Rewards and challenges of the boundary role) Patton (2002) recommends this type of "general purpose" question toward the end of an interview to elicit any perceptions not tapped by the focal questions. Such questions allow "discovery" (Ibid.) by surfacing novel ideas and aiding in the interpretation of focal questions.

Research Question 8 (Section H: Sources of organizational support) The interview 
concludes by asking respondents what they would like from their organization and manager in the way of support. It was expected that respondents' preferences would flow from the conceptual framework given in Figure 6.2 (i.e., would be related to a desire for some modification in the intra-organizational and interface context associated with effectiveness). However, questions were open-ended to allow any concept to emerge, including concepts not classifiable within the preliminary framework.

\subsubsection{Pilot interviews and adjustments to the interview protocol}

Prior to initiating interviews, the script was piloted on a sample of 3 rotational employees stationed at $\mathrm{HQ}$, and 5 employees abroad, comprising a total of 8 interviews ( 4 heads of mission, 2 mid-managers, and 2 employees at the officer level). Pilot interviews led to minor revisions to the preamble to reduce emphasis on the boundary role construct and increase emphasis on the model for effectiveness. The effectiveness model appeared to have resonance for respondents, clarified the boundary role construct for them, and enhanced the quality of responses.

The pilot also indicated that the series of questions delivered in Section A (intraorganizational role cues) was eliciting responses focussing solely on formal products and feedback from individuals in the organization. No data were emerging for the constructs of task identity or task feedback. A final question, therefore, was added to the section: "Feedback is one way we come to gauge how well we are doing in a job, but it is not the only way. Overall, how do you know when you have done a good job?" This question successfully elicited responses regarding cues from the job itself. 
The pilot indicated further that the script was too long to be completed within an hour's window. In order to ensure adequate time for the focal research elements, the original protocol was modified as follows. First, two supplementary questions were dropped from the original script. The first was an "ice breaking" question at the top of the interview asking respondents to briefly describe their jobs. The second was a lead question in Section C, which had asked respondents to list their external contacts. Both of these questions prompted unexpectedly long narratives of respondents' activities in the field. Further, neither generated novel information that was not obtainable through subsequent questions.

Second, the section addressing translation to work objectives (Section E) was dropped. As had been anticipated during protocol development, this concept was somewhat abstract, so was difficult to convey to respondents. It also became apparent that the translation dimension was "emerging" elsewhere throughout the interview, as respondents described cues for performance and interactions with local agents. Since, in qualitative research, respondents' misinterpretation of focal constructs can pose a threat to construct validity (Yin, 2003), the explicit questions surrounding translation were dropped. Instead, the researcher undertook an additional pass through the interview data to code references to translation processes wherever they occurred. This enabled the researcher to obtain the observations needed to address Research Question 5, without risking construct validity.

9.3.1.2 Administration and recording of interviews Data were collected between 
April and July 2006. All interviews were conducted by telephone by the primary researcher, and averaged one hour and 15 minutes in duration. Interviews were tape recorded with permission. Data were coded directly from the audiotapes without transcription. Coding for two of the focal elements (boundary interactions and the issueselling episodes) was supported by handwritten summaries of the episodes to enable the researcher to return to the data as concepts emerged (coding is discussed further in Section 9.4). The researcher also kept a diary of field notes to record any emerging concepts, patterns, and irregularities.

\subsubsection{Quantitative data}

Qualitative methods are particularly appropriate in instances where a phenomenon of interest has seldom been explored or where there exists a need for new insights on an old theme (Eisenhardt, 1988). It was for such reasons that a qualitative approach was chosen as the overarching framework for a study of the boundary role. However, the literature identified several measures that might aid in this conceptual task. For example, Au and Fukuda had developed a measure of the boundary role in their study of expatriate executives. Similarly, well-established scales were available from the Job Description Index (Hackman and Olds, 1974) to tap any number of features of the job context. This meant that there was the potential to use quantitative data to triangulate the data on the boundary role construct and to provide context around the conditions for effectiveness in the boundary role.

In order to minimize response burden, it was decided to keep the questionnaire 
brief. Four constructs were chosen on the basis of their perceived ability to add value to the interpretation and validation of the qualitative data: job autonomy, role ambiguity, perceived influence and a measure of the boundary role construct. These four measures and the rationale for their selection are described below. The questionnaire is attached as Appendix B.

\subsubsection{Description of the questionnaire}

1. The dimensions of the boundary spanning role This 11-item measure was included to complement the qualitative data collected to address Research Question 1 (the boundary role construct). It was adapted by the researcher from Ancona and Caldwell $(1988 ; 1992)$ and an adaptation of Ancona and Caldwell's scale given in Au and Fukuda (2002). The measure taps the four dimensions of boundary spanning identified in Figure 6.1: the ambassador role (appearing in Appendix B as items number $2,3,4,8,10$ ); the task coordinator role (items 1, 9); the scout role (items 5,6,7); and the guard role (item 11$)^{5}$

The measure asks respondents to indicate on a Likert format the extent to which each of the activities represents an important part of their jobs.

All items were modified from the original sources to make them more relevant to boundary spanning at the individual level and in a public organization. Due to these

\footnotetext{
${ }^{5}$ The imbalance in the number of items per dimension reflects the distribution of items in Ancona and Caldwell's original scale (which had included 12 items for the ambassador dimension, five for the task coordinator, four for the scout, and three for the guard dimension).
} 
modifications, reliability coefficients reported in the original studies are not applicable to this version of the instrument.

A quantitative measure of the boundary role construct was included for two reasons. The first was to allow a fuller mapping of the dimensions of the boundary role at the level of the job. The interview used the individual episode as the unit of analysis, so targeted only one interaction per respondent. It was conceivable, however, that, at the level of the individual, respondents performed many boundary functions in other interactions, in other circumstances, and with other constituents. The second reason was to obtain an indication of the relative level of importance attached to the various dimensions of the boundary role in the MNE context. This would complement the qualitative data, which, for each episode, might elicit only the most important dimension. It is important to note that the boundary role measure was designed to aid in conceptual development of the target construct for this research. The content of the measure had been derived solely from the preliminary orienting framework given by Ancona and Caldwell. The purpose of this research was to empirically test, extend, and refine that framework. This meant that the suitability of the scale to the emergent construct was not known a priori. It was anticipated that once the boundary role construct had been explored through the constant comparison method, the measure might yield quantitative data to complement it. However, it was also anticipated that the scale would be useful only to the extent that its items still aligned with the emergent construct. The enfolding of this scale into the qualitative data is discussed further in Section 9.4.3. 2. Role ambiguity This 6-item subscale is taken from Rizzo, House and Lirtzman 's 
(1970) measure of role stress (Appendix B, p. 2, items 4 through 9). Respondents indicate on a Likert format the degree to which they are certain or uncertain about what is expected of them on the job. Coefficients alpha for this subscale, as demonstrated in its use in literature published during the 1990 s, range from .71 to .95 (Fields, 2002). This measure was included because clarity around role expectations was argued to be the most fundamental of the five conditions for effectiveness (Figure 6.2). The ambiguity measure provided a direct quantitative measure of the boundary spanner's degree of clarity around what was expected on the job. It thus could be used to explore the effectiveness of the various intra-organizational role cues that emerged in the qualitative data.

3. Job autonomy This 3-item measure is adapted from Hackman and Oldman's (1974) Job Diagnostic Survey (Appendix B, p. 2, items 1 through 3). Respondents indicate on a Likert format the degree to which they believe their job provides freedom, independence, discretion and the opportunity for personal initiative. Coefficients alpha for this measure, as demonstrated in its use in literature published during the $1990 \mathrm{~s}$, range from .68 to .77 (Fields, 2002). Job autonomy was believed to be a contextual condition that might aid in the interpretation of qualitative data on influence (Question 6). For example, the level of discretion and independence afforded by the job might be expected to affect boundary spanners' decisions to initiate issue-selling, or to affect choices among potential issueselling moves. Access to a quantitative measure of autonomy would allow theses types of hypothesis to be tested within the context of the qualitative data.

4. Perceived influence The measure of perceived influence was also included to aid in the interpretation of issue-selling moves (Question 6). Dutton et al.'s work (2001) had 
suggested that the propensity to issue-sell was related in part to the degree to which individuals believed they could "make a difference" where high-level decisions were concerned. A measure of perceived influence over decision-making was judged to be a second contextual condition of value in the interpretation of the qualitative data on issueselling moves.

A search of the literature indicated that there was no existing measure of influence suited to this research. Several measures were available from the strategic management literature (e.g., Watson and Wooldridge, 2005; Wooldridge and Floyd, 1990), but these measures had been developed for use with executives, and typically referenced high-level strategic decision areas that would be beyond the scope of influence of most employees (e.g., what business the organization should be in). There were also a number of measures of specific tactics used by employees to sway others (e.g., manipulation, invoking organizational policy; Kipnis, Schmidt and Wilkinson, 1980; Schilit, 1980). However, such tactics were not deemed relevant to issue selling in the boundary spanning context. What was needed was a more global measure of perceived influence in which to situate issue-selling accounts.

In the absence of a suitable measure, three single-item measures were constructed for use in this study (Appendix B, p. 2, items 10 to 12). The first taps the respondent's perceived influence over high level decisions: "I feel I have a good deal of influence over the important decisions made in this Department". However, anticipating that most employees in large, bureaucratic organizations would not perceive themselves as having much influence over "decisions at the top", a second measure taps more local influence: 
"I feel I have a good deal of influence over the important decisions made here at post". The third measure taps influence at the most proximal level: the level of the individual job ("I feel I have a good deal of influence over decisions that affect my job").

\subsubsection{Pilot and adjustments to the questionnaire}

Prior to administering the questionnaire, the instrument was pretested on the 8 employees who had piloted the interview protocol (4 heads of mission, 2 mid-managers, and 2 employees at the officer level). Two subsequent changes were made to the boundary role scale. First, pilot respondents indicated that the references to "DFAIT"' were too narrow to capture the work of a department of foreign affairs, since respondents perceived themselves to be acting on behalf of "Canada", not the department. Three of the "ambassador" items were subsequently changed to refer to both Canada and the department (e.g., "promoting DFAIT's/ Canada's image"). Other items referring only to DFAIT were left as they were, since the department level was the appropriate referent (e.g., preventing outsiders from overloading DFAIT with requests, scanning the environment outside of DFAIT, etc.). Respondents were asked to review the revised scale and all indicated that they were comfortable with the revised version.

The second revision to the boundary role scale was made in response to the interview data that had been collected from the pilot participants. Field notes taken during the interviews indicated that all eight respondents had mentioned the importance of interpersonal relationships in their boundary interactions. A relationship-oriented function had not been suggested by the boundary spanning literature, so had not been 
represented in the scale adapted from it. The researcher, therefore, added the item, "Building working relationships and trust with individuals outside of the organization". This item appears as number 12 on the first page of the questionnaire (Appendix B).

\subsubsection{Administration of the questionnaire}

At the time of interview, respondents were asked whether they would be willing to complete the questionnaire to aid in the interpretation of their responses. Eighty-three of the 84 participants agreed. Since it was anticipated that some respondents might encounter intermittent barriers to internet access due to local infrastructure limitations, respondents were given the option of receiving the questionnaire electronically, or receiving it by diplomatic mail service. Questionnaires were tagged with an identification number and forwarded by the preferred routing option. To ensure confidentiality, all questionnaires were returned directly to the researcher via diplomatic mail service. Follow up reminders were sent to non-respondents after a 6 week wait period (diplomatic mail can take 3 to 4 weeks one way, depending on its origin and destination). A total of 75 questionnaires were returned, representing an effective response rate of $90 \%$.

\subsection{Data analysis}

Since the objective of grounded theory is conceptual development, the conceptual model is both the start point and end point of analysis. The preliminary model orients analysis and is developed and refined through analysis. The product of analysis is the confirmed, revised, or expanded model. 
Support for the preliminary model themes, or conversely, the emergence of new themes, arises through three concurrent flows of analysis: data reduction; data display, and conclusion drawing/inference (Miles and Huberman, 1994). Data reduction is made systematic by a coding procedure that is iteratively and inductively constructed from the raw data. Coding is followed by data display, the creation of conceptually-ordered matrices to summarize the codes. Data display then triggers a further level of inductive analysis by revealing patterns not evident in the coded data alone. Readers should note that the separation between coding, data display, and inference in the following sections is one of convenience. In theory-building research, these steps are concurrent and iterative.

\subsubsection{Coding}

The first task in data analysis was to organize the large volume of qualitative data by developing codes for data retrieval, manipulation, and display. Codes are tags or labels for assigning units of meaning to the descriptive or conceptual information compiled in the research (Miles and Huberman, 1994). As suggested in Eisenhardt's model, and elaborated in Patton (2002), the codes used to organize the data reflect a hierarchical ordering from the narrative description given in the raw data to conceptual ordering (abstracting categories from the descriptions). Further, once the codes are developed they can be counted, reorganized and displayed to support inferences at the level of theorizing (intuiting ideas, such as new concepts or relationships and formulating them into a logical scheme). In qualitative research, coding is analysis (Miles and 
Huberman, 1994). The coding scheme is not complete until all cases have been examined and the last item coded. This implies many iterations of the scheme, and accordingly, many returns to the data.

This research followed this inductive logic by beginning with no start list of codes. Rather, the conceptual models were used to orient observations and to allow the scheme to "emerge" from the raw data. The researcher began with the descriptive task. This involved labelling blank sheets of paper with the name of each of the models' conceptual "bins" (Miles and Huberman, 1994) and sorting the data into these bins. For example, the model of the boundary role (Figure 6.1) had identified four "bins" to guide analysis: the ambassador, scout, task coordinator and guard functions. The researcher selected an interview tape, created a brief description of the interviewee's response and hand recorded it in the appropriate "bin". This generated a series of descriptions for each case (the within-case analysis). A second tape was selected, and each of these responses added to the appropriate bin. As interviews progressed, patterns across cases emerged, and these patterns suggested categories to which the individual descriptions might be grouped. At the point where categories suggested themselves, the researcher had moved to cross-case analysis and the conceptual level of ordering.

The conceptual ordering of the data generated a start list of codes that comprised the basis for the preliminary coding scheme. As categories surfaced, they were assigned a number. These numbers and the conceptual labels describing them were transferred to a coding scheme that was used as the template for coding subsequent cases. The number of cases used to create the preliminary coding scheme was not predetermined. Development 
of the preliminary scheme was terminated when it appeared that the conceptual "bins" had been saturated and no new categories were emerging from the data. For this research, the preliminary coding scheme required analysis of approximately 25 interviews before the researcher felt sufficiently confident to move from the hand written descriptive data to a numeric coding scheme.

Once the preliminary scheme had been developed, the researcher selected a second subsample of tapes to test the scheme. Where observations matched the existing categories, they were assigned the existing code. Where observations did not match, the descriptive ordering began anew, and new codes were developed. This process continued until, again, the researcher believed no new themes were emerging from the data. At this point, a second version of the scheme was created, and a further subsample of tapes selected to test the revised scheme. This iterative process continued until all tapes had been analyzed and coded.

This study required a total of five iterations of the scheme before it was sufficiently rich to capture all of the themes that emerged from the data. A copy of the final coding scheme for this research is provided in Appendix C.

\subsubsection{Data display}

The coding scheme provides the foundation for data display. Once numeric codes had been developed for each conceptual element, the codes were entered into SPSS for storage and further analysis. This enabled the researcher to perform counts for each code category. Frequency counts help the researcher more rapidly see patterns and help keep 
the researcher "analytically honest" by preventing overweighting of particularly memorable cases (Miles and Huberman, 1994).

Since the objectives of this research were largely descriptive, frequency displays provided sufficient analysis to answer all eight of the research questions (Section 6.3). Results matrices are displayed throughout Part Five, and are consistent with the format currently in use in theory-building research in management studies (e.g., Ashill et al., 2001; Bouty, 2000; Dutton et al., 2001; Eisenhardt and Bourgeois, 1988).

Data display in grounded theory, however, is used not only to organize results, but also as the basis for further analysis. In this research, patterns emerged that went beyond description to suggest relationships and higher-order concepts not anticipated prior to the research (the theorizing inference). For example, the data display of the dimensions of the boundary role in this research suggested that the construct was indeed multi-dimensional and that certain boundary functions tended to coincide over the course of an interaction. These patterns were not evident as the data were being coded. The display of the boundary role matrix enabled the researcher to detect these patterns and test them with further runs of the data. Additional data displays such as these establish the chain of evidence for theorizing inferences so that readers can track the logic from which they were derived (Miles and Huberman, 1994).

\subsubsection{Enfolding the quantitative data}

Once matrices had been created, and patterns observed, the researcher turned to the questionnaire data as an additional line of evidence to aid in the interpretation of the 
qualitative findings. There were four quantitative measures in this research. Three of the measures (role ambiguity, autonomy, and perceived influence) were job-related outcomes aimed at providing contextual data to test hypotheses and aid in interpretation of the qualitative findings. These three measures are the topic of this section of the methodology. These measures were essentially "ready" to be enfolded, since they were independent constructs, and not the targets of conceptual development in this research. However, the fourth measure (the boundary role scale) was the target of conceptual development. That meant that, once the boundary role construct had been defined through the constant comparison method, the quantitative measure would be useful only to the extent that its items still aligned with the emergent construct. Items in the boundary role measure were iteratively compared and contrasted to the emergent construct as qualitative data were collected. The comparison process suggested a lack of convergence in many of the items. The enfolding of the data from the boundary role measure is discussed, therefore, in tandem with the qualitative findings (Part Five).

The methodology used in the analysis of the three work outcomes measures was as given by Yin (2003). He indicates that, in applying grounded theory within case study, quantitative data are intended to provide a second source of data to triangulate the qualitative data within each case. It is not appropriate, therefore, to aggregate across cases to arrive at group means. If quantitative data are pooled across individuals, then we no longer have a case study, we have a survey, and an appropriate survey methodology needs to be employed (Ibid.). In this research, sampling and data collection techniques had not been designed to support the use of inferential statistics. Further, the calculation 
of group means would strip the variables of their context, and the desire to examine the boundary role within context was the rationale for the case study design in the first place.

In using quantitative data to build theory, the scores on each measure are calculated for each case and entered into the individual's case record along with the codes for the qualitative data. These scores are then available for examination and tabulation along with the frequencies for the qualitative data. The procedure for calculating individual scores for the three work outcome measures used in this research (role ambiguity, autonomy, and perceived influence) was as follows.

First, mean scores were derived for each individual on each of the three measures. The next step was to ready the data to display in matrix format by converting individual scores on each scale to categorical data (i.e., to identify those who scored "low", "moderate", and "high" on each measure). This required the creation of cutoff values. Cutoff values were assigned such that they created three intervals corresponding directly to the questionnaire rating points (i.e., based on the 1 to 5 rating scale, mean scores less than 2.6 were coded "low"; 2.6 to 3.5 coded "moderate"; and greater than 3.5 were coded "high"). This approach respected the spirit of case study by ensuring that the respondent's own judgments, not population norms or other relative rankings, were used to determine whether the respondent should be classified as "high" or "low" on the constructs of interest.

Table 9-7 shows the results of this procedure, providing distributions for each of the three quantitative measures by job level. These distributions are provided by way of description of the sample, so observed patterns will not be discussed extensively here. 
Instead, the data will be selectively and progressively woven into the display of interview data as results are discussed in Part Five.

One pattern, however, is worth noting in advance of presenting the interview results. As expected, given the very different nature of their work, management levels tend to show a different profile from officers on these measures. HOMs, in particular, score very high on autonomy and influence, and low on role ambiguity. Officers show greater variability on all three measures. Mid-managers fall somewhat in between. Reasons for these differences will be explored later in Part Five. However, the differential pattern of response has two implications for results interpretation throughout this thesis.

First, the low variability of managers on these measures severely restricted the usefulness of the quantitative data in challenging or corroborating the qualitative findings. This restriction of range created too many "empty cells", where no cases of low autonomy or influence were available to contrast with high autonomy and influence cases. This limitation will be discussed further in Chapter 14 when qualitative findings are discussed.

Second, wherever patterns are discussed for the full sample, they are influenced by the underlying job level differences. For example, the last column in Table 9-7 indicates that over $70 \%$ of respondents scored high on autonomy. Examination of the job level columns reveals that the high level of autonomy in the full sample is attributable primarily to the pattern among HOMs and mid-managers. Only half of officers reported high autonomy in their jobs. 
The tendency for full sample findings to mask sub-sample differences is a pattern seen throughout this research. In quantitative research, this problem is handled by testing for interaction effects in advance of interpreting main effects. In qualitative research, no such technique is available. Instead, "interaction effects" are handled by tabulating data for the full sample and data for the underlying factors for independent examination. The protocol for interpreting data is described further in Section 9.5.

\begin{tabular}{|c|c|c|c|c|}
\hline & $\begin{array}{l}\text { Head of mission } \\
\qquad(\mathrm{N}=33)\end{array}$ & $\begin{array}{l}\text { Mid-manager } \\
\qquad(\mathrm{N}=16)\end{array}$ & $\begin{array}{l}\text { Officer } \\
(\mathrm{N}=26)\end{array}$ & $\begin{array}{l}\text { Total } \\
(\mathrm{N}=75)\end{array}$ \\
\hline & \multicolumn{3}{|c|}{$(\%)$} & \\
\hline \multicolumn{5}{|l|}{ Autonomy } \\
\hline High & 88 & 75 & 50 & 72 \\
\hline Moderate & 12 & 19 & 35 & 21 \\
\hline Low & -- & 6 & 15 & 7 \\
\hline \multicolumn{5}{|c|}{ Role ambiguity } \\
\hline High & 3 & -- & 27 & 11 \\
\hline Moderate & 18 & 44 & 39 & 31 \\
\hline Low & 79 & 56 & 35 & 59 \\
\hline \multicolumn{5}{|c|}{ Perceived influence } \\
\hline High & 61 & 25 & 35 & 44 \\
\hline Moderate & 33 & 50 & 23 & 33 \\
\hline Low & 6 & 25 & 42 & 23 \\
\hline
\end{tabular}

\subsection{Data interpretation}

Once data are analyzed and displayed, the qualitative researcher faces the difficult task of interpreting the findings. The central technique used to guide interpretation in 
grounded theory is the identification and comparison of patterns emerging in the data (Chapter 8). Accordingly, data display procedures described in Section 9.4 were designed to enable the researcher to more rapidly see these patterns by performing counts for each code category. Once frequency counts are displayed, however, the important question remains: what constitutes a "pattern?". How "large" does a response category have to be before it is considered "salient"? How "different" does one response category have to be from another before the researcher is justified in reporting a "difference" between them?

In order to answer these questions and articulate a criterion for interpretation, the researcher undertook two steps. First, the methodological literature was consulted to determine whether there might be an accepted convention for interpretation. This literature (Mertens, 1988; Miles and Huberman, 1994; Patton, 2002; Yin, 2003) was unequivocal in claiming that there were no guidelines for the inductive process central to interpretation. Although all authorities discussed the interpretation of findings, all noted in their discussions that qualitative research was suited to describing (answering the "what" question) and, in some instances, explaining phenomena (answering the "why"), but not to quantifying (answering "how much" or "how different"). Further, all cautioned against the temptation to fall into "quantitative molds of thinking" (Miles and Huberman, 1994, p. 252) in interpreting frequency displays. For example, were the researcher faced with a display showing that $30 \%$ of managers mentioned formal documents as a role cue, whereas only $20 \%$ of officers mentioned this cue, the researcher might be tempted to deliberate over whether or not 10 percentage points comprised a 
difference of "sufficient magnitude" to make a claim about job level differences.

Methodologists would maintain that this is a quantitative question, and requires a test of statistical significance. In qualitative research, there is no statistical test to aid in this determination.

Authorities in qualitative research methodology recommended that, in lieu of statistical significance, qualitative findings be judged by their substantive significance (Mertens, 1998; Miles and Huberman, 1994; Patton, 2002; Yin, 2003). Substantive significance is determined by judging whether observations appear to be related to other observations in the research, whether they fit within conceptual frameworks derived for the research, and whether they deepen understanding of the phenomenon (Patton, 2002). This allows researchers to limit their observations to those related to their concepts of interest and not be locked into trying to interpret patterns identified by a statistical criterion. As expressed by Miles and Huberman: "Mindless comparisons are useless. The trick is to be sure that the comparisons being made are relevant (to the concepts of interest) and that they make sense" (p. 254).

Patton (2002) recommends that qualitative analysts who find themselves guarding against bias by asking quantitative questions of their frequency counts remind themselves why they performed counts in the first place. In qualitative research, frequency counts are the safeguard against bias. They are constructed as the alternative to lengthy narratives or quotes, enabling the researcher to make sense of large masses of data without being overly influenced by one or two memorable cases. Frequency counts make patterns more salient and allow the researcher to "see" what she may not have during data 
collection. Authorities consistently noted that interpretation of patterns in frequency data will invariably be a matter of judgment, and that readers and users of the analysis will make their own value judgments about significance based on the data displayed.

Given that the consensus among methodologists was that substantive significance was the standard for interpreting qualitative findings, the second step in establishing a criterion for interpretation in this research was to ascertain whether another convention might exist in the empirical literature. The researcher thus searched the management literature for precedent: how were published authors interpreting their qualitative data? A review of five qualitative studies from the management literature (Ashill et al., 2001; Bourgeois and Eisenhardt, 1988; Bouty, 2000; Eisenhardt and Bourgeois, 1988; Zeithaml et al., 1988) indicated that all five had relied on substantive significance in interpreting their findings, as given in the methodological literature. All authors had summarized their data by listing frequencies or individual test scores in descending order. They then interpreted their displays simply by noting the ordering of these frequencies, and the extent to which they aligned with frequencies on other variables or with an expected pattern. For example, Bouty (2000), in examining resource exchanges between R\&D colleagues, listed the most frequent responses given in accounts of "instrumental" exchanges as opposed to the responses given for "equitable" exchanges. She then noted that the top responses for the instrumental exchanges "differed" from those for equitable exchanges, and described these differences. She made no effort to account for her determination of "difference", other than to present the summary data she used to support the determination. Further, the absolute values of the frequency counts and the 
differences between them were often minor. What was important to interpretation in all five studies was not the magnitude of the differences, but the suggested direction of differences and the degree to which the emerging concepts and relationships told a coherent story and linked to their conceptual frameworks. The applied approach to interpreting qualitative data was thus consistent with methodologists' (e.g., Patton, 2002) recommendation that substantive significance be judged by looking at the ordering of the data and coherence with other data or existing knowledge.

It was decided, therefore, that for the purpose of this research, patterns would be described based on the observed ordering of frequency counts (i.e, the ranking of the frequencies in each response category, rather than the magnitude of the differences between them) and the perceived relevance of the pattern to conceptual frameworks. No effort would be made to establish a statistical criterion for judging a pattern as "worth noting". This approach is consistent with the goal of discovery in qualitative research, where the aim is to describe emergent phenomena and posit relationships to prompt further inquiry. As noted by Miles and Huberman (1994), it is expected that there will be some subjectivity inherent in interpretation and that readers will have other interpretations of the data. Tabulation of findings makes this subjectivity explicit and enables readers to posit alternative interpretations. Tabulation is a convention for minimizing bias and ensuring confidence in qualitative results, and will be discussed in the following chapter. According to Patton (2002) and Miles and Huberman (1994), debate over interpretation of findings is an expected outcome of qualitative research, and a first step in moving toward clearer specification of constructs and relationships through 
quantitative analysis. 
As discussed in the previous chapter, statistical testing is not appropriate for data collected by grounded theory techniques (Mertens, 1998: Miles and Huberman, 1994). Researchers thus require an alternative method for establishing confidence in their results. There are four tests that are generally accepted to establish the quality of any empirical social science research. Eisenhardt (1989), Yin (2003) and Miles and Huberman (1994) offer variations on these for qualitative work. The application of these "quality tests" in this research are discussed below, and summarized in Exhibit 10-1.

\subsection{Construct validity}

The first test is construct validity - - the degree to which the operationalization of the construct in the study actually measures the phenomenon of interest. In theorybuilding research, there is no preexisting measure whose validity can be tested against other criteria or other measures. Grounded theory is the precursor to measurement development. It builds the evidence needed to define and measure (Eisenhardt, 1989). In this sense, the primary safeguard of validity is the constant comparative method itself, since the construct, its definition, and its measurement are not specified a priori, but emerge from the analytic process (Ibid.).

Several further steps were taken in this research to gain assurance that the study was measuring "what it was supposed to measure": as recommended by Yin (2003) and Eisenhardt (1989), multiple lines of evidence were used to enable the researcher to 
approach the phenomenon from a number of angles and sharpen definition; the wording of items in the interview protocol was taken, wherever possible, directly from seminal work on these constructs to align definitions as closely as possible with existing research (Appendix Table A-1); and the interview protocol was pretested and modified so as to promote clarity.

Also as recommended by Yin (2003), the researcher promoted construct validity by ensuring during interview that respondents had a clear understanding of the subject area and what was being asked of them. This was done by providing in the preamble to the interview a detailed description of both the boundary role construct and the model of effectiveness in the role (Appendix A). The researcher also checked for respondent understanding both prior to, and during, interviews. In general, respondents indicated a high level of understanding of the boundary role concept, and keen interest in the effectiveness model. This was apparent both in their comments around the preamble, (e.g., "I never thought of my job that way, but yes, that captures it well"); and in their comments throughout the interview as they returned to the model to frame their answers (e.g., "This organization doesn't spend enough time thinking about that 'middle bubble' in your model, about how we connect with people here in the field").

Finally, as recommended by Yin (2003), the researcher engaged organizational members post-study to verify findings (Yin, 2003). This was approached in three ways. First, a summary report was prepared for review by 10 key informants at $\mathrm{HQ}$, all of whom had prior experience abroad and all of whom dealt with employees abroad in their current work at HQ. Second, a series of focus groups was held with managers and desk 
officers at HQ responsible for engaging posts around the country strategy process. Third, the researcher hosted a concluding seminar on the findings, inviting a broad cross-section of the organization, including not only the geographic divisions who had hosted the research, but also HR, corporate divisions, and other groups responsible for training and performance management. Feedback received through these engagement mechanisms indicated that the research had captured DFAIT's work context with accuracy, and that the phenomena described in the research were familiar and "close to home".

\subsection{Internal validity}

Internal validity focuses on cause-effect relationships. A study is internally valid to the extent that it demonstrates that the outcome observed is attributable to the variables that were measured or controlled, rather than to some unobserved factor (Campbell and Stanley, 1966). Tests for internal validity are explanatory questions, so generally are not relevant for descriptive studies that are not aimed at demonstrating cause-effect relationships (Yin, 2003). However, if the notion of internal validity is extended to the broader problem of making inferences (Ibid.), then essentially, the question of internal validity arises every time an investigator infers the existence of a relationship, even where no claim is made about cause-effect. Several approaches are available in theory-building research to provide confidence around relationships that are inferred from the data.

The key threat to internal validity is the rival hypothesis- - a competing explanation for a given observation (Miles and Huberman, 1994). In qualitative research, 
concerns about rival hypotheses are addressed in two ways. The first is to frame the data collection and analysis within existing theory (Yin, 2003). This framework not only focuses the research, but also helps to identify other potentially relevant variables and any alternative explanations that should be considered. The extensive review of the literature in Part Two and the development of the conceptual frameworks for this research were intended partly to facilitate such hypothesis testing.

The second procedure is, again, an inherent feature of the constant comparative method. This procedure is what Yin (2003) calls "pattern matching". Pattern matching is essentially the "case-to-theory" comparison of the constant comparison method. Where some event seems to be happening with regularity, cases are systematically searched to identify the particular pattern of variables associated with that event. Where patterns appear to match the guiding framework, support for internal validity is provided. Patterns that don't make sense in the context of the framework are indicative of competing explanations, and provide fodder for improvements to the framework. Testing for rival hypotheses in this research will be discussed in its context as results are presented in Part Five.

\subsection{External validity}

In quantitative research, tests for external validity deal with the generalizability of the findings to other settings. The goal of grounded theory in case study is to generalize to an underlying theory, not to a broader population. In this sense, questions surrounding the external validity of a case study are off the mark (Yin, 2003). A more appropriate 
question is whether the conditions surrounding the theory's construction are articulated well enough that they might help to identify other cases to which the results are generalizable (Ibid.). Framed this way, a case study is externally valid to the extent that it has clearly articulated the boundary conditions under which the phenomenon was studied, and which might suggest limits to its generalizability. Sampling techniques that maximize variability- - and make explicit the sources of this variability- - help to specify the domain to which the findings apply (Eisenhardt, 1989). In this research external validity was enhanced by the maximum variation sampling procedure and the clear articulation of the boundary conditions to the theory constructed (mission size, geographic location, sex of the boundary spanner, etc). Articulation of these contextual factors should allow future researchers to vary the context to test whether the theory applies across a broader range of conditions.

\subsection{Reliability}

The question of reliability is the question of whether the process of the study is consistent and reasonably stable across time, researchers and methods (Miles and Huberman, 1994). The objective of a reliability test is to be sure that if a later investigator followed the same procedures as described by an earlier investigator and conducted the same case study all over again, the later investigator would arrive at the same findings (Yin, 2003). Yin is careful to stress that in the case study method, the emphasis is on "doing the same case study", not on "replicating" the results of one case by doing another. Due to their context dependence, two case studies would not be 
expected to produce the same results. Instead, reliability tests in case study research involve procedures for minimizing error and researcher bias within a given study and documentation standards that provide sufficient detail for readers to form their own judgments regarding quality.

Two procedures given by Yin (2003) were employed in this research to address reliability. The first was to document all sampling, data collection and analysis procedures. Chapters 7 through 10 of this thesis have been devoted to this documentation so that readers may judge the quality of this study. All data collection tools are given in the appendix. All data analysis is displayed in Part Five, in the format recommended by Miles and Huberman (1994), who have become somewhat of the "gold standard" in qualitative data analysis. Any subjective bias in the interpretation of results is thus open for scrutiny by readers of the research.

The second procedure was to maintain a database that was distinct from the interpretation and report of the researcher (Yin, 2003). This is analogous to the quantitative analyst's maintenance of an electronic datafile that can be exchanged between researchers for secondary analyses. This procedure is recommended to deal with the objections of some observers that it is difficult to tell in qualitative research reports where empirical narratives end and interpretation begins (Ibid.). As discussed earlier, this research numerically coded all data from interview and stored them in SPSS for analysis. With access to the coding scheme, a second researcher could subsequently manipulate data to reexamine findings or explore other phenomena. Although this does not remove the subjectivity inherent in the coding process itself, when combined with the 
tabulation of the "logic" of inferences, it provides some comfort with the reliability of the data.

\begin{tabular}{|c|c|}
\hline \multicolumn{2}{|c|}{ Quality procedures for case study research applied in this study } \\
\hline Test & Procedure \\
\hline Construct validity & 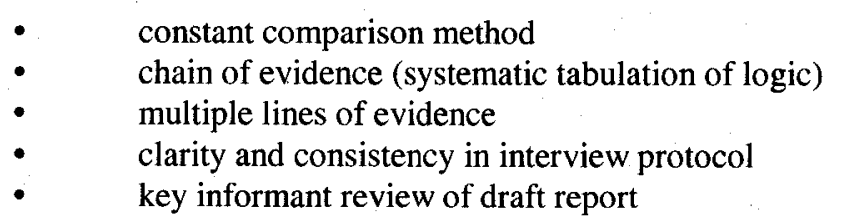 \\
\hline Internal validity & $\begin{array}{ll}\text { - } & \text { study framed in existing theory } \\
\text { - } & \text { pattern matching } \\
\text { address rival hypotheses }\end{array}$ \\
\hline External validity & $\begin{array}{l}\text { case to theory generalization } \\
\text { maximum variation sampling } \\
\text { explicit identification of boundary conditions }\end{array}$ \\
\hline Reliability & $\begin{array}{l}\text { - } \quad \text { documented case study protocol } \\
\text { chain of evidence (systematic tabulation of basis for } \\
\text { inference) } \\
\text { separate case study database }\end{array}$ \\
\hline
\end{tabular}

Source: Compiled from: Eisenhardt (1989); Miles and Huberman (1994); Yin (2003). 
This part of the thesis applies the grounded theory technique discussed in Part Four to answer the central research questions for the study (see Section 6.3). The chapters are organized around the research questions. However, because the boundary role construct is best understood within its organizational context, the questions are reordered to allow exploration of the boundary spanner's work context in advance of exploring the interface role.

The chapters thus follow the sequencing of the interview script. The first chapter (Chapter 11) presents findings related to Research Question 2. It examines how boundary spanners in this organization come to know what the organization expects of them in their roles abroad. The chapter identifies the various role cues in the boundary spanners' intra-organizational environment that communicate expectations for the boundary role. Chapter 12 turns to the boundary spanner's interface experience. It presents findings related to Research Questions 1,3 and 4: What is the nature of the boundary spanning role in this MNE context?; How does the boundary spanner come to know what local constituents expect of him or her in the role?; How does the boundary spanner reconcile organizational expectations with local demands? Chapter 13 presents findings related to Research Question 5: How does the boundary spanner translate organizational expectations to individual work objectives? Chapter 14 then explores the influence of boundary spanners in this MNE context by examining the various "issueselling" moves described by respondents (Research Question 6). Chapter 15 looks at the 
boundary spanner's perceptions of organizational and managerial support for the boundary role abroad, and what the boundary spanner might like in the way of support (Research Question 8). Job level differences (Research Question 7) are not addressed in a separate chapter, but are displayed for all research questions and discussed throughout.

\section{A note on the results reporting format}

In a quantitative study, the researcher can summarize the results of complex statistical analyses in one or two tables. Qualitative research, however, requires a large number of data displays to lay the chain of evidence around claims. Further, this study investigates a total of six conceptual "elements", rather than the single element that is typically addressed in an in-depth qualitative study (e.g., Dutton et al.'s "moves"; Ancona and Caldwell's boundary dimensions). Several decisions were taken around results reporting to try to keep the task manageable.

First, it was decided that it was not feasible to discuss in the narrative all patterns suggested in the data displays. Data displays are given for all research questions. This generated a very large volume of data; therefore, only the most salient themes and patterns are discussed in the text. Decisions as to which patterns were "salient" were made on the basis of substantive significance, as described in Section 9.5. Readers still have available to them the more detailed displays so that they may observe other patterns and draw their own conclusions.

Second, it was decided to apply the same decision rule to the discussion of the job level findings. Job level was a primary research question, so all data displays include 
findings for each of the three job categories. However, including job level as a factor increased the content of the tabular displays threefold. Again, only the most salient job level patterns are discussed in the text, with "salience" judged on the basis of substantive significance described in Section 9.5. Except where noted, the discussion format is to observe patterns for the full sample, with job level differences reserved for the end of each subsection. Readers are reminded that, where results for the full sample are discussed, they are sometimes heavily influenced by underlying job level differences (See Section 9.4). Where this occurs, it is noted in the discussion. However, it was believed that most readers would be interested in examining full sample results.

Third, the tabulation of full sample results also provided a means of ranking the most salient responses for purposes of tabulation. Generally, response categories are presented in descending order, from the most frequent response to the least. However, in a few instances, categories are presented in "conceptual" order to highlight contrasts and facilitate discussion. For example, in presenting data on local role cues, the response "people are direct in this culture" is followed immediately by the response "people are oblique here", since these related responses would have been separated in the display had they been tabulated on the basis of frequencies alone.

Fourth, in some instances, response categories were too small to be displayed. These smaller response categories, however, were included in the "roll up" to higherorder categories. For example, when questioned about the sources of role cues in their work environments, relatively large proportions of respondents mentioned reliance on business strategies and performance plans. Business strategies and performance plans are 
displayed separately in the results tabulation. Conversely, only a very small proportion of respondents mentioned having access to a job description; therefore, this response category is not shown. However, all three responses suggested reliance on formal cues, so all three were entered into a "roll-up" analysis to the higher-order category, "formal cues". Higher-order categories are displayed in the tables in bold face, with component sub-categories indented below.

Fifth, although 84 interviews were conducted, readers will note that the number of respondents may vary slightly from table to table. The number of cases for whom data were available for analysis varied by interview question or analytic theme. During interview, every effort was made to deliver all questions to all respondents. However, due to time constraints, inevitable interruptions, and the logistical challenges of overseas calls, the researcher was occasionally unable to deliver all items. Where time was perceived to be limited, the researcher focussed on the key constructs of interest (the communication of organizational expectations, the dimensions of the boundary role, and influence efforts), and omitted less focal items. So that the reader is apprised of the sample size for each item, column headings in the tables identify the " $n$ " on which each analysis is based. In the majority of instances, however, this is the full 84 respondents.

Finally, the quantitative data are applied only to support or challenge the most consistent patterns. The quantitative measures were selected for their "theoretical reach". This meant that they were judged to be sufficiently flexible to complement data on many of the research questions. However, it also meant that they might have been used "anywhere and everywhere" to generate or test hypotheses. For the purpose of this 
exploratory research, the quantitative data are used sparingly. The author looks to future quantitative research on the boundary role to explore the many bivariate and multivariate relationships suggested in the findings. 


\section{BOUNDARY SPANNER INTERACTION WITHIN THE ORGANIZATION: PERCEPTIONS OF ORGANIZATIONAL EXPECTATIONS FOR PERFORMANCE}

The model of the conditions for effectiveness in the boundary role (Figure 6.1) posited that the boundary spanner's understanding of the organization's expectations for the role was the most basic requirement for effectiveness in the role. This chapter examines the boundary spanner's intra-organizational context by identifying features of the work environment that might convey to the incumbent the organization's expectations for performance (Research Question 2). The chapter explores how the various role cues identified in the literature review (e.g., formal cues, supervisor cues, task feedback, task identity) "play out" for boundary incumbents when they are separated from their home organization by an ocean.

First, Section 11.1 provides context for the discussion by identifying respondents' reporting lines and their perceptions of what the organization expects of them in their roles abroad. Section 11.2 identifies the two most salient role cues for these employees: formal cues and cues from individuals within the organization. Section 11.3 looks at the perceived effectiveness of these cues in communicating expectations. Section 11.4 turns to cues originating from other sources, including cues from the job itself (task feedback, task identity). The chapter concludes in Section 11.5 with a summary of the study's findings regarding the communication of organizational performance expectations in this international setting. 


\subsection{Reporting structure and respondents' perceived expectations for their work abroad}

In order to understand DFAIT's intra-organizational context, it is important to understand the flow of information and strategic direction between HQ and posts. It was anticipated that the boundary spanner's understanding of what was expected in the role would be at least partly a function of the number of organizational layers between the boundary spanner and HQ. Respondents were therefore asked at the outset of the interview, "Who is your manager?"

This was a straight-forward question for mid-level managers, all of whom reported to the HOM, and for officers, all of whom reported to a mid-level program manager. HOMs, however, who by virtue of their Orders in Council, were less likely to perceive that they had a manager within the organization, interpreted this question in a variety of interesting ways. Most $(86 \%)$ responded that their "point of contact" was the Director General (DG) in the relevant geographic division at HQ, although many were quick to note that this individual may or may not be more senior than they. Two HOMs viewed the HOM of the higher order embassy in the region as their "managers". One viewed the Deputy Minister as the manager, and two said they were accountable only to the Minister or Prime Minister. These perspectives are illustrated in the following quotes, and summarized in Table 11-1.

I report to the geographic DG. The DG may have less seniority, may be lower ranking, yesterday they may have reported to me, but while I am at post I report to the DG (HOM male).

Who my manager is depends on who's asking. If it is the president of (host country), my boss is the Minister or Prime Minister, because that is what the president wants to hear. And the DM signs my mandate letter. But then if you asked who looks at my performance management agreement or who would "call me to the mat", that would be a number of ADMs (HOM female) 
The complexity of reporting lines for HOMs is a feature unique to foreign ministries, and one not shared by other organizations, where authority is typically distributed along hierarchical lines. It suggests a high level of autonomy and discretion among HOMs and implies unique challenges to this organization in terms of setting performance expectations for their top executives abroad.

Reporting lines are further complicated by a rather loosely defined "matrix" structure, whereby employees at post have accountability both to HQ and to their mission reporting lines. This "totem pole" structure was well described by one of the midmanagers interviewed:

The management dynamic is like two totem poles, one beside the other. We have the mission totem pole, headed by the ambassador, and another big totem pole at $H Q$, headed by the Deputy. Then there is interaction at various points across totem poles. My ambassador interacts with the $D G$ at $H Q$ to understand the specifics of what is expected of him. And I interact with my Deputy Director at $H Q$. Our officers have desk officers at $H Q$ with whom they interact. At the end of the day, it is Ottawa's wishes that rule. But the decisions around the "doing" are the ambassador's- - he is in tune with his rung of the totem pole, like I am in tune with mine (MID male)

The distribution of responsibility and authority in this organization thus represents an important contextual feature for understanding the boundary role in DFAIT, and is revisited throughout this chapter as the organizational context is explored further. 


\begin{tabular}{|l|r|r|r|}
\hline \multirow{2}{*}{ Table 11-1 Respondent's perceived reporting hierarchy } \\
\hline Who is your manager? & Head of mission & Mid-manager & Officer \\
\cline { 2 - 4 } & \multicolumn{3}{|c|}{ Number (\%) } \\
\hline Head of mission & - & $21(100)$ & - \\
\hline A mid-level manager at post & - & - & $28(100)$ \\
\hline Head of (higher order) embassy & $2(6)$ & - & - \\
\hline Director General at HQ & $30(86)$ & - & - \\
\hline Assistant DM at HQ & $1(3)$ & - & - \\
\hline Minister/Deputy Minister & $2(6)$ & - & $28(100)$ \\
\hline Total & $\mathbf{3 5 ( 1 0 0 )}$ & $\mathbf{2 1 ( 1 0 0 )}$ & - \\
\hline
\end{tabular}

Having discussed their reporting lines, respondents were then asked to articulate specifically what they thought DFAIT expected of them in their roles at post. This question provided an anchor for subsequent questions around how they knew what was expected. Multiple responses were accepted, and the results are given in Table 11-2. The responses closely parallelled the dimensions of the boundary role construct as developed in this thesis. Most respondents perceived they were expected to serve as representatives of Canada and to report on local events of relevance to Canada's interests. Respectively, these functions correspond to the "outward" flow of image exerted by boundary spanners over their external environment (representational function) and the "inward" flow of information boundary spanners convey into the organization to keep it attuned to environmental changes (informational function; Chapter 2). Indeed, the boundary role was so entrenched in the jobs of these employees that, in answer to this question, one mid-manager described his work with a "textbook" account of the bidirectional aspects of the boundary role: 
What is expected of me here at post? There is an inward-bound aspect and an outward aspect. On the inward aspect, I am expected to report on events and policy moves, tendencies in this country that may affect Canada's interests. On the outward aspect, we conduct an aggressive advocacy program to engage our interlocutors here on issues where Canada has a story to tell (MID male)

In addition to representation and reporting functions, one third of officers (32\%) specifically mentioned that they were expected to establish linkages to key local contacts. This was a clear articulation of the "interface" dimension of the boundary role, and consistent with officers' perception that reporting was a central part of their role (82\% of officers saw reporting as a key expectation vs. only $29 \%$ and $57 \%$ of HOMs and midmanagers respectively). Many officers directly used the term "linkage" in defining their roles:

I am expected to make sure the embassy has the best possible network of people here in positions of influence so that whatever might arise in the future, the embassy knows who to contact and how to solve the problem. So, my job is to establish the relationship with these people. I am the link (FL male)

Other job level differences were as expected, with HOMs and mid-managers more likely than officers to report mission management responsibilities (i.e., they cited non-boundary functions of managing mission resources and locally engaged staff as comprising a large part of their roles). The unique response pattern of mid-managers in this sample is worth noting, since a sizable proportion (nearly 40\%) answered that they were accountable for overseeing DFAIT's programming in their region (e.g., public diplomacy). Follow-up communication with DFAIT's Post Support Unit confirmed that financial management of program funds was a central part of program managers' role abroad and occupied much of their attention. This suggests that the work performed by 
mid-managers in this sample may be somewhat lower in "boundary relevance" than that of the other two job categories, and should be borne in mind in interpreting their data throughout this section.

\begin{tabular}{|l|c|c|c|c|}
\hline Table 11-2 Perceived organizational expectations \\
\hline \multirow{2}{*}{$\begin{array}{l}\text { What do you think DFAIT expects of you in } \\
\text { your role at post? }\end{array}$} & $\begin{array}{c}\text { Head of mission } \\
(\mathbf{N = 3 5 )}\end{array}$ & $\begin{array}{c}\text { Mid- } \\
\text { manager } \\
(\mathbf{N = 2 1 )}\end{array}$ & $\begin{array}{c}\text { Officer } \\
(\mathbf{N = 2 8})\end{array}$ & $\begin{array}{c}\text { Total } \\
(\mathbf{N}=\mathbf{8 4})\end{array}$ \\
\cline { 2 - 6 }$(\%$ mentioning) \\
\hline To represent Canada & 69 & 81 & 68 & 71 \\
\hline To report/ interpret local events & 29 & 57 & 82 & 54 \\
\hline To manage the mission's resources well & 37 & 33 & 5 & 25 \\
\hline Program delivery/ management & 14 & 38 & 11 & 19 \\
\hline Access/linkages to local contacts & 6 & 20 & 32 & 18 \\
\hline
\end{tabular}

\subsection{Sources of role cues within the organization}

Having identified the perceived expectations for their roles, respondents were asked how they knew these were the expectations. Responses and descriptions of the responses are given in Table 11-3. Results are reported in this table as described in the introduction, with proportions given for each of the cues, and then "rolled up" to an umbrella category identified in boldface.

Results indicated that formal, written cues and cues from individuals were equally salient in the minds of respondents. Nearly all respondents (96\%) mentioned at least one formal cue, largely recent products related to the country strategy "alignment suite" described in Section 7.1. A nearly equal proportion (95\%) mentioned interactions with other individuals in the organization (the respondent's manager or coworkers at post and 
HQ) as cues for performance.

\begin{tabular}{|c|c|c|c|c|c|}
\hline $\begin{array}{l}\text { How do you know what } \\
\text { DFAIT expects of you in }\end{array}$ & Description/Examples & $\begin{array}{l}\text { Head of } \\
\text { mission } \\
(\mathrm{N}=35)\end{array}$ & $\begin{array}{l}\text { Mid- } \\
\text { manager } \\
(\mathbf{N}=\mathbf{2 1})\end{array}$ & $\begin{array}{l}\text { Officer } \\
(\mathbf{N}=\mathbf{2 8})\end{array}$ & $\begin{array}{c}\text { Total } \\
(\mathbf{N}=\mathbf{8 4})\end{array}$ \\
\hline your role at post? & & \multicolumn{4}{|c|}{ (\% mentioning) } \\
\hline Formal cues & $\begin{array}{l}\text { Documented guidelines, objectives, } \\
\text { requirements }\end{array}$ & 100 & 100 & 89 & 96 \\
\hline Country strategy & $\begin{array}{l}\text { Annual mission business planning } \\
\text { document }\end{array}$ & 77 & 86 & 48 & 70 \\
\hline $\begin{array}{l}\text { Performance } \\
\text { management plans } \\
\text { (PMP/PMAs) }\end{array}$ & $\begin{array}{l}\text { Individual performance agreement } \\
\text { signed by employee and manager }\end{array}$ & 71 & 67 & 68 & 69 \\
\hline Reporting agreement & $\begin{array}{l}\text { Thematic reporting agreement signed } \\
\text { by head of mission and HQ }\end{array}$ & 40 & 38 & 36 & 38 \\
\hline Mandate letter & $\begin{array}{l}\text { Letter from Deputy to heads of } \\
\text { mission issued upon posting }\end{array}$ & 54 & 19 & 12 & 32 \\
\hline $\begin{array}{l}\text { High-level policy } \\
\text { documents }\end{array}$ & $\begin{array}{l}\text { Speech from Throne, Budget, policy } \\
\text { statements }\end{array}$ & 37. & 24 & 32 & 32 \\
\hline Meetings & $\begin{array}{l}\text { Regional meetings of heads of } \\
\text { mission/ officers }\end{array}$ & 23 & 5 & 8 & 14 \\
\hline $\begin{array}{l}\text { Cues from persons } \\
\text { internal to the } \\
\text { organization }\end{array}$ & $\begin{array}{l}\text { Direction and feedback from } \\
\text { individuals internal to the organization }\end{array}$ & 91 & 95 & 100 & 95 \\
\hline "Cues from HQ" & $\begin{array}{l}\text { Direction and feedback emanating } \\
\text { from everyday interactions with HQ } \\
\text { around tasking and reporting }\end{array}$ & 77 & 81 & 89 & 82 \\
\hline Manager & $\begin{array}{l}\text { Discussions with manager, both } \\
\text { formal (e.g. performance discussions) } \\
\text { and informal ( "pops head in door") }\end{array}$ & 43 & 76 & 86 & 66 \\
\hline $\begin{array}{l}\text { Discussions with } \\
\text { colleagues }\end{array}$ & $\begin{array}{l}\text { Informal discussions with coworkers, } \\
\text { employees, other DFAIT staff at post } \\
\text { or HQ }\end{array}$ & 49 & 62 & 39 & 49 \\
\hline Predecessor & $\begin{array}{l}\text { Informal discussion or personal "hand- } \\
\text { over notes" shared upon rotation }\end{array}$ & 6 & 24 & 32 & 19 \\
\hline
\end{tabular}

Looking at cues across these two broad categories, it can be seen that the number one role cue reported by respondents was their interaction with HQ. Four fifths of 
respondents $(82 \%)$ said they took their cues from their regular exchanges with HQ around tasking and reporting. The second and third most frequent responses reflected formal cues: $70 \%$ of respondents indicated they took cues from their mission's country strategy (the local business plan), and nearly as many (69\%) relied on their individual performance agreements. The data pattern suggests that, in this organization, formal cues are viewed as important sources of guidance while abroad, but do not serve as a replacement for the informal guidance obtained through regular interaction with the home organization. The interplay between formal and informal cues in this organization will be examined further in Section 11.3, where the effectiveness of the cues is discussed.

The fourth most salient cue for performance was the boundary spanner's manager (mentioned by $66 \%$ of respondents). That managers ranked fourth on the list of cues was an interesting finding, since research would suggest that the immediate manager is quite powerful in signalling performance expectations in most work settings (O'Driscoll and Beehr, 1994). Examination of the data, however, reveals that the comparatively lower proportion of respondents mentioning their manager as a role cue was an artifact of job type, and was strongly influenced by the inclusion of the HOM data. Only $43 \%$ of HOMs cited their manager as a cue for performance abroad, compared with $76 \%$ and $86 \%$ of midmanagers and officers respectively. Instead, HOMs seemed to rely more heavily on formal tools, such as the country strategy (cited by $77 \%$ of HOMs and only $48 \%$ of officers) and the mission's mandate letter (cited by $54 \%$ of HOMs and $12 \%$ of officers). Further, as might be expected in a position of this stature, a large proportion of HOMs said they knew what was expected in their roles on the basis of their years of professional experience 
(professional experience was cited by $57 \%$ of HOMs, as compared to only $29 \%$ of officers; data not shown).

Combined, the data suggest a pattern whereby reliance on the manager increases as you move down the hierarchy, and reliance on formal tools decreases. This pattern is consistent with mid-managers and officers having access to a co-located manager abroad, whereas the HOM reports to a geographic Director General who is an ocean away. The data suggest a situation in which the HOM relies on HQ to provide documents and other formal tools to communicate performance expectations; mid-managers and officers then rely on their co-located managers to push these tools down through the hierarchy or to interpret them in the local context. Evidence of this management dynamic is provided in the next section, where we look more closely at the perceived effectiveness of role cues in this international setting.

\subsection{Perceived effectiveness of role cues in communicating expectations}

The previous section identified the most salient role cues as perceived by people at post. It did not tell us whether the cues were perceived as effective. This section analyzes the comments made around the various cues to obtain an indication of their perceived effectiveness. These comments also provide an indication of what aspects of the cues were seen as effective, thus highlighting some of the unique needs of boundary spanners in an MNE context. Comments shed further light on the intra-organizational context in this setting, particularly with regard to the value placed on communication with HQ as a source of direction and guidance when abroad. 


\subsubsection{Perceived effectiveness of formal cues}

One of the advantages of the case study approach is the ability to select an organization that presents a rare opportunity to study the phenomena of interest. In this instance, DFAIT presented the opportunity to study the communication of expectations in an MNE setting during a time of intense strategic discussions between HQ and post (the roll-out of the country strategy planning process). This meant that respondents were experienced in the use of a variety of formal tools and highly conversant on their strengths and weaknesses. In an exploratory study, it is desirable to have participants who are conversant on the subject of research interest and who can readily identify researchrelevant situations as referents for discussion and inquiry (Miles and Huberman, 1994; Patton, 2002).

Table 11-4 summarizes the perceived effectiveness of the formal tools in the country strategy alignment suite. Because the number of interviewees who mentioned each of the components was in some instances quite small, it was not possible to tabulate specific codes for each cue. Responses are given, therefore, only for the three most frequently mentioned tools, and are grouped to those reflecting favourable reactions to the cues, those reflecting unfavourable reactions, and those reflecting mixed reactions ("a little of both"). The table identifies for each cue the number of respondents who mentioned it, followed by the percentage of those respondents who gauged the cue to be effective, not effective or "a little of both". 


\begin{tabular}{|l|c|c|c|c|}
\hline \multirow{2}{*}{ Table 11-4 Perceived effectiveness of formal role cues in communicating expectations } \\
\hline \multirow{2}{*}{ Country strategy } & $\begin{array}{c}\text { Head of } \\
\text { mission }\end{array}$ & Mid-manager & Officer & Total \\
\cline { 2 - 6 } & \multicolumn{4}{|c|}{ (\% of those mentioned the cue) } \\
\hline Effective & $\mathrm{N}=22$ & $\mathrm{~N}=18$ & $\mathrm{~N}=11$ & $\mathrm{~N}=51$ \\
\hline Ineffective & 32 & 22 & 64 & 35 \\
\hline A little of both & 36 & 11 & 18 & 24 \\
\hline Performance management plan & 32 & 67 & 18 & 41 \\
\hline Effective & $\mathrm{N}=21$ & $\mathrm{~N}=9$ & $\mathrm{~N}=14$ & $\mathrm{~N}=44$ \\
\hline Ineffective & 33 & 11 & 43 & 32 \\
\hline A little of both & 52 & 56 & 36 & 48 \\
\hline Reporting agreement & 14 & 33 & 21 & 20 \\
\hline Effective & $\mathrm{N}=10$ & $\mathrm{~N}=6$ & $\mathrm{~N}=7$ & $\mathrm{~N}=23$ \\
\hline Ineffective & 40 & 50 & 29 & 39 \\
\hline A little of both & 30 & 33 & 57 & 39 \\
\hline
\end{tabular}

The data indicate that, of the three tools, the country strategies were seen as the most effective in communicating expectations for performance (75\% of respondents who commented on country strategies saw them as effective or partially effective). Comments suggested several reasons country strategies were perceived as valuable. The first was that the development of a country strategy opened communication channels with HQ and enabled people abroad to see their mission's fit within the work of the broader organization:

The country strategy helps us see not only where we are going but where the whole organization is going. We drafted this up, we fired it back and forth with Ottawa and this gave us a sense of confirmation, a sense of whether we were on the same track as Ottawa (MID male)

I was involved in writing the strategy, I was active in updating my relevant sections. I saw drafts as they went back and forth to Ottawa. I have seen the completed strategy now, and it is very useful to me. I use the language now that we agreed upon in the strategy (FL male) 
A second reason country strategies were valued was the belief that a written document

provided an enduring source of direction in what were often turbulent environments:

There is a tendency for people to say, why plan, we are reactive, we will only get derailed. But if you don't have a plan, how do you know where you are going? When I first came to post I sat my people down for business planning and they had the same skepticism but we did the plan anyway. Then at the end of the year we sat down with it, and we had achieved 70\% of the objectives in that plan. So, that's 70\% on track in spite of "reactivity" and I think that proves the benefit of planning (HOM female)

Those who saw country strategies as ineffective tended to do so for the same reasons as those who valued them. Frustrations centred around the inability to engage HQ in dialogue around the content of the strategies...

We needed more one-on-one discussions with $H Q$. The DG has 20 or 30 missions reporting to him. There are so few people at the geographic desks. Trying to get feedback from $H Q$ on this strategy was a little like pushing on a rope (HOM male)

... and the sense that a written document was not sufficiently flexible in volatile environments:

In a turbulent boiling cauldron like international affairs, there is always a disconnect between your plans and what you spend your time on. There is a $9 / 11$ and any long-term planning processes fall apart. You're always going operational (HOM male)

A frequently mentioned inadequacy of the country strategies was the perception that objectives were too high-level to guide individual work. This was the first of many occasions during interviews where difficulties around the "translation" element of the boundary spanner effectiveness model became apparent:

The country strategy is sufficiently vague.... that translating some of these broader objectives into more concrete activities in terms of the day to day developments here.... this is an area I find very challenging (MID male) 
Comments around the second piece of the alignment suite, the performance management tools, echoed this frustration with the translation aspect of the boundary role. Performance management agreements (PMAs) were viewed very unfavourably. Table 114 indicates that nearly half of respondents $(48 \%)$ had only "bad" things to say about their PMAs. This was due largely to the fact that PMAs were seen as potentially valuable in helping individuals set local objectives, but were at an early stage of development, and not yet serving incumbents well. Comments centred around the same themes as the country strategy comments: people were frustrated by a perceived lack of dialogue with HQ around the agreements, and a sense that performance evaluations done by managers thousands of miles away were unable to take into account the unpredictability of the local work context:

I find the PMA a little squishy because there are very high level objectives, but not a lot of dialogue involved in what they actually want you to do to meet these objectives (HOM female)

The PMA is supposed to align your objectives with those of the department. But the reality is that our environment is constantly changing, and it is sometimes not feasible to adhere to those objectives. This is not always obvious to those who are thousands of miles away (MID female)

Perceptions around the effectiveness of reporting agreements fell between these two extremes. Roughly two-thirds of respondents $(61 \%)$ saw reporting agreements as effective or partially effective in communicating performance expectations. Reporting agreements are a tool of particular interest to this research. They were designed to formalize one of the key functions of the boundary role: the reporting of local developments with implications for DFAIT's performance. Agreements lay out on an annual basis the organization's expectations for reporting from a given region, given the Department's need for strategic information. Like PMAs, these tools were seen as potentially very valuable in communicating expectations for the boundary role (i.e., what should I attend to in this 
environment, what does HQ need to hear about?) Comments also indicated, however, that reporting agreements were subject to the same limitations as other pieces of the alignment suite: objectives for reporting that were too high level; issues surrounding the volatility of local environments; and a lack of dialogue and feedback around the reporting due to time constraints at $\mathrm{HQ}$. These issues again suggest that translation of organizational expectations to local objectives is a sizeable challenge for people abroad in this organization :

The contract for last year was so broad I did not find it useful. You can't just say report on human rights issues, governance, there is too much going on here, you need to tighten that up (FL male)

It's not just filling out the reporting agreement itself. We then need feedback on the reporting we do. Too often we just get an acknowledgment of receipt that tells us nothing regarding the usefulness of our reporting. We need someone who can say, in paragraph 5, you talk about such and such, can you drill down on that one. Then we could fine tune our reporting to $H Q$ 's needs (FL male)

The reporting agreement sets out high level reporting areas but I am not sure this is all we need. Where is the latitude for those "exogeneous" events? The government falls, the economy crashes. Where do those sorts of things fit into the plan? (HOM male)

Observed job level differences suggested that officers at post were more likely than the managerial groups to consider formal tools to be effective. This observation must be interpreted within the context that officers were less likely to have mentioned formal tools as a cue in the first place (i.e., they were less likely to have mentioned formal tools as performance cues, but those who did tended to value them). This suggests either that officers were more appreciative of the structure offered by written documents or that they simply had had too little exposure to the tools to have encountered potential problems with them. 


\subsubsection{Perceived effectiveness of cues from individuals within the organization}

The data discussed in the previous section suggested that individuals at post valued the high level structure provided by formal tools. However, comments also suggested that formal tools were perceived to work best when accompanied by real-time dialogue, especially dialogue with HQ. Interactions with HQ appeared to keep respondents attuned to shifting contingencies at home and enabled respondents to "fine tune" their reporting in response to shifting contingencies in the field. This section looks more closely at the nature of interactions with individuals within the organization, including interactions with HQ and interactions with the manager.

\subsubsection{Manager effectiveness in communicating expectations}

The immediate manager is typically the most salient person in an individual's work context, and has direct influence on his or her behaviour (O'Driscoll and Beehr, 1994). It is the manager who assists in goal setting, clarifies work objectives, provides feedback on performance, and sets the "psychological climate" that forms the context for everyday work.

Table 11-5 provides data on the perceived effectiveness of the boundary spanner's manager in communicating expectations. The data given in this table enhance our understanding of the management dynamic in this international setting, and highlight the complex interplay between formal cues, discussions with $\mathrm{HQ}$, and direct managerial guidance in communicating performance expectations to boundary spanners abroad. 


\begin{tabular}{|c|c|c|c|c|c|}
\hline \multirow{2}{*}{$\begin{array}{l}\text { Comments regarding } \\
\text { manager }\end{array}$} & \multirow{2}{*}{ Description/Examples } & $\begin{array}{l}\text { Head of } \\
\text { mission } \\
(\mathrm{N}=35)\end{array}$ & $\begin{array}{l}\text { Mid- } \\
\text { manager } \\
(\mathbf{N}=\mathbf{2 1})\end{array}$ & $\begin{array}{l}\text { Officer } \\
(\mathbf{N}=\mathbf{2 8})\end{array}$ & $\begin{array}{l}\text { Total } \\
(\mathbf{N}=\mathbf{8 4})\end{array}$ \\
\hline & & \multicolumn{4}{|c|}{$(\%)$} \\
\hline $\begin{array}{l}\text { Mentions that manager is } \\
\text { effective in initiating } \\
\text { structure }\end{array}$ & $\begin{array}{l}\text { Manager initiates structure for the } \\
\text { respondent through the assignment of } \\
\text { tasks, articulation of expectations, } \\
\text { and/or the identification of work goals } \\
\text { and how to attain them }\end{array}$ & 9 & 48 & 43 & 30 \\
\hline $\begin{array}{l}\text { Provides high level } \\
\text { direction }\end{array}$ & $\begin{array}{l}\text { Manager provides high-level direction } \\
\text { and broad performance parameters for } \\
\text { respondent's interpretation }\end{array}$ & 9 & 38 & 14 & 18 \\
\hline Provides HQ context & $\begin{array}{l}\text { Manager shares knowledge of current } \\
\text { strategic, relational, and other events at } \\
\text { HQ }\end{array}$ & 6 & 19 & 7 & 10 \\
\hline $\begin{array}{l}\text { Provides specific } \\
\text { direction for my job }\end{array}$ & $\begin{array}{l}\text { Manager provides specific instructions } \\
\text { at the level of the respondent's job }\end{array}$ & - & 14 & 21 & 10 \\
\hline $\begin{array}{l}\text { Provides effective } \\
\text { feedback }\end{array}$ & $\begin{array}{l}\text { Manager provides effective individual } \\
\text { feedback }\end{array}$ & - & 10 & 14 & 7 \\
\hline $\begin{array}{l}\text { Mentions manager but } \\
\text { without reference to } \\
\text { initiating structure }^{6}\end{array}$ & $\begin{array}{l}\text { Mentions manager in response to this } \\
\text { item, but does not elaborate }\end{array}$ & 34 & 27 & 43 & 35 \\
\hline $\begin{array}{l}\text { Does not mention manager } \\
\text { as role cue }\end{array}$ & & 57 & 24 & 14 & 35 \\
\hline
\end{tabular}

Consistent with the work context literature reviewed in Chapter 3, the table focuses

on the manager's perceived ability to initiate structure for the boundary spanner through the assignment of tasks or articulation of work goals. Looking across the entire sample, it

6 This response category reflects respondents who mentioned their managers when asked about role cues, but did not elaborate, and for whom time constraints precluded further prompting. It is possible that, if prompted, a proportion of these respondents might have indicated that their managers were, in fact, effective in initiating structure. The proportion of managers who were effective in initiating structure, therefore, may be underestimated in this item. However, it should also be noted that, where time constraints prevailed, it was because the respondent had already mentioned and discussed at length other role cues that were perceived as more salient than the manager. Since the purpose of the item was to identify the most salient role cues in an international setting, it was believed that failure to prompt these individuals did not unduly influence the interpretation of these findings. Further, the researcher had the opportunity to more directly explore manager initiating structure in the next segment of the interview (in the item asking for the most salient person in the organization in terms of communicating expectations; Table 11-8). 
would appear that managers were not perceived as particularly effective in providing this type of direction or guidance. Only $30 \%$ of the 84 respondents specifically mentioned that their managers were effective in initiating structure for their work. Again, however, the pattern observed across the entire sample can be seen to be strongly influenced by the unique response pattern of HOMs.

HOMs were extremely unlikely to mention that their managers provided structured direction or guidance (only 9\% of HOMs mentioned their managers were effective in initiating structure). Indeed, the majority of HOMs (57\%) did not mention their managers at all as a cue for performance abroad. The low salience of the immediate manager among HOMs is consistent with their high level of professional experience, the inherently high level of autonomy of their positions at post, and the fact that HOMs were unique in the sample in having a manager who was located at HQ (recall that $85 \%$ of HOMs identified the geographic DG as their "managers", whereas managers for other job categories were co-located at post). However, the low salience of the manager in providing direction to HOMs may also reflect the lack of a clear authority structure for HOMs in this organization. An alternative interpretation of the data is that HOMs perceive the DG at HQ more as a coordinator or "port of call" than as a source of legitimate authority or the "bearer of expectations", as illustrated in their quotes below:

I have a very senior rank. The DG to whom I report is junior to me, so I don't report in any traditional sense. This is fairly common in the foreign service, and makes for some interesting management anomalies (HOM male)

I guess I count on the DG to always have time for me, so I tend to treat the DG as my port of call in Ottawa (HOM male) 
Employees at other job levels were much more likely than HOMs to indicate that their managers were effective at initiating structure (reported by 48 and $43 \%$ of mid-level managers and officers respectively). The most frequently mentioned form of guidance offered by the manager (mentioned by 38 and $14 \%$ of mid-managers and officers, respectively) was the articulation of the department's high-level direction and the articulation of broad performance parameters. This provided boundary spanners with the "big picture", which they then used to inform their work:

My manager is good at discussing issues. Sometimes it is just confirmation of the direction I am already going. But even getting confirmation is valuable. She provides the big picture in terms of where the Department is going, and then I figure out where I need to go with that (MID male)

The second most frequently mentioned form of managerial guidance was access to information about happenings at HQ. Mid-managers (19\%), and to a lesser extent, officers (7\%) mentioned that their managers kept them apprised of shifting priorities, shifting power structures, and "current events" in Ottawa. Access to HQ context appeared to provide respondents with the important strategic and relational knowledge needed to inform their work abroad:

The HOM goes back to Canada. He meets with deputies and people around town and he will come back with a tweaked message for us. For example, he may say, yes we have a set of priorities for (this mission), but there are some changes going on in Ottawa's priorities. Let's think about what that means for us and our work out here. Following what is happening in Canada is critical for us as managers overseas. Half of our job is to understand what is going on here, but to be effective, the other half is to keep our ears to the ground on what is happening in Ottawa (MID male)

I had only been in $H Q$ for a year before posting. If I want to know what's going on, I ask my manager. He understands the system in a lot more depth than I do, and has a lot more contacts (FL female)

The third type of managerial guidance mentioned was specific direction at the level 
of one's job (mentioned by $10 \%$ of respondents). Job level differences suggested that, commensurate with their relative inexperience, boundary spanners at the officer level were more likely than other job levels to value direct guidance (reported by $21 \%$ of officers, compared to $14 \%$ of mid-managers, and none of the HOMs). The data suggest that, at the officer level, boundary spanners valued the assistance of their co-located managers in setting local objectives and in helping them determine the best path to attain them: My manager is amazing, not only in helping me set out my priorities, but also in telling me what steps I need to follow to act on them (FL female)

Combined with the data given in Table 11-3, the data on manager effectiveness suggest that access to the "high-level" picture from HQ is a highly valued resource in this organization. Table 11-3 had indicated that boundary spanners at all levels cited interaction with HQ as their number one cue for performance abroad. The data presented in this section indicate that employees turned also to their co-located managers for guidance; however, managers, too, were perceived as effective to the extent they were able to provide a "window to HQ". In this organization, policy direction is set at HQ. In order to gain access to the big picture, the boundary spanner needs either direct contact with HQ, or a conduit to HQ via their co-located manager.

Dependency on HQ was suggested at all job levels. Where mid-managers and officers perceived their local managers as unable to provide guidance, it was normally because they believed their managers too lacked the context and direction from HQ that they needed to provide more solid direction :

I wish my director here could take the decisions on what was to be given priority, but I expect he is in the same position I am. Everything from $H Q$ is presented as a priority, and we just don't have 
the context out here to sort it out ourselves (FL female)

The need for a "window to HQ" may also account for the very low reliance of HOMs on their managers at HQ for direction and guidance. Geographic DGs have a large span of control, some responsible for upward of 30 missions. These individuals may have the knowledge, but little time to share it. Often, HOMs indicated that they went elsewhere in HQ to get the contextual information they need:

It is very difficult to get the ear of my DG in Ottawa. I am not criticizing, we are a huge number of missions and there is literally a handful of people at $H Q$ dealing with this hemisphere (HOM female)

For operational purposes, I turn to whomever at $H Q$ is responsible for the area, the issue, the subject matter. That may be the geographic DG, but it may not (HOM male)

\subsubsection{HQ effectiveness in communicating expectations}

In DFAIT, HQ-post communications tend to take one of two forms. The first is a tasking request. Tasking requests are HQ-initiated. They issue directives to personnel abroad (e.g., to deliver a demarche to the host government, to prepare a program for an upcoming visit), or they request local information (e.g., "What is the mood there now on issue X?"). The second is a reporting message. Reporting messages are post-initiated. They comprise the reporting on local issues identified in mission reporting agreements, as well as occasional additional topics that the mission deems to be of strategic value to HQ.

Table 11-6 summarizes respondents' comments around these interactions with HQ. 


\begin{tabular}{|c|c|c|c|c|c|}
\hline \multirow[b]{2}{*}{ Comments regarding HQ } & \multirow[b]{2}{*}{ Description/Examples } & $\begin{array}{l}\text { Head of } \\
\text { mission } \\
(\mathrm{N}=35)\end{array}$ & $\begin{array}{c}\text { Mid- } \\
\text { manager } \\
(\mathbf{N}=\mathbf{2 1})\end{array}$ & $\begin{array}{l}\text { Officer } \\
(\mathbf{N}=\mathbf{2 8})\end{array}$ & $\begin{array}{l}\text { Total } \\
(\mathbf{N}=\mathbf{8 4})\end{array}$ \\
\hline & & \multicolumn{4}{|c|}{$(\%)$} \\
\hline Mentions HQ & & 77 & 81 & 89 & 82 \\
\hline $\begin{array}{l}\text { I take my cues from HQ's } \\
\text { response to my reporting }\end{array}$ & $\begin{array}{l}\text { Further questions from HQ upon } \\
\text { receipt of reports are used to infer } \\
\text { HQ's interest in the topics }\end{array}$ & 51 & 57 & 68 & 58 \\
\hline $\begin{array}{l}\text { I take my cues from the } \\
\text { content of HQ tasking }\end{array}$ & $\begin{array}{l}\text { Content of HQ's tasking requests are } \\
\text { used to infer HQ's priorities }\end{array}$ & 43 & 57 & 64 & 54 \\
\hline $\begin{array}{l}\text { I take my cues from } \mathrm{HQ} \text {, } \\
\text { but cues are inadequate } \\
\text { (Black Hole!) }\end{array}$ & $\begin{array}{l}\text { No response to reports, insufficient } \\
\text { context on tasking messages, no } \\
\text { rationale for requests, no follow up }\end{array}$ & 51 & 71 & 79 & 66 \\
\hline $\begin{array}{l}\text { Does not mention } H Q \text { as a } \\
\text { role cue }\end{array}$ & & 23 & 19 & 11 & 18 \\
\hline
\end{tabular}

The findings suggest that boundary spanners in this organization engage in an active search for contextual information over the course of their interactions with HQ. When asked how they knew what was expected of them in their roles abroad, over half $(58 \%)$ said they took their cues from the nature of HQ's response to their reporting:

If you send in a report, you know you are feeding in relevant information when people react. Whether $H Q$ says your perspective is right on, or whether they argue with you. Either way, you know you have hit the right button because you have their attention (HOM male)

A roughly equal proportion of respondents (54\%) indicated that they took their cues from the content of HQ's tasking requests:

I can tell what Ottawa expects when they ask very direct questions- direct tasking around subject areas. How does (country) feel about changes in the steel sector, or the automotive sector? What was (country's) reaction at recent talks in Geneva? From these kinds of questions, I can infer Ottawa's interests, and refocus my energies here accordingly (FL male)

Not surprisingly, given the large span of control of the geographic divisions at $\mathrm{HQ}$, respondents also noted that not all tasking messages from HQ were accompanied by 
context, and not all reporting generated feedback. Two thirds of respondents (66\%) said that they tended to hit a "black hole" in their interactions with HQ. When they did, they expended a fair deal of energy trying to follow up with HQ, interpret the silence, or otherwise "read between the lines":

You can't deliver a demarche without context for it. There you are, asking the (host government) for their position on something and you don't know what Canada's position is? Why should they tell you anything if you won't tell them anything? If you don't get that context from $H Q$, you have to chase it down, or you simply won't be able to carry out the request locally (FL female)

The first few months at post came as quite a shock. I was working so hard, thinking I was sending quality reports to $H Q$ and.... silence. It took me a while to come to the realization that $H Q$ is just too busy to respond to your reports. You will hear something if there is a problem, but if you are doing a good job, there's a good chance you will hear nothing. Foreign service officers are all over-achievers so this causes a lot of anxiety at first (FL male)

In the absence of HQ feedback, respondents were unable to access the "big picture" context they so valued:

Sometimes we are asked by $H Q$ to deliver our position on something to our country, or to find out their position, and we don't get feedback from Ottawa on the outcomes of that effort. What are we feeding into? What are the discussions there like? Why do you need this right now? How did our country do? I need this context to do my job effectively out here (MID female)

Silence was also likely to be misinterpreted:

Sometimes I ask the desk at $H Q$ what is happening with a certain file, and why it isn't moving. And I get no answer, so I think it must not be a priority for them. But then I find out, no, they're swamped with something from the Minister's office, and just haven't got to it. So, sometimes the black hole is just a busy signal (FL female)

Given that people at post are so reliant on HQ for direction and guidance, it might be expected that those who encountered the "black hole" would be at a disadvantage in terms of understanding the Department's expectations for their performance. The ambiguity measure provided a means for testing this assertion. 
Table 11-7 compares scores on the role ambiguity measure for boundary spanners who mentioned the black hole vs. those who did not. These data provide support for the claim that the "black hole" is associated with reduced clarity around performance expectations. Sixty percent of boundary spanners who mentioned the black hole during interview reported moderate to high levels of role ambiguity, compared with only $11 \%$ of boundary spanners who did not mention the black hole. In contrast, ambiguity was unrelated to the effectiveness of supervisor initiating structure or any of the formal cues (not shown).

Although the pattern held for all job levels, the data suggest that it is the front line who is most disadvantaged in "black hole" situations. One third of officers (33\%) reported high ambiguity in black hole settings, compared to only $6 \%$ of HOMs and none of the midmanagers. These job level differences suggest that the nature of work at the officer level may create workflow dependencies with HQ that are not as acutely experienced at other levels. As indicated in earlier quotes, it is often the officer who is tasked by HQ to gather local information or deliver a message, often on relatively short notice. For this type of task, lack of context on the request might handicap the officer in the boundary transaction. Similarly, reporting is a key function at the officer level, and lack of feedback on reports would make it difficult for the officer to target future reporting. These front line responsibilities stand in contrast to the responsibilities of mid-managers, whose jobs may be more inward focussed (i.e., lower in boundary relevance), often involving the management of funds with documented administrative guidelines. This may leave midmanagers somewhat less reliant on interaction with HQ for clarity and direction around their work. 


\begin{tabular}{|l|l|c|c|c|}
\hline \multicolumn{2}{|l|}{ Table 11-7 Role ambiguity and perceived effectiveness of interactions with HQ } \\
\hline & \multicolumn{1}{c|}{$\begin{array}{c}\text { High } \\
\text { ambiguity }\end{array}$} & $\begin{array}{c}\text { Moderate } \\
\text { ambiguity }\end{array}$ & $\begin{array}{c}\text { Low } \\
\text { ambiguity }\end{array}$ \\
\hline & Mentions black hole (N=16) & 6 & 25 & 69 \\
\hline Head of mission & Does not (N=17) & 0 & 12 & 88 \\
\hline & Mentions black hole (N=10) & 0 & 70 & 30 \\
\hline Mid-manager & Does not (N=6) & 0 & 0 & 100 \\
\hline Officer & Mentions black hole (N=21) & 33 & 43 & 24 \\
\hline & Does not (N=5) & 0 & 20 & 80 \\
\hline Total & Mentions black hole (N=47) & 17 & 43 & 41 \\
\hline & Does not (N=28) & 0 & 11 & 90 \\
\hline
\end{tabular}

Overall, the data on interaction with HQ suggest that geographic distance may pose a barrier to these boundary spanners in terms of access to the strategic and relational context they need to direct their work abroad. Further, job level differences evident in Tables 11-6 and 11-7 suggested that the black hole "got bigger" the further removed respondents were from the top of the mission. Officers, in particular, seemed to rely on their co-located managers to help them direct their work abroad, but often reported that their managers, too, lacked the context they needed from HQ to help them with their jobs.

The following section further explores interactions with individuals within the organization to see whether there are not other sources of guidance and direction when abroad.

\subsubsection{Boundary spanners' "key person" for direction and guidance}

Given the indication of a "black hole" at HQ, and the comparatively low salience of the manager as a source of direction, the question arose as to who it is was that people at 
post turned to when they needed guidance. The researcher, therefore, turned to the followup question to this series: "Is there anyone in the organization whom you consider to be extremely important to you in terms of communicating what is expected in your job?"

Responses are given in Table 11-8. These data aid in interpreting the results to this point regarding the perceived salience of managers at post. When directly asked to name an individual who was important in communicating work expectations (rather than to identify the sources of role cues in general, as in Table 11-3), the number one response was the immediate manager (cited by $48 \%$ of respondents). This suggested that, like most employees, employees in an international setting do tend to turn to their managers when they perceive they need guidance. Further, when asked specifically to name an individual, job level differences became less pronounced. The attenuation of job level differences was largely attributable to a reversal of the pattern for HOMs. Fully half of HOMs (51\%) identified their managers as their key person in response to this question, roughly comparable to, or higher than, the proportions seen at other job levels. This stands in contrast to HOMs' response pattern in earlier questions, where HOMs were much less likely than those at other job levels to mention their managers at all; Table 11-3), and, when they did, were less likely to say their managers were effective in communicating expectations (Table 11-5). Overall, the findings provide support for the earlier observation that HOMs rely primarily on their professional experience in understanding their roles abroad, and look to others for guidance comparatively rarely. When they do, however, it is their manager at HQ to whom they turn.

Other responses given in Table 11-8 indicate that employees turned to a number of people at HQ or post for direction and feedback. Other key persons identified were 
someone in the HQ reporting line (mentioned by $16 \%$ of respondents), and other

colleagues abroad or in other divisions at HQ (mentioned by $10 \%$ ). Twelve percent said

they couldn't name a key person, because it varied according to the task at hand. These

responses illustrate the high level of diffusion of responsibility and authority in this

organization:

It is almost institutionalized in our organization that there is not one key person. For me, there are three. First, there is the head of mission who runs things here. Second, there is the HQ desk. And third, there are a number of people who work in $H Q$ in various functional divisions with whom I have shared responsibility for files (MID male)

It depends on what we're talking about. For some things, I go to my HOM. For others, I am in contact with the geographic. We also get tasked by other divisions and other departments. So, this is one of the challenges. We don't have one boss. Quite often you do have conflicts between the different priorities. And then we have to balance competing priorities between $H Q$, other government departments, and our own mission. This is another thing that requires diplomacy! (MID male)

\begin{tabular}{|c|c|c|c|c|}
\hline \multirow{2}{*}{$\begin{array}{l}\text { Is there anyone in the organization whom you } \\
\text { consider to be extremely important to you in terms } \\
\text { of communicating what is expected in your job? }\end{array}$} & $\begin{array}{c}\text { Head of } \\
\text { mission } \\
(\mathrm{N}=35)\end{array}$ & $\begin{array}{l}\text { Mid-manager } \\
\quad(\mathrm{N}=\mathbf{2 1})\end{array}$ & $\begin{array}{l}\text { Officer } \\
(\mathbf{N}=\mathbf{2 8})\end{array}$ & $\begin{array}{c}\text { Total } \\
(\mathbf{N}=\mathbf{8 4})\end{array}$ \\
\hline & \multicolumn{4}{|c|}{$(\%)$} \\
\hline Manager & 51 & 52 & 39 & 48 \\
\hline Someone in HQ reporting line (other than manager) & 14 & 24 & 11 & 16 \\
\hline It varies, depending on task at hand & 14 & 14 & 7 & 12 \\
\hline Nobody's key & 9 & 5 & 21 & 12 \\
\hline Other (colleague abroad or at another HQ division) & 11 & 5 & 11 & 10 \\
\hline Head of mission & N/A & N/A ${ }^{7}$ & 11 & 1 \\
\hline Total & 100 & 100 & 100 & 100 \\
\hline
\end{tabular}

Additionally, $12 \%$ of respondents said that nobody was key to them within the

\footnotetext{
${ }^{7}$ Where mid-managers cited the HOM as their key contact, the response was coded as "manager".
} 
organization. This response might have been expected from HOMs, who, as mentioned, tended to draw on their own expertise in performing their jobs, and may not have felt the need to turn to others for guidance:

I am fairly high ranking, I have served in high positions in the organization. There is nobody who is key to me but that doesn't upset me. I say what I want to say, have the freedom to do what I need to do (HOM male)

However, consistent with the finding that the "black hole" was somewhat larger at lower levels of the organization, it was those at the officer level who were most likely to say they had no one internally who was key to them in communicating expectations. Fully one in five of the officers in this study $(21 \%)$ said they could think of no one in the organization who was important to them in terms of communicating expectations:

I am my own key person. I am the one who has to decide which files are important and what I should be doing on them (FL female)

Respondents were further asked in this series what it was that they "took away" from their exchanges with their key person (i.e., what it was that they valued in these interactions). These findings are summarized in Table 11-9. They correspond closely to the findings on boundary spanners' "take-away" from their managers (Table 11-5). When asked what they took away from exchanges with their key person, the number one response (cited by 53\% of respondents) was "context on HQ". The number two response (cited by 37\%) was high-level direction and broad performance parameters. Third, respondents indicated that their key person provided specific direction at the level of their jobs (cited by $34 \%)$.

Job level differences on this item suggest that management levels value their key 
contacts for their ability to provide context on events at HQ (HQ context was the take-away for $67 \%$ of HOMs and $56 \%$ of mid-managers, respectively). Conversely, officers appeared to take away an understanding of the broad performance parameters for their work (cited by $42 \%$ of officers) or specific direction at the level of their jobs (cited by $47 \%$ ). This pattern is also consistent with findings on the take-away from managers. It provides support for the assertion that HOMs turn to their key person more as a "port of call" in providing the context they need to set their own direction. Conversely, boundary spanners at the officer level were more likely than other job levels to value the direct guidance of their co-located managers in setting local objectives and in helping them determine the best path to attain them.

\begin{tabular}{|l|l|c|c|c|c|}
\hline Table 11-9 Respondent's “take-away" from exchanges with key person \\
\hline $\begin{array}{l}\text { What do you take away } \\
\text { from your exchanges with } \\
\text { this person? }\end{array}$ & Description/Examples & $\begin{array}{c}\text { Head of } \\
\text { mission } \\
\text { (N=24) }\end{array}$ & $\begin{array}{c}\text { Mid- } \\
\text { manager } \\
\text { (N=16) }\end{array}$ & $\begin{array}{c}\text { Officer } \\
\text { (N=19) }\end{array}$ & $\begin{array}{c}\text { Total } \\
\text { (N=59) }\end{array}$ \\
\cline { 2 - 6 } & & & \multicolumn{3}{|c|}{ (\%) } \\
\hline Context on HQ & $\begin{array}{l}\text { Contact shares knowledge of current } \\
\text { strategic, relational, and other events at } \\
\text { HQ }\end{array}$ & 67 & 56 & 32 & 53 \\
\hline $\begin{array}{l}\text { High-level direction/ } \\
\text { guidance }\end{array}$ & $\begin{array}{l}\text { Contact provides broad performance } \\
\text { parameters for respondent's } \\
\text { interpretation }\end{array}$ & 33 & 31 & 42 & 36 \\
\hline $\begin{array}{l}\text { Specific direction/ } \\
\text { guidance }\end{array}$ & $\begin{array}{l}\text { Contact provides specific instructions at } \\
\text { the level of the respondent's job }\end{array}$ & 21 & 38 & 47 & 34 \\
\hline Feedback & $\begin{array}{l}\text { Contact provides effective individual } \\
\text { feedback }\end{array}$ & 4 & 19 & 16 & 12 \\
\hline
\end{tabular}

\subsection{Cues from the job and other sources}

This section of the interview was designed to explore the extent to which boundary spanners in an international setting had access to role cues emanating from the performance of the job itself. Respondents were asked: “Feedback is one way we gauge 
how well we are doing in a job, but it is not the only way. Overall, how do you know when you have done a good job?"

Responses are given in Table 11-10. They are ordered as suggested by the literature reviewed on task identity and task feedback (Section 3.1.1). Task identity is defined as the extent to which the employee can see the fit of his or her work within a whole or identifiable product or service (Hackman and Oldham, 1975). Task identity, therefore, reflects the extent to which the boundary spanner can see the "big picture" in terms of his or her contribution to the work of the broader organizational system (e.g., the boundary spanner sees his or her text inserted in a departmental policy statement). Interviews had suggested to this point that the "big picture" was often rather opaque to these boundary spanners, due to their lack of context on events and processes at HQ and HQ's failure to close the loop on tasking requests (i.e., the "black hole"). It might be expected, therefore, that the proportion of respondents who could see "where their work went" and how it fit within the big picture would accordingly be low.

Task feedback, conversely, is defined as the extent to which the job provides direct information on the effectiveness of performance (Ibid.). Task feedback thus reflects the extent to which the boundary spanner can get direct and immediate feedback from performing a specific task in terms of how well the task was done (e.g., the boundary spanner hosts a local conference and can see it goes smoothly). Task feedback stands in contrast to task identity in that the feedback is restricted to the performance of the task, and in itself, offers no information on the contribution of that task to the work of the organization. It might be expected, therefore, that boundary spanner access to feedback at the level of the task would be somewhat higher than task identity, since the 
task is performed locally and outcomes are readily apparent.

\begin{tabular}{|c|c|c|c|c|c|}
\hline \multirow[t]{2}{*}{$\begin{array}{l}\text { How do you know when } \\
\text { you have done a good job? }\end{array}$} & \multirow[t]{2}{*}{ Description/Examples } & $\begin{array}{l}\text { Head of } \\
\text { mission } \\
(\mathbf{N}=30)\end{array}$ & $\begin{array}{c}\text { Mid- } \\
\text { manager } \\
(\mathbf{N}=18)\end{array}$ & $\begin{array}{l}\text { Officer } \\
(\mathrm{N}=27)\end{array}$ & $\begin{array}{l}\text { Total } \\
(\mathbf{N}=75)\end{array}$ \\
\hline & & \multicolumn{4}{|c|}{ (\% mentioning cue) } \\
\hline $\begin{array}{l}\text { Cues from the job } \\
\text { (task feedback, task } \\
\text { identity) }\end{array}$ & $\begin{array}{l}\text { Performance information available } \\
\text { from carrying out the work }\end{array}$ & 69 & 62 & 71 & 68 \\
\hline $\begin{array}{l}\text { Task identity: Can see } \\
\text { outcome externally }\end{array}$ & $\begin{array}{l}\text { Respondent sees contribution locally } \\
\text { (e.g., to a negotiation, business } \\
\text { launched, treaties signed) }\end{array}$ & 57 & 39 & 48 & 49 \\
\hline $\begin{array}{l}\text { Task identity: Can see } \\
\text { outcome internally }\end{array}$ & $\begin{array}{l}\text { Respondent sees contribution to an } \\
\text { internal DFAIT product, process } \\
\text { (e.g., policy /program development) }\end{array}$ & 7 & 11 & 11 & 9 \\
\hline $\begin{array}{l}\text { Task feedback: Access to } \\
\text { key local contacts }\end{array}$ & $\begin{array}{l}\text { Respondent gains access to/develops } \\
\text { relationships with external contacts } \\
\text { essential to doing the job }\end{array}$ & 23 & 11 & 30 & 23 \\
\hline $\begin{array}{l}\text { Task feedback: Can see a } \\
\text { local event has gone well }\end{array}$ & $\begin{array}{l}\text { Respondent observes desired } \\
\text { outcomes from a local event s/he has } \\
\text { organized (e.g., a visit, symposium) }\end{array}$ & 10 & 33 & 15 & 17 \\
\hline $\begin{array}{l}\text { Cues from persons outside } \\
\text { the organization (person } \\
\text { feedback) }\end{array}$ & $\begin{array}{l}\text { Praise/comments from visitors and/or } \\
\text { locals with whom respondent has } \\
\text { worked closely on a consultation, } \\
\text { event, etc. }\end{array}$ & 43 & 61 & 44 & 48 \\
\hline
\end{tabular}

The pattern of results given in Table 11-10 partially supports these predictions.

Overall, two thirds of respondents $(68 \%)$ indicated that they were able to determine how well they were doing on the job by virtue of doing the job. However, a striking finding was that, once the conversation moved to the actual work performed, respondents' frame of reference shifted abruptly from one reflecting membership within their own organizational system to one reflecting joint membership in multiple systems.

Respondents thus described their job cues almost entirely in terms of their contribution to, and feedback from, local systems, rather than cues emanating solely from within their own organizational system. 
Thus, contrary to the prediction that jobs would be somewhat low in task identity in this international setting, responses suggested the opposite. Nearly half of respondents (49\%) said they knew they had done a good job because they could see their contribution to the "big picture". However, the "big picture" was defined in terms of boundary spanners' contribution to work performed outside of their own organizational system, reflecting their joint membership in local, external systems. Boundary spanners could see their contributions in terms of a treaty signed, a business launched, or some other complete "piece of work" in the local context:

You have been working with a Canadian company that in the past may never have considered locating here, and then they spend \$2 million to open a new office here. That says something (HOM male)

In contrast, only $9 \%$ of respondents indicated that they could see their contribution to an internal DFAIT product or process (e.g., their contribution to departmental policy or program development):

If I am lucky, once in a great while, I see a policy piece out of Privy Council Office and I see a conclusion that has been drawn based on a certain evidence, and I recognize that evidence as something I have sent in a report. Sometimes you reach them and sometimes it shows (FL male)

Similarly, task feedback was defined entirely in terms of feedback obtained from tasks performed within external systems. Twenty-three percent of respondents indicated that they knew they had done a good job when they gained access to local contacts, and "doors opened to them locally:

Yesterday an academic at a top university here proposed a conference, which would be paid for largely by the university, and invited Canada to participate solely on the basis of the relationship I had developed with him. In moments like that I realize I am not changing the world, but I am getting Canada on the radar of some influential people in this society (FL female) 
You know you are doing a good job when people start to call you as opposed to your having to call them (HOM female)

Seventeen percent of respondents said they received feedback from their work when they observed that a local event they had organized went smoothly:

When a visitor leaves at the airport, it is quite clear whether you have done everything that needed to be done, the right briefings, the right people around the dinner table for conversation. You see the body language at the airport and you know if you have done a good job (HOM male)

An unexpected finding was the large proportion of respondents who, in response to this question, indicated that they knew they had done a good job when local contacts provided feedback on their work. The question had been aimed at identifying cues for performance inherent in the job, not cues available from interactions with individuals. This response, however, served as a reminder that, where the job is interaction with individuals (i.e., the core technology is boundary spanning), then cues emanating from the job will invariably include cues emanating from individuals at the interface. Nearly half of respondents $(48 \%)$ said they knew they were doing a good job when they received verbal praise from external constituents with whom they worked closely in the field. This finding is worth noting. It suggests that, given the relative "invisibility"of HQ in this international setting, members of the external role are potentially highly salient role senders:

It's much easier to take your feedback from what you do locally than from what you can get from $H Q$. Almost every week, I get a call from local clients, asking me to make a representation, can I do this for them, and they will call me afterward and thank me and tell me what a difference my contribution has made (HOM female)

Job level differences on this item were remarkably minor. Those that were 
apparent stemmed largely from the differential pattern shown by mid-managers in the sample. Mid-managers were less likely to say they knew they had done a good job when they gained access to local contacts, and more likely to say they took their cues from feedback provided by external constituents and from observing the outcomes of local events they had organized. This response pattern is consistent with the program management responsibilities of mid-managers, where a large part of the job entails hosting local events in support of departmental programming in arts, culture, education, and related areas. Involvement in these high-profile events would provide ready feedback both through observing the success of the event itself and through comments provided by individuals who attended it.

\subsection{Summary}

This chapter has explored the intra-organizational cues for performance as perceived by boundary spanners in this international setting. It was based on the assumption that the most fundamental condition for effective performance in a boundary role was the individual's understanding of the organization's expectations for the role. An international assignment removes the boundary spanner from the organizational system of which $\mathrm{s} / \mathrm{he}$ is a part. Of interest was the extent to which geographic distance separated the boundary spanner from role cues emanating from the organizational system.

Four sources of role cues emerged from the data: formal (written) cues; cues from other individuals within the organization (i.e., HQ and the manager); cues from the job itself; and cues from local individuals outside of the organization. These data form the basis for description of the sources of role cues in an MNE setting (Research Question 2). 
The data are mapped to the expanded model of the conditions for effectiveness (Chapter 16), and are discussed in turn below.

Interviews indicated that formal, written cues and cues from other organizational members were highly and equally salient cues for performance when abroad. The data suggested an interplay between the two sources of cues in an international setting. Written products were valued for their ability to provide high-level direction in an enduring format. In this MNE context, environments were perceived as highly unpredictable, and periodic reference to a written document enabled boundary spanners to "get back on track" after inevitable diversions from their core objectives. However, the volatility of local environments also meant that the objectives themselves sometimes needed to be revisited and fine-tuned. This is where interaction with others in the organization-- especially HQ- - came into play. In this public sector organization, strategy formulation is centralized at HQ. Regular and ongoing communication with HQ put the boundary spanner in touch with critical organizational knowledge that enabled the boundary spanner to recalibrate objectives in light of shifting local environments. This preference for high-level objectives combined with flexibility for local tailoring is reminiscent of Sawyer's (1992) conceptual distinction between goal clarity and process clarity (Section 3.1.1). What boundary spanners in this context appeared to prefer was central articulation of high-level goals, accompanied by local flexibility to refine objectives and determine the means to achieve them. Accordingly, respondents indicated that a primary advantage of written documents was their ability to open channels of communication with HQ. Further, individual managers and other "key persons" in the boundary spanner's work context were also perceived effective to the extent that they 
provided a conduit to HQ.

Comments around the "black hole" suggested that where context and feedback from HQ were lacking, boundary spanners had insufficient information to translate and enact high-level goals locally. The frequency of black hole comments provided support for literature that has reported associations between geographic distance and reduced social connectedness with the home organization (Birkinshaw, 1997; Gupta et al., 1999; McGraw, 2004). In this organization, contact with HQ was the single most salient cue for performance, and a highly sought-after resource. Interaction with HQ enabled boundary spanners to obtain valuable strategic and relational context which they used to focus their work abroad. As suggested by Dutton et al., (2001), strategic knowledge regarding the organization's goals, plans and priorities is essential if employees are to selectively attend to strategic issues in their local environments. In this organization, reporting on local developments was one of the primary functions of the boundary role, so the ability to connect to HQ's strategic context assumed increased salience. Relational knowledge regarding who the relevant actors were at HQ and where strategic knowledge resided was essential if the boundary spanner was to successfully navigate the organizational context to obtain the strategic knowledge they needed.

Qualitative data suggested that the "black hole" in this international setting limited access to both strategic and relational knowledge. Quantitative data suggested additionally that this lack of knowledge was associated with reduced clarity regarding the organization's expectations for performance. Job level differences indicated that the black hole "grew bigger" the further removed the boundary spanner was from the top of the mission. Accordingly, the officer level in this sample experienced the greatest level of 
ambiguity regarding the expected role at post, and sought guidance from their co-located managers and other key individuals within the organization.

Cues originating from the performance of the job itself (task identity, task feedback) emerged only when prompted by the follow-up question, "How do you know you have done a good job?" This question directed respondents away from the "expectations" of individuals within the organization, shifting the frame of reference from the home organization to the local context. This means that it was not possible to directly rank the salience of job-related cues against the salience of the other (intra-organizational) cues explored. However, the question generated some insight into the comparative availability of role cues emanating from within the organizational system and role cues emanating from local systems. The data suggested that job-related cues were more readily available from the local work environment than from the home organization: respondents described both task identity and task feedback in terms of cues emanating from local, external organizational systems.

Respondents' identification of cues from individuals external to the organization at this point of the interview was unanticipated. The objective of this series of questions, including the question about cues from the job itself, was to identify cues internal to the organization. The emergence of this category of cues suggests that the separation of internal and external cues may be one of conceptual convenience, but one that is somewhat artificial from the perspective of the boundary spanner. Membership in multiple systems is the defining feature of the boundary role (Kahn et al., 1994). Once the frame of reference in this interview shifted to the actual work performed, it seemed it was not possible for the boundary spanner to discuss the job without "spilling over" to 
discuss the interface context. The next chapter further explores the boundary interface. 


\section{BOUNDARY SPANNER INTERACTION WITH LOCAL CONSTITUENTS: THE INTERFACE}

The model of the conditions for effectiveness in the boundary role (Figure 6.2) posited that a second requirement for effectiveness in the role was the ability to connect with local agents and to successfully engage them in pursuit of organizational objectives. This chapter examines the boundary spanner's experience at the interface.

Section 12.1 examines the sources of role cues in the boundary spanner's local environment by investigating how the boundary spanner determines who will be important to the job and how he or she develops local contacts (Research Question 3a). Section 12.1 also identifies the ways in which local contacts communicate their expectations to the boundary spanner (Research Question 3b). Section 12.2 develops the boundary role construct (Research Question 1) by having respondents target and discuss a recent interaction with a key external agent. Section 12.2 then applies the quantitative data to test the extent to which the dimensions emerging from the individual episodes are judged by boundary spanners to be an important part of their roles abroad. Section 12.3 uses the target episode to identify the types of demands placed on boundary incumbents at the interface (Research Question 3c). Section 12.4 then turns to the strategies boundary spanners use to deal with constituent expectations where they are perceived to conflict with the expectations of the boundary spanner's organization (Research Question 4). The chapter concludes in Section 12.5 with a summary of the findings regarding the boundary spanner's interface experience in this MNE setting. 


\subsection{Sources of role cues in the local environment}

This segment of the interview was intended to elicit from respondents a listing of the salient external cues for the boundary role (i.e., specific constituent behaviours or other sources of information that might contribute to the boundary spanner's understanding of local expectations for the role). The first question in the series was, "How do you develop your contacts?" This question was intended to orient respondents to the interface concept before moving to explore more specific cues. However, the orienting question itself suggested cues that were employed by boundary spanners as they began to explore their environments. Two approaches to contact development were suggested. Responses are given in Table 12-1. 
Table 12-1 Gaining knowledge of local expectations: Approaches to developing contacts

\begin{tabular}{|c|c|c|c|c|c|}
\hline \multirow{2}{*}{$\begin{array}{l}\text { How do you develop } \\
\text { your contacts when } \\
\text { you first arrive at } \\
\text { post? }\end{array}$} & \multirow[t]{2}{*}{ Description/Examples } & $\begin{array}{l}\text { Head of } \\
\text { mission } \\
(\mathrm{N}=35)\end{array}$ & $\begin{array}{l}\text { Mid- } \\
\text { manager } \\
(\mathrm{N}=\mathbf{2 1})\end{array}$ & $\begin{array}{l}\text { Officer } \\
(\mathrm{N}=28)\end{array}$ & $\begin{array}{c}\text { Total } \\
(\mathrm{N}=\mathbf{8 4})\end{array}$ \\
\hline & & \multicolumn{4}{|c|}{ (\% mentioning the approach) } \\
\hline \multicolumn{6}{|c|}{ A. Relationship-based approaches } \\
\hline Mapping & $\begin{array}{l}\text { Deliberate and focussed search to map } \\
\text { the landscape of potential allies and } \\
\text { partners (e.g., consulting predecessor } \\
\text { and experienced mission staff, } \\
\text { diplomatic community, scanning media) }\end{array}$ & 83 & 100 & 96 & 92 \\
\hline $\begin{array}{l}\text { Gaining access/ } \\
\text { Relationship } \\
\text { cultivation }\end{array}$ & $\begin{array}{l}\text { Initial contact early in the relationship } \\
\text { aimed at testing viability of the contact } \\
\text { and/or developing the relationship (e.g., } \\
\text { a cold call, making an overture at a } \\
\text { reception, "take them to lunch") }\end{array}$ & 57 & 57 & 64 & 60 \\
\hline Network extension & $\begin{array}{l}\text { Opportunistic and constant vigilance for } \\
\text { occasions to extend network (gain } \\
\text { introductions, active networking) }\end{array}$ & 31 & 43 & 32 & 35 \\
\hline They come to you & $\begin{array}{l}\text { Respondent notes that contacts tend to } \\
\text { identify themselves (e.g., courtesy calls, } \\
\text { invitations, requests for funding or } \\
\text { assistance) }\end{array}$ & 17 & 4 & 4 & 12 \\
\hline \multicolumn{6}{|c|}{ B. Rational/inferential approaches } \\
\hline $\begin{array}{l}\text { Given by institutional } \\
\text { relationships }\end{array}$ & $\begin{array}{l}\text { Respondent notes that contacts are given } \\
\text { by the history of institutional } \\
\text { relationships, known views and } \\
\text { platforms (e.g., your primary contact is } \\
\text { always your host government } \\
\text { interlocutor, academics are known as a } \\
\text { source of local intelligence) }\end{array}$ & 57 & 57 & 47 & 54 \\
\hline $\begin{array}{l}\text { Given by work } \\
\text { objectives }\end{array}$ & $\begin{array}{l}\text { Respondent notes that contacts are } \\
\text { identified on the basis of strategic } \\
\text { objectives: What do I want to do here, } \\
\text { and who do I need to achieve that? }\end{array}$ & 46 & 38 & 46 & 44 \\
\hline
\end{tabular}

The first set of responses suggested approaches that were aimed at establishing and deepening relationships. Responses suggested an active and ongoing process of relationship development, ranging from the initial identification of key individuals (mapping), to making the initial contact (gaining access), deepening the relationship 
(relationship cultivation), and expanding the network (network extension). Over the course of this process, respondents appeared to be laying the foundation for a better understanding of the motives and expectations of contacts in an unfamiliar setting. Some respondents mentioned only one or two of the steps in the relationship development process. Others, such as the following mid-manager, offered responses that illustrated a systematic search incorporating all of the steps:

Your staff, colleagues, maybe your HOM may point you in the direction of certain contacts (mapping). So, you inherit contacts. But then you come to find that some suit your interests, but others cannot give you the information and reach that you need. So, you do some research (mapping), and do some courtesy calls (gaining access), invite them to events and try to develop the relationships you need to understand them better (cultivation). Once you've built some trust, they will often introduce you to others who will also turn out to be valuable contacts (network extension; $M I D$ male)

The second set of responses focussed on the thought processes boundary spanners engaged in prior to initiating the active search for contacts. These were labelled "rational/inferential" approaches. These approaches included strategies driven by the boundary spanner's knowledge of the contact's institutional affiliation or knowledge of long-standing institutional relationships...

Academics are renowned for being local experts. They have insights and intelligence you couldn't possibly get from the media or the local government. And they like to talk. So, that's the first place you go if you want something other than the party line (FL female)

I am very lucky here because 1 work on a file dealing with a multilateral organization, and Canada's relationship with others in this organization is very well defined. So it is very straight forward to know who to approach (FL female)

... or strategies driven by work objectives:

To develop my contacts, I used our reporting agreement with $H Q$. On this, we had laid out our quarterly reporting plans and what we were going to report on. I then thought, what are the stories I want to tell HQ on a quarter by quarter basis, and who do I need to talk to to get this story? (MID female) 
Job level differences were as expected and minor. Due to their "figurehead" status and high visibility, HOMs were slightly more likely than other job categories to say that contacts tended to "come to them". Also as expected, the front line was slightly less likely to cite knowledge of institutional relationships as a factor, likely reflecting their comparative inexperience. The most noteworthy observation from this table is the absence of job level differences, suggesting a rather shared perception of the key aspects of the contact development process.

Responses to this initial question thus called attention to an important precursor to effectiveness at the interface. Before a boundary spanner on international assignment can effectively engage locals, s/he has to find them. Determining who will be an important contact relies on a degree of both institutional knowledge (known views and interorganizational relationships associated with institutional membership) and relational knowledge (who are the players here, who is knowledgeable on this issue, and who will talk to me?)

Having explored how contacts were developed, the researcher then asked respondents how they came to know what these contacts expected of them in their roles. Since this question lacked a referent contact person (i.e., was phrased in the abstract), interpretations of the question were varied. Responses aligned closely with the two categories emerging from the previous question. Some respondents described specific cues emanating from one-on-one interactions. These were labelled "transaction-based cues". Other respondents described cues emanating from thought processes that allowed the boundary spanner to infer the contact's expectations from the boundary spanner's 
general knowledge or, again, from the contact's institutional affiliation. Consistent with

Table 12-1, these cues were labelled "rational/inferential" cues. The two sets of cues are

described in Table 12-2.

Table 12-2 Gaining knowledge of local expectations: Sources of role cues in the external environment

\begin{tabular}{|l|l|l|l|l|l|}
\hline $\begin{array}{l}\text { How do you come } \\
\text { to know what your } \\
\text { local contacts } \\
\text { expect of you in } \\
\text { your role? }\end{array}$ & Description/Examples & $\begin{array}{c}\text { Head of } \\
\text { mission } \\
(\mathbf{N}=\mathbf{3 0})\end{array}$ & $\begin{array}{c}\text { Mid- } \\
\text { manager } \\
(\mathbf{N}=18)\end{array}$ & $\begin{array}{c}\text { Officer } \\
(\mathbf{N}=26)\end{array}$ & $\begin{array}{c}\text { Total } \\
(\mathbf{N}=74)\end{array}$ \\
\hline
\end{tabular}

\section{A. Transaction-based cues}

\begin{tabular}{|c|c|c|c|c|c|}
\hline $\begin{array}{l}\text { People are direct } \\
\text { here }\end{array}$ & $\begin{array}{l}\text { Respondent notes that people are direct and } \\
\text { forthcoming in local culture ("they'll tell } \\
\text { you"; "obvious from their } \\
\text { correspondence") }\end{array}$ & 50 & 44 & 58 & 51 \\
\hline $\begin{array}{l}\text { People are oblique } \\
\text { here }\end{array}$ & $\begin{array}{l}\text { Respondent notes that it is not easy to tell, } \\
\text { that people are indirect in the local culture, } \\
\text { that it is inappropriate to say "no" or to ask } \\
\text { outright }\end{array}$ & 10 & 39 & 35 & 26 \\
\hline $\begin{array}{l}\text { You have to have } \\
\text { the language }\end{array}$ & $\begin{array}{l}\text { Respondent notes the importance of } \\
\text { understanding the language to } \\
\text { understanding local expectations }\end{array}$ & 43 & 33 & 25 & 35 \\
\hline $\begin{array}{l}\text { I rely on body } \\
\text { language and other } \\
\text { non-verbal cues }\end{array}$ & $\begin{array}{l}\text { Respondent cites non-verbal behaviours } \\
\text { from which s/he interprets the contact's } \\
\text { perspective (e.g., eye contact, laughing, } \\
\text { fidgeting) }\end{array}$ & 17 & 22 & 8 & 15 \\
\hline \multicolumn{6}{|c|}{ B. Rational/inferential-based cues } \\
\hline $\begin{array}{l}\text { Given by } \\
\text { institutional } \\
\text { relationships }\end{array}$ & $\begin{array}{l}\text { Respondent notes that contacts' } \\
\text { expectations can be inferred from the } \\
\text { history of institutional relationships, their } \\
\text { known views and platforms, and from } \\
\text { respondent's own role ("I assume what they } \\
\text { want is what a diplomat offers: information } \\
\text { and a conduit to my government") }\end{array}$ & 47 & 67 & 50 & 53 \\
\hline $\begin{array}{l}\text { Views of } \\
\text { knowledgeable } \\
\text { others }\end{array}$ & $\begin{array}{l}\text { Respondent consults predecessor, mission } \\
\text { staff, diplomatic community, etc. }\end{array}$ & 23 & 22 & 8 & 18 \\
\hline $\begin{array}{l}\text { Intuition, years of } \\
\text { experience }\end{array}$ & $\begin{array}{l}\text { Respondent notes that } s / \text { he comes to know } \\
\text { through inferences/intuition based on years } \\
\text { of experience }\end{array}$ & 27 & 17 & - & 15 \\
\hline
\end{tabular}

Rational/inferential cues were similar to those cited for the previous question. 
Respondents tended to indicate that they knew what was expected of them because they knew the affiliation and histories of the organizations to which their contacts belonged. Other inferential approaches were to do research on the contact by consulting more experienced local colleagues or to call on one's own intuition and experience.

Transaction-based cues tended to centre on the importance of cultural understanding in "reading" contact expectations. Responses such as "people are oblique here", "people are direct", or "you have to have the language" suggested that understanding the expectations of individual contacts was a function of understanding the culture in which they were operating. Intercultural differences and the cultural adjustment of expatriates have been explored extensively elsewhere, so will not be discussed here. However, the data serve as a reminder that a further antecedent to boundary spanner effectiveness in the MNE context is an understanding of culture and local language. ${ }^{8}$

\subsection{The boundary role construct}

This section addresses the central research question of the study: the description of the dimensions of the MNE boundary role construct (Research Question 1). Respondents were asked to think of a recent exchange with someone outside of the organization who was extremely important to them in terms of doing their jobs. They were then prompted

\footnotetext{
${ }^{8}$ Although several job level differences are suggested in these data, they are not interpreted for purpose of this discussion. Although some are intuitive (e.g., HOMs were more likely than other job categories to say that they called on their years of experience to infer contacts' expectations), other apparent job level differences may have been more attributable to the country to which the respondent was assigned than job level per se (e.g., specific references to culture and language). Since cultural issues associated with geographic location were not a topic of primary research interest, the researcher chose not to speculate on these differences. Readers interested in relating these responses to the geographic distribution of the sample are referred to Table 9-3.
} 
to describe this exchange: who was the person; why was connecting with this person important to their work and to the organization; what happened over the course of the exchange? This series of questions oriented the respondent to the nature of the activity in which they engaged and the purpose of this activity in terms of value to the organization. This method enabled the researcher to apply the grounded theory technique to abstract the dimensions of the boundary role in this MNE context.

\subsubsection{Overview of boundary episodes}

Seventy-nine of the 84 respondents (94\%) were able to recall a recent encounter to serve as the target episode. The contact persons identified in these episodes are given in Table 12-3.

\begin{tabular}{|l|c|c|c|c|}
\hline Table 12-3 Target person identified in boundary episodes & \multicolumn{1}{|c|}{ (\% of cases) } \\
\hline & $\begin{array}{c}\text { Head of } \\
\text { mission } \\
\text { (N=32) }\end{array}$ & $\begin{array}{c}\text { Mid-manager } \\
\text { (N=20) }\end{array}$ & $\begin{array}{c}\text { Officer } \\
\text { (N=27) }\end{array}$ & $\begin{array}{c}\text { Total } \\
\text { (N=79) }\end{array}$ \\
\hline Target person & & 35 & 41 & 47 \\
\hline Host government & 59 & 20 & 19 & 15 \\
\hline Academic & 9 & - & 19 & 11 \\
\hline NGO & 13 & 10 & 4 & 8 \\
\hline Private sector (local) & 9 & - & 11 & 5 \\
\hline Member of multilateral organization & 3 & 35 & 7 & 14 \\
\hline $\begin{array}{l}\text { Other (Canadian private sector, arts and } \\
\text { culture industry, media, etc.) }\end{array}$ & 6 & 100 & 100 & 100 \\
\hline Total & & & & \\
\hline
\end{tabular}

Consistent with the nature of political-economic work abroad (delivering demarches, gauging host government positions), roughly half of respondents (47\%) cited a 
recent interaction with a representative of the host government. Fifteen percent mentioned an interaction with an academic, consistent with respondents' earlier comments that academics were excellent sources of local insight. Eleven percent mentioned an encounter with a member of an NGO, and the remainder mentioned interactions with a variety of other contacts, such as those from the local private sector, the arts and culture industry, media or a multilateral organization (e.g., EU, NATO).

Observed job level differences in the data are worth noting, since the nature of the contacts with whom boundary spanners interact determines to a large extent the nature of the interaction. For example, consistent with the nature of political work abroad, HOMs and political officers were most likely to cite an interaction with a member of the host government. Mid-managers, conversely, were likely to cite an interaction with a member of the media, Canadian industry, or the arts and culture community. Mid-manager engagement with members of these sectors reflects their responsibility for public diplomacy and other programming aimed at "showcasing" Canada abroad through conferences, fora, and cultural displays. Further, none of the mid-managers cited an interaction with an NGO. The implications of these differences for activities at the boundary are discussed throughout this chapter.

The exchanges cited in these episodes were overwhelmingly "real-time", synchronous interactions (not shown). Eighty percent of respondents described a face-toface encounter (a lunch, a meeting, a corridor conversation at an event); 15\% described a phone call. Only $5 \%$ cited an email exchange. The preference for real-time interactions with key contacts in the field is an interesting observation, and is consistent with respondents' perceived need for the development of interpersonal relationships in their 
dealings with local contacts, as expressed by this head of mission:

Face-to-face exchanges are what diplomacy is about. Email is a wonderful tool for transmission of information, but this is a business that is about personal trust and confidence and that cannot be developed through the impersonal medium of electronics. It has to be done by looking that individual in the eye and knowing that he or she shares the trust and confidence that you have tried to establish (HOM male)

Also reflecting the value placed on relationship development, the majority of respondents indicated that the interaction cited was with an individual with whom they were already acquainted (not shown). Thirty-five percent said they had known this individual prior to the interaction; an additional $27 \%$ stressed that they had made sincere efforts to maintain and nurture this relationship. A fair proportion, however, (38\%) reported a first encounter. This was a favourable outcome, since it suggested a rather balanced distribution across levels of involvement with the target person, and provided a maximum range of responses for exploration.

When asked, "Why was this person important to your job ?”, all respondents were readily able to identify the purpose of their interaction and link it to the Department policy or program objective it served. This is consistent with the heavy emphasis respondents placed on objectives-based contact development, as discussed in the preceding section. Although the policy objective for each interaction was not coded, the examples below illustrate the linkages respondents made between their interaction and the effective functioning of the organization:

- Invites a public broadcaster from Canada to give a talk to local media. This is aligned with Government of Canada objectives in promoting media ethics and serves the higher level organizational objective of the promotion of human rights (MID male) 
- Asks a university professor to cohost a Canadian expert to speak to local students on the topic of the UN. Broadly, this is aligned with Government of Canada objectives in promoting regional cooperation on security issues. Specifically, students of Canada(country) relations in this professor's university were the target audience for the promotion of Canadian values in regional cooperation. This professor was, therefore, the gatekeeper of the audience (FL female)

- Declines a request for funding from an NGO because it is outside of DFAIT's programming area. The project, however, is aligned with DFAIT policy priorities. Refers NGO to CIDA for funding, serving DFAIT's mandate as a convener (FL female)

\subsubsection{A typology of the dimensions of the boundary role}

From a list of descriptions of interactions, such as the three illustrated above, the researcher applied the constant comparison technique to abstract themes that reflected categories of activities and the purposes served by these activities. Nine themes emerged from the data. These themes were systematically compared to the four dimensions of the boundary role as developed by Ancona and Caldwell (1992; Figure 6.1). Two of the themes fit fairly well to the "task coordinator" and "guard" dimensions, so were sorted into these conceptual "bins", and the categories retained. However, the remaining seven were poor fits to the "ambassador" and "scout" dimensions. These functions were too gross to capture the nuances of the data at hand, often combining functions that were conceptually distinct in this research, did not occur in tandem, and involved different strategies at the interface. Further, several of the emergent themes had no counterparts in the framework at all. Overall, the four-category typology proved a poor fit to the data. 
The researcher, therefore, returned to Ancona and Caldwell's (1988) original 15item classification (see Table 2-3) to search for matches. Some of these more granular classifications appeared to better suit the emergent data. Several of these classifications, therefore, were retained for this research. Where no existing classification seemed appropriate, new classifications were derived. Comparisons with Ancona and Caldwell's dimensions are made throughout this section as the emergent typology is discussed.

The final typology emerging from this research is given in Exhibit 12-1 (frequencies for each of the dimensions are given by job level in Table 12-5). Consistent with the macro-level conceptualization of the boundary construct (Section 2.1.1; Section 6.1), the basis for micro-level conceptualization was to identify for each transaction observed: (1) the nature of the boundary activity; (2) what was flowing across the boundary and the direction of the flow; and (3) the purpose served by the transaction in terms of contributing to the organization's response to its external environment.

The emergent typology given in Exhibit 12-1 thus comprises five columns. The first column identifies the emergent dimensions of the boundary role. The second column describes the boundary activity associated with each dimension. The third column describes the boundary exchange associated with that activity in terms of what was crossing the boundary and the direction of the flow. The fourth identifies the purpose of the activity in terms of the work of the boundary spanner's organizational system and the organization's relationship to its external task environment. The fifth column provides examples to illustrate each of the dimensions. A discussion of the emergent dimensions follows the exhibit. Discussion of job level differences is reserved for the end of the section. 


\begin{tabular}{|c|c|c|c|c|}
\hline Dimension & Description of activity & $\begin{array}{l}\text { Movement of } \\
\text { inputs and } \\
\text { outputs at } \\
\text { boundary }\end{array}$ & Functional purpose of activity & Examples \\
\hline Representing & $\begin{array}{l}\text { Modeling the } \\
\text { organization's views } \\
\text { and values to an } \\
\text { individual external } \\
\text { agent }\end{array}$ & $\begin{array}{l}\text { Opens boundary to } \\
\text { outward flow of } \\
\text { "image" }\end{array}$ & $\begin{array}{l}\text { Enhances the organization's } \\
\text { reputation or legitimacy among } \\
\text { other players in the } \\
\text { organization's external } \\
\text { environment }\end{array}$ & $\begin{array}{l}\text { Modeling the organization's values over the course of the } \\
\text { interaction, demonstrating through own behaviour the } \\
\text { norms, ethics, or values associated with organization's } \\
\text { image (e.g., showing respect, a cooperative spirit, showing } \\
\text { adherence to accepted international principles) }\end{array}$ \\
\hline Scouting & $\begin{array}{l}\text { Focussed search for } \\
\text { non-sensitive } \\
\text { information or ideas } \\
\text { needed to inform the } \\
\text { boundary spanner's } \\
\text { immediate task } \\
\text { demands }\end{array}$ & $\begin{array}{l}\text { Opens boundary to } \\
\text { inward flow of } \\
\text { task-relevant } \\
\text { information }\end{array}$ & $\begin{array}{l}\text { Brings into the organization } \\
\text { general information that is } \\
\text { needed to support the } \\
\text { organization's workflow }\end{array}$ & $\begin{array}{l}\text { Requesting information from an external agent regarding a } \\
\text { particular file, seeking information regarding agent's } \\
\text { activities or plans where these plans might affect the work } \\
\text { of the boundary spanner's organization }\end{array}$ \\
\hline $\begin{array}{l}\text { Intelligence } \\
\text { gathering }\end{array}$ & $\begin{array}{l}\text { Focussed search for } \\
\text { sensitive, "privileged" } \\
\text { or "insider" } \\
\text { information not } \\
\text { available through } \\
\text { regular channels }\end{array}$ & $\begin{array}{l}\text { Opens boundary to } \\
\text { inward flow of } \\
\text { privileged } \\
\text { information }\end{array}$ & $\begin{array}{l}\text { Brings into the organization } \\
\text { privileged information that is } \\
\text { needed to anticipate } \\
\text { environmental fluctuations and } \\
\text { protect the organization's core } \\
\text { work from uncertainty }\end{array}$ & $\begin{array}{l}\text { Making inquiries to identify the perspectives of local } \\
\text { individuals or groups and major interests at stake. May be } \\
\text { first-hand and specific information (e.g., inquiring as to the } \\
\text { reasons behind a delay in a project) or secondary expert } \\
\text { knowledge (e.g., meeting with an academic or other } \\
\text { knowledgeable "barometer" on the region) }\end{array}$ \\
\hline $\begin{array}{l}\text { Relationship } \\
\text { building. }\end{array}$ & $\begin{array}{l}\text { Effort to build or } \\
\text { maintain a relationship } \\
\text { with external agent }\end{array}$ & $\begin{array}{l}\text { Opens boundary to } \\
\text { the outward flow } \\
\text { of affect }\end{array}$ & $\begin{array}{l}\text { Lays foundation of trust, } \\
\text { encourages reciprocity to } \\
\text { enable future exchanges of } \\
\text { value to the organization }\end{array}$ & $\begin{array}{l}\text { Building rapport, inquiring about contact's family or work } \\
\text { interests, "making deposits in the relationship bank" }\end{array}$ \\
\hline Molding & $\begin{array}{l}\text { Effort to influence the } \\
\text { external agent's } \\
\text { agenda, sway the } \\
\text { agent's views, } \\
\text { persuade agent to } \\
\text { support the work of the } \\
\text { boundary spanner's } \\
\text { organization }\end{array}$ & $\begin{array}{l}\text { Opens boundary to } \\
\text { outward flow of } \\
\text { influence }\end{array}$ & $\begin{array}{l}\text { Directly modifies the } \\
\text { organization's external } \\
\text { environment in a manner } \\
\text { conducive with the work of the } \\
\text { organization }\end{array}$ & $\begin{array}{l}\text { Persuading a key player to participate in a conference } \\
\text { hosted by the boundary spanner's organization, efforts to } \\
\text { convince host government to support the position of the } \\
\text { boundary spanner's organization }\end{array}$ \\
\hline
\end{tabular}




\begin{tabular}{|c|c|c|c|c|}
\hline $\begin{array}{l}\text { Coordinating/ } \\
\text { negotiating }\end{array}$ & $\begin{array}{l}\text { Communicating with } \\
\text { external agent in areas } \\
\text { of mutual workflow } \\
\text { dependencies and } \\
\text { shared projects or } \\
\text { mandates }\end{array}$ & $\begin{array}{l}\text { Opens boundary to } \\
\text { the two-way flow } \\
\text { of influence }\end{array}$ & $\begin{array}{l}\text { Enables the work of the } \\
\text { organization to proceed where } \\
\text { the work is dependent on } \\
\text { contribution of outside agent }\end{array}$ & $\begin{array}{l}\text { Organizing visits and events, negotiating division of } \\
\text { responsibilities on a shared project, coordinating schedules } \\
\text { for consultations or policy input }\end{array}$ \\
\hline Delivering & $\begin{array}{l}\text { Delivering information } \\
\text { or other resources in } \\
\text { response to the } \\
\text { demands of the external } \\
\text { agent ("delivering the } \\
\text { product") }\end{array}$ & $\begin{array}{l}\text { Opens boundary to } \\
\text { outward flow of } \\
\text { resources } \\
\text { (goodwill, } \\
\text { financial, human, } \\
\text { or information } \\
\text { resources) }\end{array}$ & $\begin{array}{l}\text { Disposes of the outputs of the } \\
\text { organization's productive work } \\
\text { where agent's expectations are } \\
\text { perceived as legitimate and } \\
\text { aligned with the organization's } \\
\text { work }\end{array}$ & $\begin{array}{l}\text { Delivering program funds, delivering information or } \\
\text { intelligence, delivering the support or good will of the } \\
\text { organization (endorsing a resolution, casting a vote, } \\
\text { signing a treaty), granting request for public appearance or } \\
\text { attendance at an event or function }\end{array}$ \\
\hline Guarding & $\begin{array}{l}\text { Refusing agent's } \\
\text { demands for } \\
\text { information or other } \\
\text { resources; avoiding, } \\
\text { delaying, or ignoring } \\
\text { requests }\end{array}$ & $\begin{array}{l}\text { Closes boundary } \\
\text { to inward flow of } \\
\text { influence and } \\
\text { closes boundary to } \\
\text { outward flow of } \\
\text { resources } \\
\text { (goodwill, } \\
\text { financial, human, } \\
\text { or information } \\
\text { resources) }\end{array}$ & $\begin{array}{l}\text { Protects the work of the } \\
\text { organization by preventing an } \\
\text { exhange where the agent's } \\
\text { expectations are unknown or } \\
\text { misaligned with the work of the } \\
\text { organization }\end{array}$ & $\begin{array}{l}\text { Refusal to provide information, service or resources not in } \\
\text { organization's area of responsibility; refusal to affiliate } \\
\text { where organization's image is threatened (e.g., refuse an } \\
\text { invitation to a political event); delaying response to buy } \\
\text { time to consider implications; delaying response to } \\
\text { discourage task overload in areas of low priority (e.g., } \\
\text { postponing response to funding requests); redirecting agent } \\
\text { to appropriate agency }\end{array}$ \\
\hline Intermediary & $\begin{array}{l}\text { Brokering } \\
\text { introductions, referrals } \\
\text { between two or more } \\
\text { external agents }\end{array}$ & $\begin{array}{l}\text { Opens boundary to } \\
\text { outward flow of } \\
\text { influence }\end{array}$ & $\begin{array}{l}\text { Indirectly modifies the } \\
\text { organization's external } \\
\text { environment in a manner } \\
\text { conducive with the work of the } \\
\text { organization }\end{array}$ & $\begin{array}{l}\text { Bringing together external parties with common interests } \\
\text { and/or complementary resources (e.g., introducing } \\
\text { Canadian business person to member of local industry } \\
\text { association; introducing Canadian expert in human rights } \\
\text { issues to local academics) }\end{array}$ \\
\hline
\end{tabular}




\begin{tabular}{|l|c|c|c|c|c|}
\hline Table 12-5 Dimensions of the boundary spanning role \\
\hline & $\begin{array}{c}\text { Head of mission } \\
\mathbf{( N = 3 2 )}\end{array}$ & $\begin{array}{c}\text { Mid-manager } \\
(\mathbf{N}=\mathbf{2 0})\end{array}$ & $\begin{array}{c}\text { Officer } \\
(\mathbf{N = 2 7})\end{array}$ & $\begin{array}{c}\text { Total } \\
\text { (N=79) }\end{array}$ \\
\hline Functional activity & \multicolumn{2}{|c|}{$(\%$ of episodes in which the dimension was described) } \\
\hline Relationship building & 63 & 70 & 52 & 61 \\
\hline Molding & 63 & 50 & 37 & 51 \\
\hline Intelligence gathering & 28 & 50 & 30 & 34 \\
\hline Delivering & 34 & 25 & 41 & 34 \\
\hline Coordinating/negotiating & 25 & 30 & 30 & 28 \\
\hline Guarding & 22 & 20 & 30 & 24 \\
\hline Scouting & 6 & 20 & 33 & 19 \\
\hline Representing & 19 & 13 & 4 & 11 \\
\hline Intermediary & & 15 & 7 & 11 \\
\hline
\end{tabular}

1. Relationship building The single most frequently cited dimension of the boundary spanning role was to build the interpersonal relationship between the boundary spanner and the external agent (mentioned in $61 \%$ of episodes). The relationship dimension can be seen to be analogous to the exchange of affect, or friendship, as described in the social network perspective (Tichy et al., 1979). Relationship building was almost always cited in conjunction with another objective for the interaction, since it was perceived as the enabler of future transactions. This enabling characteristic is also consistent with the social network perspective, which would maintain that the exchange of friendship resources is instrumental in obtaining other resources, such as information or resources needed to support the workflow:

My job was to create the conditions for this person to open up.You seldom achieve this over one meeting. You build the relationship and the exchange becomes deeper over time. The relationship will ultimately become the foundation for achieving your work objectives (MID male)

My desired outcome for that one meeting was not to obtain huge movement on the issue. It was 
for him to see me as a person. The short-term outcome I wanted was for him to say to me, yes, I will receive your telephone calls directly, not through my receptionist, or I will call you directly if I need you. So, I left the room feeling I liked this guy, and I felt a certain amount of trust in him, and he in me, and that was what I wanted (MID male)

A key theme among those who mentioned the relationship function was the need for reciprocity. Many respondents indicated that they wanted to make sure over the course of their interaction that they were able to make a "deposit in the relationship bank": if you expected to get, you had to be seen to give:

You build relationships not because they are going to have a specific output. But because you want to build up a pool or wellspring of good intention, good feeling, you're buying chits for the future. So, in two or three years, if you need something, you can count on them as a friend or ally (MID male)

HQ was viewed as a major player in ensuring people abroad had "something to give" in these exchanges, and this likely accounts for some of the frustrations expressed in Chapter 11 around the lack of context from HQ in tasking requests:

The very foundation of these "bilateral relationships" is the little things that you do every day. Because if you don't have this foundation, if you can't show you are present and sensitive to (your contact's) issues, when you need them for the "bold new Canadian initiatives", you can't call on them for the support you need. That's why it is important that HQ equip us so that we have something to give in these exchanges (HOM male)

Relationships in general, and reciprocity in particular, were seen as especially important in achieving work objectives in cultures where business relationships were mediated by personal relationships...

This is a very Oriental society. A society that depends on personal contact and networking and face means everything (HOM male)

I navigated this (interaction) carefully, I have worked hard to develop this relationship. This culture is very focused on face and status. And I have seen people going into deliberations all concerned with the substance of the discussion, when they could totally have won concessions based on attention to form alone. So, I was focusing on the relationship and I was focusing on form (HOM male) 
In this society, things are based on relations, not like in Anglo-Saxon society where institutional relationships prevail. So, for example, in Germany, it may not matter whether you and your German colleague get along well, the job is there to be done and you both understand that. Here, it is much more subtle. You have to develop the trust, and that is based on a sometimes subtle, but often not-so-subtle system of exchanging favours. Not gifts and bribes. More like you get to know me, Mr. Ambassador, and I will introduce you to some members of the business community. Sometimes this kind of thing seems distasteful, but it is the reality, and our training prepares us for this before we go abroad (HOM male)

... or in cultures where people were perceived as "oblique" (see Table 12-2), or "slow to warm up":

My experience in this country is that people are very social, everybody knows everybody and will talk to you, but they often will not talk frankly on first meetings. It takes about three meetings before they will open up. So, this means everybody is worth meeting at least twice! (FL male)

The relationship-building function had no counterpart in Ancona and Caldwell's (1992) four-category scheme. It was somewhat similar to one of the original 15 items- "opening communication channels"- - an activity occurring early in the development of their project teams. However, that function was described as a series of introductions of the team to other organizational members, in anticipation of a working relationship. Qualitatively, it lacked the salience, intensity and instrumentality of relationship-building as described in this research.

2. Molding was the second most frequently cited dimension (51\%). Molding activity involved attempts by the boundary spanner to directly influence the external agent's agenda to suit the agenda of his or her own organization. The functional purpose of this activity was to preserve the work of the organization by "shaping" or "molding" the external environment so as to better align with it:

(A local elected official) was hosting (a high-profile event), and Canada was not on the list of invitees. This posed a threat to Canada's image as a progressive player in this key policy area, 
so we would be conspicuous by our absence. I needed to persuade (the interlocutor) to talk to the organizers and make sure Canada was invited (MID male)

The emergence of the molding dimension in this research represented the point at which the "ambassador" dimension was deemed to be too gross to capture the nuances of the data at hand. The molding function had been a discrete category given in Ancona and Caldwell's (1988) 15-item typology. It was one of the functions that they later subsumed under the "ambassador" category (Ancona and Caldwell, 1992). Their assignment of molding to the ambassador category was based on their statistical analysis, in which items reflecting persuasion efforts loaded on the same factor as items reflecting lobbying for support and other resources and protecting the team from external pressures. They labelled this factor "ambassadorial" activity, since they deemed all three functions (persuading, protecting, and lobbying) to be characteristic to the promotional or "ambassadorial" behaviour of product team members in their interactions with organizational members outside of the team.

An important point of departure, however, between Ancona and Caldwell's work and this research was that the organizational members with whom product team members interacted in performing the ambassador function were largely top management. Product team members had to repeatedly "sell" the product to top management, lobby for continued support and financial resources, and protect the team from the impatience of management until the project was completed. Ambassadors were thus portrayed as “cheerleaders" (Ancona and Caldwell, 1988; p. 477), whose molding efforts were largely directed at trying to project the team in a favourable light and build management "buy-in" for the team's projects. 
Whereas molding may have corresponded to lobbying and protection functions in the "upward" persuasion efforts of product development teams, the data emerging from this research did not correspond to this conceptualization. Boundary spanners in this sample were dealing, not with executive within their own organization, but with agents outside of the organization. This meant that the agents with whom they dealt did not always hold a power position over them. The boundary spanner was thus not limited to lobbying, "cheerleading" or other less assertive efforts. In some instances, molding in this research did take the form of lobbying, particularly where the boundary spanner was highly dependent on the cooperation or support of the external agent (and hence, the agent did hold some degree of power over the boundary spanner):

This was our first meeting. My predecessor had never been able to develop a relationship with this person and it was critical that I do if I were to work with this country. So, I set the meeting, and when we met, I began by outlining Canada's importance to (his country), and that we were important trade partners. I wanted to give him a sense of what Canada was about and hoped to convince him of the value of having Canada as a partner (HOM female).

In other instances, however, molding took the form of more assertive efforts to bring the agent's agenda in line with that of the boundary spanner's organization. These efforts were quite different in flavour from "lobbying for support". However, they were still clearly aimed at shaping or "molding" the behaviour of the outside agent:

I was working with an officer in the (local foreign ministry) to arrange a workshop. I needed to book the hotel rooms. My contact, however, was not there for the same purpose, he wasn't even on that page yet. In his (hierarchical) society, the working level cannot take a decision on their own (such as to book the rooms). He was there just to obtain a few points of clarification to take the message back to his boss for decision. I knew this, but I was running out of time. So, sometimes you just have to take the lead on these things. I impressed on him that I really needed agreement by the end of the day, or people would have nowhere to stay when they arrived. This seemed to do it and he contacted his boss for decision while I waited (FL male)

Assertive molding efforts, such as that illustrated above, would not have been observed in 
Ancona and Caldwell's sample. In dealing with agents outside of the organizational hierarchy, the power balance is much more variable. The molding function, therefore, assumed a more variable character in this research as well.

The molding dimension, therefore, was conceptualized for the purpose of this research to include all direct efforts to persuade or sway the external agent's agenda, and was not limited to lobbying efforts or other resource-seeking behaviour. This broader conceptualization was consistent with macro conceptualizations of "control", whereby the organization exerts outward energy to modify its external task environment to better align it with organizational goals (Adams, 1976; Aldrich and Herker, 1977; Thompson, 1967; see Table 2-1). Further, the protect function, which had also loaded on Ancona and Caldwell's "ambassador" dimension, was coded "guard" (as per Ancona and Caldwell's original 15-item typology), since it essentially involved "closing the boundary", not opening it to exert outward control. The guard dimension will be discussed further later in this section.

3. Intelligence gathering was the third most frequently cited dimension (34\%). This dimension involved the effort to obtain privileged or "insider" information about the local environment with implications for the work of the boundary spanner's organization. Intelligence gathering served to bring into the organization information needed to anticipate potential environmental changes, and thus served to enable the organization's work and protect it from uncertainty. Sometimes, intelligence involved expert knowledge that was critical to understanding the local government, economy, or society:

There are those who say you can learn everything you need on the Internet. But, really, CNN reports on two or three hot countries, and that is it. This (local academic) really understands this country, has seen it all. The people I connect with here have the true insights. Many of them 
wouldn't even have access to Internet (MID male)

Other times, intelligence involved comparatively "minor" issues, but issues that posed potential impediments to the boundary spanner's work. Obtaining this intelligence enabled the boundary spanner to remove roadblocks or plan around them:

I had been working with (host government interlocutor) on the wording to this (document) for a very long time, and I thought we were getting somewhere. But suddenly, the tone changed, and my interlocutor began delaying on this. So, I went to see him to ask what was really going on at his end, so I could continue to move this forward (FL female)

The intelligence function had no counterpart in Ancona and Caldwell's $(1992 ; 1988)$ typologies. The closest category was "scouting", a category which subsumed both the search for "information about the competition" and "general scanning" for ideas and trends (see Table 2-4). Information "about the competition" may have been similar to the intelligence function as it emerged in this research, since, conceivably, it may have included privileged information about the competition's products or activities. However, if this is what was intended by Ancona and Caldwell, it was not articulated.

Intelligence, as it emerged in this research, appeared to be quite distinct from any "general purpose" scanning for ideas. Few respondents in this research spent interface time seeking "general" information from their contacts, particularly that which was available in public domains. Further, the search for intelligence typically involved a very considered and cautious approach, and access to sensitive information, as illustrated in the quote below:

I needed information on this country's current situation: was the government stable, was the society on the verge of collapse? Where are they in need of support, and should we support them? (This contact) is a barometer on tensions in the region. He can enlighten me on the local perspective because he is of the local perspective (MID male) 
Presumably, access to the type of intelligence suggested in the above quote would be one of the primary purposes of an international assignment- - to obtain knowledge of local developments that would be invisible to the organization without local presence. Intelligence was thus maintained as a distinct category, and the scouting dimension was reserved for the (less frequent) function of collecting "general" information.

4. Delivering This dimension involved the delivery of information or other resources in response to the demands of the external agent (mentioned in $34 \%$ of episodes). This dimension was consistent with the delivery function identified in Ancona and Caldwell's 15-item typology. Delivery involved opening the boundary to dispose of the organization's outputs ("deliver the goods"), in instances where the demands of the agent were perceived to be legitimate and aligned with the work of the organization. In some instances, the resources delivered were tangible, such as in the dispensing of program funds. More often, however, and consistent with the work of a public organization, the "goods" delivered were intangible- - the provision of information, intelligence, a personal appearance, or a gesture of goodwill:

This country was looking at establishing (an agreement) with developing countries, and this was something we too had worked through in the context of Canada's agreement. So, I was sharing with her details on how this was specified in our agreement so that she could learn (FL female)

(My contact) had been pressing for the Ambassador to speak at (this event). I knew that this was a topic that the Ambassador felt strongly about, so, I agreed to make the arrangements (MID male)

I offered to take a tour of the artist's exhibit. I could not provide the full funding they needed, but I wanted to show support and goodwill for this important work (which was highly illustrative of Canadian values). So this was at least partial delivery of the kind of support they were looking for (MID male) 
5. Coordinating/negotiating The fifth dimension mentioned was that of coordinating and negotiating with the external agent in areas of work interdependencies and shared mandates $(28 \%)$. The functional purpose of this activity was to enable the work of the organization in instances where the work was dependent on the contribution and cooperation of the outside agent.

This dimension was consistent with the task coordinator dimension as identified in the orienting framework (Ancona and Caldwell, 1992) and the coordinate/negotiate dimension in the 15-item typology (Ancona and Caldwell, 1988; see Table 2-3). For the purpose of this research, however, the "coordinate/negotiate" label was reinstated from the 15-item typology, in recognition that the nature of coordination and negotiation in a foreign ministry extended well beyond the technical "task" coordination observed in Ancona and Caldwell's product development teams (where coordination typically involved resolving scheduling conflicts). Rather, the transactions observed in this research focussed on the coordination of the content and substance of events, consultations, or other shared projects:

We were reviewing the agenda to ensure that the topics and speakers reflected the messaging our respective countries wanted to send in this event (FL male)

As implied in the name of this dimension, and as described by Ancona and Caldwell, the coordinator function involved both coordination and negotiation. Although these appear to be separate activities, interviewees in their research, and in this research, tended to discuss them together. Seldom did the coordination of shared projects not involve negotiation and "give and take" over respective roles and responsibilities: This is a very hierarchical society. We were putting together a program for this (co-hosted) 
event, and my contact wanted to name the co-chairs, one from my country and one from his. I said, no, Canada actually needed to have two representatives, one was a provincial representative and one represented the federal government. Canada, therefore, needed to have two names on the program. This idea of shared representation for a single country was incomprehensible to (my contact), since in his country, there was room for only one at the top, and that was it. It took a fair bit of back and forth on this to work out a suitable solution (FL male)

In respect of the give and take inherent in the coordinating function, the coordinating/ negotiating dimension is the only dimension that identifies a two-way exchange across the boundary.

6. Guarding Guarding was mentioned by $24 \%$ of respondents. This dimension was as given in Ancona and Caldwell's (1988) 15-item typology. Guarding activity involved avoiding, delaying, or refusing agents' requests, in instances where the legitimacy of the demands was unknown or where demands were perceived to be misaligned with the work of the organization:

She was from an NGO and came to me for funding. I had to tell her I was not a development officer, so could not support the project, and I referred her to the appropriate agency (FL female)

He wanted the HOM to speak, to represent Canada at this function. I decided that this particular function did not suit Canada's objectives in this region and I had to turn him down (FL male)

This (government contact) had gone ahead with this (process) without our signature to the agreement. He now wanted me to release our share of the funds. I told him this was not in line with the Department's procurement guidelines, and there would be no release of funds without a new agreement (HOM female)

As suggested in the above examples, a guarding activity effectively closes the boundary to exchanges. The guard function is invoked in circumstances where an external agent is making a demand on the boundary spanner and the boundary spanner is unsure of the agent's motives or perceives the demand o be misaligned with the goals of the boundary spanner's own organization. By refusing to grant the demand, the guard function thus 
serves a dual purpose. As described by Ancona and Caldwell (1988, p. 479), the guard function both protects the organization from outside pressure (i.e., prevents an inward flow of influence), and prevents the release of information or other resources demanded by the external agent (i.e., prevents an outward flow). For this reason, the guard function is characterized in Table 12-1 as an activity that closes the boundary to flow in either direction.

7. Scouting The scouting dimension represented the focussed search for information or ideas from outside of the organization, prompted by the immediate demands of the boundary spanner's work (cited in $19 \%$ of episodes). The functional purpose of this activity was to bring into the organization general information needed to enable the workflow. This dimension was distinguished from the intelligence function on the criterion that the information sought was deemed to be non-sensitive and could conceivably be in the public domain. However, typically, the information was not publically documented and thus required contact with the external agent who held the knowledge. Often, scouting involved the pursuit of details around events or files where the boundary spanner and the external agent had mutual responsibilities:

The desk at the European Union holds files for this country. So, I needed to ask him for a summary of recent developments with Country $X$ from their records so I could convey this to Ottawa to inform a decision they were trying to take ( $F L$ female)

I just wanted to collect information on what work he had been doing around this symposium. I had worked with (this academic) before and had had a bad experience with the way he organized things and I was really seeking information around his agenda for the event to reassure myself this would go smoothly (FL female)

Given the non-sensitive nature of the information characteristic to this type of exchange, 
the scout dimension was reserved exclusively for the search for non-privileged information. Collectively, the search function and the intelligence function replace Ancona and Caldwell's (1992) "hybrid" scouting dimension.

8. Representing This dimension (cited in $11 \%$ of episodes) involved efforts to model the organization's values or views to an external agent over the course of the interaction. The functional purpose of this activity was to project an image of the organization that would enhance the legitimacy or reputation of the organization among other players in the organization's environment:

I wanted to be sure in my interaction with this person that I modeled the principles of negotiation and cooperation as accepted by the international community. Part of advocating for democracy and good governance is showing how it's done (HOM male)

In meeting this person for the first time, I was embodying the Canadian point of view, showing my collegiality, and reinforcing by my visit the long-standing cooperative relationship Canada has enjoyed with this country (HOM female)

The representation dimension had no direct counterpart in Ancona and Caldwell's typologies. In their 15-item typology, the idea of projecting the organization's "image" had been subsumed under the "molding" dimension (and later further subsumed under the ambassador dimension). They defined the molding function as "representing the group in a favourable light... in order to secure resources" $(1988$, p. 477$)$. This was a limited and somewhat instrumental interpretation of representation, and was not consistent with the "modeling" aspect of representation characteristic to this sample. It was also not consistent with more accepted definitions of the representation function as developed in the macro-level literature on boundary spanning (Aldrich and Herker, 1975; Adams, 1976; 
Katz and Kahn, 1966; Thompson, 1967). The typology developed for this research, therefore, respects Adams' (1976) distinction between representation as "informationpresenting behaviour", which is designed to convey information on the organization's values to enhance legitimacy in a changing institutional environment, and "influence behaviour" which is contrived to secure immediate outcomes. The representation function was reserved for the former (information-presenting) interpretation. Although, admittedly, projecting a particular image may, over time, enhance the organization's ability to secure resources, the episodes cited for this research did not suggest this motivation. Where narratives did suggest an immediate instrumental purpose, such as to project the organization in a favourable light so as to obtain support, the interaction was coded molding. This conceptualization thus respects the macro-level distinction (Table 21) between the adaptive function of representation (aimed at enhancing legitimacy among institutional players) and control (aimed at exerting influence to directly modify the behaviour of others in the task environment).

9. Intermediary The intermediary function (cited in $11 \%$ of episodes) involved brokering introductions between two or more external agents who had shared interests or complementary resources in the hope that the two agents might begin to work together. Like molding, this activity served to modify the external environment in a way that was conducive to the work of the boundary spanner's organization. Unlike molding, however, the influence exerted on the environment was indirect in that the boundary spanner was brokering a relationship between the two external agents in the hope that they might together work in a direction consistent with the goals of the boundary spanner's 
organization. For example, the boundary spanner might introduce a funder of development projects to an NGO seeking development assistance, thus indirectly enabling aid to developing countries. The funder and the NGO could then work independently in pursuit of objectives that were aligned with DFAIT's interests in areas such as peace, security, or the eradication of poverty:

As part of our public diplomacy effort, we try to develop partners not only to work with us, but partners who can work over the long term without the input or presence of the embassy. This is the work I was trying to do in this meeting, to bring these two partners together. When we do this, we can see projects going forward without our involvement, without our financial support. But together they continue to pursue goals locally that are also Canada's goals (FL female)

The intermediary dimension had no counterpart in Ancona and Caldwell's work with product development teams. It was consistent, however, with an interesting intermediary function cited in early theoretical work by Aldrich and Herker (1975). In this example, they described the case of Navajo health aides who served as intermediaries between physicians and Navajo patients. The aides were observed to "draw the two sides together... by offering a different side to each party involved" (p. 220). In serving as intermediary, the boundary spanner essentially acted as "interpreter" by using his or her expert local knowledge to facilitate relationship development between two external agents. The "interpreter" aspect of the intermediary function as it emerged in this research is reflected in the quote below:

One of the most rewarding things for me is bringing together two parties who I know would never have come together without my involvement. They are just in worlds that are too far removed. But because I understand both of those worlds, I know exactly where each of them is coming from and I can anticipate their reactions to each other. So, I can help them find the right language to get the dialogue going and start things happening (HOM male)

With the exception of Aldrich and Herker's isolated reference to the function, the 
intermediary dimension had not been noted in previous conceptualizations of the boundary construct at either the macro or micro level. Although the similarity to molding is noted here, the intermediary dimension is retained as a separate dimension in the belief that it may represent an emerging boundary function in the contemporary organization, particularly in international settings. For example, in entering new markets, it might be to an organization's advantage to bring together external partners who can create the local infrastructure needed to support the organization's market entry (e.g., brokering alliances between local distributors and retailers to bring the organization's products to the local market). Brokering such external partnerships may represent an innovative approach to modifying the external environment that may not have surfaced thirty years ago when macro conceptualizations of the boundary role were first advanced. It is thus retained as a separate category in the hope of stimulating further research on this interesting emergent function.

\section{Job level differences}

Table 12-5 examines job level differences in the frequency with which the various dimensions were mentioned. The relationship function was the most frequently cited dimension at all job levels, reinforcing the perceived importance of this function in crossboundary interactions. Beyond this, the trend seemed to be for the molding, representational, and intermediary functions to become more prevalent as you moved up

the hierarchy, and the scouting dimension to become less prevalent. For example, $63 \%$ of HOMs described molding efforts vs. only $37 \%$ of officers; $19 \%$ of HOMs described a representational effort vs. $4 \%$ of officers; and $13 \%$ of HOMs mentioned an intermediary 
effort vs. $7 \%$ of officers. Conversely, $33 \%$ of officers reported scouting activities in their episodes, compared to only $6 \%$ of HOMs. These patterns are consistent with expected job level differences in the boundary role, where HOMs, due to their comparatively high rank and visibility may be more engaged in representing the organization, may be approached more frequently for introductions to others ("they come to me'), and may attempt to use their high rank and status to achieve influence over others. Officers, on the other hand, may be engaged in more routine transactions, searching for information as part of their regular reporting responsibilities, or collecting information to do the groundwork in preparation for an event involving the HOM. The complementarity of the officer scouting function and the HOM representation function is illustrated in the following quote from one of the HOMs interviewed:

Really, all of the work on this had been done by our officers prior to our meeting. With this kind of thing, the groundwork has been done, the officers have been back and forth sharing the necessary information with the host government, and the agreement is essentially reached. Both (my external contact's) time and mine are limited, so essentially, what I am doing in this meeting is blessing the project (HOM male)

The proportion of episodes involving the functions of delivery, co-ordination, and guard appeared to be fairly equal across job levels. This suggests some commonalities in the boundary role, irrespective of job level. Boundary spanners in this organization appeared to be equally likely to be engaged in coordinating work shared with outside agents, equally likely to deliver information and other resources requested by outside agents, and equally likely to feel the need to protect the organization from unwanted demands imposed on them at the interface. These apparent similarities will be discussed further in Section 12.3 when examining the nature of demands at the interface. Although 
these three dimensions were shared across job levels, it will be seen that the content of these transactions occasionally differed as a function of job level.

Although job level differences in the nature of the boundary role were suggested by the data, observed patterns should be interpreted with caution. The unit of analysis for exploring the boundary role construct was the episode, not the individual. We are justified, therefore, in making claims only about the episode. We do not know to what extent these episodes were typical of boundary transactions for individuals. It was conceivable that respondents performed many boundary functions in other interactions and in other circumstances. Gauging the importance of the various dimensions of the role to the job in general was the purpose of the questionnaire.

\subsubsection{Enfolding the quantitative data}

Prior to analyzing the quantitative data on the boundary role, it was necessary to reexamine the questionnaire items for correspondence with the emergent categories. It is important in triangulating data that the data converge on the same construct (Yin, 2003). Any original questionnaire item that did not reflect the characteristics of the emergent dimensions was a threat to construct validity, so could not be included in the analysis.

The mapping of the original questionnaire items to the items as used in analysis is summarized in Appendix Table B-1. The procedure for reviewing and, where necessary, reclassifying questionnaire items, was as follows.

First, the guard dimension was assessed against the questionnaire items. There had been only one questionnaire item to access this dimension (item number 11). This item, involving the monitoring of external demands, was consistent with the conceptualization of 
the guard dimension as it emerged in the interview data, so the item was retained for analysis.

Second, the coordinate/negotiate dimension was assessed. Two items had addressed this dimension in the questionnaire (items 1 and 9). These items involved obtaining technical input and negotiating around events, respectively. These, too, were consistent with the conceptualization of the coordinate/negotiate dimension as it emerged in interview data, so these items were also retained for analysis.

Third, the relationship dimension was compared to the questionnaire. This item (number 12, regarding the formation of working relationships and trust) had been constructed for the current study based on interview data given during the pilot. It, therefore, corresponded directly to the interview data and was retained.

Fourth, the intermediary dimension was compared to the questionnaire. This dimension had no counterpart in Ancona and Caldwell, so no quantitative data were available for purposes of corroboration.

Fifth, the researcher compared the scout function to the questionnaire items. There had been three questionnaire items addressing this dimension (items 5,6 , and 7 , reflecting the search for information on other organizations, scanning for emerging developments, and gathering new ideas, respectively). However, all three of the items in the scout subscale were uninterpretable, because they failed to distinguish between whether the information was sensitive, or whether it reflected "general purpose" information. This distinction comprised the central criterion in this research for classifying boundary activities as "intelligence-gathering" vs. "scouting". All three of the questionnaire items on the scout dimension, therefore, were discarded. 
The seventh step was the most complex. It involved reviewing all questionnaire items that had been included under the single "ambassador" dimension. During interviews, this dimension had been deemed too gross to capture the emergent data. It, therefore, needed to be disaggregated to render the questionnaire items comparable to dimensions in the emergent typology.

There had been five items on the questionnaire originally intended to access the ambassador dimension. The first (item 3) was "persuading outsiders that DFAIT performed important activities". This item involved a persuasive effort aimed at modifying the outsider's agenda, so was recoded to the emergent molding dimension.

The second item (item 2) was "gauging external support or opposition". This item was problematic. It had been included by Ancona and Caldwell as an ambassadorial activity since it was viewed as a preparatory step for team lobbying efforts (i.e., determining who was on side and who was not). It was thus considered for possible inclusion in the molding category. It could not be classified as a molding effort, however, since it did not involve an active attempt to persuade (the exercise of outward influence). Instead, the term "gauging" in this item suggested the collection of some kind of information regarding the perspectives of outsiders. It was thus considered also for inclusion in one of the information-seeking dimensions (i.e., scouting or intelligence). Again, however, since it was not clear what kind of information this involved, the item was deemed ambiguous and discarded.

The third item (item 8) involved the acquisition of financial, physical, and human resources from outside agents (in Ancona and Caldwell's research, this involved largely the acquisition of financial resources and materials needed in the product development 
process). There was no counterpart to this item in the emergent typology, so it, too, was discarded.

The fourth item (item 4) was "preventing outsiders from overloading DFAIT with too much information or too many requests". This item was considered for possible inclusion in the guard function, consistent with its classification in Ancona and Caldwell's original 15-item typology. In the context of the interview data, however, this item was judged to be double-barrelled. As described by interviewees, many guarding activities were aimed at protecting the organization from being overloaded with requests. However, in the context of boundary spanning in the international setting, seldom was the boundary spanner overloaded with information. To the contrary, information was often hard to come by. This item was deemed uninterpretable in light of these distinctions in the emergent data, so was also discarded.

Finally, the fifth item in the ambassador subscale had been item 10, " promoting DFAIT/ Canada's visibility or image". This item aligned closely with the representation dimension emerging in this research. It was coded to the representation dimension.

In summary, the questionnaire review procedure left six of the original 12 items for analysis, enabling triangulation on five of the nine emergent dimensions (the relationship, molding, coordinate/negotiate, guard, and representation functions). Table 12-6 presents the analysis of the questionnaire data on these five dimensions. 


\begin{tabular}{|l|c|c|c|c|c|}
\hline Table 12-6 Quantitative support for selected dimensions of the boundary role \\
\hline & Head of mission & Mid-manager & Officer & Total \\
\hline Functional activity & (\% rating the dimension as moderately to highly important in the job) \\
\hline Relationship building & 100 & 100 & 100 & 100 \\
\hline Molding & 89 & 62 & 57 & 71 \\
\hline Intelligence gathering & - & - & - & - \\
\hline Delivery & - & - & - & - \\
\hline Coordinating/ negotiating & 81 & 75 & 96 & 85 \\
\hline Guarding & 79 & 69 & 68 & 73 \\
\hline Scouting & - & - & - & - \\
\hline Representation & 94 & 76 & 86 & 87 \\
\hline Intermediary & - & - & - & - \\
\hline
\end{tabular}

Unfortunately, lack of quantitative data for four of the nine dimensions precluded assessment of the typology as a whole. However, the available data suggest that five of the dimensions abstracted from the interview data were perceived to be important to the job in general, and were not idiosyncrasies of the episodes targeted for discussion. In particular, the importance of establishing relationships in boundary interactions is strongly supported, with $100 \%$ of respondents identifying relationships as moderately or highly important to the job (indeed, over $90 \%$ of respondents at all job levels rated relationships as highly important; not shown).

The quantitative data also provided general support for the job level differences suggested in the qualitative data (Table 12-5). Consistent with the qualitative findings, the representation and molding functions were more prevalent at the HOM level. Also consistent with the qualitative findings, the guard function was reported in roughly equal proportions across job levels. The coordination-negotiation function also comprised an 
important part of the job at all levels, although the quantitative data suggested it was rated particularly highly by officers (rated as important by $96 \%$ of officers, compared to 75 to $80 \%$ of managers). Qualitative data had suggested that the coordination-negotiation function emerged only slightly more frequently in the accounts of officers than in the accounts of managers (cited in 30\% of officer episodes vs. 25\% of HOMs'). Again, however, the methodology for this research is not suited to statistically testing the significance of differences, including differences between qualitative and quantitative findings. Using the criterion of substantive significance, we can claim only that the quantitative data support the qualitative data in identifying the coordination-negotiation function as important to the boundary role at all job levels. Further, the quantitative data identify the same general direction of job level differences as the qualitative data, with the coordination-negotiation function being more prevalent at the officer level.

The quantitative findings thus provide preliminary corroboration of the dimensions of the boundary role identified in the emergent typology. Further testing of the themes suggested in the typology awaits future research with a more complete set of measures. In addition, the quantitative measures used in this research warrant testing and refinement, having been based on the few existing measures of the boundary role available at the time this study was conducted. Ancona and Caldwell did not identify the scale construction techniques used to derive their items, so it is not known to what extent these items actually tap the constructs they purport to measure.

\subsubsection{Patterns observed within boundary episodes}

The most striking aspect of the MNE boundary role emerging from this research 
was the importance of relationships at the interface. Many of the quotes cited earlier indicated that, although relationships were valuable in their own right, they also were instrumental in achieving other objectives ("if you wanted to get, you had to give"). This suggested that the relationship function might assume prominence in settings where the boundary spanner is dependent on the resources held by the external contact for the attainment of other objectives. This interpretation is consistent with social network theory (Brass. 1984; Tichy et al., 1979), which posits that affect is not, of itself, an organizationally valued resource, but is valued for its instrumentality in gaining access to other resources (e.g., as the basis for the exchange of information or goods and services associated with the workflow). Previous applications of social network theory to the study of boundary spanners has tended to focus on the mediating role of affect in acquiring resources held by the internal organizational network (Brass, 1984; Manev and Stevenson, 2001a; Tushman and colleagues, 1983; 1981a; 1981b). However, because the boundary spanner's network comprises members external to the organization, it follows that affect similarly might be used at the interface to mediate access to resources held by outside agents.

The researcher, therefore, undertook further exploration of the data to determine the contextual conditions under which the relationship function was most likely to emerge. First, the researcher explored whether the frequency with which the relationship function was cited might be related to the type of contact with whom the individual was dealing. To explore this, the relationship dimension was mapped to the target person identified in the episode. Other dimensions were also included to allow for comparison. Data are shown in Table 12-7. 


\begin{tabular}{|c|c|c|c|c|c|}
\hline & $\begin{array}{c}\text { Host } \\
\text { government } \\
(\mathbf{N}=37)\end{array}$ & $\begin{array}{c}\text { Academic } \\
(N=12)\end{array}$ & $\begin{array}{l}\text { NGO } \\
(N=9)\end{array}$ & $\begin{array}{c}\text { Local } \\
\text { private } \\
\text { sector } \\
(N=6)\end{array}$ & $\begin{array}{c}\text { Multilateral } \\
\text { organizatio } \\
n \\
(N=4)\end{array}$ \\
\hline Functional activity & \multicolumn{5}{|c|}{ (\% of cases in which the dimension was described) } \\
\hline Relationship building & 62 & 58 & 44 & 83 & 25 \\
\hline Intelligence gathering & 38 & 42 & 11 & 50 & 25 \\
\hline Molding & 65 & 25 & 56 & 33 & 25 \\
\hline Delivery & 38 & 25 & 33 & 17 & 75 \\
\hline Coordinating/negotiating & 32 & 42 & - & - & 25 \\
\hline Guarding & 16 & 25 & 44 & 17 & - \\
\hline Scouting & 14 & 25 & 33 & 17 & 25 \\
\hline
\end{tabular}

The data suggest that the relationship function was cited frequently in dealings with all contacts. However, the data also suggest that the relationship function may have been particularly important in high-dependency situations. For example, the relationship function was mentioned in over $80 \%$ of interactions involving a private sector contact. Interactions with the private sector often involved settings where the private sector was not dependent on government support, but was perceived by the boundary spanner as an important ally in achieving government objectives:

I was trying hard to establish a relationship with (this CEO). Other countries are developing relationships with the private sector in order to garner insights into the barriers and facilitators

${ }^{9} \mathrm{~N}$ 's appearing in the column headings indicate the number of episodes involving contacts from the sector cited. Percentages given in the table indicate the proportion of these episodes in which the various dimensions were mentioned (e.g., 37 episodes involved dealings with a member of the host government; of these, $62 \%$ involved the relationship dimension). In some instances, therefore, the percentages expressed in the table represent a very small number of actual episodes. In spite of this limitation, the percentages did suggest patterns consistent with the hypothesis that the relationship function is invoked in high-dependency settings. The data are presented to illustrate the chain of evidence for this claim. Confirmation of this pattern awaits future research with larger samples. Note that the intermediary and representation functions yielded such small cell sizes that they could not be tabulated. 
around trade in this region. I thought we too needed to develop better connections and begin to collect those data in a systematic way so that we were not scurrying or saying "I don't know" whenever $H Q$ asked us questions around this (FL male)

Similarly, the relationship function was also prevalent in interactions involving the host government. Diplomatic work is heavily reliant on access to, and reciprocity from, the host government on policy issues, often on short notice. Establishing key contacts within the host government is essential to ensure they are "there for you" to deliver resources when needed:

We were definitely of opposing views on this issue, but we navigated through it with a smile. We knew we would be working together frequently over the next few months, and neither of us wanted an enemy as a partner ( $F L$ female)

In contrast, the relationship function was seldom cited in interactions involving multilateral organizations (e.g., NATO, EU). In these settings, cooperation is essentially institutionalized and information and other resources flow readily across organizational boundaries. Further, were it the case that one organizational contact were unable to provide the resource the boundary spanner needed, it was likely another contact could be found (i.e., there were "transaction alternatives; Thompson, 1967; Brass, 1984). Thus, the need for longer-term relationship development may not have been necessary. The number of episodes involving multilateral organizations was small. However, the interpretation that relationship development was not a key feature of these interactions was supported by the prevalence of the delivery function in these episodes (three of the four episodes involved simply "delivering the goods"; only one involved the relationship function).

Data on NGO interactions also suggested an association between the relationship function and the level of dependency on the external contact. In this setting, the direction 
of the dependency is reversed: typically it is the NGO who is seeking financial or other support from the Government of Canada. Accordingly, the boundary spanner is less likely in these interactions to focus on the relationship (cited in $44 \%$ of NGO episodes), and more likely to focus on influencing the contact's behaviour (molding; 56\%), or protecting the organization from the contact's demands (guarding; 44\%).

The second approach to examining the contextual conditions associated with the relationship function was to observe its connection with other boundary functions. If the relationship was the enabler of other functional activities, what functions did it enable? The first step in answering this question was to explore the data to identify episodes in which more than one function was mentioned. Table 12-8 shows these results. The data provide strong support for the multidimensionality of the boundary role. Only $10 \%$ of episodes entailed a single functional activity. Nearly $40 \%$ entailed two, and over $50 \%$ entailed three or more.

\begin{tabular}{|l|c|c|c|c|c|}
\hline \multicolumn{1}{|l|}{ Table 12-8 Evidence of the multidimensionality of the boundary role } \\
\hline & $\begin{array}{c}\text { Head of mission } \\
(\mathbf{N = 3 2})\end{array}$ & $\begin{array}{c}\text { Mid-manager } \\
(\mathbf{N = 2 0})\end{array}$ & $\begin{array}{c}\text { Officer } \\
(\mathbf{N = 2 7})\end{array}$ & $\begin{array}{c}\text { Total } \\
(\mathbf{N}=79)\end{array}$ \\
\hline $\begin{array}{l}\text { Number of dimensions observed per } \\
\text { boundary episode }\end{array}$ & & \multicolumn{2}{c|}{ (\% cases) } & 10 \\
\hline One & 9 & 5 & 15 & 38 \\
\hline Two & 38 & 40 & 37 & 29 \\
\hline Three & 28 & 35 & 26 & 17 \\
\hline Four & 22 & 10 & 15 & 6 \\
\hline Five or more & 3 & 10 & 7 & 100 \\
\hline Total & 100 & 100 & 100 & 10 \\
\hline
\end{tabular}

Data were then sorted to select all episodes involving the relationship function. For 
these, a list was generated of other functions cited within the same episode. This procedure revealed the most frequent pairings with the relationship function. Results appear in Table $12-9$.

Table 12-9 Pairings of boundary dimensions with the relationship function

\begin{tabular}{|l|c|c|c|c|c|}
\hline & $\begin{array}{c}\text { Head of mission } \\
(\mathbf{N}=\mathbf{2 0})\end{array}$ & $\begin{array}{c}\text { Mid-manager } \\
(\mathbf{N = 1 4 )}\end{array}$ & \multicolumn{2}{|c|}{$\begin{array}{c}\text { Officer } \\
(\mathbf{N = 1 4})\end{array}$} & $\begin{array}{c}\text { Total } \\
\text { (N=48) }\end{array}$ \\
\hline $\begin{array}{l}\text { Dimensions mentioned in conjunction } \\
\text { with relationship function }\end{array}$ & \multicolumn{2}{|c|}{ (\% of cases in which the dimension was described) } \\
\hline Intelligence gathering & 40 & 43 & 50 & 44 \\
\hline Molding & 55 & 36 & 21 & 40 \\
\hline Delivery & 35 & 29 & 57 & 40 \\
\hline Coordinating/negotiating & 25 & 21 & 29 & 25 \\
\hline Scouting & 10 & 21 & 29 & 19 \\
\hline Guarding & 10 & 21 & 21 & 17 \\
\hline Representation & 20 & 14 & 7 & 15 \\
\hline Intermediary & 15 & 14 & 7 & 13 \\
\hline
\end{tabular}

The data indicate that the three most frequent pairings of the relationship function were with the intelligence function, the molding function, and the delivery function. These findings provide evidence for the claim that the relationship function is of instrumental value in attaining other objectives, and may be invoked in high-dependency settings. Intelligence, by definition, entails information that is not in the public domain. This implies it is held by few individuals, and the individuals who hold it mediate access to the valued resource. Comments around the intelligence function suggested that contacts were unlikely to be forthcoming with sensitive or privileged information in the absence of a basis of trust. Hence, boundary spanners seeking intelligence were likely to focus first on relationship cultivation or maintenance, often beginning the interaction with friendly 
exchanges:

I took him to lunch. Diplomats face criticism for their hospitality budgets. But food is a powerful tool in this society. When you invite them to lunch, it says I am putting a special emphasis on this relationship. They know the meeting will be longer, the conversation deeper, and the relationship to the longer-term benefit of both. Then you can move forward to the sensitive issues you really want to discuss (MID male)

Similarly, boundary spanners seeking to sway the contact's behaviour or point of view (molding) were in positions of dependency. Molding involved situations where the contact's point of view was unknown or misaligned with the work of the organization. However, the boundary spanner was in need of the contact's cooperation or support to attain his or her objectives. In these instances, boundary spanners also tended to invoke the relationship in the hope of obtaining movement on the issue:

I couldn't go plunging in making demands for support. First, I reminded him of the long relationship our countries had enjoyed together, and turned it into a more personal appeal for a similar working relationship at the one-on-one level (HOM male)

The relationship function was also likely to be observed in connection with the delivery function. The delivery function entailed opening the boundary to the outward flow of resources in instances where the agent's demands were already aligned with the work of the system. Unlike the other two functions, delivery did not always entail high-dependency situations (as in the instance of the boundary spanner delivering a gesture of goodwill to a local artist). However, examination of the records of the boundary episodes revealed that, where the relationship function was paired with delivery, it was typically in anticipation of future high-dependency exchanges. Sometimes, the "delivery" itself was a deliberate "deposit in the relationship bank", as in the following example of the delivery of 
information:

I really needed this individual to speak at the conference, but I also knew that his time was extremely limited. So, the first thing I did was to show up for the meeting with information that he had requested on an unrelated issue (delivery). So, I could start the meeting by saying, "oh, here, I tracked down the information you asked for last week". This showed him I had something to give to him (relationship) before I started asking him to give something to me (molding; FL female)

Sometimes the boundary spanner used the occasion of a delivery to build the relationship in anticipation of future transactions:

I had just arrived at post. My official business was to deliver the demarche (delivery of endorsement on an issue). This took all of five minutes. Then I used the opportunity to spend an hour with him, to get to know him better, as a basis for future work we would be doing together (relationship; HOM male)

Finally, the dimensions least likely to pair with the relationship function also provided evidence of a positive association between the relationship function and high-dependency settings. All five functions involved settings in which either the contact's position was already aligned with the work of the organization (e.g., coordinating/ negotiating in areas of shared mandates; serving as an intermediary between two potential partners with shared interests), or the contact was not in control of a valued resource or was impeding the work of the organization (e.g., scouting for general purpose information; representation; and the guard functions).

\subsection{Demands at the interface}

The boundary episodes described in the previous section also allowed examination of the types of demands placed on the boundary spanner at the interface (Research Question 3c). After having described their objectives in interacting with their external 
contact, respondents were asked what they thought the contact expected of them over the course of the interaction. Since the data were as reported by the respondent, the question taps only the respondent's perception of contact expectations. However, the data do provide some indication of the challenges, or conversely, rewards, encountered by boundary spanners at the interface. Responses are given in Table 12-10.

\begin{tabular}{|c|c|c|c|c|c|}
\hline \multirow[t]{2}{*}{$\begin{array}{l}\text { What do you think your } \\
\text { contact expected of you? }\end{array}$} & \multirow[t]{2}{*}{ Description/Examples } & $\begin{array}{l}\text { Head of } \\
\text { mission } \\
(\mathrm{N}=30)\end{array}$ & $\begin{array}{c}\text { Mid- } \\
\text { manager } \\
(\mathbf{N}=\mathbf{2 0})\end{array}$ & $\begin{array}{l}\text { Officer } \\
(\mathbf{N}=27)\end{array}$ & $\begin{array}{c}\text { Total } \\
(\mathbf{N}=77)\end{array}$ \\
\hline & & \multicolumn{4}{|c|}{$\begin{array}{l}\text { (\% in each job category mentioning the } \\
\text { demand) }\end{array}$} \\
\hline $\begin{array}{l}\text { Wanted me to deliver } \\
\text { something }\end{array}$ & $\begin{array}{l}\text { Contact wanted to obtain something } \\
\text { of value from the respondent (a } \\
\text { service, a financial, human or } \\
\text { physical resource; information, } \\
\text { intelligence }\end{array}$ & 47 & 55 & 67 & 56 \\
\hline $\begin{array}{l}\text { Wanted me to work on the } \\
\text { task at hand }\end{array}$ & $\begin{array}{l}\text { Contact wanted respondent to work } \\
\text { with him/her to complete the task at } \\
\text { hand in an area of shared mandate } \\
\text { (e.g., on a joint project, a negotiation } \\
\text { process) }\end{array}$ & 30 & 30 & 22 & 27 \\
\hline $\begin{array}{l}\text { Wanted to persuade me to } \\
\text { change my agenda or } \\
\text { point of view }\end{array}$ & $\begin{array}{l}\text { Contact wanted to change my } \\
\text { perspective or agenda ("wanted me to } \\
\text { see it his way", or "do it her way") }\end{array}$ & 30 & 10 & 33 & 26 \\
\hline $\begin{array}{l}\text { Wanted to develop the } \\
\text { relationship }\end{array}$ & $\begin{array}{l}\text { Contact wanted to establish, nurture, } \\
\text { or maintain the relationship (e.g., } \\
\text { "she just wanted to make a deposit in } \\
\text { the relationship bank", "he owed me } \\
\text { one") }\end{array}$ & 20 & 35 & 19 & 23 \\
\hline $\begin{array}{l}\text { Wanted me to hear his or } \\
\text { her views }\end{array}$ & $\begin{array}{l}\text { Contact appeared to merely want to } \\
\text { advance his views, be understood } \\
\text { (e.g., "it is flattering to be asked for } \\
\text { an opinion"; "academics just like to } \\
\text { share their views") }\end{array}$ & 7 & 40 & 22 & 21 \\
\hline $\begin{array}{l}\text { Wanted me to broker an } \\
\text { introduction }\end{array}$ & $\begin{array}{l}\text { Contact wanted an introduction to a } \\
\text { third party who was external to both } \\
\text { the boundary spanner's and the } \\
\text { contact's organizations (e.g., "he } \\
\text { wanted to be introduced to a } \\
\text { Canadian business contact" }\end{array}$ & 10 & 15 & 4 & 9 \\
\hline
\end{tabular}


The data suggest that boundary spanners encounter both rewards and challenges in their interface dealings. Conceivably, instances where the contact is perceived to be making demands on the boundary spanner are instances in which the boundary spanner might encounter challenges. Over half of respondents (56\%) perceived that their contact wanted something of them: the delivery of a service, or the provision of information or intelligence (which the boundary spanner may or may not have been able to deliver). One quarter of respondents $(26 \%)$ indicated that they believed their contact was trying to influence them, trying to change their point of view or agenda. From the boundary spanner's perspective, this was akin to being on the "receiving end" of a molding effort, whereby the contact was trying to exert outward influence to modify his or her external environment. Sometimes these efforts were very subtle, and revealed the sensitivity required of boundary spanners if they were to accurately "read" their contacts' motives:

I was trying to persuade him that his minister should attend our conference. And he was asking me a rather revealing series of questions.... what would be the role of his minister in the conference, when would he appear, what topics would be addressed at the event, and with whom would he sit. So I read this as saying, you are more likely to have success in getting us to attend if our minister can play a prominent role and can make comments to advance his current agenda on the issue (MID male)

However, the data also indicated that demands at the interface may be balanced by interactions that are rewarding, if not flattering, to the boundary spanner. Roughly one quarter perceived the contact to be trying to develop the relationship. A nearly equal proportion indicated that the contact just wanted the boundary spanner to hear his or her views:

Everybody likes to be thought of as an expert, so if you call and say, I have heard you have 
interesting insights on such and such, there is an ego piece there I think. Often people will throw in an aside, like "I also consult to the American embassy on this sort of thing". So you know they are to a degree proud of being the contact of a diplomat (FL male)

Observed job level differences in interface demands are useful in refining our interpretation of differences in the frequency of boundary dimensions advanced in Section 12.2.2 (Table 12-5). One of the patterns observed in Section Table 12-5 was that there were few job level differences in the prevalence of the delivery function in the episodes discussed. Table 12-10, however, suggests that contact demands for delivery may have been somewhat more frequently encountered by officers than by management levels. Sixty-seven percent of officers reported requests for delivery (compared to roughly half of the those in management positions). Further analysis of the nature of delivery requests (not shown) indicated that the content of delivery requests might also have been more challenging for officers: $44 \%$ of the delivery requests made of officers involved requests for the provision of funding, time, facilities or other resources, compared to $36 \%$ among HOMs. Conversely, 57\% of HOMs' delivery requests involved requests for support, goodwill, personal appearances, or the opportunity to be seen to be associated with Canada. Job level differences in the nature of delivery demands may reflect not only differences in the rank and the status of officers vs. HOMs but also differences in the profile of the contacts with whom they deal. The potential for contacts to make funding demands of officers is consistent with their frequent dealings with NGOs (Section 12.2.1; Table 12-3), whereas requests for personal appearances, support, or goodwill are consistent with HOMs' frequent dealings with the host government. In dealing with the host government, contact demands might be expected to be more politically motivated or of a more official nature: 
Canada is viewed as a model of integration in the area of immigration and this country has had many challenges around illegal aliens. I think he wanted to work with me on this issue to be seen to be associated with a leader (HOM female)

Table 12-10 also suggests that mid-managers may have encountered interface demands that were somewhat less challenging and perhaps more rewarding than those encountered by boundary spanners at other job levels. Thirty-five percent of mid-managers sensed that their contact wanted to develop the relationship (compared with roughly $20 \%$ of other job categories). Further, $40 \%$ of mid-managers perceived that their contact merely wanted to share his or her perspective on an issue (compared to $20 \%$ or fewer of other job categories); and only $10 \%$ perceived that their contact was trying to persuade them to change their perspective (compared to $30 \%$ or more in other job categories). The unique profile of the mid-manager category again likely stems from the unique nature of their work. As noted in the profile of external contacts (Table 12-3), program management responsibilities frequently brought mid-managers into contact with academics, Canadian industry, and the arts and culture community. Members of these communities would not be expected to make serious demands of the boundary spanner, other than to voice their expert opinions or offer to showcase their works at upcoming events.

As was the case with the dimensions of the boundary role itself, job level differences in interface demands should be interpreted with caution. The data reflect patterns evident in the episodes chosen for discussion, but the representativeness of these demands in terms of the job in general is unknown.

\subsection{Reconciliation strategies}


The last aspect of the interface experience examined in this chapter is the boundary spanner's strategies for reconciling differences in perspective that might arise over the course of transactions (Research Question 4). The interview script had been designed to deliver this series of questions only to those respondents whose primary boundary transaction involved a difference in perspective. The availability of data for analysis, therefore, was based on the "luck of the draw". However, as interviews progressed, so few episodes appeared to involve a difference in opinion that the researcher made an attempt to prompt for another example for discussion. The question was thus approached in two ways.

First, where a difference in perspective was apparent within the target episode, reconciliation strategies were coded directly from the episode. Thirty of the 74 boundary episodes involved a difference in perspective, so these were retained for analysis. Where there appeared to be no difference in perspective, respondents were prompted to select another example for discussion. Ten respondents identified another recent episode (i.e., with another external contact) for discussion. The remaining respondents (representing 44 individuals or roughly half of the sample) were unable to recall a recent instance in which they had attempted to resolve a difference in opinion. The fact that half of the boundary spanners interviewed could not recall a recent difference of opinion was an interesting observation of itself. The finding may have reflected the reality of political work abroad (i.e., were it the case that diplomats seldom encountered differences of opinion!) Conversely, it may have reflected a dynamic of the interview setting itself, including the difficulty inherent in recalling such an episode "top of mind", respondent reluctance to discuss an uncomfortable experience, or simple fatigue resulting from having just described 
at length another boundary interaction. Such competing explanations make it difficult to speculate in the absence of followup questions.

The final number of episodes available for analysis was $40,75 \%$ from the target episode and $25 \%$ from another example. The emergent strategies are described in Exhibit12-1, and the frequencies of each strategy by job level are given in Table 12-12. Like boundary dimensions, multiple strategies were coded for each respondent, since typically, strategies were used in combination with one another over the course of an interaction.

Due to the smaller subsample screened into this question, readers are reminded that some of the percentages in the Table 12-12 reflect a small number of actual cases. However, since the objective of exploratory research is to identify and describe, not to obtain statistical representation of a broader population, the data were believed to be adequate for preliminary exploration of the range of reconciliation of strategies employed at the interface. 


\begin{tabular}{|c|c|c|}
\hline Strategy & Description & Examples \\
\hline Probe, listen and learn & $\begin{array}{l}\text { Effort to learn more about the external contact's motivation or position, either } \\
\text { active and direct, as in questioning, or passive, as in "active listening". Often } \\
\text { a search for common ground or where contact is "hard" or "soft" on an issue }\end{array}$ & $\begin{array}{l}\text { Direct questioning, circling the issue (e.g., " } 20 \text { questions"), asking for } \\
\text { clarification }\end{array}$ \\
\hline Persuade & $\begin{array}{l}\text { Effort to change the external contact's point of view. May or may not be } \\
\text { accompanied by explanation }\end{array}$ & $\begin{array}{l}\text { Acknowledge contact's position, offer a "history lesson", point out } \\
\text { inconsistencies in their position }\end{array}$ \\
\hline Explain & $\begin{array}{l}\text { Effort to provide explanation of own situation or that of the organization. } \\
\text { May or may not be associated with persuasion. Often an effort to preserve } \\
\text { relationship following a guard transaction }\end{array}$ & $\begin{array}{l}\text { A description of the organization's mandate or program objectives, a } \\
\text { description of a recent change in policy, an account of why a decision has } \\
\text { been delayed }\end{array}$ \\
\hline Reframe & $\begin{array}{l}\text { Effort to reposition the issue so as to make it more palatable to the external } \\
\text { contact }\end{array}$ & $\begin{array}{l}\text { Couch issue in perspective of contact's organization ("I know this would } \\
\text { be aligned with your country's current efforts to...."), offer an approach } \\
\text { that allows contact to "save face" }\end{array}$ \\
\hline $\begin{array}{l}\text { Invokelappeal to the } \\
\text { relationship }\end{array}$ & $\begin{array}{l}\text { Effort to call on the relationship to achieve the objectives at hand, or to use the } \\
\text { opportunity of the disagreement to deepen the relationship }\end{array}$ & $\begin{array}{l}\text { Stress how much the contact is needed on the issue ("I'd rather have you } \\
\text { work on this than someone else"), remind contact of previous "deposits } \\
\text { in the relationship bank", give contact something of value in achieving } \\
\text { his or her own work objectives ( "here, I brought the information you } \\
\text { asked for"), ask for contact's expert advice ("I'm in a bind here, you } \\
\text { know the issue, can you see a suitable solution") }\end{array}$ \\
\hline Surface the conflict & $\begin{array}{l}\text { Effort to bring the point of departure into the open for examination and } \\
\text { discussion. Aimed at moving the discussion forward or breaking an impasse. } \\
\text { May also precede an agree to disagree or retreat move }\end{array}$ & $\begin{array}{l}\text { Acknowledge the "elephant in the corner", "come clean" that there is an } \\
\text { issue at hand }\end{array}$ \\
\hline Assert & $\begin{array}{l}\text { The use of polite persistence and/or direct and relatively forceful language to } \\
\text { send the message that there is no room for negotiation on an issue }\end{array}$ & $\begin{array}{l}\text { "Dogged politeness", direct assertion that a request is unacceptable, not } \\
\text { aligned with the organization's values and ethics, "set the game rules" for } \\
\text { future interaction }\end{array}$ \\
\hline Agree to disagree & $\begin{array}{l}\text { Effort to "set aside" a point of departure to move the discussion forward or to } \\
\text { preserve the relationship after a fallout. }\end{array}$ & $\begin{array}{l}\text { Normally comprises overt statements made to contact ("I guess we have } \\
\text { to just disagree on this one") }\end{array}$ \\
\hline Retreat and regroup & $\begin{array}{l}\text { Effort to terminate the transaction either to buy time to reconsider strategy or } \\
\text { to return to the organization for further direction or approval }\end{array}$ & $\begin{array}{l}\text { "I'll get back to you"; "I'm not authorized to release that information, let } \\
\text { me check"; "Can you bring that up again next week?" }\end{array}$ \\
\hline
\end{tabular}




\begin{tabular}{|l|c|c|c|c|c|}
\hline Table 12-12 Reconciliation strategies & $\begin{array}{c}\text { Head of } \\
\text { mission } \\
(\mathbf{N}=\mathbf{1 7})\end{array}$ & $\begin{array}{c}\text { Mid- } \\
\text { manager } \\
(\mathbf{N = 1 0})\end{array}$ & $\begin{array}{c}\text { Officer } \\
(\mathbf{N = 1 3})\end{array}$ & $\begin{array}{c}\text { Total } \\
\text { (N=40) }\end{array}$ \\
\hline Strategy & (\% of cases in which the strategy was described) \\
\hline Explain & 47 & 60 & 69 & 57 \\
\hline Assert & 47 & 60 & 54 & 53 \\
\hline Probe, listen and learn & 41 & 50 & 46 & 45 \\
\hline Persuade & 47 & 50 & 31 & 43 \\
\hline Invoke/appeal to the relationship & 41 & 20 & 8 & 25 \\
\hline Reframe & 29 & 20 & 8 & 20 \\
\hline Agree to disagree & 24 & 10 & 8 & 15 \\
\hline Surface the conflict & 12 & 20 & 15 & 15 \\
\hline Retreat and regroup & 18 & - & 15 & 13 \\
\hline
\end{tabular}

The most frequently employed strategy was to explain to the contact

DFAIT's/Canada's perspective on the issue of departure (cited by $57 \%$ of respondents).

This often took the form of accounting for the rationale behind a particular position or decision, or may have involved simply explaining policy or program guidelines.

The second most frequently employed strategy (53\%) was to assert one's position to indicate to the external contact that there was no room for negotiation on a given issue.

Where assertion was used, it was almost always in response to requests for funding or where requests were perceived to be inappropriate or misaligned with Canadian values (i.e., an assertion strategy was associated with the guard function):

This request was contrary to our funding guidelines. So, finally, I had to give him an ultimatum- here are three options, and that's all I have to offer. And he chose one of these options, a bit under pressure, but I had no choice but to be direct on this one (FL female)

Respondents also relied on "active listening": $45 \%$ said an important step in 
reconciling differences was to "probe, listen, and learn". This was the third most frequently mentioned reconciliation strategy. Many responses suggested that careful listening and frequent "perception checking" were motivated by cultural considerations:

When you are dealing with civil society here, it is not always clear where they are coming from. So, with these members of society, I ask very open ended, very general questions, give them a chance to explain who they are or what they want before I will reveal where I am coming from (MID male)

You must be very clear on the words. If you do not understand a word, you must stop and ask, because your understanding of the language can make or break the deal. Without the language, you are always watching the movie in black and white (HOM male)

Persuasion was also a rather common approach to reconciling differences (cited by $43 \%$ of respondents), consistent with the prevalence of the molding function in the boundary role.

The importance of relationships also surfaced in reconciliation strategies, with $25 \%$ of the sample indicating they directly "appealed to the relationship" to move past impasses. A nearly equal proportion (20\%) indicated that they made efforts to reframe their issues to make them more palatable to the external agent, often in effort to allow their contact to save face. A somewhat smaller proportion (15\%) used the strategy of "agreeing to disagree". Often these three strategies occurred in combination, generally reflecting an effort to preserve the relationship in the face of potential conflict:

(In this country) you must always, always allow people to save face. Even if you are vehemently opposed to their perspective, you must express it in a way that they come out looking good. Because if you take away somebody's face, you have lost your relationship. He will become your implacable enemy, he will defeat anything you are working toward, because you have done what is the most unpardonable thing. You will win the argument and lose the war (HOM male)

That personal relationship you have developed is the foundation for all of your interactions. So, you use that relationship when you see a conflict coming. If you realize that there is not going to be a (mutually beneficial) outcome, that the powers-that-be must agree to disagree, then you too must agree to disagree. However, you both understand that you and he will still be the best of friends 
(HOM male)

Job level differences in strategies were very apparent. The tendency to persuade, reframe, and appeal to the relationship increased as you moved up the hierarchy, and the tendency to explain decreased. This pattern aligns with job level differences in the dimensions of the boundary role (Table 12-5), where HOMs were observed to be more engaged than others in efforts to persuade (molding), consistent with their high rank and perceived legitimacy as representatives of their organizations. Conversely, officers, lacking such rank and legitimacy, might be expected to be in less of a power position in the eyes of their external contacts. They also might be expected to be in less of a power position within their own organizations, and may perceive they have less decision latitude at the interface. Officers thus may rely on less direct strategies to reconcile differences, such as explaining their organization's point of view on an issue.

On the other hand, job level findings also suggest that rank may have its limits as a source of influence when one is dealing with someone who is not a member of one's own organization. In addition to their tendency to use persuasion strategies to reconcile differences, HOMs were also very likely to invoke the relationship or reframe their arguments to allow their contacts to "save face". The observation that HOMs used both persuasion and relationship-based strategies to reconcile differences is reminiscent of the observed pairings of boundary dimensions identified in Table 12-9, where the relationship function was noted to frequently occur in tandem with molding efforts. Like the data on the pairing of boundary dimensions, the data on reconciliation strategies suggest that, in the absence of hierarchical authority, the relationship function may be invoked to achieve 
influence at the boundary.

Again, job level differences evident in these episodes are suggestive only, particularly in light of the small number of cases available for analysis. Further exploration of the boundary role using the individual as the unit of analysis is required to confirm these patterns.

\subsection{Summary}

This chapter has explored the interface experience of boundary spanners in this MNE setting. Interest in the interface experience was prompted by the observation that boundary spanners were "dual citizens", defined by their membership in both their own organizational systems and the systems of their external constituents. Effectiveness in the boundary role, therefore, would be determined at least partly by the incumbent's ability to effectively engage external constituents in the pursuit of organizational objectives. Of interest was the nature and purpose of these boundary interactions in the special case of the MNE, and the implications of interface factors for individual effectiveness in the expatriate boundary role.

The data presented in this chapter provided a preliminary exploration of both of these issues. First, the data yielded a typology of the boundary spanning role. This typology describes the dimensions of the boundary spanning role in the MNE (Research Question 1), and yields the expanded conceptual model of the boundary construct that will be discussed in Chapter 16. Second, the data explored the conditions believed to be associated with effectiveness at the interface. This yielded a description of the ways in which the boundary spanner comes to know what local constituents expect of him or her in the boundary role 
(role cues in the external environment; Research Question 3) and a description of the strategies the boundary spanner uses to reconcile local expectations with the expectations of the home organization (reconciliation strategies; Research Question 4). These data are mapped to the model of the conditions for effectiveness in the boundary role (Chapter 16), and are discussed in turn below.

\subsubsection{Dimensions of the boundary role construct}

The boundary role typology emerging from this research identified a complex, multidimensional construct, with clear connections between the boundary transactions of individuals and the productive work of the organization. The typology suggests that previous conceptualizations of the boundary role- - those focusing on intra-organizational boundaries (Ancona and Caldwell, 1988; 1992; Thomas, 1994) and the team as the level of analysis (Ancona and Caldwell, 1988; 1992) - - may have limited applicability to the boundary spanning role at the level of the individual, and particularly in the MNE setting. Overall, Ancona and Caldwell's (1992) four-dimension typology proved too gross to capture the nuances of one-on-one boundary interactions. It also was not able to capture the relationships between these interactions and contingencies at the interface. The emergent typology suggests that conceptualizations of the individual boundary role in the MNE setting (e.g., Thomas, 1994) might be enhanced through clearer articulation of the linkages or "bonds" (Simon, 1973) between individual boundary behaviours and environmental contingencies.

Unlike previous boundary spanning typologies, this typology suggested that relationships were the cornerstone of boundary spanning at the individual level. 
Relationships were perceived to be the precursors to, and enablers of, future transactions. This finding was consistent with social network theory in suggesting that exchanges of affect (i.e., friendship or liking) are instrumental in obtaining from various role set members the information and other resources needed to support the workflow (Brass, 1984; Tichy et al., 1979). However, the finding extends the social network perspective by serving as a reminder that, in the special case of the boundary spanner, both the role set and the workflow extend beyond the organizational boundary; hence, the exchange of affect may play a similar enabling role in cross-boundary transactions. Further, affect may play an even greater role in interactions with the external role set than it does with the internal role set, since in boundary transactions, the incumbent lacks legitimate authority over external role set members (Kahn et al., 1964) and there is no shared higher authority to whom to appeal. In the absence of formal authority, affect may be invoked to exert influence over external agents in pursuit of valued resources.

The relative frequency with which the relationship function was paired with intelligence and persuasion functions (i.e., molding) suggested that relationships might be of particular importance in high-dependency situations. The pattern suggested that the greater the level of dependency on the resources held by the external agent, the greater the likelihood that the boundary spanner will invoke the relationship in trying to obtain them. The pattern identifies how specific interface contingencies, such as the degree to which the boundary spanner is dependent on the resources held by the agent, might shape the dimensions of the boundary role exhibited within any given interaction. Such interface contingencies were the conceptual linkages missing in Thomas' (1994) model of the MNE boundary spanning role. Thomas defined the concept of "dimensional fit" as the fit between 
the organization's "acceptance" of the various dimensions of the boundary role and the behaviour exhibited by the individual boundary spanner. However, Thomas' model was silent on the nature of interpersonal interaction at the interface. This research suggests that dimensional "fit" must extend beyond the alignment between the boundary spanner's behaviour and the organization's needs. If the valued resource is held by an external agent, then the boundary spanner who wishes to obtain it must align his or her behaviour (achieve "fit") with the needs of both the organization and the external agent.

Job level differences in the boundary role suggested more commonalities than differences, with the relationship function figuring prominently at all job levels. However, qualitative data suggested that the representation, molding and intermediary functions may have comprised a more important part of the boundary role among HOMs, consistent with their visibility and legitimacy as representatives of the organization. Quantitative data provided partial support for this finding. Confirmation of job level differences in the boundary role awaits further quantitative testing with a more complete and refined set of measures.

\subsubsection{Limitations of the emergent dimensions}

Worth noting in the emergent typology is the relative absence of dimensions depicting an "inward flow" of resources. Although this typology has respected the macro distinction in capturing adaptive flow in two directions, the typology seems to favour dimensions involving "outward flow". Five of the nine dimensions depict functions wherein the boundary spanner attempts to modify the external environment by exerting outward flow (representation, molding, delivering, intermediary, and the relationship function). Other than the two information-seeking behaviours (scouting and intelligence), 
none of the dimensions suggests behaviours where the boundary spanner seeks expressly to bring resources into the organization. Macro theory had suggested that boundary units sought to obtain a wide range of inputs needed to support the work of the internal system, including raw materials, capital, personnel, institutional support and "goodwill"(Adams, 1976; Section 2.1.1). Conceivably, therefore, there would be instances in which the boundary spanners in this research might seek resources other than information.

There are at least three reasons for the apparent imbalance in the adaptive flow depicted in this typology. The first possibility is that this finding accurately reflects the work of a foreign ministry in that such an organization is in fact more involved than other organizations in activities that involve outward flow (e.g., advocacy). A foreign ministry also may be less likely to rely on outside agents for resources. For example, there are no physical raw materials needed as "inputs" to diplomatic work, and financial resources and personnel are obtained internally from HQ. However, a foreign ministry clearly does rely on more abstract inputs to support its productive work, such as the support and goodwill of the international community. Whereas a foreign ministry, therefore, may have a smaller range of inputs than other organizations, it is likely that at least some of its boundary activity would be directed at "receiving" resources such as support and goodwill and conveying these resources to internal agents. The unique nature of diplomatic work, therefore, cannot fully explain the relative lack of inward flow observed in this typology. The second, and more likely, explanation for the comparative lack of inward flow in this research is that, although not explicit, inward flow is implicit to several of the dimensions. The first is the molding function, where the boundary spanner embarks on a deliberate effort to sway the external agent's views. Some molding efforts were directed at 
persuading the external agent to support DFAIT's position. The decision to classify appeals for support as molding behaviour was based on the observed "persuasion" features of support-seeking behaviour (in that seeking support involves an outward flow of influence) and on the desire to obtain consistency with Ancona and Caldwell (1988), who had also classified support-seeking activity as molding. Presumably, however, support-seeking behaviour would at some point succeed in obtaining a gesture of support from the external agent, and hence, would result in an inward flow of support or goodwill. However, in work as long-term and complex as diplomacy, success would likely accrue over a large number of such efforts, and may not have been apparent in any given episode. Further, even at the most senior levels, the best outcome that might be anticipated from an appeal for support would be to have the external agent leave the interaction with an agreement to take the request back to his or her internal colleagues for endorsement. As a result, the inward flow of support simply did not emerge, and hence, could not be included in the typology on an empirical basis.

Other dimensions in which inward flow was implied, but not explicit, were the coordinate-negotiate and guard functions. In the coordinate function, the boundary spanner "opens" the boundary to a two-way exchange of influence to enable the workflow on shared tasks. As implied in the description of this function, the boundary spanner is in this instance alternating between exerting influence over the outside agent and, in turn, being influenced by the agent through the process of "give and take". Inward flow, therefore, is an inherent "subdimension" of the coordinate-negotiate function, but cannot be separated from the overall dimension while still respecting its "give and take" spirit. In the case of the guard function, the boundary spanner "closes" the boundary to exchanges to protect the work of 
the organization under conditions of uncertainty or misalignment with organizational goals. Presumably, however, there would be other instances in which the external agent might approach the boundary spanner with demands that were aligned with the work of the organization, would be acceptable to the boundary spanner, and thus would be "granted". Such instances might result in the emergence of a dimension, such as Ancona and Caldwell's (1988) “granting entry" where R\&D teams were seen to grant external members temporary membership on team committees to gain access to the contacts' expertise (i.e., to enable an inward flow of technical resources). Again, however, such a dimension did not emerge in the episodes cited for this research, so could not be included, given the empirical data.

The last reason that inward flow might have been underrepresented in this typology is an artifact of the methodology. The strategy for deriving the typology was to identify through the interview a boundary interaction that represented a site of high dependency between the boundary spanner's organization and the external environment (See Appendix Table A-1 for rationale for interview items). Consistent with wording given by Kahn et al. (1964), respondents were thus instructed to think of a recent interaction with someone outside of the organization who was extremely important to them in terms of doing their jobs. The majority of respondents, therefore, chose examples of boundary interactions in which they had been the "demandeur" (i.e., they had been the initiator of the contact). It might be expected that in these instances, the boundary spanner might be seeking either to obtain information to support the work of the organization or to influence the agent to achieve some other organizationally-relevant goal (i.e., the interaction would involve either an inward information flow or an outward flow of influence). Conversely, such episodes 
would be somewhat less likely to reflect instances where the external agent came to the interaction expecting to influence the boundary spanner or to "deliver" resources (i.e., in which case the external agent would have been the demandeur, and the interaction might have enabled the researcher to observe a dimension involving an inward flow of resources).

The typology of the boundary role emerging in this research, therefore, may be incomplete. This preliminary investigation, however, opens the door to refinement of the dimensions through quantitative testing or exploratory research in other settings. Confirmation and further development of the typology awaits such research.

\subsubsection{Conditions for effectiveness at the interface}

Consistent with the salience of relationships in the boundary construct, relationships also figured prominently in respondents' accounts of the ways in which they came to "read" the local environment and understand what was expected of them in their boundary roles abroad. When asked how they developed their contacts, most respondents cited "relationship-based" approaches which involved mapping and actively "testing" the landscape of potential contacts through meetings, events, and other face-to-face encounters. However, relationship development was facilitated through knowledge of the local institutional structure and knowledge of long-standing interorganizational relationships in the region. The data also suggested that, where language and culture were unfamiliar, relationships laid the foundation for "reading" contacts' verbal and non-verbal cues over the course of individual boundary interactions. This was evident in comments around the need to hold several meetings in order to understand where contacts were "coming from" (i.e., "everybody here is worth meeting at least twice"). These data suggest that, in addition to 
mediating the ultimate exchange of resources, relationships may mediate role cuing over the course of the exchange. In other words, the more developed the relationship, the greater the ability of the boundary spanner to understand and anticipate the external agent's needs, thus increasing the likelihood of a successful exchange.

Data on the various reconciliation strategies employed by boundary spanners also reflected efforts to invoke, build, or preserve the relationship in instances where boundary interactions reached impasses. All strategies were what Tsui et al. would have classified as "constituency-oriented", focusing on the perspective of the external agent, rather than on self-interest or problem avoidance. Strategies such as "active listening", agreeing to disagree, and reframing seemed of particular value in cross-cultural interactions, where boundary spanners appeared to exert great effort in trying to understand local nuances.

Job level differences in the nature of interface demands and the various reconciliation strategies invoked at the interface suggested that those at lower levels of the organization might encounter more challenging interface experiences. Officers were more likely than management levels to encounter demands for the delivery of funding and other resources, and were more likely to have to resort to explaining their points of view to deal with differences of opinion when they occurred. Conversely, HOMs were more likely to encounter somewhat more flattering demands, such as requests for personal appearances and goodwill. They also appeared to have at their disposal a more sophisticated repertoire of relationship-oriented approaches to dealing with differences of opinion (e.g., reframing or "agreeing to disagree"). Although speculative, the findings suggest that boundary spanners at lower levels of the organization might be at somewhat of a "power disadvantage" in their efforts to achieve their objectives at the interface. In the eyes of their external contacts, 
boundary spanners at junior levels may be perceived to have less legitimacy than higher ranking officials, and thus may encounter more difficulty in achieving the influence over external agents needed to get the job done. In the eyes of their own organizational members, boundary spanners at junior levels may at the same time be entrusted with less decision latitude at point of contact to respond to influence efforts imposed on them. Further, the boundary spanner's rank may be particularly important in the international setting where hierarchical authority may be highly respected. These interesting hypotheses remain to be tested.

In sum, the data explored in this chapter shed light on the unique circumstances faced by boundary spanners in an international setting. Whereas language and cultural barriers have been extensively documented in the expatriate adjustment literature, the data collected for this research identify a number of features of the boundary spanner's interface experience that have not been previously examined and which may equally determine effectiveness in an MNE setting. In particular, the findings call attention to the importance of interpersonal relationships at the interface, the importance of understanding the local institutional and relational context in order to identify, and gain access to key external agents, and the importance of understanding potential job level differences in the nature of the boundary role. 


\section{THE TRANSLATION OF ORGANIZATIONAL EXPECTATIONS TO INDIVIDUAL WORK OBJECTIVES}

A further condition for effectiveness in the boundary role identified in the conceptual model (Figure 6.2) was the ability of the boundary spanner to integrate perspectives from "both sides" of the boundary in the development of individual work objectives. This chapter looks at this translation process and the factors taken into account in setting local work objectives (Research Question 5).

As discussed in the methodology chapter, the translation concept was particularly difficult to investigate, as there was no existing literature to suggest how boundary spanners might incorporate multiple perspectives in designing their work goals or carrying out their tasks (See 9.3.1.1). Unlike other research questions, this concept was not investigated through a targeted series of interview questions. The translation concept emerged throughout the interview as respondents described their interactions with HQ, their interactions with local colleagues, and the rewards and challenges of their work abroad. The researcher, therefore, undertook a separate pass through the data to code translation themes wherever they occurred in the interview. Findings are discussed in Section 13.1, and summarized in Section 13.2.

\subsection{Components of the translation process}

Table 13-1 provides a summary of the salient components of the translation process that emerged during interviews. The themes were abstracted from any references interviewees made to the factors they took into account when setting their work objectives. By "taking into account", we refer both to factors that respondents believed were working 
effectively for them in the translation process, and factors they believed would be helpful, but which needed improvement. What the table provides is insight into where boundary spanners are looking for cues or guidance in setting their local objectives.

The factors cited suggested a two-step translation process. First, boundary spanners "read" various cues within the organization that communicated to them the organization's expectations for their performance abroad. Second, they "filtered" these expectations through what might be labelled their local "lens". Filtering essentially involved taking decisions as to how to incorporate the organization's expectations into their everyday work, given their specialized knowledge of the local context.

The first two panels of the table are structured around these two components. They provide the chain of evidence for this conceptualization by identifying the nature of the responses that suggested the two themes. To add richness to the data, a third panel is also included. The third panel summarizes themes that emerged during the accounts that suggested the unique challenges associated with translation in the international context. 


\begin{tabular}{|c|c|c|c|c|}
\hline \multirow[b]{2}{*}{ "Read" organizational expectations: } & $\begin{array}{l}\text { Head of } \\
\text { mission } \\
(\mathrm{N}=18)\end{array}$ & $\begin{array}{l}\text { Mid-manager } \\
\qquad(\mathrm{N}=15)\end{array}$ & $\begin{array}{l}\text { Officer } \\
(\mathrm{N}=18)\end{array}$ & $\begin{array}{l}\text { Total } \\
(\mathbf{N}=\mathbf{5 1})\end{array}$ \\
\hline & \multicolumn{4}{|c|}{$(\%)$} \\
\hline Performance management plan & 39 & 27 & 39 & 35 \\
\hline Hi-level objectives from $\mathrm{HQ}$ & 39 & 27 & 22 & 29 \\
\hline $\begin{array}{l}\text { Formal strategic planning processes at } \\
\text { mission }\end{array}$ & 28 & 20 & 22 & 24 \\
\hline $\begin{array}{l}\text { Informal discussions with manager, } \\
\text { colleagues, local staff }\end{array}$ & 11 & 20 & 22 & 18 \\
\hline $\begin{array}{l}\text { Formal planning discussions with } \\
\text { manager }\end{array}$ & - & 13 & 28 & 14 \\
\hline \multicolumn{5}{|l|}{$\begin{array}{l}\text { Filter organizational expectations } \\
\text { through "local lens": }\end{array}$} \\
\hline $\begin{array}{l}\text { Call on predecessor, more experienced } \\
\text { colleagues at post or HQ }\end{array}$ & 30 & 38 & 24 & 30 \\
\hline Call on personal local knowledge & 39 & 7 & 11 & 20 \\
\hline $\begin{array}{l}\text { Special challenges in international } \\
\text { context }\end{array}$ & & & & \\
\hline $\begin{array}{l}\text { Translation is difficult: No indicators } \\
\text { and/or need help with this! }\end{array}$ & 17 & 47 & 28 & 29 \\
\hline Guard against "localitis" & 17 & 33 & 19 & 21 \\
\hline $\begin{array}{l}\text { HQ has no basis for judging your } \\
\text { performance }\end{array}$ & 34 & 21 & - & 17 \\
\hline
\end{tabular}

Fifty-one of the 84 respondents ( $61 \%$ of interviewees) made reference to the translation process at some point in the interview. As discussed in Chapter 11, many of these references occurred in response to the initial interview question investigating how boundary spanners came to know what their organization expected of them in their roles abroad. It was during these comments that boundary spanners described the process by which they "read" the organization's expectations for their performance from the 
organizational cues available to them at post.

The process of "reading" organizational expectations was mentioned most often in association with the formal tools DFAIT had designed expressly to assist employees in setting their objectives abroad. Formal tools provided the overarching framework to guide objective-setting at the individual level. Over one third of respondents (35\%) indicated that they turned to their performance management agreements/plans (PMAs/PMPs) as an initial step in setting objectives. As noted in Chapter 11, many respondents (nearly $70 \%$ ) had mentioned PMAs/PMPs as a means by which expectations were communicated to them. Those who mentioned the PMA process in reference to translation said additionally that PMA tools helped them take those expectations and create something more meaningful at the level of their jobs. Also, as mentioned in Chapter 11, most of the comments around PMAs and PMPs said there was considerable work to be done on these tools before they could be used effectively at the individual level:

The biggest reform in planning has been the stronger link between the department's objectives and what your objectives are as head of mission, and this comes through designing your personal PMA. There is still room for improvement, the specific link to my work is still not refined. We could use clearer articulation of priorities from $H Q$ - - less of this, more of that. Then I could use this to sharpen my objectives at this end (HOM male)

Twenty-nine percent of respondents who mentioned translation indicated that they used various high-level statements and policy documents (e.g., Speech from the Throne, departmental policy statements) to set their work objectives:

I am the channel where priorities from Canada, starting from the Minister's wishes, the Speech from the Throne, are translated to concrete action at the mission level and made to happen here (FL male)

Nearly one quarter of respondents $(24 \%)$ mentioned that the translation of organizational 
objectives to individual objectives was made easier, or would be made easier, by access to a formal strategic planning process within their mission. Such a process was described by one of the HOMs who led one:

I have devised my own formal planning system. I set two or three core objectives in consultation with my people. I do this through a formula, we do this through a number of retreats where I work with my staff and they hear my values and my vision of what I would like to do, and then they provide a reality check based on their longer experience, especially in the case of the local staff, how we might get to the goals that I have set out. We go back and forth with a couple of iterations on paper, and the goal is to get on one piece of paper our simple goals so everybody can have this at their workstation. You can have all the business plans you want but these are not going to filter down to the people who need to implement them unless you can distill them into something that is in clear language and means something to them (HOM male)

The process of "reading" the organization's expectations abroad also involved discussions with the manager and co-workers. Consistent with intra-organizational role cues identified in Chapter 11, these findings suggest that formal mechanisms for setting individual objectives are perceived as most effective when accompanied by real-time discussions. Eighteen percent of respondents mentioned the importance of informal discussions with the manager or co-workers; $14 \%$ said that they had, or would like to have, formal discussions with their managers. The following quotes suggest an interplay between formal, written, cues and the more informal "person" cues at post. In these comments, respondents describe a translation process wherein formal tools comprise the overarching structure for objective-setting, and managers are engaged in refining and revisiting objectives as contingencies change:

I have a rough set of objectives, which I wrote. I did this as part of my appraisal process. I sat down, with the input of my counselor, and said what are the kinds of things coming in, what are the mission priorities, and so what do I sense to be my job? It was very helpful, I didn't have this well defined initially, but as mission priorities shifted, we changed my objectives, and this has worked (FL female)

I contributed to the country strategy in terms of fitting the objectives of my program area into it, 
and it would have been much easier if I had had more guidance from above on this. Things change so rapidly here. I am looking for my manager to say, you know what, this year we will try to do these three things. But it is seldom that clear (FL female)

The "filtering" component of the translation process involved the application of the "local lens" to organizational objectives. This cognitive aspect of translation was abstract and often difficult for respondents to articulate. The notion was suggested, however, in references to seeking out local expertise or knowledge to help decide how best to implement HQ's higher-level objectives, or how to enact PMA objectives. Although there are likely many such sources of expertise, respondents mentioned two: calling on more knowledgeable colleagues and calling on one's own expert knowledge.

Nearly one third (30\%) mentioned turning to a predecessor or other knowledgeable colleague to help them bring the local lens to their work:

Setting your local objectives is a living process, not a fixed process- - you learn the local situation and how best to work within it through discussions with colleagues at post, at other posts, with local staff. These all come together (MID female)

To figure out my objectives at the operational level, I had to integrate what was in my PMA, what was in my mandate letter, with the local-level detail. So, I had a discussion with my ambassador (at the higher-order embassy) who was also new at the time of my posting, and we had some good dialogue there. So we had his priorities (from the higher-order embassy), the $H Q$ priorities from my PMA and the mandate letter, and I integrated all that with the needs of my mission here (HOM male)

Twenty percent of respondents said they filtered HQ's expectations through the lens of their own expert knowledge of the region.

I try to keep the broadest perspective I can in my work. This is what I am paid to do, not to report, not to do the job of a journalist, but to learn from my local environment and act within that context. How I do my job is based always on my own interpretation of the local environment (HOM male)

You bring together HQ's expectations with the local scene by trying to find points of intersection. I ask myself, what is my government's (HQ's) interest in this? Then I ask, what do I know about the local (corporate and government) interest in this? And then I find the overlap and that is the point where I find my own objectives (HOM female) 
The two-step translation process as described above conceivably might apply to the boundary role in any setting. Due to their unique structural location on the organization's periphery, boundary spanners in any organization might be challenged with having to filter the expectations of their organization through the lens of the external environment with which they are in contact. The last panel of Table 13-1 identifies three sets of comments that suggested how the translation process might differ in the unique case of the international assignment.

First, a sizeable proportion of respondents mentioned directly that setting individual objectives abroad was no easy task: $29 \%$ of interviewees said that they found it very difficult to set individual work objectives in the field. This difficulty was attributed largely to the incremental nature of political work and the "unmeasurability" of outcomes at the individual level. Whereas local, short-term results were highly visible (e.g., access to local contacts, managing successful local events; Chapter 11), there was a high level of uncertainty regarding the degree to which these "baby steps" took individuals any closer to realizing organization-level policy objectives:

You can't often see concrete outcomes in this job. Often, it's what you don't see that suggests you're doing your job- - the absence of irritants in your relationship with a country for example is evidence of a tremendous success. But it's very difficult to set the "absence of something" as an objective (HOM female)

You can get caught up in visits and events, you see that things have gone well, everyone is fed, they have had conversations, things fell into place. But you realize that, although the activity has gone ok, in "country strategy speak", you really don't know if the activity has achieved results (MID male)

Sure, you can see Canada's logo on something, and that you made that happen, but do you really ever know if the logo works? How much is my little piece? It's always so abstract (MID female)

The second theme suggesting that translation might be especially challenging in the 
international setting was a somewhat frequent reference to the need to guard against being afflicted by "localitis" (mentioned by $21 \%$ of respondents). "Localitis" referred to a tendency to identify with, and internalize, the needs of local constituents over time. Localitis was perceived to pose a risk to objectivity in translating the organization's goals to local objectives, a risk that was well known to respondents who mentioned the phenomenon, and for which they were well prepared before leaving Canada. The phenomenon was described as follows:

There comes a point in your assignment where you finally get the feeling of coming home after a day's work, the same kind of feeling that you get in Canada when you come home. And at that point, you are starting a new process, you are becoming a local. And in that state of mind, you would no longer be the ambassador of Canada to your host country. You would be the ambassador of your host country to Canada. This would be a bad thing. That's why three years' rotation is just right, long enough to get familiar with the country, not long enough to go native (HOM male)

After you have been in a country a while, you get a different perspective on things. This is good, but you have to be careful you don't develop localitis. You need to go there at least part way, in order to understand your local contacts. You have to be able to put your head into their head to an extent. That is how you can anticipate their reactions to your moves and plan yours. But you cannot go too far down that path or you lose your sense of self. This is something we are all aware of, and, in fact, are trained around this before being sent abroad (MID male)

The last quote above suggests that, in the international context, "localitis" may represent an extreme case of the notion of "dual allegiance" (Organ, 1971), whereby boundary spanners develop a sense of being "caught in the middle" between the needs of their own organizations and the needs of their external contacts. On the one hand, respondents noted that sensitivity to the local perspective was essential in the translation process in order to understand local needs and choose courses of action that would be well received locally. On the other hand, they also noted that this sensitivity needed to be balanced by occasional "reality checks" on objectivity. This was especially the case since the local contacts with whom respondents dealt everyday could become more salient role senders than respondents' 
own organizational members, who remained an ocean away. Although speculative, it is possible that awareness of the threat of localitis may have been one of the reasons that boundary spanners in this sample so highly valued their interactions with HQ (Chapter 11):

It is so easy to see results in terms of people benefitting locally. You have to be careful there, because your objective is not to make your local people happy. It is to make Ottawa happy (MID male)

The Department's objectives are always front and centre. If they are not, you have gone native and you are in big trouble (HOM male)

When you know you are on the right track is when you get that message back from Ottawa saying that what you are doing is actually finding an audience in Ottawa. Otherwise, your localitis takes you too far into issues, and you can no longer judge the level of interest in Ottawa (MID male)

Finally, $17 \%$ of respondents indicated that it was difficult to set local objectives because it was difficult to get direction and feedback on those objectives from an organization that was geographically distant. These comments typically arose in reference to the "black hole" in interactions with HQ (Chapter 11). However, translation was implied where respondents specifically mentioned that HQ was too far away to be in a position to judge their performance. Geographic distance was perceived to limit HQ's ability to provide feedback and performance-contingent reward:

I don't mean this critically, but I don't get a sense that Ottawa can really appreciate how good a job I do because we are thousands of miles apart. The only way they would know if you are doing a good job is if they get comments from someone else, maybe partner departments who also have staff located here. It must be very difficult for them come PMA time (HOM female)

People in Ottawa are not there with you, they do not see the multitude of things you do that do not get reported. So, the feedback you get can be pretty limited (HOM male)

Job level differences suggested in Table 13-1 are noteworthy. They suggest that HOMs tend to look largely to their expert local knowledge in setting their objectives (apply 
their own "local lens"), assisted by formal policy documents out of Ottawa and their individual PMAs. None of the HOMs mentioned formal planning discussions with their managers as useful or potentially useful. This was consistent with HOMs' low level of reliance on their geographic Directors General for guidance (Chapter 11). It was also consistent with HOMs' perception that HQ was too distant to have a sense of what they should be doing locally and how well they were doing it: $34 \%$ of HOMs mentioned that HQ had no basis for judging their performance. It is important to note, however, that HOMs also perceived that having a home organization an ocean away had its advantages:

$H Q$ entrusts you to set your local objectives because you are here and they are there, and they cannot see what the situation is locally. This definitely also has its upside. At mission, you do not on a day to day basis have to go through five layers of bureaucracy to buy a light bulb. You make a speech where you want to when you want to. The autonomy is balanced by a high level of accountability, but locally, you are at the top of your pyramid (HOM male)

Conversely, the officer level tended to look first to their PMA/PMPs in constructing their objectives, often mentioning the value of support from their (co-located) managers. As expected, given their more limited professional experience, they were unlikely to filter their objectives through the lens of their local expertise (only 11\% mentioned local expertise, as opposed to nearly $40 \%$ of HOMs).

The mid-management profile was remarkably different from that of the other two job categories. Objectives-setting at this level seemed especially challenging (nearly half of mid-managers indicated that setting individual objectives was difficult and that they would value organizational assistance with this). It is not possible to account for differences in the mid- management profile, without more contextual information than was available in a onehour interview. However, combined, the findings suggest that the translation process in the boundary role abroad may assume different configurations. These configurations seem 
dependent on job level, and suggest the need for support interventions tailored to the unique needs of individuals at various levels of the organization.

\subsection{Summary}

The data discussed in this chapter provide preliminary insight into the process by which boundary spanners might integrate perspectives from both sides of the boundary in developing their individual work objectives. The data provide the basis for describing the translation of organizational expectations to individual work objectives (Research Question 5) and are mapped to the model of the conditions for effectiveness in Chapter 16.

Findings suggested a two-step process, whereby boundary spanners "read" various intra-organizational cues that communicated to them the organization's expectations for their performance abroad, and then "filtered" these expectations through their local "lens". Intra-organizational cues associated with translation comprised largely the formal and "person" cues that had been identified in Chapter 11 as important sources of role cuing abroad. Respondents "read" their cues from their PMAs and various documents, and, in some instances, were further assisted in understanding these expectations through local strategic planning sessions or direction from co-located managers.

The step of "filtering" organizational expectations through the local lens was assisted through consultation with more experienced colleagues or reliance on one's own expert knowledge. Comments made throughout suggested that filtering might be especially challenging for boundary spanners in an international setting where external constituents are, by definition, more physically proximal role senders than are members of their own organization. Comments provided insight into the "dual allegiance" phenomenon (Organ, 
1971) as it might play out in an international setting, as evidenced in the high level of awareness in this sample of the need to safeguard against"localitis". Awareness of the risks of "localitis" were reminiscent of the findings on task feedback and identity (Chapter 11), where respondents noted ready access to feedback from locals and limited access to feedback from HQ. Further, comments indicated that translation might be particularly challenging due to the "invisibility" of the boundary spanner to HQ and the intangibility of performance outcomes in political work abroad. On the one hand, "invisibility" came with its advantages in terms of autonomy, particularly for HOMs. However, the perception that HQ was simply too far away to fully understand the local context is consistent with literature that has noted there may be difficulties associated with performance management for expatriates who remain largely out of management's sight (Caligiuri, 1997; Gupta et al., 1999; McNulty and Tharenou, 2005; Shay and Baack, 2004).

In instances where work outcomes are largely unmeasurable and local feedback highly accessible, boundary spanners may rely heavily on intra-organizational cues to set their local objectives and to maintain their sense of organizational membership. The need to preserve their sense of organizational membership under conditions of geographic distance may be yet another reason that boundary spanners in this sample so highly valued their interaction with HQ (Chapter 11). 
This chapter explores the last condition for boundary spanner effectiveness given in Figure 6.2. It examines boundary spanners' efforts to influence management on issues of strategic importance (Research Question 6).

The ability to exert influence over the organization's direction in response to changing environmental contingencies was believed to be central to boundary spanners' ability to contribute to organization-level adaptation. Influence was of particular interest in the international setting, where it was not known whether geographic distance might make it easier or more difficult for the boundary spanner to influence organizational decision makers. Social network theory yielded two contradictory predictions (Section 4.2). On the one hand, it predicted that boundary spanners in the MNE might be highly influential since, by virtue of their assignments, they would hold a high level of specialized local information that HQ did not have (i.e., they would mediate access to valued information resources; Jemison, 1984). On the other hand, social network theory also predicted that boundary spanners might be less influential should physical distance from HQ limit their access to the critical internal networks needed to build relationships and obtain the contextual knowledge needed to "sell" their issues (Dutton et al., 2001).

This chapter explores these predictions by examining a sample of issue-selling episodes described by respondents. The chapter is structured as follows. The first section (Section 14.1) describes the initial screening question used to identify issue-selling episodes for analysis. Section 14.2 identifies the nature of the issues advanced in the episodes. Section 14.3 describes the various issue-selling moves that emerged in the data, and 
compares and contrasts them to the moves observed by Dutton et al. Section 14.4 looks at the perceived success of the issue-selling attempts. Section 14.5 then applies the quantitative data to test patterns suggested in the qualitative findings. Section 14.6 discusses several normative beliefs in this organization ("theories-in-use") that might account for the pattern of moves observed. The chapter concludes in Section 14.7 with a summary of the findings regarding boundary spanner influence efforts and what these findings might suggest about boundary spanners' access to the organization's strategic, relational and normative knowledge when abroad.

\subsection{Responses to the screening question: Have boundary spanners tried to advance an issue from post?}

Prior to collecting the anecdotes, it was necessary to establish whether respondents had ever tried to influence management on an issue of perceived importance (i.e., whether they had a "story to tell"). Practically, this step served as a screening question to identify a target episode for discussion. The step, however, was also of research interest, since the first decision taken in selling an issue is not how to sell it, but whether one should "go to bat" (Dutton and Ashford, 1993, p. 406) for the issue in the first place. Since it was not known to what extent geographic distance might increase or impede the propensity to "sell", it was of substantive interest to initially determine what proportion of respondents had or had not attempted to bring an issue forward.

The initial screening question thus asked respondents whether, over the course of their current assignment abroad, they had ever tried to sell management on a strategic issue. "Management" was defined loosely to allow respondents to identify the geographic location 
of management from whom they sought attention. Defining "management" in broad terms allowed for the possibility that some boundary spanners, particularly those at lower levels of the organization, might achieve influence, not by engaging $\mathrm{HQ}$, but by engaging their colocated managers or other personnel within the mission. This approach was consistent with the conceptualization of "strategic influence" developed for this research (i.e., defined as the ability to either participate directly in the organization's "strategic conversation" or to transmit boundary information to internal agents who were part of the conversation; Chapter 6).

Table 14-1 presents an overview of responses to this initial question. The data suggest that, in this organization, geographic distance does not deter boundary spanners from initiating selling. Eighty-two percent of respondents identified an instance in which they had tried to sell management on an issue. Of these, only 10\% (representing seven individuals: two mid-managers and five officers) said they attempted to move their issue by acting only at the mission level (not shown). This suggests that HQ management was by far the most frequent target of influence efforts. The perceived need to engage HQ in selling efforts is consistent with the high degree of centralization of policy formulation in this organization. Decision-making resides at $\mathrm{HQ}$, and, accordingly, those who wish to influence decision-making perceive they must engage HQ. 


\begin{tabular}{|l|c|c|c|c|c|}
\hline Table 14-1 Influence effort: Overview of response categories for analysis \\
\hline $\begin{array}{l}\text { Have you ever tried to get management attention on } \\
\text { a strategic issue? }\end{array}$ & $\begin{array}{c}\text { Head of } \\
\text { mission } \\
(\mathbf{N = 3 5})\end{array}$ & $\begin{array}{c}\text { Mid- } \\
\text { manager } \\
(\mathbf{N = 2 1})\end{array}$ & $\begin{array}{c}\text { Officer } \\
(\mathbf{N}=\mathbf{2 8})\end{array}$ & $\begin{array}{c}\text { Total } \\
(\mathbf{N}=\mathbf{8 4})\end{array}$ \\
\hline & & $76)$ & 96 & 82 \\
\hline Yes, have sought management attention on an issue & 74 & 10 & 4 & 11 \\
\hline No, have never tried & 17 & 10 & - & 6 \\
\hline Have moved an issue myself & 9 & - & 5 & - & 1 \\
\hline No response & $\mathbf{1 0 0}$ & $\mathbf{1 0 0}$ & $\mathbf{1 0 0}$ & $\mathbf{1 0 0}$ \\
\hline Total & & & & 6 \\
\hline
\end{tabular}

Only $11 \%$ of the sample (representing nine individuals: six HOMs, two midmanagers and one officer) had never tried to move an issue from post. Follow up questions administered to these individuals indicated that the primary reason for not having tried was the belief that they were too new to the assignment to have had time to identify the important issues (data not shown). A second reason cited, however, was the belief that it was more difficult to engage HQ on strategic issues when you were abroad than when you were at HQ. This response suggested a normative belief about "the way things work" in DFAIT that may have deterred at least some boundary spanners abroad from advancing their issues. These "theories-in-use" (Agyris and Schon, 1982) are explored further in Section 14.6 .

Finally, 6\% of the sample, all of them managers (three HOMs and two midmanagers), said they had moved their issues themselves and had not perceived the need to engage anyone above them in the hierarchy. This finding is consistent with the high level of job autonomy reported by managers in this sample (Table 9-7). Although this meant that these five episodes were not available for analysis of issue-selling "moves", they are worth 
noting. The episodes suggest the notion of emergent strategy (Anderson, 2004), whereby lower level managers dispersed throughout the organization indirectly affect the organization's strategic direction by taking their own initiatives in response to changing environmental conditions. Such instances of independent local action illustrate an alternative and legitimate means by which boundary spanners abroad might provide the organization with direct and immediate adaptation to changing environmental contingencies.

The initial screening question also enabled the researcher to classify episodes for analysis, eliminating those with insufficient information to support exploration of issueselling moves. The procedure for identifying the final subsample for analysis of moves is given in Table 14-2. First, from the original sample of 84 respondents, one case was removed due an unanticipated interruption that precluded completion of the interview. Second, the nine respondents who had never moved an issue were removed from the sample, as were the five who had taken independent action on their issues. This left 69 cases for the analysis of influence moves. Further, 12 of the these 69 respondents indicated that they were uncomfortable identifying the specific issue due to the sensitivity of its content. They were, however, willing to discuss in "hypothetical" terms how they went about moving it. Since these respondents had a specific referent for their responses, their data were included in the analysis of moves. The 12 cases, however, were not amenable to analysis of the nature of the issue advanced. This procedure thus yielded a total of 69 cases for the influence moves, and 57 cases for full analysis of moves and the nature of the issues advanced. 


\begin{tabular}{|c|c|c|c|c|}
\hline & $\begin{array}{l}\text { Head of } \\
\text { mission }\end{array}$ & $\begin{array}{c}\text { Mid- } \\
\text { manager }\end{array}$ & Officer & Total \\
\hline & \multicolumn{4}{|c|}{ (Number) } \\
\hline Starting sample & 35 & 21 & 28 & 84 \\
\hline \multicolumn{5}{|c|}{ Step 1. Identify cases available for analysis of influence moves. Remove cases where: } \\
\hline No response to influence item & $(-)$ & -1 & $(-)$ & -1 \\
\hline Respondent has never tried to move an issue & -6 & -2 & -1 & -9 \\
\hline $\begin{array}{l}\text { Respondent has moved an issue, but done so independently } \\
\text { (did not seek management attention) }\end{array}$ & -3 & -2 & $(-)$ & -5 \\
\hline Cases remaining for analysis of influence moves & 26 & 16 & 27 & 69 \\
\hline \multicolumn{5}{|c|}{ Step 2. Identify cases available for analysis of nature of issue. Remove cases where: } \\
\hline Respondent describes hypothetical issue only & -6 & -1 & -5 & -12 \\
\hline $\begin{array}{l}\text { Cases remaining where respondent has provided account } \\
\text { of actual episode for full analysis of moves and the issue }\end{array}$ & 20 & 15 & 22 & 57 \\
\hline
\end{tabular}

\subsection{The nature of issues advanced}

Table 14-3 categorizes the types of issues respondents described in their stories. The nature of the issues identified indicated that this question had succeeded in eliciting examples of strategic, rather than operational, issues. The failure to distinguish between strategic influence and influence over more routine issues had been a shortcoming of previous boundary spanning literature (e.g., Tushman and Romanelli, 1983; Brass, 1984).

Nearly half of the issues (47\%) involved an attempt to shift HQ's attention to an emerging local issue:

We do "regular" reporting on agreed-upon topics. But, in addition to this, one thing that I have tried to do is to propose reports on policy-related topics I think $H Q$ needs to look at, and which I know are not on their screen (FL female) 


\begin{tabular}{|c|c|c|c|c|}
\hline & $\begin{array}{l}\text { Head of } \\
\text { mission } \\
(\mathrm{N}=20)\end{array}$ & $\begin{array}{l}\text { Mid- } \\
\text { manager } \\
(\mathrm{N}=15)\end{array}$ & $\begin{array}{l}\text { Officer } \\
(N=22)\end{array}$ & $\begin{array}{c}\text { Total } \\
(\mathrm{N}=\mathbf{5 7})\end{array}$ \\
\hline What was the issue you were trying to advance? & \multicolumn{4}{|c|}{$(\%)$} \\
\hline To shift HQ's attention to an emerging local issue & 55 & 33 & 50 & 47 \\
\hline $\begin{array}{l}\text { To persuade HQ that a new approach was needed to } \\
\text { engaging local contacts }\end{array}$ & 10 & 7 & 36 & 19 \\
\hline To get an official to speak on an issue, to get a visit & 10 & 20 & 14 & 14 \\
\hline $\begin{array}{l}\text { Mission management issue (needed more locally } \\
\text { engaged staff, new facilities, etc.) }\end{array}$ & 20 & 20 & - & 12 \\
\hline $\begin{array}{l}\text { Other (e.g., suggestions for improving HQ processes/ } \\
\text { logistics that have implications for local effectiveness) }\end{array}$ & 5 & 20 & - & 5 \\
\hline Total & 100 & 100 & 100 & 100 \\
\hline
\end{tabular}

One in five issues (19\%) involved efforts to persuade HQ that a new approach was needed to engaging local contacts. A key part of the boundary role in this organization is to work with the host government or other local partners in pursuit of DFAIT's objectives for the region. Boundary spanners, therefore, often tried to convince HQ that a new approach to interacting with these local contacts was needed if DFAIT hoped to achieve its objectives locally:

This country does not think like we do, and we have tended to have challenges in the past in negotiating with this country, so I was trying to argue to $H Q$ that we needed to take an approach to negotiation this time that was different (FL female)

A rather small proportion of respondents $(14 \%)$ recounted an instance in which their expressed purpose was to encourage a visit or similar event, or to have an official speak on an issue. Subsequent discussion of these types of issues revealed that lobbying for visits or events was in many cases an issue-selling strategy in this organization. The event was not seen as the issue, but rather as a mechanism for drawing management attention to an issue. 
This "piggybacking" strategy is explored further in the discussion of process moves in

\section{Section 14.3.}

Job differences in the nature of the issues advanced were notable. HOMs and officers tended to cite issues focusing on getting HQ's attention on new policy issues. Officers, however, were much more likely than other job categories to cite an attempt to change the way of engaging local agents on an issue. This is an interesting finding, since it illustrates a potential application of the translation process. Where boundary spanners choose options for engaging local contacts based on their knowledge of the needs of those contacts, they apply the "local lens" in the execution of (centrally formulated) organizational objectives. The boundary spanner's awareness of the appropriate engagement strategy brings to the transaction local relational knowledge that would not be available to the organization without local presence:

The spirit of the agreement had been changed by (my MFA interlocutor) and $H Q$ wanted to take $a$ hard line to insist on the original draft. But I told them they would seriously lose their momentum if we did this, that we now had the attention of (very senior local officials), and that we needed to take a softer stand or lose this momentum (FL male)

Mid-level program managers showed a unique profile, tending to cite issues related to mission management (i.e., they advanced issues related to what were essentially nonboundary functions involving the management of the mission's financial resources and locally engaged staff ). They also were likely to lobby for officials to visit their region or speak on an issue. Again, this suggests that program managers in this sample may be engaged in different work than those in other job categories, perhaps spending more time on mission resource issues or on events related to the specific programs for which they are responsible. Mid-managers, however, did tend to link their mission management issues to 
effectiveness at the local level, suggesting that they perceived the issues they advanced to be of strategic value and not reflective of "routine" operational issues:

I was lobbying for better facilities for the mission. There was no meeting room that could accommodate more than 12 people. It was not well appointed. In this country, you are judged by your appearance, and we would simply not look like a serious player here if we tried to host (officials) in this atmosphere (MID male)

\subsection{Issue-selling "moves"}

This section examines the moves described by respondents in their issue-selling stories. Dutton et al.'s (2001) three categories of moves (involvement, packaging, and process moves) were well suited to the data, so were retained as the basis for coding and analysis. Nuances in the data, however, led to reconceptualization of some of the moves subsumed within the three categories, and the emergence of several moves not anticipated in Dutton et al.'s scheme. An overview of these three categories is provided in Table 14-4 and described and contrasted with Dutton et al.'s (2001) scheme in the discussion that follows.

\begin{tabular}{|l|c|c|c|c|}
\hline Table 14-4 Influence efforts: Overview of moves mentioned in issue-selling accounts \\
\hline & $\begin{array}{c}\text { Head of } \\
\text { mission } \\
(\mathbf{N = 2 6 )}\end{array}$ & $\begin{array}{c}\text { Mid- } \\
\text { manager } \\
(\mathbf{N = 1 6 )}\end{array}$ & $\begin{array}{c}\text { Officer } \\
(\mathbf{N = 2 7 )}\end{array}$ & $\begin{array}{c}\text { Total } \\
(\mathbf{N = 6 9 )}\end{array}$ \\
\hline & \multicolumn{5}{|c|}{ (\% of respondents mentioning move) } \\
\hline Involvement & 100 & 100 & 100 & 100 \\
\hline Process & 100 & 100 & 100 & 100 \\
\hline Packaging & 88 & 93 & 93 & 91 \\
\hline
\end{tabular}

\subsubsection{Involvement moves}

Involvement moves comprise decisions regarding which individuals should be consulted, engaged, or informed in an issue-selling effort. By involving others, sellers can 
learn more about an issue, increase its visibility, elicit commitment, or secure support in advancing it. Knowing who to involve in selling an issue requires access to the organization's relational context (i.e., knowledge regarding the responsibilities, private stakes and interests of other organizational members; Dutton et al., 2001). The analysis of involvement moves in this research was aimed at understanding how boundary spanners' relational knowledge might be affected by geographic distance.

The data suggested that targeting the right people for involvement is perceived to be as important a move in this international setting as it would be in any setting: $100 \%$ of respondents mentioned involvement moves in their issue-selling accounts. Involvement data are given in Table 14-5. The data present an "inventory" of the individuals who were the targets (Dutton et al., 2001) of involvement over the course of the effort (the "who"). The nature of their involvement (the "when" and "why" of their involvement) reflects the orchestration of the effort, so is discussed under process moves (Section 14.3.3).

\begin{tabular}{|c|c|c|c|c|}
\hline \multirow[t]{2}{*}{ People the respondent involved in advancing the issue } & $\begin{array}{c}\text { Head of } \\
\text { mission } \\
(\mathrm{N}=26)\end{array}$ & $\begin{array}{c}\text { Mid- } \\
\text { manager } \\
(\mathrm{N}=16)\end{array}$ & $\begin{array}{l}\text { Officer } \\
(\mathrm{N}=27)\end{array}$ & $\begin{array}{l}\text { Total } \\
(\mathrm{N}=69)\end{array}$ \\
\hline & \multicolumn{4}{|c|}{ (\% of respondents mentioning move) } \\
\hline Regular HQ reporting line & 58 & 75 & 67 & 65 \\
\hline My manager & 46 & 69 & 52 & 54 \\
\hline Other HQ (functional divisions, corporate, etc.) & 31 & 44 & 56 & 44 \\
\hline $\begin{array}{l}\text { Senior level(s) above my reporting line } \\
\text { (ADM/DM/Minister) }\end{array}$ & 46 & 31 & 15 & 30 \\
\hline Network/colleagues & 19 & 31 & 22 & 23 \\
\hline Local contacts and outside experts & 23 & 13 & 15 & 17 \\
\hline Coalition & 31 & 13 & 7 & 17 \\
\hline Mission staff & 12 & 6 & 16 & 16 \\
\hline Head of mission & - & - & 37 & 16 \\
\hline
\end{tabular}


Generally, the findings suggest the same targets of involvement identified in Dutton et al.'s scheme. Boundary spanners sought to involve those above them in the organization and those at the same level. The added layer of complexity in the international setting, however, was that most of these targets were an ocean away. This made it somewhat difficult to know either who to involve or what their stakes in the issue might be. Further, the diffusion of responsibility for issues in this organization was evident in boundary spanners' tendency to engage multiple constituencies in advancing their issues. Although the most frequent involvement move was to engage the "regular" reporting line $(65 \%$ engaged the desk or geographic DG on the issue), none of the respondents tried to move their issue by involving only their regular reporting line (not shown). Instead, they emailed, phoned, or otherwise enlisted many individuals in their effort, including those in other branches or divisions at $\mathrm{HQ}$, those at more senior levels of the organization, and their own networks and local contacts. Sometimes this "multi-pronged" approach was considered and strategic:

We sent our reports (on this issue) not only to our regular reporting line at $H Q$, but also to other divisions where I knew officers were making budget decisions and were in a position to provide us with future financial support for this (MID male)

Often, however, the engagement of multiple constituencies represented a "shotgun" approach where virtually everyone was copied on messaging, usually because the boundary spanner did not know who the key players were, or where responsibility for the issue resided:

The decision tree on this in Ottawa and the allocation of responsibility between departments was not at all clear to me. So, I more or less sent an email to all ADMs, hoping to hit the right one. This would definitely not have been my approach had I been at $H Q$, but here at the mission, this is often the only option available to you (HOM male) 
The "shotgun" approach was suggestive of a decay in relational knowledge (i.e., knowledge about who is responsible for the issue, and the key interests and stakes in the issue; Dutton et al., 2001) as a function of distance. This provides some support for the assertion that geographic distance might limit access to the intra-organizational networks needed to support effective issue-selling:

It's funny since we have all been at post at one time or another, but the longer you are at post or the longer you are at $H Q$, the more out of touch you get and the more you tend to forget what's going on on the other side. I knew who the key players were, but I didn't know where they would sit on this issue, so I copied them all (MID male)

If you're back in Ottawa, there are those corridor conversations that can tell you who's doing what and the why of certain things, but you don't have that out at the mission (HOM male)

In terms of job level differences, HOMs were most likely to "aim high", targeting HQ at the most senior levels, or building coalitions to obtain strength in numbers:

I targeted the ADMs, partner departments, the DM, even the Minister. I made sure I had an ally in high places (HOM female)

I deliberately built allies. Within the organization and without. We are focused on coordinating efforts across government now, so this was a key lever. I called partner departments, I showed how this was strategically an issue for them as well, how we would do better if we moved this in concert, and I secured their support (HOM male)

Mid-managers and officers tended to involve their (co-located) managers at the mission. A fairly large proportion of officers (37\%) involved their HOMs, suggesting that HOM commitment to the issue was perceived to be central to the ability to influence HQ decision makers:

I kept my HOM informed at all times, it is absolutely essential that you have your HOM's commitment to your issue (FL female)

Due to HOMs' more frequent contact with HQ, involving one's HOM was also a strategy 
for "driving" the issue at senior levels, as will be seen later in the chapter.

\subsubsection{Packaging moves}

"Packaging" moves refer to the logical presentation of the issue: how it is framed and the way its relevance established. Knowing how to package an issue requires access to the organization's strategic context (i.e., knowledge regarding the organization's goals, plans, and priorities; Dutton et al., 2001). Strategic knowledge enables the seller to tailor the presentation of their issue to what matters in the organization.

Packaging moves were mentioned by $90 \%$ of respondents, suggesting that getting an issue "framed" the right way was perceived to be a success factor in moving an issue from post. Packaging moves are described in Table 14-6.

\begin{tabular}{|c|c|c|c|c|}
\hline \multirow{2}{*}{$\begin{array}{l}\text { How the respondent packaged or positioned the issue } \\
\text { to move it forward }\end{array}$} & $\begin{array}{l}\text { Head of } \\
\text { mission } \\
(\mathrm{N}=23)\end{array}$ & $\begin{array}{l}\text { Mid- } \\
\text { manager } \\
(\mathbf{N}=14)\end{array}$ & $\begin{array}{l}\text { Officer } \\
(N=25)\end{array}$ & $\begin{array}{l}\text { Total } \\
(\mathrm{N}=62)\end{array}$ \\
\hline & \multicolumn{4}{|c|}{ (\% of respondents mentioning move) } \\
\hline \multicolumn{5}{|l|}{ Packaged the issue to appeal to HQ's interests } \\
\hline Aligned with policy and priorities & 26 & 36 & 60 & 42 \\
\hline Positioned in terms of the bottom line or efficiency & 4 & 36 & 12 & 15 \\
\hline Kept it succinct & 13 & 14 & 4 & 10 \\
\hline \multicolumn{5}{|l|}{ Packaged the issue with expert local knowledge } \\
\hline Packaged with a strong evidence base & 74 & 57 & 60 & 65 \\
\hline $\begin{array}{l}\text { Presented as a threat to Canada's image, reputation, } \\
\text { security }\end{array}$ & 35 & 21 & 24 & 27 \\
\hline Packaged with clear objectives and path to get there & 22 & 14 & 24 & 21 \\
\hline Aligned with the positions of other countries & 17 & 7 & 16 & 15 \\
\hline Hard to know how to package the issue from post & 17 & 21 & 16 & 18 \\
\hline
\end{tabular}


The data indicate that boundary spanners' strategic knowledge of the organization's priorities was important to framing issues in this international setting. The first set of responses given in Table 14-6 reflect packaging moves designed to "play to their audience" by appealing to HQ's interests and preoccupations. These moves are listed under the heading, "Packaged the issue to appeal to HQ's interests". Over $40 \%$ of respondents said they packaged their issue by aligning it with current departmental priorities and policy directions. The prevalence of the "align with priorities" move suggests another reason why contact with HQ may have been such a highly valued resource for these boundary spanners (Chapter 11). Information regarding HQ's current policy directions was a key piece of strategic knowledge needed by boundary spanners abroad if they were to selectively attend to their environments and frame their issues to reflect HQ's interests:

I knew from my discussions with $H Q$ around the country strategies that these strategies were a huge priority for the department right now. So I knew that anything dealing with the country strategy would hold currency for $H Q$. I used the country strategy priorities to show how this local issue flowed from the department's priorities through to those of the mission (FL male)

A second packaging strategy was to frame the issue as a way of achieving resource savings. Fifteen percent of respondents said they packaged their issue in terms of the bottom line or efficiency concerns. This strategy showed sensitivity to ongoing pressures in Ottawa to show increased accountability in public spending. Boundary spanners perceived they were more likely to obtain increased funding for mission operations if they were able to show local efficiencies and sound money management:

Our goal was to obtain an increase in our programming funds for the next year by demonstrating through every report we sent to $H Q$ how our events represented an efficient use of our current resource level ( $M I D$ male)

The last strategy designed to feed into HQ's interests reflected an awareness that the 
time and attention of senior officials was limited. The best proposals were perceived to be those that were packaged succinctly (mentioned by $10 \%$ ):

If you want HQ's attention, it has to be short and sweet. There is so much information coming into $H Q$, and executives have little time. If you can't distill it into a deck or a two-pager, it is very difficult to get a decision (HOM male)

Interestingly, however, the remainder of the moves cited in Table 14-6 did not directly reflect efforts to bundle the issue with HQ's interests. Instead, the moves suggested a packaging strategy that may have been somewhat unique to incumbents of a boundary role. In these instances, respondents indicated that they framed their issues by packaging them with insights about the local context. These moves are listed under the heading "Packaged the issue with expert local knowledge". This set of moves provides some support for social network theory's prediction that boundary spanners might leverage their specialized local knowledge in their efforts to achieve influence over HQ.

The most frequently cited move was to package the issue with a strong base of evidence (used by $65 \%$ of respondents in moving their issues). Boundary spanners were in a unique position to obtain this evidence due to their proximity to the local context.

Evidence showed the boundary spanner's credibility on an issue ...

Because I was actually in the local context, I was able to conduct primary research around this. I went into the field, spoke with government officials, NGOs, academics. This gave me a broad perspective and a system of cross-checks between different sectors that provided solid evidence for $H Q$ (FL female)

I made the case that three businesses had been in touch with me to lobby for (this initiative), that it was a barrier to their doing business in this country. I needed to tell HQ this so they could see that there was a strong case and a need here (HOM male)

... and provided a way for the boundary spanner to help HQ understand a local issue that 
would have been invisible to them without the boundary spanner's input:

You have to totally explain the case to Ottawa. That's your job, you must educate them, they are not there, so cannot see the local importance without your evidence (FL male)

Evidence also was perceived to protect one's reputation and to show objectivity on an issue.

Evidence served as a safeguard against being seen as too "pushy" or having been afflicted with "localitis":

When you are writing your note, it must contain only the evidence, only the facts. We remove all signs of emotion, no personal opinion, we try to make correspondence as neutral as possible, so we don't appear to be operating from self interest (MID male)

We edit each others' emails to ensure we are not perceived as having been afflicted with localitis (MID male).

Other moves in this category included framing the issue as a threat to Canada's image or security (mentioned by $27 \%$ of respondents) or arguing that the issue was aligned with the positions of other international players (15\%). Again, these moves reflected the use of specialized local knowledge- - this time knowledge regarding the perspective of the local international community- - to attempt to influence HQ on issues of strategic importance:

The department cares what its EU partners are doing, and they often want this before finalizing their own position. I have this knowledge and I used it to make my case because I knew it would carry weight (FL female)

My messaging tends to be less around what we should do than what we should not do. Often I want to point out to Ottawa the threat of action or non-action to Canada's visibility or image on an issue. They cannot see this because they are not here (FL female)

The last move in this category was to advance the issue with clear local objectives and the path to get there $(21 \%)$. In these instances, the boundary spanner used his or her 
familiarity with the local situation to propose specific courses of action. Again, these were courses of action that would not have been apparent to HQ without the boundary spanner's assessment of the local scene. Where the proposal came packaged with options, HQ was perceived to take quicker decisions :

We laid out both the rationale and our plan of action. We included in every report not only a description of the event we wanted to have, but also the departmental objective it would serve and the outcomes it would obtain locally. HQ cannot appreciate the value otherwise, or may not have the faith that you can carry it forward. They need you to lay that out for them, because they simply cannot see you or the appropriateness of proposed actions. You need to include specific options if you are going to sell $H Q$ (MID male)

Finally, the last panel of the table indicates that a substantial minority of respondents believed that it was difficult to know how to package an issue when abroad. Eighteen percent of respondents volunteered at some point in their descriptions of packaging moves that it was difficult to know what HQ's preoccupations were, or what might appeal to them. This was largely attributable to feeling cut off from the "strategic conversation":

You want to make sure you address all the right issues in your package. But it is hard to know what the right issues might be. It doesn't take long before you lose touch with what the priorities are over there (HOM male)

Job level differences in packaging moves were relatively minor. Mid-managers were more likely to frame their issues as a bottom line concern, again reflecting their unique roles in mission administration and their accountability for the effective management of the mission's programming funds. Officers were more likely than others to package their issues by aligning them with policy and priorities. It is difficult to account for this latter finding, since officers relied on other packaging moves to roughly the same degree as other job levels (i.e., it seemed not to be the case that they had few other strategies in their repertoires- - they simply used the alignment strategy more often). Some accounts 
suggested that the "align with priorities" strategy may have provided a means for those at lower levels to get the attention and support of local managers, where they lacked the "heft" to move the issues themselves. In these instances, officers showed how their proposals aligned with mission priorities, and thus had the potential to help the HOM deliver on his or her commitments:

I wanted this series of visits. So what I did was to take my HOM's mandate letter, extract the key objectives for this mission, identify his key commitments, and show how these visits would help him meet them (FL male)

\subsubsection{Process moves}

In addition to decisions regarding the best way to frame an issue and who to involve in moving it, issue sellers also make decisions regarding how best to "roll the issue out" and manage their effort over time. Like Dutton et al., this research refers to these as process moves. Process moves involve the planning, timing, and orchestration of the effort. Process moves require access to the organization's normative knowledge (Dutton et al., 2001). According to Dutton et al., issue selling is deeply embedded in the organization's normative and political context. Knowing "how things are done around here", including when to act and when to hold back, can be central to effective issue selling.

Dutton et al.'s process category had involved three sub-categories of moves: preparation for the move ("doing the homework"); getting the timing right; and the choice between using informal vs. formal organizational mechanisms in advancing the issue. The data collected for this research corroborated the preparation and timing phases. However, the choice between formal and informal mechanisms was only one of several very considered and strategic approaches to moving an issue that emerged in this research. The 
final set of moves emerging from these data represented a more extensive set of process moves, including strategies to prepare, drive, and manage the effort over time.

The process moves identified in this research are given in Table 14-7. They were cited by $100 \%$ of respondents. Process moves fell into four categories. The first category involved the preparation phase, consistent with Dutton et al. ("doing one's homework"). Preparation enabled the seller to learn both about the issue itself and about the potential responses of organizational members to the issue.

As expected, given the importance of evidence in packaging issues (Table 14-6), the most frequent preparation move was to collect the local evidence needed to establish the relevance of the issue. The remaining preparation moves involved consultations.

Consultations with individuals within the organization allowed the boundary spanner to tap into their knowledge on the issue (strategic knowledge), or to gauge their level of support so as to identify and handle potential pockets of resistance (relational knowledge):

I talked to people at $H Q$ who had knowledge on this file so that I could get the details right. But I also talked to people who didn't work on the file, but who were people I knew and trusted. I got their points of view not only on the issue, but also on the process- - are there barriers hidden over there behind some cloaking device? And l even asked them to do homework on my behalf, like to ask around, to feel out their own managers, that kind of thing (FL male)

Ottawa is receptive to ideas if there is no downside for them. So, you want to make sure you address the downside in your package. But it is hard to know what that downside might be (since if there is one, sometimes your only cue is that you got no response to your suggestion). So, you have to tease that out, you have to ask, is it the Minister's schedule that is the problem, is it the idea itself, that kind of thing (MID male) 


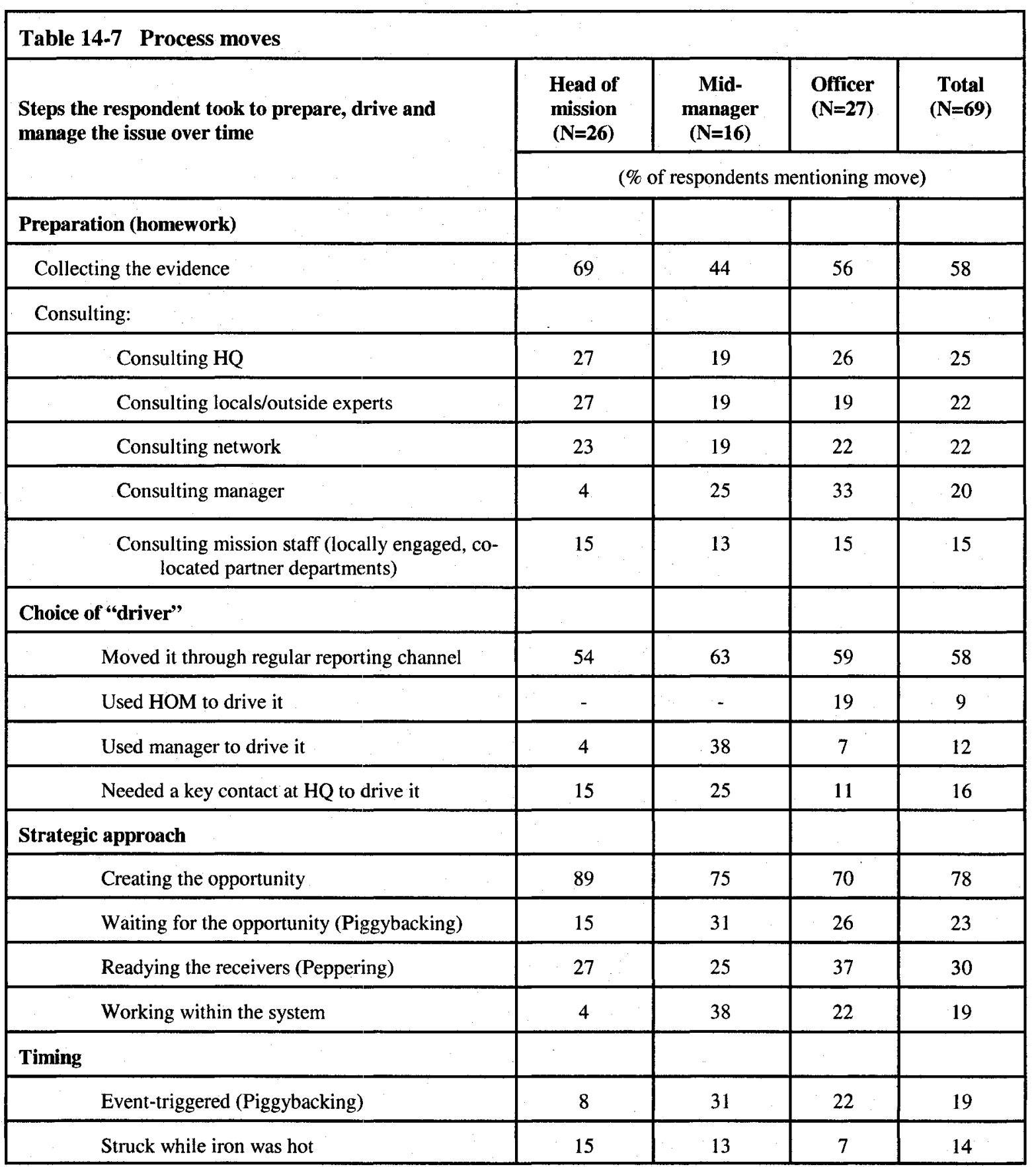

However, again unique to the boundary role, there was also a relatively high level of consultation with local contacts in preparation for moving an issue, including conversations with local networks and locally engaged staff:

I needed to garner information and the international perspective on the issue, so I repeatedly went 
to international organizations here, the Commonwealth office, for example, and asked what was developing on this front ( FL 237 male)

The second category of moves involved selecting a person to serve as the "driver" for the issue. Co-opting others to drive the issue was not a move identified by Dutton et al. This move suggested an awareness on the part of these boundary spanners that being abroad may place them at a disadvantage in advancing an issue. The primary disadvantage appeared to be the lack of interpersonal contact needed to sway organizational members at HQ and gauge their responses to the issue:

They have to see your face before you can convince them. Otherwise, you are just the anonymous officer banging out messages from post. When you are at $H Q$, you can frame your argument in the context of the discussion at hand to make sure it is positioned properly and heard. You can't do that from here, so you need someone else to help you move your issue, someone whose face they can see (FL female)

As was the case in the discussion of involvement moves (Section 14.3.1), the majority of respondents (58\%) attempted to move their issues by means of their regular reporting line, but seldom relied solely on the reporting line. This was attributable to a belief that the geographic division was often stretched too thin to devote the time needed to drive an issue: There is not always someone in the geographic who can work on your behalf. They have 10 or 20 other missions reporting to them. Now, if you have a crisis, $H Q$ is right there for you. But normally, they are just too busy. This is nobody's fault, it is just the way it is (HOM female)

Sixteen percent of respondents mentioned specifically that they needed a key connect at HQ to drive their issues on their behalf. This person may have been at any level of the organization, but the commonality was that this was a known and trusted individual whom they believed to be committed to making sure their perspective was heard. In effect, this individual helped overcome the potential barrier of interpersonal distance by assuming the 
role of "internal boundary spanner", connecting the boundary spanner abroad to key

individuals within the organization:

To sell an issue, you need your key people at Ottawa. You need to know who can help you move that issue. $H Q$ rotates every 3 years too, so sometimes you're in the spot of losing your network. New people come in, and then it's getting to know one another all over again, building the trust all over again (FL male)

The geographic desk was critical as a conduit on this and critical as a champion (HOM female)

There was also a perceived need to obtain local management support to effectively drive an issue. Both officers (19\%) and mid-managers (38\%) tended to enlist their HOMs to move their issues. The typical pattern was to do the homework, "line up the ducks", and then have the HOM move the issue through some strategically placed phone calls or, preferably, face-to-face contact with HQ. The reliance on HOMs to sell an issue seemed attributable not only to the belief that HOMs had the hierarchical authority needed to move the issue, but also to the belief that HOMs had greater opportunity for the synchronous communication and face-to-face interaction with HQ needed to sell the issue effectively: I sent out emails, felt everybody out on the idea, outlined the specific steps and alternatives I had in mind. Then my HOM took over, and distributed the actual proposal at the next HOM meeting (FL male)

While I was sending reports through the regular reporting line, my HOM was phoning his key people at $H Q$ and highlighting the same issue (MID male)

I drafted the note, but for sign off from the head of mission. There are times when you know that you need to pull out the big guns. If it requires senior attention, "your excellency" seems to go further than "your officer" (FL male)

The third category of moves identified in Table $14-7$ represented the "strategic approach" used to sell the issue. Sellers used these approaches singly or in combination. 
These moves reflect the conscious plans of attack or "campaigns" adopted to move the issue. Whereas involvement and packaging moves provided insight into the strategic and relational context in this organization, the approach taken to advancing the issue revealed a good deal about the normative context. The moves suggest how implicit beliefs about the "way things work" in this organization might facilitate or impede the flow of information and input from abroad.

The most frequently cited approach was labelled "creating the opportunity" (cited by $78 \%$ of respondents). This was the most direct of the four strategic approaches. It involved a decision by the seller to take ownership of the issue, and subsequent actions by the seller to get it on the screen. Often it took the form of the seller creating products to highlight the issue. Sometimes these independent actions were sufficient to get a response to the issue. Normally, however, they represented only the first step in the effort, and were followed by one of the three more subtle moves discussed below. The defining feature of a "create the opportunity" approach was the realization that at least some action on the issue was within the scope of the respondent's influence and that, without the respondent's action, this was not going to happen. Respondents, therefore, "created the opportunity" to sell the issue by taking personal initiative:

This was an issue of mine I had felt strongly about before I went to post, this was a serious violation of (policy area) that was not on our policy screen. So when I went to post, I began gathering evidence, and writing small reports back to HQ on the topic (FL male)

$I$ brought representatives from this organization together with people from $H Q$ and people from (partner departments). I sat them all down for lunch and I arranged for the right DFAIT people to be there, people with decision making power (HOM female)

In contrast to "creating the opportunity" was an approach labeled "waiting for the 
opportunity" (cited by $23 \%$ of respondents). This approach entailed looking for opportunities to "piggyback" one's issue on an HQ-initiated event, often a visit, conference, or meeting. This approach was often motivated by the belief that it was not acceptable to be "too pushy" in seeking HQ's attention, and that the best time to advance an issue was when you already had HQ's attention:

We had backed off on this issue before since we did not want to come on too strong. But right now we are renewing the charge by piggybacking this issue on the upcoming tour to (country). Any visit, any event, any deadline is an opportunity to get your issue on the screen. It's a lever. Then you can give $H Q$ a deadline and say, we need some kind of response on this (issue) to ensure the (visitor) is not caught off guard on the issue. You use HQ's interest in the event to get what you want out of the visit. You get action on your issue, but it is still win-win because $H Q$ needed agenda items or needed key messaging to support the visit and you have provided it (FL male)

A third strategic approach to moving the issue was to attempt to advance it incrementally over time in effort to "ready the receivers" to hear the message (cited by $30 \%$ of respondents). Sellers using this strategy tended to sprinkle, or "pepper" the message around HQ to give receivers time to adjust to the idea:

I needed to set the stage a bit for this around $H Q$. So, I began watching the media, watching the types of requests locals made of me. And every time I saw this issue raising itself here, I reported on it to HQ. Just wove it into my regular reporting. As in, here's this issue again, and oh, look, here it is again (FL male)

Like piggybacking, peppering served to preserve the seller's credibility by ensuring he or she did not appear to be too "pushy" or to be "jumping the queue":

Nobody wants some junior person lecturing to them about how they can do things better. You can't be gung ho. So, instead, you lay low and keep coming at them with subtle messaging, embedding it in your regular reporting, whenever the opportunity presents itself. You want to let management play in a safe zone, not paint them into a corner, give them the chance to say maybe before they say no (FL male)

I know my audience. I know that I am in a mission that is not of particularly high priority right now, so I tend to be low key at first in advancing my issues. Then I slowly escalate it, turn up the temperature over time. The $H Q$ knee jerk reaction is to say, no, we're not interested, so you're better to let it simmer a bit to help them make up their minds slowly (HOM male) 
The last strategic approach reported by issue sellers was to "work within the system" (cited by $19 \%$ of respondents). This was the most passive of the four approaches, similar to Dutton et al.'s category of using “formal" processes for moving issues. Sellers who worked within the system essentially waited for an invitation to bring their issues forward. They used existing processes or mechanisms, such as a formal consultation process or the creation of a task force to insinuate their issue within that dialogue:

There was an annual report on this policy issue, and I was writing our section of it, so I insinuated this topic there as an emerging policy issue worthy of attention (FL female)

I advanced my issue by writing my lines into the country strategy, and I consider this a success because they are still there, and I have now seen these lines in other documents out of HQ (MID female)

The strategic approach to the issue appeared related to job level. As expected, HOMs were most likely to take more direct approaches, such as initiating the selling campaign themselves ("creating the opportunity"). HOMs seldom "worked within the system" by waiting for the right engagement process to present itself. Conversely, midmanagers and officers were more likely to "piggyback" their issues on an event, again reflecting mid-manager involvement in programming that involved high-profile events, and officers' responsibility to provide support in preparation for such events. Officers were extremely likely to take a peppering approach, readying the receivers through repeated messaging. This typically took a subtle approach, often within the context of their regular reporting schedule.

The tendency to involve the immediate manager, in either a consultative capacity or as the key driver for the issue, was strongly related to job type. One quarter to one third of mid-managers and officers engaged their co-located managers in a consultative capacity 
(cited by $25 \%$ and $33 \%$ of mid-managers and officers respectively). Conversely, only $4 \%$ of HOMs indicated they consulted their DG at HQ in selling their issues. When it came to driving the issue, however, both mid-managers and officers turned to their HOM. Thirtyeight percent of mid-managers said they used their HOM to drive their issue, as did $19 \%$ of officers. In fact, none of the officers said they used their immediate manager to drive their issue, suggesting that the HOM's endorsement of the idea and his or her reach to HQ were believed to be critical factors in moving an issue from post. Again, only $4 \%$ of HOMs said they turned to their HQ DG to drive their issue. Instead, HOMs were unlikely to indicate they used a driver at all (not shown), but drove the issues themselves by directly approaching the appropriate parties at $\mathrm{HQ}$.

Combined, the findings on manager involvement suggest a pattern wherein lower levels of the mission hierarchy (mid-managers and officers) consult their local managers on their issue, and then turn to the HOM to move it forward. HOMs then either take the necessary actions themselves, or proceed through the appropriate channels at HQ, including targeting the highest levels, including the ADM, Deputy, or other senior colleagues at HQ. It is important to interpret these process moves, however, in light of the involvement moves cited in Table 14-5. Whereas process moves indicate that HOMs seldom consulted their HQ manager in advance of moving their issue- - or expressly used their manager to drive it- they did ensure that their HQ DG was informed as the work progressed (46\% of HOMs involved their managers at some point during the issue-selling move; Table 14-5). The tendency for HOMs to "keep the DG in the loop", rather than seeking the DG's advice or action, is consistent with HOMs' perceived reporting relationship with this individual. The HQ DG is often a person who is junior to the HOM, and is often viewed more as a "port of 
call" than as a manager with hierarchical authority (Chapter 11). Instead, HOMs have sufficient authority and reach to drive the issues themselves, and go directly to the person responsible for the issue, including those above the DG.

Finally, only a minority of boundary spanners mentioned the timing of their selling efforts in their accounts. Typically, timing was event-triggered, driven by the desire to piggyback an issue:

My DG came to town, so this was an opportunity to revisit the issue, to have him actually meet with (local interlocutors) and see what their perspective was on this. This would help build my case (MID female)

Only rarely did respondents' comments suggest a deliberate effort to "read the mood" at HQ and wait for an opportune moment to "strike while the iron was hot":

I needed to know whether something else was preoccupying $H Q$. When it is, you can wait it out, or better yet, tie your issue to their preoccupation (HOM female)

To "strike while the iron is hot", one must have sufficient strategic and relational knowledge to know what is preoccupying HQ management and why. This move was cited largely by HOMs, supporting earlier observations that boundary spanners at management levels in this organization may have greater access to HQ context than those at lower levels. Generally, however, the data suggested that distance rendered events at HQ somewhat opaque to most boundary spanners in this sample. Unless a specific event presented itself, respondents appeared to lack the HQ context they needed to gauge HQ's appetite for an issue and time their selling efforts accordingly.

\subsection{Perceived success of issue-selling efforts}

It would have been of interest to determine in this MNE context the extent to which 
the various issue-selling moves proved to be effective. Dutton et al. (2001) had identified the moves associated with success by prompting respondents to describe both a successful and unsuccessful issue-selling effort and then contrasting the moves that emerged within each. As discussed in the methodology (Chapter 9), however, time constraints precluded prompting respondents to describe both a successful and unsuccessful attempt. This meant that the researcher's ability to analyze the factors associated with success was dependent on whether interviews elicited sufficient numbers of successful and unsuccessful attempts to support analysis.

The distribution of the issue-selling accounts in terms of perceived success is given in Table $14-8$.

\begin{tabular}{|l|c|c|c|c|}
\hline Table 14-8 Perceived success of influence effort \\
\hline Was your effort successful? & $\begin{array}{c}\text { Head of } \\
\text { mission } \\
(\mathbf{N = 2 0})\end{array}$ & $\begin{array}{c}\text { Mid- } \\
\text { manager } \\
(\mathbf{N = 1 4})\end{array}$ & $\begin{array}{c}\text { Officer } \\
(\mathbf{N}=22)\end{array}$ & $\begin{array}{c}\text { Total } \\
(\mathbf{N}=56)^{10}\end{array}$ \\
\hline & \multicolumn{4}{|c|}{$(\%)$} \\
\hline Yes & 70 & 43 & 68 & 63 \\
\hline No & 25 & 36 & 14 & 23 \\
\hline Don't know & 5 & 21 & 18 & 14 \\
\hline Total & 100 & 100 & 100 & 100 \\
\hline
\end{tabular}

As might have been anticipated, most respondents had described a successful attempt. When asked at the end of their accounts whether they perceived their efforts to have achieved the result they had hoped for, nearly two-thirds of respondents (63\%) said "yes"; roughly one quarter (23\%) said "no", and the remaining $15 \%$ said either that they did

\footnotetext{
${ }^{10}$ Smaller $\mathrm{N}$ reflects non-responses on the success item
} 
not know or that it was too soon to tell. The small number of unsuccessful attempts meant that it was not possible to contrast the various moves made in the successful efforts with those made in the unsuccessful efforts in order to make claims regarding effectiveness. For example, the total number of unsuccessful attempts was 13 (5 HOMs, 5 mid-managers, and 3 officers). Once these numbers were cross-tabulated with moves (e.g., to determine the proportion who used a peppering strategy, or the proportion who involved their manager in the effort), cell sizes became too small for analysis. It was not possible, therefore, to empirically derive from the episodes the factors associated with success.

Accordingly, it is also not possible to comment on the job level differences suggested in Table 14-8. The response pattern suggests that mid-managers in particular appeared to have a rather high proportion of unsuccessful attempts (36\%). Given the small number of episodes available for analysis, it is not possible to link these findings to individual moves. Further, it is important to note that the success of an effort is a function of a large number of factors, not the least of which is the nature of the issue itself. Given that mid-managers were involved in a different range of issues than those at other job levels, their relative lack of success may reflect the issues themselves, rather than the moves they used to advance them. Mid-manager issue-selling efforts tended not to be related to policy, but to mid-managers' mission and program management responsibilities, typically aimed at obtaining increased resources, modifying central processes initiated at $\mathrm{HQ}$, or encouraging a visit (Table 14-3). These are very "tough sells" at HQ, where resources are scarce, central processes are hardwired within the bureaucracy, and the time of senior officials is at a premium.

Given that the factors associated with success could not be empirically derived from 
the episodes, the researcher turned to the concluding question to this series to identify what respondents perceived to be the critical success factors in selling their issues. Results are given in Table 14-9.

\begin{tabular}{|l|c|c|c|c|}
\hline Table 14-9 Perceived success factors in moving issues & $\begin{array}{c}\text { Head of } \\
\text { mission } \\
(\mathbf{N = 2 0})\end{array}$ & $\begin{array}{c}\text { Mid- } \\
\text { manager } \\
(\mathbf{N = 9 )}\end{array}$ & $\begin{array}{c}\text { Officer } \\
(\mathbf{N = 2 1 )}\end{array}$ & $\begin{array}{c}\text { Total } \\
(\mathbf{N}=\mathbf{5 0})^{\mathbf{1 1}}\end{array}$ \\
\hline & \multicolumn{4}{|c|}{$(\%)$} \\
\hline Packaging & 40 & 33 & 29 & 34 \\
\hline "Alignment of planets" & 25 & 22 & 33 & 28 \\
\hline My persistence, reputation, personal characteristics & 20 & 22 & 33 & 26 \\
\hline Having a key contact at HQ to drive it & 20 & 22 & 14 & 18 \\
\hline Peppering & 20 & 22 & 14 & 18 \\
\hline Working within the system & 5 & 33 & 14 & 14 \\
\hline Support from a coalition & 20 & - & 10 & 12 \\
\hline
\end{tabular}

For the most part, respondents linked their success to their choice of moves. One third of respondents $(34 \%)$ indicated that their success was due to their approach to packaging the issue. This finding was of theoretical interest, since one of the key packaging strategies used by boundary spanners in this research was to support their issue with local evidence and expert local insight. This provided limited support for the potential mediating role served by boundary spanners in the MNE setting, in that it suggested that boundary spanners at least perceived that their success was attributable to their having leveraged valued information resources in their selling effort.

Interestingly, the next most frequent response did not involve a success factor at all,

11 Smaller $\mathrm{N}$ reflects non-responses on critical success factor item 
but reflected a belief that the respondent really couldn't take credit for their success. When asked for the critical factor associated with their success, $28 \%$ of respondents said that their success had been fortuitous and happened when the "planets aligned" in their favour.

Sometimes this appeared to reflect the awareness that movement on international issues required a confluence of pressures and was unlikely to be achieved by any individual's efforts. In these instances, success was associated with another force that coincided with the boundary spanner's efforts:

After several months of effort, I couldn't convince HQ on my own that attending this summit was important, but as it turned out, I went on leave for a week and when I returned, suddenly we were making the trip. As it turned out, there was a highly visible (contemporaneous local occurrence) here that put the issue on the screen, and it was deemed important for Canada to be there. So, the successful outcome was not entirely my success, but I'll take my successes however I can get them (HOM male)

However, some "alignment of planets" responses also reflected the boundary spanner's lack of connectedness to internal networks at HQ and the inability to fully understand what "went right":

You never know what will fly at Ottawa. It moves when you get high level attention to something, from the DM maybe, but you don't really know from post when that has happened or why. You just infer it because suddenly your issue is visible (FL female)

"Alignment of the planets" responses were reminiscent of earlier references to events at HQ being somewhat opaque to boundary spanners abroad, and suggested how lack of contextual knowledge might limit boundary spanners' ability to obtain feedback on their efforts. (The possibility that events at HQ were invisible to the boundary spanner was also consistent with the fact that $15 \%$ of respondents had not known whether they had been successful or not!)

Roughly one quarter of respondents $(26 \%)$ attributed their success to some personal 
characteristic, such as persistence or determination. This success factor was normally described in association with a "create the opportunity" move, where respondents commented that the issue would not have gained attention without their personal initiative.

Other success factors associated with the choice of move included having used a peppering strategy (18\%), working within the system (14\%) and enlisting support from a coalition $(12 \%)$. It is also important to note that $18 \%$ of respondents said that having someone at HQ to drive the issue had been key to their success.

Job level differences generally reflected job level differences previously seen in the choice of moves. Mid-managers were more likely to attribute their success to having worked within the system, consistent with the constraints they face in working within established programming guidelines and their need to adhere to protocol in the budgeting cycle. HOMs were more likely to attribute their success to their coalitions, consistent with their preference for moving their own issues, and their tendency to build a team of colleagues to support them in their effort.

\subsection{Enfolding the quantitative data}

Having explored boundary spanners' issue-selling accounts, the next step was to turn to the questionnaire data to look for opportunities to challenge or corroborate the qualitative findings. Two measures had been included in the questionnaire to provide contextual data for the issue-selling analysis: job autonomy and perceived influence.

There were many potential applications of these measures to the data. To focus the analysis, two applications were chosen, based on the patterns observed in the qualitative data. First, it was of interest to see whether these measures were related to the decision to 
sell. The job autonomy measure was of interest in this regard, since it was expected that boundary spanners who enjoyed a high level of discretion and independence on the job might be more likely to "go solo" on important issues and simply move their issues themselves. Those who sensed little autonomy might be more likely to perceive the need to sell others. Second, it was of interest to see whether the measures might be related to the choice among issue-selling moves. The perceived influence measure was of interest in this regard, especially as it related to process moves. The various strategic approaches to selling an issue implied varying degrees of initiative and assertiveness (e.g., a subtle "peppering" approach versus "creating the opportunity"). Accordingly, sellers who perceived they had sufficient influence to "make a difference" might be more willing to undertake the more assertive campaigns. The influence measure was thus used to test the hypotheses that perceived influence played a role in the choice among strategic approaches to issue selling.

\subsubsection{Job autonomy}

Unfortunately, it was not possible to use the job autonomy measure to test the data on decisions to sell. As indicated in Section 9.3, scores on the autonomy measure showed restriction in range, so were of limited use in testing the patterns observed in the qualitative data. Nearly three quarters of the sample (72\%) rated their jobs as high in autonomy. Only $7 \%$ (representing only 5 of the 75 individuals who returned questionnaires) rated their jobs as low in autonomy (Table 9-7). When applied to the data on decision to sell, all of the individuals who had advanced their issues themselves reported they were in high-autonomy jobs (not shown). But, then, the majority of those who had never tried to advance an issue also reported high-autonomy jobs. In both scenarios, the "low-autonomy" cell was empty. 
There were simply too few low-autonomy cases to contrast with high-autonomy cases on this variable.

Overall, the autonomy measure was useful as corroboration of respondents' claims that work abroad was highly independent and was performed in relative isolation from interaction with HQ (the "black hole"; Chapter 11). The measure thus provided a useful contextual backdrop against which to view the case data. The measure, however, was of limited use in testing specific findings.

\subsubsection{Perceived influence}

The interview data had identified four strategic approaches to issue selling. The influence measure provided the opportunity to test whether choices among these four approaches might be a function of boundary spanners' perceived ability to influence decision-makers in the organization. For example, it might be expected that those who perceived themselves as highly influential might take the more assertive approaches, and "create their own opportunities" to sell. Those who perceived themselves to have little influence might be more likely to adopt subtle approaches, such as "peppering" messaging throughout the organization or working within the system through the use of consultation processes and other sanctioned mechanisms.

Qualitative support for these hypotheses had been suggested in the observation that HOMs' issue-selling episodes were more likely to involve assertive moves, and officers' more likely to involve subtle moves (Table 14-7). Since HOMs also were more likely than officers to report high levels of influence (61\% of HOMs reported high influence as compared with $35 \%$ of officers; Table 9-7), it was conceivable that the observed job level 
differences in issue-selling moves were attributable at least partly to differences in perceived influence.

Table 14-10 cross-tabulates the four strategic approaches with scores on the influence measure. The first panel shows findings for the full sample. The data provide support for the assertion that the choice of strategic approach is related to perceived influence. First, "creating the opportunity" was the most frequent approach, regardless of the perceived level of influence. This is attributable to the fact that most boundary spanners' issue-selling efforts began with at least some preliminary action to get attention to the issue (e.g., a phone call, an email campaign, a report). Second, there appears to be no substantive difference in the frequency of subtle moves employed by high- versus lowinfluence respondents (i.e., both high-and low-influence groups were likely to pepper, piggyback or work within the system). It is in the behaviour of boundary spanners in the moderate category where a potential relationship between influence and issue-selling strategies is suggested. ${ }^{12}$

\footnotetext{
${ }^{12} \mathrm{~N}$ 's in Table 14-10 are small, as are some of the proportionate differences discussed in support of observed patterns. Differences, however, are in the expected direction, and consistent conceptually with the claim that boundary spanners with moderate influence may be more likely than those with higher or lower levels of influence to rely on subtle moves. The data, therefore, meet the criterion for substantive significance (Section 9.5), so are presented for discussion here. Readers will likely see other patterns in the data as well.
} 


\begin{tabular}{|c|c|c|c|c|}
\hline & $\begin{array}{l}\text { Creating the } \\
\text { opportunity }\end{array}$ & $\begin{array}{l}\text { Waiting for the } \\
\text { opportunity } \\
\text { (piggybacking) }\end{array}$ & $\begin{array}{l}\text { Readying the } \\
\text { receivers } \\
\text { (peppering) }\end{array}$ & $\begin{array}{l}\text { Working } \\
\text { within the } \\
\text { system }\end{array}$ \\
\hline & \multicolumn{4}{|c|}{$\%$} \\
\hline \multicolumn{5}{|l|}{ Total sample } \\
\hline High influence $(\mathrm{N}=26)$ & 77 & 19 & 27 & 12 \\
\hline Moderate influence $(\mathrm{N}=19)$ & 90 & 37 & 32 & 21 \\
\hline Low influence $(\mathrm{N}=16)$ & 63 & 19 & 38 & 25 \\
\hline \multicolumn{5}{|l|}{ Head of mission } \\
\hline High influence $(\mathrm{N}=15)$ & 80 & 13 & 20 & 7 \\
\hline Moderate influence $(\mathrm{N}=8)$ & 100 & 25 & 38 & - \\
\hline Low influence $(\mathrm{N}=2)$ & 100 & - & - & - \\
\hline \multicolumn{5}{|l|}{ Mid-manager } \\
\hline High influence $(\mathrm{N}=2)$ & 100 & - & - & 50 \\
\hline Moderate influence $(\mathrm{N}=6)$ & 100 & 50 & 17 & 33 \\
\hline Low influence $(\mathrm{N}=3)$ & - & 33 & 67 & 33 \\
\hline \multicolumn{5}{|l|}{ Officer } \\
\hline High influence $(\mathrm{N}=9)$ & 67 & 33 & 44 & 11 \\
\hline Moderate influence $(\mathrm{N}=5)$ & 60 & 40 & 40 & 40 \\
\hline Low influence $(\mathrm{N}=11)$ & 73 & 18 & 36 & 27 \\
\hline
\end{tabular}

The pattern suggests that respondents with moderate influence are: (1) more likely than those in the high- and low-influence groups to start their campaign by "creating the opportunity" (reported by $90 \%$ of moderate-influence respondents, compared to $77 \%$ of those with high influence and $63 \%$ of low-influence sample) and (2) more likely to employ one or more of the subtle moves (e.g., 37\% of moderate-influence respondents piggybacked their issue, compared with only $19 \%$ of the high- and low-influence samples). This pattern 
suggests that boundary spanners who perceive they have moderate influence may believe they have sufficient influence to "get the ball rolling", but insufficient influence to actually "make it happen". Accordingly, they strategically accompany their initial effort with more subtle "follow-up" moves designed to maintain momentum and keep the issue on the screen.

This interpretation is generally supported by job level differences evident in panels two through four. HOMs tend to have a high level of perceived influence overall. However, those who perceive themselves to be moderate in influence are more likely than their high-influence counterparts to follow up their initial move with the more subtle moves of peppering (38\% among moderate-influence HOMS vs. $20 \%$ among high-influence HOMs) or piggybacking (25\% among moderate-influence HOMs vs. $13 \%$ among those with high influence). The same pattern is evident among mid-managers, where $17 \%$ of those with moderate influence peppered their issues (compared to none of the high-influence managers); and 50\% piggybacked (compared again to none of the high-influence managers). Although there is some variation within the officer level, the trend is also generally supported, with $40 \%$ of moderate-influence officers piggybacking (as opposed to $33 \%$ of those with high influence), and $40 \%$ working within the system (as opposed to $11 \%$ of those with high influence).

The interpretation that boundary spanners with moderate levels of influence may perceive a greater need for subtle strategies to support their issue-selling efforts is consistent with interview data where respondents frequently described strategies of "laying low", waiting for opportunities to return to their issues, or gradually "turning up the heat" over time. The quantitative data thus corroborate qualitative data in suggesting that the choice 
of issue-selling strategy may be related to perceived influence. Combined, the findings suggest that effective issue-selling may require a combination of having sufficient confidence in one's level of influence to initiate a move and having the organizational savvy to know how to keep it moving.

Although the data suggest that the choice of issue-selling moves may be related to perceived influence, these findings should be interpreted with caution. A quantitative measure of influence is insensitive to the situation-specific context in which issue-selling is embedded. Perceived influence measures a global work orientation. Although it is likely that an individual's overall sense of influence at least partly determines his or her choice of moves in a given situation, its effect may be minor in comparison to the effect of situationspecific factors. Issue-selling is highly situated (Dutton et al., 2001). Because influence was so strongly related to job level, boundary spanners' choice of moves may reflect, not differences in perceived influence, but differences in the opportunities for issue-selling that presented themselves to boundary spanners at different levels of the organization, and differences in their assessments of appropriate actions, given their positions in the organization. Indeed, those who are influential may have attained their influence by knowing when to make a move and when to hold back. The choice among moves may be determined more by issue sellers' knowledge of "what works" in a specific situation than by their global work orientations. The qualitative data revealed a number of beliefs about "what works" in this organization that issue sellers may have relied on in navigating the organizational context to sell their issues. The next section returns to the qualitative data to identify these "theories-in-use". 


\subsection{Theories-in-use}

Table 14-11 summarizes the theories-in-use that emerged in boundary spanners' issue-selling accounts. The numbers represent the proportion of respondents who explicitly mentioned the various theories as they told their stories. These theories provide insight into the system of norms, values, and routines that may shape issue-selling from abroad in this organization.

\begin{tabular}{|c|c|c|c|c|}
\hline & $\begin{array}{l}\text { Head of } \\
\text { mission } \\
(\mathrm{N}=29)\end{array}$ & $\begin{array}{c}\text { Mid- } \\
\text { manager } \\
(\mathrm{N}=12)\end{array}$ & $\begin{array}{l}\text { Officer } \\
(\mathbf{N}=21)\end{array}$ & $\begin{array}{r}\text { Total } \\
(\mathbf{N}=62)\end{array}$ \\
\hline & \multicolumn{4}{|c|}{$(\%)$} \\
\hline You can't be too pushy & 28 & 42 & 38 & 34 \\
\hline Only high priority posts can move ideas & 31 & 8 & 19 & 23 \\
\hline You can't be seen as having "localitis" & 17 & 33 & 19 & 21 \\
\hline You can't move ideas from post & 24 & 25 & 10 & 19 \\
\hline You need your HOM's support & - & 25 & 24 & 13 \\
\hline You need your manager's support & - & - & 33 & 11 \\
\hline Only senior people can move ideas & 7 & 17 & 10 & 10 \\
\hline
\end{tabular}

Whereas previous data suggested that relational and strategic knowledge may be somewhat subject to erosion when abroad, these data suggest that normative knowledge remains remarkably intact. The nature of the normative beliefs expressed here is consistent with the rather conservative approach to issue-selling that emerged in this research. One third of the sample claimed that "you can't be too pushy" in selling issues, suggesting a normative barrier to aggressive issue-selling campaigns in this organization:

The squeaky wheels get grease only when they have a very strong case and a link to government 
priorities. If you don't have these, you not only negate the effect of the request at hand, you influence their response to any future request. $H Q$ will just say, this person doesn' $t$ get it, all they want is "me, me, me" (HOM female)

We got no response to our initial suggestion through our regular reporting line. I have seen individuals in this organization ruin their reputations by not knowing when to drop an issue, so we let it ride for a while and looked for other occasions to strategically either connect our concern to broader issues or piggyback it on other things (MID male)

Consistent with the respect for hierarchy typical of many bureaucratic organizations (Dutton et al., 2001), many of the theories-in-use involved references to the need to involve more senior levels to move an issue. Thirteen percent indicated you needed to have your HOM's support to move an issue, $11 \%$ mentioned needing the manager's support, and $10 \%$ mentioned the belief that "only senior people could move ideas":

The culture here is that you would never report directly to the Deputy Minister. This is an absolute no-no. The proper channel is through your desk to the Director (HOM female)

Three of the theories-in-use, however, reflected normative beliefs that would be unique to an international setting. Roughly $23 \%$ indicated that only high priority posts could move ideas, largely due to the demands of operating in a global environment where natural disasters, conflict, and other crises understandably diverted the limited time resources of $\mathrm{HQ}$ :

$H Q$ has real emergencies to deal with. I am in a small mission in a small country. There are missions where, let's face it, whatever local information you may get, $H Q$ is not going to have time to deal with it. I accept that and try to keep low key (HOM male)

The desire to avoid appearing to have been afflicted with "localitis" also was unique to an international setting (cited by $21 \%$ of respondents). The belief that it was important to guard against being seen as having "gone local" was often mentioned in conjunction with the need to package an issue with evidence, or as illustrated in the quote below, the need to 
take more subtle approaches to issue-selling:

If you lobby too passionately for something, you will be perceived to have gone local. Of course, only you have that local insight, so it's your job to bring it forward, but you have to find that balance (MID male)

Finally, 19\% of the sample stated simply that "you can't move ideas from post". These comments normally reflected the perception that the key to effective issue-selling was faceto-face interaction. Issue-selling was thus easier when it was done from within HQ:

I can't wait to get back to $H Q$ so I can make a difference. You can send someone an email from post, but you have no sense of the support it gets, you can't bump into someone in the hall and fold them in. You can write an email, but not too often, or Ottawa will say ok, enough now. You can have a great idea, but it will not get results unless people really trust and know the sender. You can't build trust in cyberspace (MID female)

Many of the job level differences in theories-in-use correspond to job level differences seen in the issue-selling moves. The belief that you can't be too pushy was prevalent at all levels, but more so at the mid-manager and officer level than at the HOM level. This is consistent with the greater reliance on subtle approaches (e.g., working within the system, peppering) at lower levels of the organization. The belief that you need your manager's support, particularly the support of your HOM, was evident at both the mid-manager and officer level, consistent with their tendency to involve their managers in the selling effort and to use their HOM's "heft" to drive it. Conversely, none of the HOMs believed they needed their manager's support to move an issue, consistent with their earlier comments regarding their generally low level of reliance on their DGs at HQ (Chapter 11). Interestingly, only a small proportion of officers (10\%) believed that they could not move issues from post, compared with $25 \%$ of those at higher levels. This suggests a socialization aspect to the acquisition of normative knowledge in this organization. Three 
quarters of these officers were on their first assignment. They appeared to have learned quickly not to be too pushy and not to jump the hierarchy. Likely, they carried these norms with them from their pre-posting experience at HQ. However, they apparently had not yet come to the conclusion that they couldn't move an issue at all from abroad. This finding is consistent with the outcome to the screening question (Table 14-1), where only one of the 28 officers interviewed reported that they had never tried to sell an issue from post. This suggests that more junior levels of the organization may need targeted support early in their assignments to encourage and capitalize on their willingness to bring ideas forward. Potential support for the boundary spanning role is the topic of the next chapter.

\subsection{Summary}

The conceptual model developed for this thesis identified individual influence as a critical condition for effectiveness in the boundary spanning role. The ability of the boundary spanner to transmit local intelligence and exert influence over the organization's direction was believed to be fundamental to the organization's ability to adapt to changing contingencies at the boundary. The data presented in this chapter provide a description of the strategies used by boundary spanners in this international setting to influence management on issues of perceived importance. The data are mapped to the expanded model of the conditions for effectiveness in the boundary role (Chapter 16) and are discussed below.

The issue-selling moves identified in this research suggested several means by which boundary spanners in an international setting may attempt to influence strategic decisionmaking. Although the methodology for the research precluded examination of the 
effectiveness of the moves, it does allow us to describe the perceptions of these boundary spanners in terms of "what works" when selling issues from abroad. These perceptions afford preliminary insight into the potential effects of geographic distance on boundary spanner influence.

The findings provided support for both of the predictions of social network theory regarding the potential influence of boundary spanners in an international setting. The proposition that boundary spanners may achieve influence over other organizational members due to their mediation of valued information resources found support in boundary spanners' descriptions of their issue "packaging" moves. The most common approaches involved packaging the issue with local evidence, including the perspectives of the local international community and the boundary spanner's assessment of potential courses of action given the local scene. Boundary spanners' access to specialized local knowledge- knowledge that would have been invisible to HQ without their input- - placed boundary spanners in somewhat of a privileged position with respect to information resources. Accordingly, boundary spanners also reported that their packaging of the issue had been a key factor in their success.

However, the findings also provided support for the prediction that geographic distance might pose barriers to the ability of boundary spanners to exert influence over organizational members. Several of the issue-selling moves suggested that access to the organization's strategic and relational context may be somewhat diminished in international settings. The potentially deleterious effect of distance on relational knowledge was suggested in "involvement" moves, where boundary spanners commented that distance from HQ sometimes made it difficult to strategically target their selling efforts, leading to 
"shotgun" approaches in their efforts to involve others. The potential effect of distance on strategic knowledge was suggested in packaging and process moves, where boundary spanners commented that it was often difficult to know what issues were occupying management attention at $\mathrm{HQ}$, and accordingly, how best to frame their arguments and time their moves. Further, comments offered in conjunction with several of the moves suggested that the lack of face-to-face contact inherent in an international assignment made it difficult for the boundary spanner to communicate nuances, read reactions, and gauge interests at HQ. Accordingly, one in five respondents cited as a critical success factor the importance of having an "internal boundary spanner" at HQ who could bridge the geographic divide and exert the interpersonal influence needed to drive issues on the issue-seller's behalf.

In contrast to the risks to strategic and relational knowledge suggested in the data, normative knowledge appeared to remain remarkably intact over geographic distance. In this organization, strong normative beliefs prescribing a respect for hierarchy led to rather subtle approaches to moving issues. Conservatism in issue-selling is not unique to the international setting, but is characteristic to many large, bureaucratic organizations (Dutton et al., 2001). However, it is possible that in the international setting, conservatism in issueselling combined with the somewhat diminished access to contextual knowledge inherent in an international assignment, may create the conditions for impediments to information flow from the boundary. This interpretation of the data suggests that organizations that wish to maximize the inward flow of information from their boundary spanners abroad may need to exert extra effort to overcome this potential "liability of distance". The next chapter examines potential sources of organizational support for boundary spanners in the international setting. 


\section{BOUNDARY SPANNER PERCEPTIONS OF ORGANIZATIONAL SUPPORT FOR THE BOUNDARY ROLE}

Toward the end of the interview, respondents were asked what types of support were provided to them by their organization and by their managers, and what they might like in the way of support for their boundary roles abroad (Research Question 8). This chapter discusses these findings. The chapter looks first at support at the level of the organization, then at support provided by the manager. It concludes with a summary of implications for creating an organizational context that supports boundary spanners in an international setting.

\subsection{Organizational support}

Table 15-1 provides a summary of boundary spanners' perceptions of the sources of support provided by the organization. 


\begin{tabular}{|c|c|c|c|c|c|}
\hline \multirow{2}{*}{$\begin{array}{l}\text { Is there anything the } \\
\text { organization does that } \\
\text { helps you perform } \\
\text { more effectively in } \\
\text { your role abroad? }\end{array}$} & \multirow{2}{*}{ Description/Examples } & $\begin{array}{l}\text { Head of } \\
\text { mission } \\
(\mathrm{N}=33)\end{array}$ & $\begin{array}{l}\text { Mid- } \\
\text { manager } \\
(\mathrm{N}=15)\end{array}$ & $\begin{array}{l}\text { Officer } \\
(N=26)\end{array}$ & $\begin{array}{c}\text { Total } \\
(\mathrm{N}=74)\end{array}$ \\
\hline & & \multicolumn{4}{|c|}{$(\%)$} \\
\hline $\begin{array}{l}\text { Provides clarity in high- } \\
\text { level objectives }\end{array}$ & $\begin{array}{l}\text { Organization communicates high-level } \\
\text { objectives to missions abroad }\end{array}$ & 27 & 47 & 23 & 30 \\
\hline $\begin{array}{l}\text { Supports interaction } \\
\text { and dialogue with HQ }\end{array}$ & $\begin{array}{l}\text { Organization provides opportunities for } \\
\text { interaction between HQ and missions } \\
\text { (e.g., annual meetings, conference calls) }\end{array}$ & 15 & 13 & 23 & 18 \\
\hline Provides autonomy & $\begin{array}{l}\text { Organization provides latitude to } \\
\text { employees abroad (e.g., freedom to set } \\
\text { your agenda, "not a tight leash") }\end{array}$ & 24 & 7 & 4 & 14 \\
\hline $\begin{array}{l}\text { Provides family and } \\
\text { relocation support }\end{array}$ & $\begin{array}{l}\text { Organization recognizes individual and } \\
\text { family needs arising from work abroad }\end{array}$ & 12 & 13 & 15 & 14 \\
\hline
\end{tabular}

Responses to this question largely reflected themes that had already emerged in the research. Data previously discussed indicated that boundary spanners in this organization highly valued their interaction with $\mathrm{HQ}$ as a source of strategic direction and as a source of the contextual knowledge needed to inform their jobs (Chapter 11). Accordingly, the organization was perceived to be supportive to the extent that it created the intraorganizational conditions needed to communicate objectives and enable interaction with HQ. Thirty percent of respondents indicated that they felt supported in their role abroad when DFAIT provided clarity in terms of high-level objectives for the region. Many of these comments referred specifically to the value of the formal tools discussed in Chapter 11:

I think they are on the right track with this (country strategy) suite, this cascading of priorities, starting with the government's objectives and then working down to what we actually do here, and what I individually do. That works for me. The process shapes your thinking (HOM male)

\footnotetext{
${ }^{13}$ Excludes very small categories of responses and responses indicating that there was no policy or practice at the organizational level that the respondent found helpful
} 
Eighteen percent of respondents said that DFAIT supported them by providing opportunities for interaction with HQ. These respondents especially valued formats that helped bridge intra-organizational "distance" by enabling real-time dialogue. Synchronous, and ideally, face-to-face, communications were perceived to promote a level of interpersonal contact that could not be obtained through electronic media:

Conference calls are very valuable. There are sensitive topics that come out in these calls that you wouldn't discuss otherwise, that maybe you wouldn't want to put down in writing, so calls are very important when you are abroad (HOM male)

Anytime there is a visit, or anytime someone from the division comes to post, that's the most helpful thing they can do. First, it gives us that face-to-face contact and time to interact, and an opportunity to clear misunderstandings and chart our way forward. Second, it helps $H Q$ see the context we are working in and get a first hand appreciation so they better understand our perspectives (MID female)

Several respondents commented further that the organization supported interaction though a sophisticated telephone technology that enabled high-quality and instantaneous real-time dialogue when face-to-face interaction was not an option:

Our phone system is wonderful, I can dial anywhere in the world in six digits, and the transmission is crystal clear. Our communications system is among the best. My diplomatic colleagues are jealous. The investments we have made in technology over the last 20 years have paid back in great dividends (FL male)

A third way in which the organization was perceived to be supportive was in providing the boundary spanner with freedom and discretion in doing his or her job. Fourteen percent of respondents indicated that they enjoyed a high level of autonomy on the job. This response was given almost exclusively by HOMs, who indicated that autonomy was necessary if they were to take decisions that were responsive to the local environment. These comments reflected a perception that HQ entrusted them to take local decisions, since 
the HOM was in the best position to assess the local context. Consistent with the data on influence (Chapter 14), this again suggested that boundary spanners may obtain a somewhat privileged position as a result of their ability to mediate access to specialized local knowledge:

They support me by leaving me to do my job. At post, you get to do it small and simple. You want to have a discussion on an issue, you walk into the next office. You want to take a decision, you take it. You don't have to have an agenda, call a meeting, do a time line. For the most part, the best part of being abroad is running your own ship. You are trained to run the ship and trusted to do it. You can make a difference locally this way (HOM male)

That's why I'm here. To make the decisions that HQ can't because they don't have the full information they need to make them. They can't be everywhere, so you are trusted to be their eyes and hands abroad (HOM female)

Although respondents had been prompted to focus specifically on support for their boundary roles, it was interesting to observe that a minority of respondents addressed family issues in their answers. Fourteen percent of respondents said that the organization supported them by providing various destination services, such as spousal employment assistance and relocation support. This set of responses served as a reminder that, although not a focal construct in this research, adjustment to the local environment remains a very salient feature of the expatriate experience. Support for this adjustment was perceived to be an important role for the organization :

When we are moved abroad, DFAIT takes good care of us in terms of moving, getting settled. When you compare us with other developed countries, you realize they take better care of us than many (FL male)

They take care of the bureaucratic clutter, they see that your phone is hooked up, repair your air conditioning, do the logistics around paying your bills. They get you a drivers' license. My colleagues in the private sector who are relocated here have to get their own license, and this is a big deal. You have to take off a day and a half of work to line up for this. On the one hand, it seems as if I am pampered. On the other hand, if you have to line up at the bank for three hours to pay a utility bill, that's three hours of lost productivity (FL male)

Respondents were then asked what they might like from the organization in the way 
of support. Responses to this question are summarized in Table 15-2.

\begin{tabular}{|c|c|c|c|c|c|}
\hline \multirow{2}{*}{$\begin{array}{l}\text { Is there anything you } \\
\text { would like from the } \\
\text { organization in the way } \\
\text { of support? }\end{array}$} & \multirow{2}{*}{ Description/Examples } & $\begin{array}{l}\text { Head of } \\
\text { mission } \\
(\mathrm{N}=\mathbf{3 3})\end{array}$ & $\begin{array}{c}\text { Mid- } \\
\text { manager } \\
(\mathrm{N}=19)\end{array}$ & $\begin{array}{l}\text { Officer } \\
(\mathrm{N}=\mathbf{2 8})\end{array}$ & $\begin{array}{l}\text { Total } \\
(\mathbf{N}=\mathbf{8 0})\end{array}$ \\
\hline & & \multicolumn{4}{|c|}{$(\%)$} \\
\hline $\begin{array}{l}\text { More interaction and } \\
\text { dialogue with } \mathrm{HQ}\end{array}$ & $\begin{array}{l}\text { More opportunities for interaction and } \\
\text { substantive discussion with HQ (come } \\
\text { to post, bring us to } \mathrm{HQ} \text {, more conference } \\
\text { calls) }\end{array}$ & 34 & 32 & 25 & 30 \\
\hline $\begin{array}{l}\text { Clearer objectives/ } \\
\text { translation of } \\
\text { objectives }\end{array}$ & $\begin{array}{l}\text { Clearer articulation of objectives } \\
\text { (objectives currently too high level); } \\
\text { support in translating high-level } \\
\text { objectives to attainable local objectives }\end{array}$ & 30 & 26 & 32 & 30 \\
\hline Fix the black hole & $\begin{array}{l}\text { Specifically mentions "black hole" in a } \\
\text { call for better feedback on reporting and } \\
\text { better feedback to mission proposals and } \\
\text { suggestions }\end{array}$ & 9 & 26 & 18 & 16 \\
\hline $\begin{array}{l}\text { Make better use of my } \\
\text { knowledge upon } \\
\text { repatriation }\end{array}$ & $\begin{array}{l}\text { More opportunities to share and apply } \\
\text { knowledge when returning from abroad }\end{array}$ & 12 & 11 & 25 & 16 \\
\hline $\begin{array}{l}\text { More interaction and } \\
\text { dialogue with peers }\end{array}$ & $\begin{array}{l}\text { More opportunities for interaction and } \\
\text { substantive discussion with peers (more } \\
\text { meetings, conference calls) }\end{array}$ & 18 & - & 14 & 13 \\
\hline $\begin{array}{l}\text { Greater access to } \\
\text { high-level context }\end{array}$ & $\begin{array}{l}\text { More sharing of high level context } \\
\text { (policy documents, position papers, etc.) }\end{array}$ & 6 & 5 & 18 & 10 \\
\hline
\end{tabular}

The data pattern is consistent with that in the previous table in that the most frequent responses revolved around the need for clarity in objectives and more dialogue with HQ. The data support the claim that contact with $\mathrm{HQ}$ is a valued resource abroad in that it enables the boundary spanner to obtain the strategic and relational knowledge needed to perform the job effectively. When asked what they would like in the way of support, $30 \%$ of respondents said they would like more interaction and dialogue with HQ. Some respondents noted that time differences posed a barrier to interaction, and believed that the organization needed to devote special attention to encouraging linkages between 
organizational members to overcome potential temporal barriers:

Due to the time difference at this post, I can do very little networking either with $H Q$ or with HOMs at other missions. We need this to be encouraged and supported at the organizational level (HOM female)

An equal proportion of respondents $(30 \%)$ said that they would like more clarity in their objectives, particularly in translating the high-level objectives to local performance objectives. The typical pattern of response was to indicate that the organization was improving in many regards, but there was still work to be done:

We have the tools, but now the challenge is to ensure that these tools get into the hands of everyone who needs them. Things like the mandate letter should be filtered down to the officer level. If they could systematize this, so in consultation with the geographic desk, before you leave, you are handed a job description, your objectives, all the way through the country strategy, a branch strategy, the department's strategy. Give them to me so that these are all in one place for my reference (FL male)

I have a colleague at another mission who has, pasted beside her desk, the departmental-level objectives, mission-level objectives, section-level objectives, and then her own. Everything she does is supposed to tie into these objectives. I wish I had access to such a tool, but I think it is the exception and not the rule (FL female)

Not surprisingly, a proportion of respondents $(16 \%)$ specifically called for the organization to "fix the black hole" by providing better feedback on reporting and more context in tasking. Further, the importance of access to the "big picture" was evident in the proportion of respondents $(10 \%)$ who indicated they would value greater access to policy documents and position papers from HQ that could provide the high-level context needed to inform their work abroad.

An unanticipated response to this question was a call for the organization to make better use of the boundary spanner's knowledge when he or she returned from post (cited by $13 \%$ of respondents). The international management literature suggests that one of the 
reasons for high turnover among expatriates upon repatriation is the sense that the home organization does not provide opportunities for the expatriate to share and apply the extensive knowledge they have acquired abroad (McNulty and Tharenou, 2005). These responses, therefore, were of particular interest since many included concrete suggestions for ways in which organizations might better capture and "hardwire" boundary spanners' expert knowledge into the organizational system:

When you return from post, there should be a way to download your knowledge into the system. There isn't even always a spot for our most senior HOMs when they return. Why can you not have a senior advisor on the Middle East or a senior advisor on Asia who can provide a challenge function, who has that expert local and institutional knowledge? Not in a tokenistic way, not put out to pasture. But glean the very best, and have them work in partnership with top executive, with the ADM, the DM. Why don't we lend people out to other departments who need that expertise? This kind of knowledge is rare and should be better utilized (HOM female)

Other departments have an arrangement where, when you return from post, you don't have to compete for your job if you go straight to work in the geographic for the region to which you have just been posted. This is a good way to take advantage of what you know, while solving the perennial problem of trying to find an available spot at the appropriate level and squeeze you in (HOM female)

There is always an international "crisis" somewhere, and HQ is necessarily preoccupied with these. However, this also means that we are seldom pulled aside when we get back from post and asked what we have learned, and what we believe should be on the horizon for this region. Sometimes this happens, but not often enough. So, even an hour's debrief with your geographic division upon return would be a valuable thing (FL male)

In concluding this section, it is informative also to note what boundary spanners did not say in response to these questions. Nearly all of the responses referred to ways in which the organization might adjust the intra-organizational context to better support the boundary spanner in the boundary role (e.g., providing clarity in objectives, enhancing dialogue with HQ, capturing expert knowledge). Virtually no one mentioned organizational support for the interface aspects of the role. For example, only $7 \%$ of respondents indicated that the organization provided support by providing pre-posting training on the local culture or local language; similarly, only $5 \%$ of respondents said they 
would have liked more training or preparation to support them in their work at the interface (not shown). Combined, these findings suggest that boundary spanners may not see a direct role for the organization in helping them perform more effectively in their local interactions. Instead, they see an indirect role, whereby HQ sets the broad objectives and policy context, and the boundary spanner determines the means of effecting these objectives at the interface.

Job level differences were apparent both in terms of perceived support from the organization (Table 15-1) and preferred support (Table 15-2). HOMs, as mentioned earlier, were much more likely than other job levels to say that the organization provided them with autonomy on the job, consistent with their high rank and their leadership roles abroad.

Officers were more likely than management levels to indicate that they found the organization supportive when it promoted interaction and dialogue. This was consistent with their having reported greater problems with the "black hole" (Chapter 11). Accordingly, when asked what they would like from the organization, they also were more likely to say they would welcome greater access to high-level context.

The most striking job level difference, however, was the tendency for mid-managers to perceive the organization as supportive when it provided clarity in objectives (Table 151). Nearly half of mid-managers interviewed (47\%) said they thought the organization was becoming more supportive in its efforts to set high-level objectives, compared to only one quarter of officers and HOMs (23-27\%). The unique pattern for mid-managers may be related to their responsibility for managing program funds. Programs serve specified local objectives and come with clear guidelines and accountabilities. Conversely, the political work of HOMs and foreign service officers may have less tangible goals. Again, the finding 
is difficult to interpret without a more focussed exploration of the work context of program managers in this organization.

\subsection{Manager support}

Table 15-3 provides data on boundary spanner perceptions of the types of support provided by their managers. Because the reporting relationship for HOMs is distinct from that for mid-managers and officers (in terms of both hierarchical reporting lines and the fact that HOMs' managers are geographically distant), it is not possible to discuss these findings without reference to job level. This section, therefore, is structured differently from others in the thesis. Rather than reserve the discussion of job level differences for the end of the section, the discussion is woven into the overall pattern of findings.

\begin{tabular}{|c|c|c|c|c|c|}
\hline \multirow{2}{*}{$\begin{array}{l}\text { Is there anything your } \\
\text { manager does that helps } \\
\text { you perform more } \\
\text { effectively in your role at } \\
\text { post? }\end{array}$} & \multirow{2}{*}{ Description/Examples } & $\begin{array}{l}\text { Head of } \\
\text { mission } \\
(N=25)\end{array}$ & $\begin{array}{l}\text { Mid- } \\
\text { manager } \\
(\mathrm{N}=18)\end{array}$ & $\begin{array}{l}\text { Officer } \\
(N=26)\end{array}$ & $\begin{array}{l}\text { Total } \\
(\mathrm{N}=69)\end{array}$ \\
\hline & & \multicolumn{4}{|c|}{$(\%)$} \\
\hline $\begin{array}{l}\text { Provides interpersonal } \\
\text { support }\end{array}$ & $\begin{array}{l}\text { Manager takes time to listen, has } \\
\text { an open-door policy }\end{array}$ & 24 & 56 & 46 & 41 \\
\hline Provides strategic support & $\begin{array}{l}\text { Manager engages respondent in } \\
\text { discussions on strategic issues, } \\
\text { including context on priorities } \\
\text { and events at HQ }\end{array}$ & 44 & 33 & 27 & 35 \\
\hline $\begin{array}{l}\text { Provides specific direction } \\
\text { and objectives for my job }\end{array}$ & $\begin{array}{l}\text { Manager provides specific } \\
\text { instructions at the level of the } \\
\text { respondent's job }\end{array}$ & - & 28 & 15 & 17 \\
\hline Provides effective feedback & $\begin{array}{l}\text { Manager provides effective } \\
\text { individual feedback }\end{array}$ & 12 & 6 & 12 & 10 \\
\hline
\end{tabular}

\footnotetext{
${ }^{14}$ Excludes very small categories and responses indicating that there was nothing that the manager did that the respondent found helpful
} 
Interpersonal support was the most frequently mentioned type of managerial support. This finding is consistent with management literature that indicates that employees value supervisors who are approachable and understanding, listen to the employee, and show personal interest in the employee's well-being (i.e., managers who would be characterized as high in consideration; Kerr, Schriesheim, Murphy, and Stogdill, 1974). Where the manager was co-located, interpersonal support normally took the form of the manager simply signalling that he or she was available to the boundary spanner for discussion when needed:

Very open door policy. My HOM is just across the hall, and I am welcome to pop my head in the door any time I need to (MID male)

Occasionally, support appeared to take the form of a mentoring relationship, where the manager who was more experienced in the local context provided expert guidance: My manager is constructive in his comments to me around my role as a manager and how to look at issues here in a methodical fashion (MID male)

However, in the case of HOMs, the manager was geographically distant. These relationships were necessarily quite different. Although roughly one quarter of HOMs mentioned that they enjoyed a good relationship with their geographic Director General, this comment was typically accompanied by a further comment that they actually seldom spoke one-on-one with this individual. There appeared to be an awareness that the DG was simply too busy to engage in dialogue with all of the HOMs for whom she or he was responsible, or was not in a position to deliver on all HOM requests. Instead, they sensed that the DG was there for them if needed, or supported them "in spirit":

I just get the sense that she is always interested in what I have to say. She may not be able to 
deliver on $100 \%$ of what I am looking for, but as long as I can believe that when we speak, she is genuinely interested in my point of view, that's three quarters of the battle (HOM male)

DG-led conference calls, rather than one-on-one discussions, appeared to be the primary mechanisms for communicating with HOMs. DGs scheduled these calls so as to be sensitive to time differences between HQ and points abroad:

Conference calls are indispensable and my geograhic DG has gone to some lengths to make these work for us. I know he comes in pretty early in the morning to make sure these calls take place during regular work hours for us here (HOM male)

Conference calls were even favoured over more sophisticated communications technologies, such as videoconferencing, due to the technological inadequacies of these media in some regions:

Ideally, you would like to videoconference, but the reality is that the delay in these signals is so enormous here that a conversation takes forever. We rely instead on the good old-fashioned telephone, and that seems to work for us (HOM female)

The remaining three response categories mirrored the data on manager effectiveness discussed in Chapter 11 (Table 11-5). These responses indicated that boundary spanners found their managers to be supportive when they initiated structure for their work through the identification of work goals or assignment of tasks (i.e., their managers would be characterized as high in initiating structure; Ibid): over one third of respondents $(35 \%)$ indicated that their managers provided support by engaging them in discussions about strategic issues, often by sharing information and context from HQ; $17 \%$ said their managers provided support in the form of specific direction and instructions at the level of the respondent's job; $10 \%$ mentioned their managers were effective at feedback. 
Again, job level differences were very apparent in these data. Nearly half of HOMs (44\%) said that their DG supported them by engaging them in strategic discussions and sharing context on events at HQ. None of the HOMs said their DG supported them by providing specific direction at the level of their jobs- - nor did their responses suggest they would have valued such specific guidance:

He provides the high-level context and that is all I need. I don't want direction. I need context and I will set my own direction (HOM male)

Lower levels of the organization were less likely to say that their managers supported them by engaging them in strategic dialogue and sharing context from HQ. Whereas $44 \%$ of HOMs had said that their managers at HQ supported them by sharing strategic context, only $33 \%$ of mid-managers said that their managers (the HOM) provided them with strategic context, and only $27 \%$ of officers said that their managers (the mid-manager) provided them with strategic context. These data are reminiscent of the bottleneck in downward information flow suggested in Chapter 11 and the somewhat greater prevalence of the "black hole" at lower levels.

Table 15-4 presents data on the types of support boundary spanners would have liked from their managers. The data in this table aid further in the interpretation of job level differences seen in the previous table. 


\begin{tabular}{|l|l|c|c|c|c|}
\hline \multicolumn{2}{|l|}{ Table 15-4 Preferred support from manager } & $\begin{array}{c}\text { Head of } \\
\text { mission } \\
\text { (N=22) }\end{array}$ & $\begin{array}{c}\text { Mid- } \\
\text { manager } \\
\text { (N=15) }\end{array}$ & $\begin{array}{c}\text { Officer } \\
\text { (N=23) }\end{array}$ & $\begin{array}{c}\text { Total } \\
\text { (N=60) } \\
\text { like from your manager in }\end{array}$ \\
\cline { 2 - 6 } & Description/Examples & & \multicolumn{3}{|c|}{$(\%)$} \\
\hline Nothing needed & $\begin{array}{l}\text { Respondent indicates that manager } \\
\text { is already supportive }\end{array}$ & 27 & 40 & 30 & 32 \\
\hline $\begin{array}{l}\text { More specific direction } \\
\text { and objectives for my job }\end{array}$ & $\begin{array}{l}\text { More specific instructions at the } \\
\text { level of the respondent's job }\end{array}$ & 9 & 13 & 42 & 22 \\
\hline Better feedback & More clarity around feedback & 35 & 6 & 17 & 21 \\
\hline More strategic support & $\begin{array}{l}\text { Better support in the form of } \\
\text { discussions on strategic issues, } \\
\text { including better context on } \\
\text { priorities and events at HQ }\end{array}$ & 30 & 13 & 13 & 19 \\
\hline
\end{tabular}

Consistent with the fact that fairly large proportions of respondents had already indicated that their managers were supportive (Table 15-3), one third of respondents (32\%) said that there was nothing they wanted from their manager that he or she did not already provide. In terms of what they would have liked, responses were fairly evenly split among: wanting more specific direction at the level of the job (22\%); wanting better feedback (21\%); and wanting more discussion on strategic issues (19\%).

Again, the pattern for the full sample masks important job level differences. First, in spite of the level of autonomy inherent in HOMs' jobs, and in spite of their indicating that they did not want specific "direction" from their managers, HOMs did want feedback on their work (35\% of HOMs said they would prefer better feedback from their DGs, compared with only $6 \%$ and $17 \%$ of mid-managers and officers respectively). The desire for more feedback is consistent with HOMs' claims that DGs at HQ had too large a span of control to allow them to spend one-on-one time with those abroad (the 
"black hole", Chapter 11), and the observation that most of the communication from the DG was in the form of conference calls. Combined the data suggest a situation where HOMs obtain their broad direction through conference calls, set their local objectives, but then want one-on-one time with their managers to obtain individual feedback on those objectives.

The second observation of value in interpreting job level differences was the pattern of responses among officers. In spite of having reported comparatively low access to high-level context from HQ, when asked what type of support they would most like from their managers, officers overwhelmingly indicated that they wanted, not HQ context, but specific instructions from the manager at a level appropriate to their jobs. Over $40 \%$ of officers indicated that they wanted more specific instructions from their managers, compared with $13 \%$ of mid-managers and $9 \%$ of HOMs. This finding is consistent with the pattern observed in Chapter 11, where officers appeared to value managerial support in interpreting high-level direction emanating from $\mathrm{HQ}$.

\subsection{Summary}

To date, literature on boundary spanner support has been limited by its reliance on global perceptions of organizational support, such as satisfaction with compensation levels or career development (e.g., Stamper and Johlke, 2003). The data presented in this chapter advance this literature by defining support specifically as it relates to the unique needs of the boundary role. By examining boundary spanner support within the framework of a model of effectiveness, the findings identify specific aspects of the work environment that might be modified to enable boundary spanners to more effectively 
perform their jobs and ensure that the organization has access to their specialized knowledge.

In general, the types of support that emerged from the data flowed directly from the model of effectiveness (Figure 6.2). The organization and the manager were perceived to be supportive to the extent that they provided clarity in performance objectives and enabled interaction with HQ to obtain the contextual knowledge needed to attain these objectives. These findings corroborate the patterns observed in Chapters 11 and 14 , which had identified reduced access to strategic and relational knowledge as potential barriers to effectiveness in the boundary role. The organization and the manager were perceived to be supportive where they were able to mitigate these potential barriers, either through the provision of formal documents that specified expectations, or through informal dialogue that helped the boundary spanner understand and interpret the expectations for performance.

These findings suggest that both the organization and the immediate manager have critical roles to play in the international setting if they are to assist boundary spanners abroad in overcoming potential "liabilities of distance". Findings indicated that in the international setting, ensuring access to strategic and relational knowledge at $\mathrm{HQ}$ required that two further potential barriers be overcome. The first potential barrier was technological. In this organization, the provision of a sophisticated departmental telephone system enabled real-time dialogue and was of particular value in overcoming the potential limitations of email and other remote technologies. Investments in distance technologies such as this telephone system would seem an important organizational intervention in supporting dialogue among an internationally dispersed workforce. 
The second potential barrier was temporal. At the managerial level, Directors General at HQ recognized the potential temporal barriers posed by distance, and scheduled conference calls so as to be sensitive to time differences between HQ and points abroad.

Job level differences apparent in the findings suggested the need for interventions targeted to the needs of boundary spanners at different levels of the organization. Consistent with their comparatively high level of authority, boundary spanners at the most senior levels (HOMs) communicated directly with HQ to obtain the strategic context needed to guide their work. Their responses suggested they then worked independently to set their local direction, but wanted follow-up with HQ on an as-needed basis to obtain feedback on the direction they pursued. However, the pattern of responses at less senior levels suggested that mid-managers, and particularly, officers, needed support from their co-located managers both to access and interpret HQ context and to formulate their local objectives. At these levels of the organization, boundary spanners have less authority to chart their own paths, and rely on their co-located managers to share information and help them use it in setting local objectives. This is an interesting pattern, suggesting that boundary spanners at more junior levels may need targeted support to ensure they have a "window" to HQ and are not subject to bottlenecks in information flow. Although it is not known to what extent these job level differences might apply in other organizations, the pattern suggests the need for a two-pronged approach to support, one that enables one-on-one discussions with the manager at all levels, and ensures that all levels of the organization have access to the HQ context they need to do their jobs. Such interventions are discussed further in Chapter 17 in the 
discussion of implications of this research for management practice.

Finally, two responses not anticipated from the model of effectiveness are worth noting. First, although respondents were directed to focus on supports for the boundary role, a proportion still mentioned that the organization supported them by taking care of the logistics of relocation and helping with family-related needs. Because the expatriate management literature has shown no relationship between adjustment and job performance (Caligiuri, 1997), this element is not included in the model of effectiveness. However, the finding reinforces the notion that, at the most fundamental level, boundary spanners see an important role for the organization in ameliorating some of the initial stresses of the relocation experience.

A second unanticipated response was the emergence of a set of suggestions for ways in which the organization might better exploit the boundary spanner's knowledge upon repatriation. The model had predicted that an important condition for effectiveness in the boundary role was the boundary spanner's ability to influence the organization by feeding in local information while abroad. Responses to the support items, however, suggested that a further mechanism for influencing the organization's strategic direction might be to find ways to feed information into the organizational system upon return. Respondents cited a number of ways this might be done, including debriefs, strategic job placements, and alternative career paths at HQ. These ideas are well aligned with the model of effectiveness. Such suggestions might prove valuable to organizations who want to support their expatriates upon return from assignment and who want to take maximum advantage of their expertise. 


\section{PART SIX: DISCUSSION AND CONCEPTUAL REFINEMENT}

This research was driven by two conceptual tasks. The first was to conceptualize, at the level of the individual employee, the nature of the boundary spanning role. The second was to conceptualize the conditions for individual effectiveness in the role. These conceptual tasks were supported by use of the preliminary orienting frameworks developed in Part Three. The findings of the research reported in Part Five now enable refinement and, where indicated, expansion of the conceptual elements given in the preliminary models. This part of the thesis maps the study's findings to these preliminary models to obtain a richer conceptualization of the dimensions of the boundary role and a better understanding of the factors underlying effectiveness in the international setting.

Consistent with Part Three, this part of the thesis comprises a single chapter. The first section (Section 16.1) presents and discusses the expanded conceptual model of the dimensions of the boundary role. Section 16.2 develops the expanded model of the conditions for effectiveness in the role. Both of these models are descriptive in that they serve only to identify the features or qualities of the target concepts (Bacharach, 1989). However, in the case of the conceptualization of the boundary role construct, the data proved sufficiently rich to suggest relationships among some of the elements in the expanded model. Where this occurs, Section 16.1 also weaves into the discussion selected propositions to support hypothesis formulation and testing in future research. This progressive development of propositions within the discussion of qualitative findings is consistent with formats used in Bouty (2000), Eisenhardt and Bourgeois 
(1988) and Zeithaml et al. (1988).

Further, the data on the conditions for effectiveness suggested two additional elements that had not been anticipated in the orienting framework, but which might enhance or constrain boundary spanner effectiveness in the special case of the international assignment. Section 16.3 , therefore, incorporates these elements within the expanded model to present an "emergent" model of the conditions for effectiveness in the expatriate boundary spanning role. 


\section{DISCUSSION AND CONCEPTUAL REFINEMENT}

\subsection{An expanded conceptual framework of the dimensions of the boundary spanning role}

The expanded conceptual framework of the dimensions of the expatriate boundary spanning role was developed in conjunction with the reporting of findings in Chapter 12. The resulting nine-dimension typology given in Exhibit 12-1 meets the requirements of Research Objective 1, so is summarized in Exhibit 16-1 for reference and discussion. 


\begin{tabular}{|c|c|c|c|}
\hline Dimension & Description of activity & $\begin{array}{l}\text { Movement of inputs and } \\
\text { outputs at boundary }\end{array}$ & Functional purpose of activity \\
\hline Representing & $\begin{array}{l}\text { Modeling the organization's views and values to } \\
\text { an individual external agent }\end{array}$ & $\begin{array}{l}\text { Opens boundary to } \\
\text { outward flow of "image" }\end{array}$ & $\begin{array}{l}\text { Enhances the organization's reputation or legitimacy among } \\
\text { other players in the organization's external environment }\end{array}$ \\
\hline Scouting & $\begin{array}{l}\text { Focussed search for non-sensitive information or } \\
\text { ideas needed to inform the boundary spanner's } \\
\text { immediate task demands }\end{array}$ & $\begin{array}{l}\text { Opens boundary to inward } \\
\text { flow of task-relevant } \\
\text { information }\end{array}$ & $\begin{array}{l}\text { Brings into the organization general information that is needed } \\
\text { to support the organization's workflow }\end{array}$ \\
\hline $\begin{array}{l}\text { Intelligence } \\
\text { gathering }\end{array}$ & $\begin{array}{l}\text { Focussed search for sensitive, "privileged" or } \\
\text { "insider" information not available through } \\
\text { regular channels }\end{array}$ & $\begin{array}{l}\text { Opens boundary to inward } \\
\text { flow of privileged } \\
\text { information }\end{array}$ & $\begin{array}{l}\text { Brings into the organization privileged information that is } \\
\text { needed to anticipate environmental fluctuations and protect the } \\
\text { organization's core work from uncertainty }\end{array}$ \\
\hline $\begin{array}{l}\text { Relationship } \\
\text { building }\end{array}$ & $\begin{array}{l}\text { Effort to build or maintain a relationship with } \\
\text { external agent }\end{array}$ & $\begin{array}{l}\text { Opens boundary to the } \\
\text { outward flow of affect }\end{array}$ & $\begin{array}{l}\text { Lays foundation of trust, encourages reciprocity to enable future } \\
\text { exchanges of value to the organization }\end{array}$ \\
\hline Molding & $\begin{array}{l}\text { Effort to influence the agent's agenda, sway the } \\
\text { agent's views, persuade agent to support the } \\
\text { work of the boundary spanner's organization }\end{array}$ & $\begin{array}{l}\text { Opens boundary to } \\
\text { outward flow of influence }\end{array}$ & $\begin{array}{l}\text { Directly modifies the organization's external environment in a } \\
\text { manner conducive with the work of the organization }\end{array}$ \\
\hline $\begin{array}{l}\text { Coordinating/ } \\
\text { negotiating }\end{array}$ & $\begin{array}{l}\text { Communicating with external agent in areas of } \\
\text { mutual workflow dependencies and shared } \\
\text { projects or mandates }\end{array}$ & $\begin{array}{l}\text { Opens boundary to the } \\
\text { two-way flow of influence }\end{array}$ & $\begin{array}{l}\text { Enables the work of the organization to proceed where the work } \\
\text { is dependent on contribution of outside agent }\end{array}$ \\
\hline Delivering & $\begin{array}{l}\text { Delivering information or other resources in } \\
\text { response to the demands of the external agent } \\
\text { ("delivering the product") }\end{array}$ & $\begin{array}{l}\text { Opens boundary to } \\
\text { outward flow of resources } \\
\text { (goodwill, financial, } \\
\text { human, or information } \\
\text { resources) }\end{array}$ & $\begin{array}{l}\text { Disposes of the outputs of the organization's productive work } \\
\text { where agent's expectations are perceived as legitimate and } \\
\text { aligned with the organization's work }\end{array}$ \\
\hline Guarding & $\begin{array}{l}\text { Refusing agent's demands for information or } \\
\text { other resources; avoiding, delaying, or ignoring } \\
\text { requests }\end{array}$ & $\begin{array}{l}\text { Closes boundary to inward } \\
\text { flow of influence and } \\
\text { closes boundary to outward } \\
\text { flow of resources } \\
\text { (goodwill, financial, } \\
\text { human, or information } \\
\text { resources) }\end{array}$ & $\begin{array}{l}\text { Protects the work of the organization by preventing an exchange } \\
\text { where the agent's expectations are unknown or misaligned with } \\
\text { the work of the organization }\end{array}$ \\
\hline Intermediary & $\begin{array}{l}\text { Brokering introductions, referrals between two } \\
\text { or more external agents }\end{array}$ & $\begin{array}{l}\text { Opens boundary to } \\
\text { outward flow of influence }\end{array}$ & $\begin{array}{l}\text { Indirectly modifies the organization's external environment in a } \\
\text { manner conducive with the work of the organization }\end{array}$ \\
\hline
\end{tabular}


Consistent with the conceptual goals of this research, the typology given in Exhibit 16.1 enhances our understanding of how the behaviour of individual organizational members might ultimately contribute to the adaptive behaviour of organizations. Katz and Kahn (1966) defined the "adaptive function" as the process by which organizations supported the work of their internal organizational system and monitored, detected and responded to fluctuations in the external environment that posed threats to the system. This function was performed at the organization's boundary. This research shifts the analytic lens to examine the behaviour of the individual who operates at this boundary. The research thus targets the site of the "adaptive function" (Katz and Kahn, 1966) for examination at the micro level. As expressed by Aldrich and Herker (1977), the place to begin to understand organizational adaptation is not with the organization as a whole, but with the impact of the environment on incumbents of boundary positions in the immediate vicinity of the environment-organization relationship.

In examining the environment-organization interface, the typology respects at the micro level the conceptual distinctions articulated in macro-level theory. Relying on the adaptive function as the basis for classification, the typology specifies for all boundary dimensions the content of the exchange, the direction of the exchange, and the perceived purpose of the exchange in terms of organizational functioning. According to Katz and Kahn (1966), the adaptive "flow" moved in two directions. First, it might exert outward influence to dispose of outputs or attempt to attain control over the external environment. Five of the nine dimensions emerging in this research reflected outward flow at the micro level: representation, relationship building, molding, delivering, and the intermediary 
function. Conversely, the organization might exert inward influence to modify the organization's own structures or processes in response to changing contingencies. Two of the dimensions in this typology reflected inward flow: scouting and intelligence gathering. One dimension involved bidirectional movement over the course of the same transaction (coordinating-negotiating). Finally, one of the dimensions illustrated how the exchange of no resources at all might serve an adaptive purpose: the guard function protected the organization by closing the boundary to transactions in instances where the intentions of external agents were unknown or were perceived to be misaligned with the work of the internal system.

By respecting the adaptive function in the classification of boundary transactions, the typology emerging from this research takes us a step closer to specification of the mid-level linkages that had been lacking in characterizations of the boundary role to date. First, the emergence of nine dimensions of the boundary role in this typology confirms the multidimensionality of the role at the individual level, and suggests how an individual boundary spanner might choose among alternative boundary behaviours to adapt to changing contingencies at the interface. Central to the notion of the adaptive function is its role in uncertainty reduction for the organization (Thompson, 1967). One of the criticisms levied at Thomas' (1994) model of the expatriate boundary role was its failure to identify linking mechanisms between the micro and macro level of analysis. This was especially the case in his effort to link environmental uncertainty to individual "boundary spanning behaviour". Thomas posited in his model that individuals would "increase" their boundary spanning behaviour in response to environmental uncertainty. However, the link between the individual and the environment was underspecified (i.e., from the 
perspective of the individual, how did uncertainty "manifest" at the interface?) Further, Thomas' ability to specify this link was limited by his unidimensional operationalization of the boundary role as comprising the informational function only. This operationalization limited his ability to articulate the potential range of individual responses to varying contingencies at the interface.

The typology generated in this research, conversely, is both multidimensional and focussed expressly on the individual-environment link. It thus is capable of suggesting how uncertainty might manifest at the interface, and the means by which the boundary spanner might manage uncertainty at the one-to-one level. The typology identifies five functional activities that entail boundary spanner judgments regarding environmental uncertainty: the "scout", "intelligence", "molding", "delivery", and "guard" functions. Two of the functions are informational (scout and intelligence). These functions reflect a global judgment by the boundary spanner that he or she is lacking in information about the local environment, and a resulting decision to obtain the needed information from individual contacts. In these instances, one-to-one contact is sought in order to reduce uncertainty by obtaining information from individuals deemed to be more knowledgeable about the local context. The uncertainty reduction aspect of these functions was apparent in boundary spanners' descriptions of the ways in which they came to develop their contacts when first assigned, and the ways in which they came to understand local institutions or political structures through their interactions with local agents. These two functions are similar to Thomas' characterization of the boundary role as an informational function, and, like Thomas' model, give rise to the following propositions: 
P1 Under conditions of perceived environmental uncertainty, the boundary spanner will invoke the scout function

P2 Under conditions of perceived environmental uncertainty, the boundary spanner will invoke the intelligence function

However, the remaining three boundary functions do not entail global judgments regarding an unfamiliar environment, but, instead, entail judgments regarding the expectations of the external agent with whom the boundary spanner is dealing. In these instances, the source of uncertainty is not the broader extra-organizational environment, but the specific behaviour of the external agent. This suggests that the boundary spanner performs an adaptive function for the organization at a second, more proximal level, through his or her ability to assess, and react to, immediate interface contingencies.

The typology, therefore, introduces two further interface elements that may assist in specifying inter-level linkages: the boundary spanner's degree of uncertainty regarding the contact's expectations and the boundary spanner's perception of the degree to which the contact's expectations are aligned with the work of the organizational system. The boundary spanner responds to contact demands in accordance with his or her assessment of the contact's expectations on these two dimensions. Where the contact's expectations are unknown or perceived to be misaligned with the work of the system, the boundary spanner reduces uncertainty for the organization by denying the request or delaying response pending clarification: 
P3 Under conditions of uncertainty regarding contact expectations, the boundary spanner will invoke the guard function to delay response pending clarification

P4 Under conditions of uncertainty regarding contact expectations, the boundary spanner will invoke the scout function to seek clarification

P5 Under conditions of perceived misalignment of objectives, the boundary spanner will invoke the guard function to prevent a cross-boundary exchange

Further, where the contact's expectations are unknown or perceived to be misaligned with the work of the organization, the boundary spanner may seek to reduce uncertainty by attempting to modify the contact's expectations to align with the work of the organization:

P6 Under conditions of uncertainty regarding contact expectations, the boundary spanner will invoke the molding function to align contact expectations with those of the organization

P7 Under conditions of perceived misalignment of objectives, the boundary spanner will invoke the molding function to align contact expectations with those of the organization

Conversely, in instances where the contact's expectations are known and are perceived to 
be aligned with the work of the organization, the contact's demands are met:

P8 Under conditions of relative certainty regarding contact expectations, and perceived alignment with organizational objectives, the boundary spanner will invoke the delivery function in response to contact demands

Examination of these boundary functions across transactions, however, does not allow insight into the conditions under which the boundary spanner might choose one boundary behaviour over another in a given interaction. For example, the above propositions suggest that under conditions of uncertainty about the contact's expectations, the boundary spanner may choose to invoke the guard function (P3), the molding function (P6) or both. Examination of the pairing of dimensions within interactions, however, identified a further variable that may shape the dimensions of the boundary role exhibited within a given interaction, and hence, contribute to clearer specification of inter-level linkages. The frequency with which the relationship function was observed to pair with other functions suggested that, at the individual level, relationships may be central to cross-boundary resource exchanges, and to the decision as to what type of exchange to pursue.

The salience of the relationship function in these interactions and examination of the circumstances under which it surfaced suggested that the degree of resource dependency may comprise a further interface element of relevance to a boundary spanning model such as Thomas'. Consistent with the predictions of social network theory (Brass, 1984; Tichy et al., 1979), the relationship function appeared to be of 
particular importance where the boundary spanner was highly dependent on the resources held by the external agent:

P9 The greater the level of dependency on the resources held by the external agent, the greater the likelihood that the boundary spanner will invoke the relationship function over the course of the interaction

The relationship function was frequently paired with the molding and intelligence functions, where the need to influence is high, yet the degree of alignment between the contact's objectives and those of the boundary spanner may be low or unknown. This finding suggests further that:

P10 The relationship function mediates the acquisition of resources in instances where resource dependency is high, but the objectives of the external agent are unknown or are misaligned with those of the boundary spanner

Further, boundary spanners' descriptions of their approaches to contact development and their various strategies for reconciling interface conflicts suggested that the relationship function played a role in helping boundary spanners understand nuances in unfamiliar settings. Where the contact's language and culture were unfamiliar, the development of a relationship with individual contacts facilitated the boundary spanner's ability to "read" body language and other cues over the course of their interactions: 
P11 The relationship function facilitates role cuing over the course of boundary interactions

The dimensions of the typology developed for this research, therefore, identify four interface factors that may prove useful in future efforts to specify linkages between individual boundary spanning behaviour and adaptive behaviour at the level of the organization. The findings suggest that boundary spanner behaviour at the interface may be jointly determined by an interplay among: (1) the degree of unfamiliarity and perceived uncertainty about the local environment; (2) the degree of perceived uncertainty about specific contact expectations; (3) the degree of perceived alignment of the contact's expectations with the work of the organization; and (4) the degree to which the boundary spanner is dependent on the contact for access to resources. Further, the findings suggest that the relationship function may play a mediating or moderating role in the boundary spanner's ability to assess contact expectations and, by extension, in the ultimate exchange of resources across organizational boundaries. Although it is beyond the scope of this research to position these variables within Thomas' model, the propositions advanced suggest inter-level linkages that might potentially enrich such a model. Refinement of the propositions, specification of the conditions under which they might pertain, and the development of measures and hypotheses for testing await future research. 


\subsection{An expanded conceptual framework of the conditions for individual effectiveness in the boundary spanning role}

The preliminary conceptual model of the conditions for individual effectiveness in the boundary role was developed in Figure 6.2. The findings of the research reported in Chapters 11 through 14 enabled specification of the intra-organizational and interface factors underlying each of the conceptual elements given in the preliminary model. In accordance with the requirements of Research Objective 2, these factors are now summarized and mapped to create the expanded model of the conditions for effectiveness (Figure 16.1). Due to space limitations in this figure, it was not possible to insert full detail within each of the elements. Individual elements, therefore, are expanded further in Figure 16.1.1.

Like the typology of the dimensions of the boundary role, Figure 16.1 respects the central tenets of macro-level theory in specifying the conditions for individual effectiveness in the role. Open systems theory defined organizational effectiveness in terms of the ability of the organization to adapt to its environment. Central to organizational adaptability was the concept of homeostasis (Thompson, 1967), whereby the organization both maintained the stable functioning of its internal system and detected and responded to fluctuations in the external environment that posed threats to the system (Katz and Kahn, 1966). The conceptualization at the individual level, therefore, has depicted boundary spanner effectiveness as a feedback loop, whereby the boundary incumbent both carries out boundary transactions aligned with the organization's strategic direction and informs and influences the strategic direction in the event of a changing environment. 
Figure 16.1 specifies for each of the components of this feedback loop the intraorganizational and interface factors that might enhance or constrain boundary spanner effectiveness at the individual level. First, Element 1 identifies intra-organizational factors. It was expected that the most fundamental requirement for effectiveness at the individual level was an understanding of the organization's expectations for the boundary role. Findings suggested that boundary spanners in this international setting relied on the same sources of intra-organizational role cues as they might in any work setting. Boundary spanners took their cues from written documents provided by the organization, from their everyday interactions with others within the organization, and from the performance of the job itself. An emergent feature unique to the boundary role, however, was the tendency for boundary spanners to describe cues from the job itself in terms of factors both internal and external to the organization. It appeared that it was not possible for the boundary spanner to discuss the job without "spilling over" to discuss the interface context. This finding provided an illustration of the boundary spanner's membership in multiple systems, the defining feature of the boundary role (Kahn et al., 1966). 


\section{Figure 16.1 Expanded conceptual framework of the conditions for individual effectiveness in the boundary spanning role}

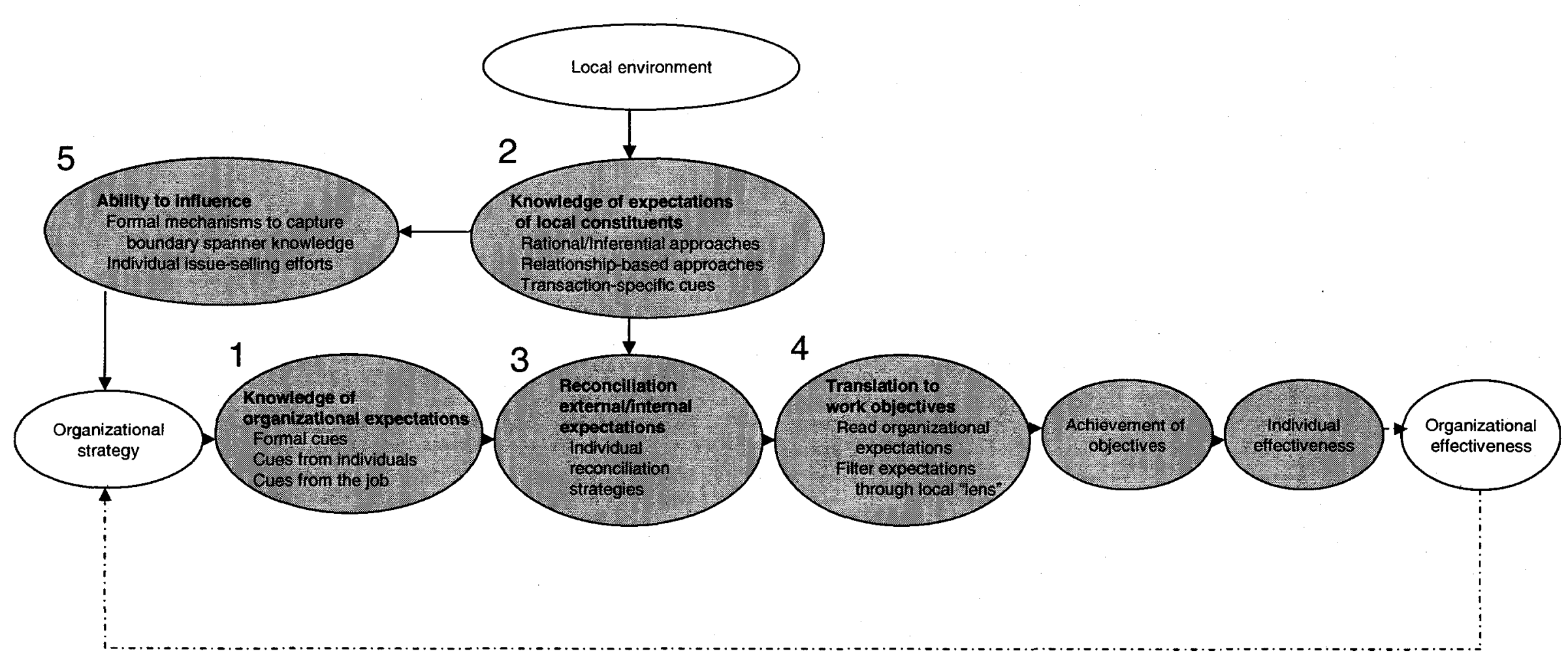

Numbered elements are the concepts of primary interest and are elaborated in Figure 16.1.1 


\section{Figure 16.1.1 Individual elements of the expanded conceptual} framework

\section{Element 1: Knowledge of organizational expectations}

Formal cues

Country strategies

Performance management agreements

Reporting agreements

Mandate letter

High-level policy documents

Annual meetings

Cues from individuals

HQ staff

Manager

Colleagues

Predecessor

Cues from the job

Observe external (local) outcomes

Observe internal (organizational) outcomes

Element 2: Knowledge of expectations of local constituents

Rational/inferential approaches

Knowledge of institutional relationships

Views of knowledgeable others

Own intuition/experience

Relationship-based approaches

Mapping

Gaining access/relationship cultivation

Network extension

"They come to you"

Transaction-specific cues

Cues emanating from one-on-one interactions

(e.g., people are oblique, people are direct, read body language) 


\section{Figure 16.1.1 Individual elements of the expanded conceptual framework (Continued)}

\section{Element 3: Reconciliation of external/internal expectations}

Individual reconciliation strategies

Probe, listen and learn

Persuade

Explain

Reframe
Invoke the relationship

Surface the conflict

Assert

Agree to disagree

Retreat and regroup

Element 4: Translation to work objectives

Read organizational expectations

Performance management plan

Hi-level objectives from $\mathrm{HQ}$

Formal strategic planning processes

Informal discussions with colleagues, manager

Formal planning discussions with manager

Filter expectations through local "lens"

Call on predecessor/more experienced colleagues

Call on personal local knowledge

\section{Element 5: Ability to influence}

Formal mechanisms to capture boundary spanner knowledge

While abroad: Reporting agreements

Upon return: Debriefs, strategic job placements, alternative career paths

Individual issue selling efforts

Involvement moves

Packaging moves

Appeal to HQ's interests

Package with expert local knowledge

Process moves

Homework

Choice of driver

Strategic approach (Create opportunity, piggyback, pepper,

Timing work within the system) 
Second, the model examines interface factors. It was expected that a further condition for effectiveness in the boundary role was the boundary spanner's ability to identify and connect with local agents who were important to the attainment of organizational objectives. This was of particular interest in the international setting where the effects of cultural and language barriers on boundary interactions was unknown. Figure 16.1 (Element 2) allows us to specify three potential sources of role cues in the boundary spanner's external environment. Respondents' descriptions of their approaches to developing contacts suggested that an initial source of cuing in the international context is obtained through a "rational/inferential" process, whereby the boundary spanner reads available cues in the local institutional, political, and cultural context. This preliminary exploration of the local landscape is aimed at identifying potential allies and adversaries in an unfamiliar setting, and enables the boundary spanner to anticipate contacts' points of view based on a global sense of what a member of that constituency might want. The second source of role cuing was the "relationship-based" cue. These cues were derived through a process of mapping and actively "testing" the landscape of potential contacts through meetings, events, and other face-to-face encounters. Where language and culture were unfamiliar, relationships were perceived to lay the foundation for "reading" contact expectations and better understanding the local culture. At the most proximal level, boundary spanners drew on "transaction-specific" cues emanating from verbal or non-verbal cues expressed over the course of any given interaction.

Third, Figure 16.1 (Element 3) identifies specific strategies used by boundary spanners to manage their interactions at the interface. Interface strategies had not 
previously been explored in the management literature. The data suggested little overlap between these strategies and the strategies reported in intra-organizational contexts (Tsui et al., 1995). First, all of the interface strategies were constituency-oriented (i.e., focussed on the perspective of the external agent Ibid.), rather than self- or avoidanceoriented, with most aimed at obtaining a better understanding of the agent's views or allowing the agent to "save face". Strategies such as active listening, agreeing to disagree, and reframing appeared to be of particular value in cross-cultural interactions, where boundary spanners appeared to exert great effort in trying to understand local nuances. The importance of relationships surfaced here as well, as many respondents indicated that they invoked the relationship to reconcile differences. The repeated references to relationships in this research extends the social network perspective (Brass, 1984; Tichy et al., 1979) by suggesting that exchanges of affect may be particularly instrumental in cross-boundary transactions where they may enable other resource exchanges. In the absence of formal authority structures, affect may be one of the few means by which the boundary spanner can exert influence over external agents in pursuit of information and other resources needed to support the internal workflow.

Fourth, Figure 16.1 (Element 4) summarizes findings on the translation process used by boundary spanners to integrate perspectives from "both sides" of the boundary in designing individual work objectives. Findings suggested a two-step process, whereby boundary spanners "read" various intra-organizational cues that communicated to them the organization's expectations for their performance abroad, and then "filtered" these expectations through their local "lens". Respondents read their cues from their performance plans and various documents available from $\mathrm{HQ}$, and, in some instances, 
were further assisted in understanding these expectations through local strategic planning sessions or direction from co-located managers. Respondents then "filtered" these expectations through the local lens by means of consultation with more experienced colleagues or reliance on their own expert knowledge.

Finally, Figure 16.1 (Element 5) summarizes findings on the last condition for effectiveness in the boundary role: the ability of the boundary spanner to influence management on issues of perceived strategic importance. Findings identified two means by which boundary spanners might be able to exert influence over decision-makers at HQ: individual issue-selling efforts initiated by the boundary spanner; and formal mechanisms designed by the organization expressly to capture the boundary spanner's knowledge. With respect to the former, Dutton et al.'s $(1993 ; 2001)$ work on the issueselling behaviours of mid-managers proved a useful framework for studying issue selling in the context of boundary spanners. Findings indicated that boundary spanners in this organization employed a similar range of approaches to selling their issues as that suggested by Dutton et al. Moves included decisions regarding who to involve in the effort, how to package the issue for best effect, and a number of strategic "process" moves aimed at finding the right approach to orchestrating and managing the issue over time. Respondents' descriptions of their moves provided many insights into how the boundary spanner's access to the organization's strategic, relational, and normative knowledge might be affected when abroad. These moves also provided illustrations of how boundary spanners might leverage their access to specialized local knowledge to "get HQ's ear" on issues of perceived importance. These findings will be explored further in Section 16.3 in discussing the unique features of the boundary role in the 
international setting.

Figure 16.1 also adds to the influence element the notion of formal mechanisms as a potential vehicle for enhancing boundary spanner influence in international settings. One of the advantages of having selected for this case study an organization that was "extreme" on the boundary spanning dimension was the opportunity to identify best practices that an experienced organization may have developed to overcome the potential barriers of distance. Two mechanisms formalized the important feedback loop in this organization. First, reporting agreements laid out on an annual basis the organization's expectations for reporting from a given region, given the organization's need for strategic information. Data suggested that these agreements were valued by boundary spanners in that they both systematized regular input and promoted dialogue with HQ around their content. Second, several geographic divisions appeared to have developed means for capturing boundary spanner knowledge upon return from assignment. These approaches ranged from an hour's debrief with senior management to rather creative approaches to enabling the boundary spanner to "download" knowledge into the system, including targeted job placements or alternative career paths at $\mathrm{HQ}$. Findings indicated that, unlike reporting agreements, mechanisms for capturing knowledge upon return had not been fully formalized, but rather, appeared to be used by certain divisions or on an ad hoc basis. However, consistent with the research goal of identifying and describing, these interesting options are included in the model to spark further exploration. 


\subsection{An emergent conceptual framework of the effects of intra-organizational and interface distance on the conditions for effectiveness in the boundary spanning role}

Figure 16.1 satisfies the descriptive task of Research Objective 2 by specifying the qualities of each of the five conceptual elements in the model. Examination of Figure 16.1, however, indicates that the model is rather lean, and indeed, might apply to any employee in a boundary role. The central goal of this research was to explore the boundary role in the special case of the international assignment. A purely descriptive model can identify the salient features of the conditions for effectiveness, but it cannot capture the many nuances of the data that suggested how these conditions might be affected in the special case of the international assignment.

The central distinguishing features of the international assignment are the geographic distance between the home and host country (Govindarajan and Gupta, 2001) and the expatriate's unfamiliarity with the local context (Tung, 1981). As was evident in the discussion of findings throughout this thesis, the data were rich with references to the unique challenges associated with performing the boundary role in the context of the international assignment. For example, geographic distance from HQ appeared to be associated with somewhat reduced access to the organization's relational and strategic context, and created barriers to the communication needed to obtain direction and feedback (the "black hole"). Similarly, perceived "distance" from the local culture created barriers in terms of the boundary spanner's ability to identify and connect with key external constituents and understand the nuances of local custom and language (e.g. “people are oblique here"). 
Such nuances in the data were not apparent in Figure 16.1. In order to capture these nuances and to better understand the special considerations for managing the boundary role in international settings, the researcher undertook a final pass through the data. In this concluding step, the entire dataset was examined to identify all explicit or implicit references to potential barriers associated with the notion of "distance"- - both in terms of geographic distance from the home organization, and in terms of "perceived distance" 15 from the local culture. These factors were sorted into two categories, and were labeled respectively " intra-organizational distance" and "interface distance". These labels were chosen to reflect the distinction between intra-organizational context and interface context used to structure the literature review (Chapter 3 ). The distinction respects the tenets of role theory (Kahn et al., 1964; Katz and Kahn, 1966) which provided the theoretical basis for this research. Given boundary spanners' membership in multiple systems, their effectiveness was posited to be jointly determined by role cuing emanating from both their own organizational systems and the systems of their external constituents (Section 3.2). Thus, effectiveness in the expatriate boundary role was posited to be a function of the expatriate's ability to overcome potential barriers of "distance" in their interactions with role set members both within the home organization and at the organization-environment interface.

Consistent with the goals of exploratory research, the purpose of this final analysis was to identify the various aspects of "distance" that might constrain

${ }^{15}$ The term "perceived distance" is used in a generic sense to refer to the individual's perception of unfamiliarity in a foreign environment. It is not intended to denote "psychic distance", a concept of popular interest in the international marketing literature, and typically used in reference to differences between the home market and foreign markets in terms of culture or business practices (Evans and Mavondo, 2002). 
effectiveness in the expatriate boundary spanning role. The purpose was not to specify the relative proportions of respondents for whom distance posed an advantage or a disadvantage. In many instances, respondents mentioned that distance was a potential barrier, but that they or their organization had overcome it through various means. The criterion for coding was that distance had been identified as a potential challenge to effectiveness in the boundary role. Identification of such challenges is an important first step in understanding barriers to boundary spanner effectiveness in international settings and creating work contexts that better support expatriates in their boundary spanning roles.

The analysis suggested that each of the two forms of distance was itself multidimensional. The results of the analyses, with examples of the emergent dimensions of "distance", are displayed in Tables 16-1 and 16-2. 


\begin{tabular}{|c|c|c|}
\hline & Description/Examples & $\begin{array}{l}\text { \% of respondents } \\
\text { who mentioned } \\
\text { divide } \\
(\mathrm{N}=\mathbf{8 4})\end{array}$ \\
\hline Strategic divide & $\begin{array}{l}\text { Differences between HQ and post in terms of respective goals, } \\
\text { priorities, and intentions ("What are HQ's/mission's strategic goals? } \\
\text { Priorities? Why are they asking me this? What are they doing with } \\
\text { the information I give them?") }\end{array}$ & 80 \\
\hline Cultural divide & $\begin{array}{l}\text { Differences between HQ and post in terms of work context, task } \\
\text { environment, pace of work and rewards ("HQ is focussed on the } \\
\text { Ottawa powers-that-be"; "Government here is sifting through paper } \\
\text { files to answer HQ's questions; things don't work as fast here as } \\
\text { they do in Ottawa"; "HQ wants it right now and right now there are } \\
\text { monkeys on my desk") }\end{array}$ & 79 \\
\hline Relational divide & $\begin{array}{l}\text { Lack of understanding between HQ and post regarding which } \\
\text { individuals are important to their issues; lack of knowledge in terms } \\
\text { of each others' stakes, private goals and territories ("Who at HQ } \\
\text { knows this file? Who do I involve in this issue? Who has the power } \\
\text { to take action on it? Who would object, and what is at stake for } \\
\text { them?") }\end{array}$ & 68 \\
\hline $\begin{array}{l}\text { Interpersonal } \\
\text { divide }\end{array}$ & $\begin{array}{l}\text { Inability to achieve work objectives due to the lack of synchronous } \\
\text { communication and/or the lack of face-to-face contact needed to } \\
\text { communicate nuances, read reactions, and gauge interests ("Can't } \\
\text { walk across the hall to clarify"; "Hard feelings over the simplest } \\
\text { communication"'; "You're not there to look out for your interests") }\end{array}$ & 57 \\
\hline Temporal divide & $\begin{array}{l}\text { Communication, logistical, and performance challenges arising from } \\
\text { HQ and post being temporally out of phase ("One hour windows to } \\
\text { connect by phone"; "Unrealistic deadlines because Ottawa's days } \\
\text { are our nights") }\end{array}$ & 36 \\
\hline $\begin{array}{l}\text { Technological } \\
\text { divide }\end{array}$ & $\begin{array}{l}\text { Inadequate technological infrastructure ("Email goes down, the } \\
\text { phones go down": "We lack the set-up for videoconferencing here") }\end{array}$ & 21 \\
\hline
\end{tabular}

16 This analysis is designed to identify the special challenges associated with HQ-boundary spanner interactions in international settings. The table thus reflects the proportion of respondents whose comments suggested the potential for one of the "divide" factors to interfere with their interactions with HQ. Numbers do not reflect the proportion who reported an actual problem in each of the areas. For example, $21 \%$ mentioned that technological challenges needed to be addressed to enable distance communication. However, the majority of these respondents mentioned this when commenting that the departmental phone system was excellent in overcoming potential technological barriers. 


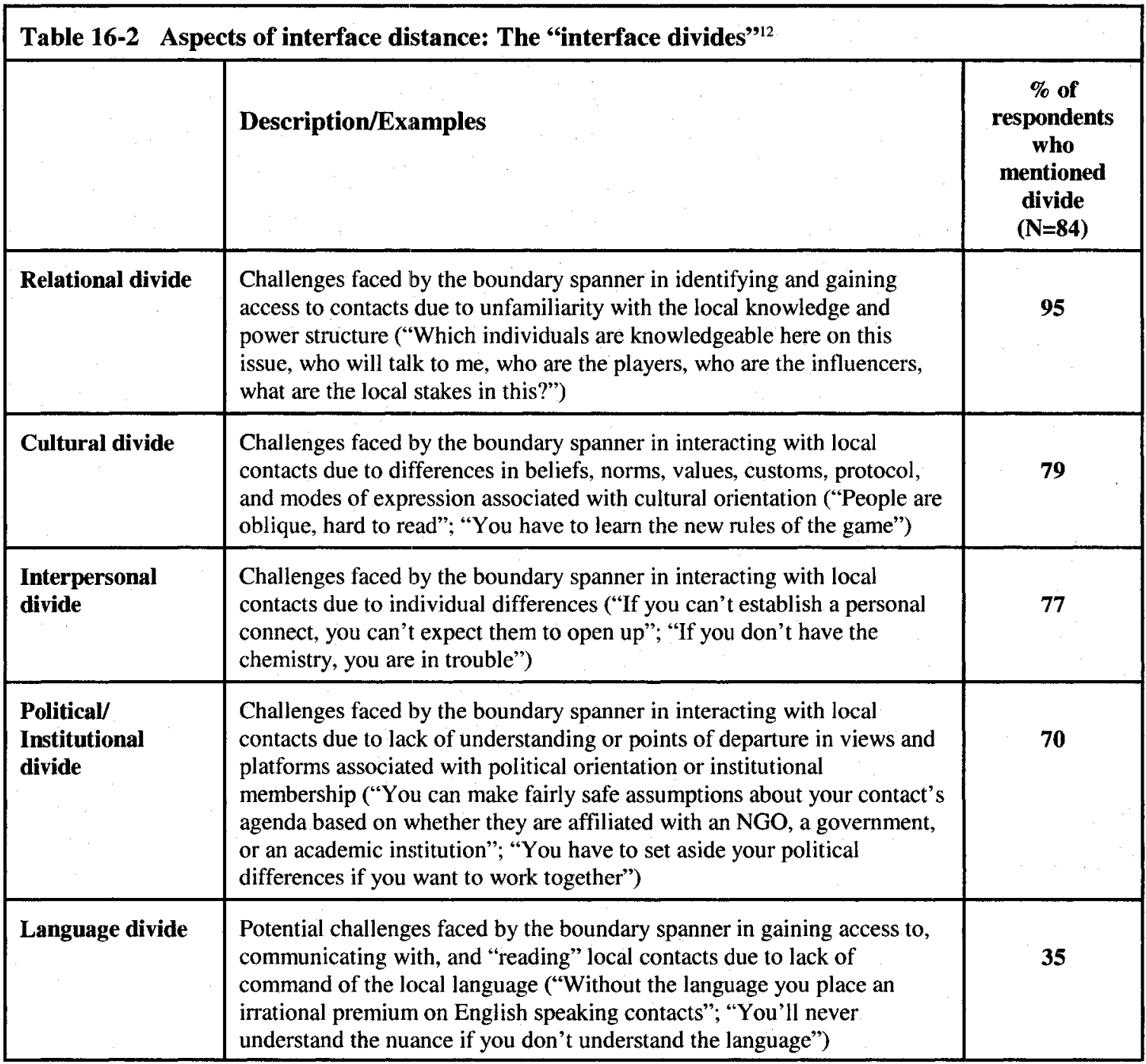

Table 16-1 presents the set of factors that emerged in association with the boundary spanner's geographic distance from other members of his or her organizational system. This set of factors was labelled "intra-organizational distance". Intraorganizational distance included the logistical factors intuitively associated with geographic distance, such as temporal and technological barriers to communication.

\footnotetext{
12 This analysis is designed to identify the special challenges encountered by boundary spanners when interacting with external agents in an international setting. The table thus reflects the proportion of respondents whose comments suggested the potential for one of the "divide" factors to interfere with their boundary interactions. Numbers do not reflect the proportion who reported an actual problem in each of the areas. For example, $70 \%$ mentioned the importance of knowing their contact's institutional affiliation in understanding what the contact's agenda was; however, the vast majority of these respondents found that knowing the institutional affiliation of their contacts made it easier to interact with them.
} 
However, having framed much of this research from the perspective of Dutton et al. (2001), the researcher was sensitized to the possibility that there may also be psychological and social dimensions to geographic distance. Table 16-1, therefore, also includes as dimensions of intra-organizational distance factors associated with barriers to interpersonal relationships and reduced access to the organization's strategic, cultural, and relational context. Indeed, boundary spanners' references to potential interpersonal and contextual barriers were much more frequent than their references to the more obvious challenges of temporal and technological issues.

There are at least three reasons that interpersonal and contextual issues figured more prominently in interviews than the more logistical issues. The first is that this organization has such sophisticated communications technologies that technological and temporal barriers have largely been surmounted. This interpretation is supported by respondents' references to DFAIT being the "envy" of other foreign ministries in terms of remote technologies. The second is that this organization has such extensive experience in international settings that logistical barriers to communication with HQ are taken as "given", and, when prompted about their work context, boundary spanners neglected to mention them. The third interpretation, and the one that is most consistent with the findings on the whole, is that geographic distance by definition removes the boundary spanner from the organizational system, and, therefore, is the most salient aspect of "intra-organizational distance" when the boundary spanner is questioned about his or her work context.

References to the need to overcome potential geographic barriers to contextual knowledge were pervasive. The importance of access to the intra-organizational context 
was mentioned in conjunction with boundary spanners' ability to understand what was expected in the role, in conjunction with their ability to influence HQ on issues of strategic importance, and in conjunction with their ability to attend selectively to their local environment to effectively engage local contacts in pursuit of organizational objectives. For example, where boundary spanners mentioned explicitly that they had an "internal" boundary spanner at HQ, they indicated that this individual kept them apprised of events and priorities at HQ that enabled them to appropriately direct their attention abroad to issues of strategic interest. Conversely, boundary spanners who were uncertain of their performance objectives abroad often lacked access to HQ context either directly through an "internal" boundary spanner, or indirectly, via debriefs from their managers. Further, in spite of sophisticated communications technologies, access to the organization's strategic and relational knowledge appeared to be further constrained by the lack of face-to-face contact needed to communicate nuances, read reactions, and gauge interests.

By "unpacking" the notion of geographic distance, we are able to obtain a more thorough understanding of the expatriate boundary spanner as a member of a larger organizational system. This conceptualization of distance enriches existing international management research which has tended to focus on barriers to the frequency or quality of communication in global settings (Montoya-Weiss et al., Maznevski and Chudoba, 2000). This research positions this communication within its broader organizational context by examining the purposes that such communications serve in terms of connecting the boundary spanner to the internal organizational system. The findings suggested that such connections are essential if the boundary spanner is to tap in to the 
strategic and relational knowledge needed to perform effectively abroad. Further, such connectedness is facilitated through synchronous communication which is best suited to bridging the interpersonal "divide".

Table 16-2 presents the set of factors that emerged in association with the cultural and psychological distance between the boundary spanner and the local agents with whom he or she interacted in order to carry out organizational objectives abroad. This set of factors was labelled "interface distance". Interface distance included cultural and language barriers, which have tended to dominate the expatriate adjustment literature, and which have been extensively documented elsewhere. However, the data collected for this research, especially those emerging from respondents' contact development strategies, suggested that interface distance also included potential barriers to the knowledge needed to identify and gain access to key contacts in unfamiliar environments (i.e., "before the boundary spanner can effectively engage locals, s/he has to find them"). Locating potential contacts relied on a degree of both political/institutional knowledge (known views and interorganizational relationships associated with institutional membership) and relational knowledge ("who are the local players, who is knowledgeable on this issue, and who will talk to me?"). Table 16-2, therefore, adds to the oft-mentioned cultural and language "divides", the relational and political/institutional "divides" as further aspects of interface distance.

Further, since boundary transactions ultimately take place at the level of individuals, interpersonal barriers were suggested to be as much of a factor in dealing with contacts in international contexts as they would be in domestic settings. It would be short-sighted to presume that once language and cultural nuances had been mastered, all 
interactions would go smoothly. Boundary spanners' descriptions of their boundary transactions included many references to the need for "chemistry" over the course of these transactions and a foundation of "trust". Indeed, the relationship theme so prevalent in this research was evidence of the perceived importance of interpersonal relationships in enabling cross-boundary exchanges. Table 16-2 thus includes the interpersonal divide as a further dimension of interface distance. The factors associated with "intra-organizational" and "interface" distance can now be positioned within the descriptive model given in Figure 16.1. Figure 16.2 presents this emergent model. This model is better able to capture the nuances of the data in suggesting how the conditions for effectiveness in the boundary role might be affected in the special case of the international assignment. The two sets of factors are positioned such that they are suggested to exert influence on the "wires" connecting the conceptual elements in the model. Each point of contact identifies a point at which intra-organizational or interface distance might constrain effectiveness in the boundary role.

Intra-organizational distance is posited to exert its effects wherever the boundary spanner is in direct contact with the organization. It, therefore, is shown to pose potential constraints at two points in the model. First, the model posits that, in instances where distance from the home organization reduces boundary spanners' access to the organization's strategic or relational context, boundary spanners may lack the information they need to fully understand the organization's expectations for the role (constraining their knowledge of organizational expectations; Element 1). Similarly, the model posits that, where distance reduces boundary spanners' access to organizational context, boundary spanners lack the information they need to identify issues of interest to 
HQ and to effectively package and sell issues (constraining their ability to influence the organization; Element 5). No direct connections are posited between intraorganizational distance and other elements in the model. However, indirect effects might be expected, since intra-organizational distance "breaks the link" at its most fundamental level: the understanding of expectations for the role. It might be expected, therefore, that lack of clarity on expected performance might, in turn, interfere with the boundary spanner's ability to both reconcile these expectations with those of external agents (Element 3) and to translate these expectations to individual work objectives (Element 4). Interface distance is posited to affect those conditions for effectiveness that emanate from the local environment. Interface distance is suggested to have the potential to interfere with boundary spanners' understanding of the expectations of local constituents (Element 2), and with their ability to effectively manage their transactions at the interface (Element 3). No other direct connections are posited. However, as was the case with intra-organizational distance, a lack of understanding of the expectations of local constituents might be expected to interfere indirectly with the boundary spanner's ability to apply the local lens as a "filter" in translating expectations to personal work goals (Element 4).

Consistent with the goals of an exploratory study, Figure 16.2 has identified the potential elements of an overarching model of the conditions for effectiveness in the expatriate boundary spanning role. It has also suggested potential relationships between intra-organizational and interface distance and the basic elements of the model. Further specification of either the constructs or the relationships between them awaits future research that can identify measures and derive specific hypotheses for testing. 


\section{Figure 16.2 Emergent conceptual framework of the potential effects of intra-organizational and interface distance on the conditions for effectiveness in the boundary spanning role}

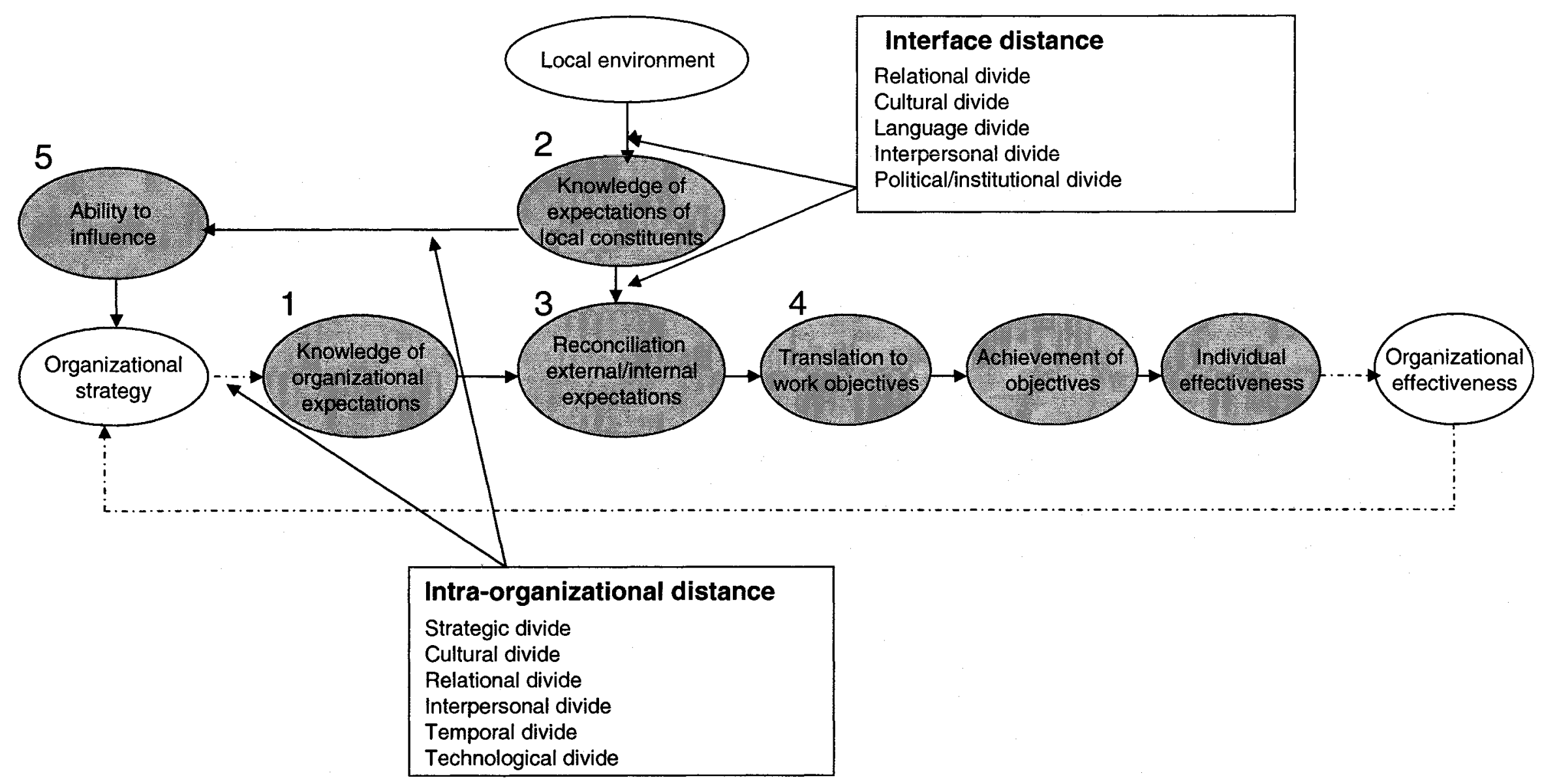




\section{PART SEVEN: CONCLUSIONS}

This final chapter presents the conclusions that have been drawn from this research, the contributions of the study, and its potential limitations. The chapter concludes with a discussion of directions for future management research and practice. 


\section{CONCLUSIONS}

\subsection{Conclusions and contributions of this research}

This exploratory case study responds to recent calls for greater attention to individual-level phenomena in international management research ( $\mathrm{Au}$ and Fukuda, 2002; Bartlett and Ghoshal, 1995; Birkinshaw, 1997; Werner, 2002), and in particular, to the actual work context of the expatriate on international assignment (Harrison and Schaeffer, 2005). The research has applied existing knowledge from the micro domains of role theory, social network theory, job design, and strategic influence to construct a model of the expatriate boundary spanning role. It has been the premise of this research that a boundary spanning framework is suited to capturing the central elements of the expatriate's work role abroad and thus provides the conceptual tool needed to better understand this unique work context.

Through application of the grounded theory technique, the research generated a typology of the dimensions of the boundary spanning role. At the time of this writing, this typology represented the only known characterization of the boundary role at the level of the individual. The emergent typology suggested that the boundary role comprised a rich, multi-dimensional construct. Like earlier typologies developed at the level of the team and in the context of intra-organizational boundaries (Ancona and Caldwell, 1988; 1992), the typology suggested that the individual boundary role served many adaptive purposes for the organization in unfamiliar environments, including bringing local information and intelligence into the organization, influencing external agents in pursuit of organizational objectives, and protecting the core work of the 
organization from uncertainty and outside pressures. However, unlike earlier typologies, the typology emerging from this research indicated that these functions were enabled by interpersonal relationships, suggesting that relationships may be pivotal to effective transactions at the level of the individual, and when working across inter-organizational boundaries. The model developed for this research, therefore, might prove useful in the exploration of the micro-level phenomena involved in a host of inter-organizational relationships, particularly those of interest in the growing body of international management literature addressing joint ventures, co-operative alliances, governmentbusiness partnerships, buyer-supplier relationships, and cross-cultural teams (Bird and Osland, 2006; Buckley, Glaister and Husan, 2002; Kealey, Protheroe, MacDonald and Vulpe, 2005). As noted by Hoon-Halbauer (1999), “... the combination of organizations is actually a joining together of individuals and groups... (one needs to) understand the culture and develop the relationships... sounds simple but many people cannot do it" (p. 345).

The grounded theory technique also enabled the development and expansion of a model of the conditions for effectiveness in the boundary role. Having constructed this model from existing micro-level management theory, the research was able to identify similarities and points of departure from the literature when the model was applied to the special case of the international assignment. The distinguishing features of the boundary role in an international setting are the expatriate's geographic distance from the home organization and the expatriate's unfamiliarity with the local environment. Previous research has examined these features somewhat unidimensionally by operationalizing intra-organizational distance in terms of reduced communications with the home 
organization (the "black hole"; Black and Gregersen, 1999; Yip, 2003), and operationalizing interface challenges in terms of language and culture (expatriate adjustment; Tung, 1981). The framework developed for this research enabled a more comprehensive examination of the phenomena. The emergent typologies of "distance" revealed multiple dimensions to both intra-organizational and interface distance in terms of the boundary spanner's access to important organizational and local knowledge needed to perform the job. This expanded conceptualization may open the door to further theoretical exploration of the notions of intra-organizational and interface distance. It may also help to identify interventions targeted at specific aspects of "distance" that may enable organizations to better support their boundary spanners in international settings. Several such interventions are suggested in Section 17.4 in the discussion of implications for management practice.

The research also responds to recent calls for research that can examine the important work of the many expatriates who work at non-management levels (Bonache, 2005; Bartlett and Ghoshal, 2004; Sinangil and Ones, 2005). The data suggested many similarities between the work of the executives in this sample and employees at nonmanagement levels, consistent with Caliguiri's (1997) observation that jobs that are nonmanagerial in domestic settings may take on managerial aspects in international settings, particularly in terms of developing local working relationships and serving as the representative of the organization to customers or the public. The findings suggested, however, that the boundary role may be somewhat more challenging for those at nonmanagement levels, in terms of both intra-organizational and interface contexts. Within the organization, non-management employees seemed less able than those at more senior 
ranks to obtain access to HQ for consultation and feedback. At the interface, nonmanagement employees seemed to be tasked with delivering messages, often on short notice, and running interference to deflect unwanted inquiries. Conversely, executives reported somewhat more ready access to $\mathrm{HQ}$ for direction and guidance, and enjoyed a rather privileged status at the interface as they enacted their representational roles. Although corroboration of these findings awaits future research in other employee populations, the job level differences emerging in this research suggest the need for tailored approaches to supporting boundary spanners at different levels of the organization.

In sum, the findings of this research take a first step toward filling the micro-level gap in the international management literature (Mendenhall, 2002; Werner, 2002). In particular, the boundary spanning framework advances the literature by conceptualizing expatriate effectiveness in terms of his or her contribution to the organization's effectiveness, rather than in terms of personal adjustment and turnover intentions. Hopefully, this conceptualization may contribute to the development of more organizationally relevant performance measures in the future. Further, it is believed that the examination of influence efforts in this organization, particularly at non-management levels, contributes to the broader management literature as well. To date, both the boundary spanning literature and the strategic decision-making literature have been dominated by a focus on the strategic influence of mid- and high-level managers. As expressed by Wooldridge and Floyd (1990), in today's fast-paced environment, “... research should recognize the possibility of a broad scope of strategic involvement well beyond the managerial ranks". The current study suggests how the actions of employees 
throughout the organization might translate to the day-to-day practices that result in change. It is hoped, therefore, that in addition to contributing to the international management literature, this research can advance understanding of the organizational conditions that support strategic involvement throughout organizations.

\subsection{Limitations of this research}

In spite of its anticipated contributions, this research is subject to a number of limitations. The first pertains to the narrowness of the sample, and the extent to which the dimensions of the boundary role generated from a study of foreign service professionals might have relevance to the boundary role in the broader population of expatriates. Whereas it is acknowledged that the specific dimensions of the boundary role emerging from this research may or may not generalize to other populations, what is generalizable is the approach to conceptualization. A primary value of this research was to distinguish between purpose and activity in the conceptualization of the boundary role and to connect this to adaptative value at the level of the organization. This is an approach that is now generalizable so that future researchers might employ it in testing the dimensions in other populations. Further, the focus on linking the performance of the individual to the performance of the organization contributes theoretically to advancing multilevel analysis, where the tendency has been to underspecify inter-level linkages (e.g., Thomas, 1994). Hopefully, this approach might contribute to multilevel theory with greater bond strength (Simon, 1973) at the individual-organization interface.

A second, and related, potential limitation of this research is the extent to which the findings regarding the conditions for effectiveness might pertain to the work context 
in other settings, particularly in the private sector. The decision to study a foreign service ministry was taken with an eye to locating an MNE representing the extreme in boundary spanning- - an organization with a very high dependency on its environment, an extensive international presence, and a long history of managing boundary spanning employees at all organizational levels. The selection of such an organization was believed to introduce sufficient variability in responses to tap a broad spectrum of organizational and interface factors that might enhance or constrain individual effectiveness in the boundary role. It is believed that the rich dataset generated by this case suggested constructs and relationships that will prove sufficiently general and inclusive to be useful in the study of boundary spanning in other organizations. In addition, it has been suggested that when it comes to the pressures encountered in operating in foreign environments- - and the managerial response to these pressures- there may be more similarities than differences between for-profit MNEs and public/nonprofits (e.g., tensions between centralization and localization; frequent and disruptive restructurings, strict financial accountabilities, cultural adjustment issues, and the nature of challenges faced by the expatriate manager; Brewster, 2002; Manev, 2003). To the extent that these elements are shared across public and private organizations, the model of effectiveness emerging from this research should have sufficient generality to be applied to the study of boundary spanning in the private sector firm as well. Further, as has been noted frequently in the expatriate literature, in today's global environment, all expatriates are, in essence, "diplomats" (Bonache, 2005; Buckley et al., 2002; Caliguiri, 1997; Harvey and Novicevic, 2004; Kealey et al., 2005). Accordingly, some organizations are seeking to define and provide training for their expatriates in a set of 
"diplomatic skills" (Buckley et al., 2002). Regardless of the generalizability of the model of effectiveness, there may be lessons inherent in this in-depth examination of the diplomat's role.

A third limitation of the research pertains to the potential lack of comprehensiveness of the typology of the boundary role. Although the typology revealed a rich, multidimensional construct, most emergent dimensions suggested an "outward" adaptive flow. Other than information-seeking behaviours, few of the emergent dimensions reflected an "inward" flow of resources. Future research is needed to determine whether this apparent imbalance is an accurate reflection of the individual boundary role in the contemporary MNE or whether it is an artifact of the interview methodology employed.

A fourth limitation pertains to the lack of comprehensiveness of the model of the conditions for effectiveness. Although the model allowed the investigation of a range of intra-organizational and interface elements that might affect boundary spanner effectiveness, it did not examine the potential contributions of psychological or other individual differences. Individual factors, such as motivation, work attitudes and personality, are likely equally important to the ability and willingness to perform in the boundary role and remain a topic for future research.

A final limitation of the research was a methodological constraint. The methodology as originally designed sought to triangulate the qualitative data with quantitative measures. This approach met with some success where the scales employed were well-tested measures from the management literature. However, the measures of the boundary role construct derived from Au and Fukuda and from Ancona and 
Caldwell's work lacked correspondence with the emergent data, so were of limited use in corroborating the emergent boundary role dimensions. The preferred approach, and one in keeping with the spirit of qualitative research, would have been to devise the quantitative measures iteratively as the concepts emerged from the interview data. However, practical limitations arising from a narrow window for data collection precluded this approach, and required that all questionnaire materials be prepared in advance of going into the field. This left many of the emergent dimensions without quantitative items to substantiate them. It was, therefore, not possible to apply the scales to determine whether the observed dimensions constituted an important aspect of the job as a whole, or whether they were specific to the episodes cited. In addition to corroborating the existence of these dimensions in other employee populations, future research might look to developing quantitative measures that can tap a fuller range of the dimensions.

\subsection{Directions for future research}

The implications of this case study for future research are twofold. The first direction for research is to test the external validity of these conceptual frameworks by examining their transferability to other populations and settings. At the most basic level, this might be done by replicating the interviews with other samples, including those from the private sector and those from other government and non-governmental organizations. The goal of further qualitative research at this point would be to determine whether the new data fit the conceptual frameworks emerging from this study, or whether the frameworks require further refinement. Once confident that the constructs have been 
adequately defined, researchers might move toward the development of measures of the constructs and the formulation of hypotheses for quantitative testing.

The second potential direction for research would be to move toward hypothesis testing where measures already exist. With respect to the boundary role construct, several propositions have been advanced in this research which may be suited to further elaboration and testing. One of the central themes of these propositions was that the relationship was the cornerstone of boundary spanning at the individual level and the enabler of other resource exchanges. This assertion is consistent with social network theory and a model might be constructed to position affect as the mediator of crossboundary exchanges of information or workflow resources. The model might be tested with the aid of various quantitative measures of trust or affect, such as those given in the knowledge transfer literature (e.g., Levin and Cross, 2004). Research employing the dyad as the unit of analysis might be particularly fruitful in this regard, as it would enable the research to capture the degree of reciprocity in affect, as judged by both participants in the boundary exchange.

With respect to the conditions for effectiveness, the typologies of intraorganizational and interface distance also provide opportunities for elaboration and testing. The conceptualization arising from this exploratory study identifies the potential aspects of "distance", but no effort has been made to theoretically position these aspects with respect to one another. For example, the intra-organizational typology suggested that the most salient aspect of intra-organizational distance was the lack of connectedness to the organization's strategic and relational context, and the least salient aspects were the temporal and technological aspects. Somewhere in the middle was the perceived 
interpersonal divide. However, this pattern suggests a hierarchical ordering in the dimensions, such that it might be posited that temporal and technological barriers create barriers to interpersonal contact, which in turn, create barriers to the ability to access the organization's contextual knowledge. Future research might test such inter-relationships to further specify the model and better understand the aspects of intra-organizational and interface distance identified in this research.

Finally, it is noted that the distance typologies derived in this research focus exclusively on potential challenges to effectiveness in the boundary role. However, the research also suggested that distance came with its advantages. For example, geographic distance from HQ was associated with a high level of autonomy on the job, and access to specialized local knowledge that the boundary spanner was able to exploit to obtain influence over HQ. Similarly, perceived distance from the local culture also had its benefits, since diplomatic work was seen as a prestigious role and the boundary spanner was held in some esteem in the eyes of local contacts ("everybody wants to be seen with a diplomat"). Future research, therefore, might explore further the extent to which intraorganizational and interface distance might yield benefits for the boundary spanner in the international setting.

\subsection{Implications for practice}

Whereas further conceptual development and the testing of theoretical relationships await future research, the results of this study seem to have several direct implications for management practice. Implications for practice can be inferred from the model of the conditions for effectiveness in the boundary role and the nature of the intra- 
organizational and interface "divides" that emerged in the research (Figure 16.2).

Findings indicated that the intra-organizational "divides" inherent in the international assignment had the potential to limit boundary spanners' access to the strategic and relational knowledge needed to understand their roles abroad and to influence management on issues of perceived importance. Hence, any modification to the intra-organizational context that might enhance the boundary spanner's access to the organization's strategic and relational context might be expected to contribute also to enhanced effectiveness. Such modifications might include: the articulation of clear objectives for the assignment prior to departure; the development of accountability frameworks so that individuals at both HQ and abroad understand these objectives and their respective responsibilities in meeting them; measures to promote regular contact with HQ over the course of the assignment to fine-tune objectives and enable the boundary spanner to obtain the context needed to effectively "sell" their issues from abroad; frequent opportunities for real-time and, preferably, face-to-face dialogue through conference calls, videoconferencing and meetings; and adequate investments in remote technology to support this dialogue. Interviewees' comments around the value of having a contact at HQ to support the two-way flow of information between HQ and points abroad suggest that boundary spanners in international settings might benefit also from access to a dedicated "internal boundary spanner". The findings also identified a range of creative measures that organizations might adopt to facilitate the "downloading" of boundary spanner knowledge upon return from assignment, including debriefs, strategic job placements, and alternative career paths at $\mathrm{HQ}$.

The findings indicated further that the interface "divides" potentially posed risks 
to the boundary spanner's ability to locate and gain access to key local contacts and to engage them effectively in boundary exchanges. Interventions that can support the boundary spanner in the interface role might also be of value. Measures might include: pre-assignment training, including cross-cultural and country-specific training (for discussions, see Kealey et al., 2005; O’Sullivan, 1999), language training, training in negotiating and partnering skills, and where feasible, the introduction of an overlap period to allow the boundary spanner to shadow his or her predecessor abroad.

Finally, the observed job level differences in this research point to the need for management interventions tailored to boundary spanners at different levels of the organization. Whereas it is important to ensure a two-way flow of information between HQ and boundary spanners at all levels, findings suggested that the more junior boundary spanner may be at somewhat of a disadvantage in terms of access to the intraorganizational context, and in terms of having to deal with somewhat more stressful or challenging situations at the interface. Further research is needed to determine whether these job level differences are idiosyncratic to this sample. However, to the extent that they are shared in other organizations, there may be a need to target boundary spanners at more junior levels for enhanced support. Such measures might seek to prevent hierarchical bottlenecks in information flow by: delivering strategy documents directly to boundary spanners at junior levels, rather than indirectly through executive heads; providing managers with training and support to ensure that the context to which they are privy is communicated downward through the hierarchy; and providing more junior levels with structured opportunities for dialogue with HQ. Support might also be provided at the interface by: encouraging overlap with the predecessor; expending extra 
effort in pre-departure training; and ensuring that boundary spanners at the front line are equipped with the information they need to respond to interface demands and make occasional "deposits in the relationship bank".

Although such recommendations seem rather intuitive, international management research suggests that, to date, most organizations do not well prepare their expatriates either in terms of setting initial objectives for the assignment (Black and Gregersen, 1999; Bonache, 2005; Cartus, 2004; Light, 1997; Kraimer and Wayne, 2003) or in terms of maintaining communication over the course of the assignment (Black and Gregersen, 1999; Mercer HR Consulting, 2003; Yip, 2005). Further, there is evidence of inadequate attention to language, cross-cultural, and country-specific training (Cartus, 2004; Light, 1997; Peppas, 2004). It would seem that the theoretical context provided by a boundary spanning framework might serve to remind organizations of the value of such interventions and the potential risk to the organization of inadequately supporting their expatriates in their important boundary spanning roles. This exploration of intraorganizational and interface "distance" begins that theoretical work, and might prove fruitful in beginning to bridge these aspects of the geographic "divide". 


\section{REFERENCES}

Adams, J. (1976). The structural dynamics of behavior in organizational boundary roles. In: M. Dunnette (Ed)., Handbook of industrial and organizational psychology, 11751199. Chicago: Rand McNally.

Agyris, C. and Schon, D. (1982). Theory in practice. San Francisco: Jossey-Bass.

Aldrich, H., and Herker, D. (1977). Boundary spanning roles and organization structure. Academy of Management Review, 2, 2, 217-230.

Ancona, D. and Caldwell, D. (1988). Beyond task and maintenance: Defining external functions in groups. Group and Organization Studies, $\underline{13}, 4,468-494$.

Ancona, D., Caldwell, D. (1992). Bridging the boundary: External activity and performance in organizational teams. Administrative Science Quarterly, 37, 634-665.

Andersen, O. (1993). On the internationalization of firms: A critical analysis. Journal of International Business Studies, 24, 2, 209-231.

Anderson, T. (2004). Integrating decentralized strategy making and strategic planning processes in dynamic environments. Journal of Management Studies, 41, 8, 1271-1299.

Ansoff, H. (1965). Corporate strategy. New York: McGraw Hill.

Aryee, S. and Stone, R. (1996). Work experiences, work adjustment and psychological well-being of expatriate employees in Hong Kong. International Journal of Human Resource Management, , 1, 150-164.

Ashill, N., Meadows, S., and Stewart, D. (2001). Factors influencing boundary spanner stress and subsequent managerial intervention: an exploratory investigation. Journal of Strategic Marketing, 9, 269-284.

Au, K. and Fukuda, J. (2002). Boundary spanning behaviors of expatriates. Journal of World Business, 37, 285-296.

Bacharach (1989). Organizational theories: Some criteria for evaluation. Academy of Management Review, 14, 496-514.

Balogun, J., Huff, A.S., and Johnson, P. (2003). Three responses to the methodological challenges of studying strategizing. Journal of Management Studies, 40, 1, 197-224.

Barkema, H., Bell, J., and Pennings, J. (1996). Foreign entry, cultural barriers, and learning. Strategic Management Journal, 17, 2, 151-166. 
Bartlett, C. and Ghoshal, S. (1991). Global strategic management: Impact on new frontiers of strategy. Strategic Management Journal, 12, 5-16.

Bartlett, C. and Ghoshal, S. (2004). The myth of the generic manager: New personal competencies for new management roles. In: C. Bartlett, S. Ghoshal and J. Birkinshaw, Transnational management, 813-831. New York: McGraw-Hill.

Birkinshaw, (1997). Entrepreneurship in multinational corporations: The characteristics of subsidiary initiatives. Strategic Management Journal, 18, 3, 207-229.

Black, J.S. and Gregersen, H. (1999). The right way to manage expats. $\underline{\text { Harvard }}$ Business Review, March-April.

Bonache, J. (2005). Job satisfaction among expatriates, repatriates and domestic employees. Personnel Review, 34, 1, 110-124.

Bourgeois, L. and Eisenhardt, K. (1988). Politics of strategic decision making in highvelocity environments: Toward a midrange theory. Academy of Management Journal, $\underline{31}, 4,737-770$.

Bouty, I. (2000). Interpersonal and interaction influences on informal resource exchanges between $R \& D$ researchers across organizational boundaries. Academy of Management Journal, 43 , 1, 50-65.

Brass, D. (1984). Being in the right place: A structural analysis of individual influence in an organization. Administrative Science Quarterly, 29, 518-539.

Brewster, C. (2002). Human resource practices in multinational companies. In: Gannon, M. and Newman, K. (Eds.), Blackwell Handbook of Cross-cultural Management, 126141. Oxford: Blackwell.

Buckley, P., Glaister, K. and Husan, R. (2002). International joint ventures: Partnering skills and cross-cultural issues. Long Range Planning, 35 113-134.

Burgelman, R. (1983a). A process model of internal corporate venturing in the diversified major firm. Administrative Science Quarterly, 28, 223-244.

Burgelman, R. (1983b). A model of the interaction of strategic behavior, corporate context and the concept of strategy. Academy of Management Review, $\underline{8}, 1,61-70$.

Buss, D. and Craik, K. (1983). The act frequency approach to personality. Psychological Review, 90, 105-126.

Caligiuri, P. (1997). Assessing expatriate success: Beyond just "being there". In: Z. Aycan (Ed.), New approaches to employee management, vol 3, 117-140. Greenwich CT: 
JAI Press.

Campbell, D. and Stanley, J. (1966). Experimental and quasi-experimental designs for research. Chicago: Rand McNally.

Cartus (2004). Emerging trends in global mobility: Policy and practices survey 2004. Chicago: Cartus/ Cendant Mobility Services.

Collier, N., Fishwick, F., Floyd, S. (2004). Managerial involvement and perceptions of strategy process. Long Range Planning, 37, 67-83.

Dutton, J. and Ashford, S. (1993). Selling issues to top management. Academy of Management Journal, $\underline{18}$, 3, 397-428.

Dutton, J., Ashford, S., Lawrence, K., and Miner-Rubino, K. (2002). Red light, green light: Making sense of the organizational context for issue selling. Organization Science, $13,4,355-369$.

Dutton, J., Ashford, S., O'Neill, R. and Lawrence, K. (2001). Moves that matter: Issue selling and organizational change. Academy of Management Journal, 44, 4, 716-736.

Doz, Y. and Prahalad, K. (1991). Managing DMNCs: A search for a new paradigm. Strategic Management Journal, 12, 145-164.

Doz, Y. and Prahalad, K. (1984). Patterns of strategic control within multinational corporations. Journal of International Business Studies, 15, 2, 55-72.

Eisenberger, R., Huntington, R., Hutchison, S. and Sowa, D. (1986). Perceived organizational support. Journal of Applied Psychology, 71, 500-507.

Eisenhardt, K. (1989). Building theories from case study research. Academy of Management Review, 14, 4, 532-550.

Eisenhardt, K. and Bourgeois, L. (1988). Politics of strategic decision making in highvelocity environments: Toward a mid-range theory. Academy of Management Review, 31, 4, 737-770.

Evans, J. and Mavondo, F.T. (2002). Psychic distance and organisational performance: An empirical examination of international retailing. Journal of International Business Studies, $\underline{33}, 3,515-532$.

Fayol, H. (1937). The administrative theory of the state. In: L. Gulick and L. Urwick (Eds.), Papers on the science of administration. New York: Institute of Public Administration, p. 99. 
Feldman, D. and Thomas, D. (1992). Career management issues facing expatriates. Journal of International Business Studies, 23, 2, 271-293.

Fields, D. (2002). Taking the measure of work. Thousand Oaks, CA: Sage.

Floyd, S. and Lane, P. (2000). Strategizing throughout the organization: Managing role conflict in strategic renewal. Academy of Management Journal, 25, 1, 154-177.

Floyd, S. and Wooldridge, B. (1989). Strategic process effects on consensus. Strategic Management Journal, 10, 3, 295-302.

Floyd, S. and Wooldridge, B. (1997). Middle management's strategic influence and organizational performance. Journal of Management Studies, 34, 3, 465-485.

Galbraith, J. (2000). Designing the global corporation. San Francisco: Jossey-Bass.

Gersick, C. (1988). Time and transition in work teams. Toward a new model of group development. Academy of Management Journal, 31, 9-41.

Glaser, B. and Strauss, A. (1967). The discovery of grounded theory. Strategies of qualitative research. London: Wiedenfeld and Nicholson.

Govindarajan, V. and Gupta, A. (2001). Building an effective global business team. MIT Sloan Management Review, Summer, 63-71.

Gupta, A., Govindarajan, V. and Malhotra, A. (1999). Feedback-seeking behavior within multinational corporations. Strategic Management Journal, $\underline{3}$, 205-222.

Hackman, J. and Oldham, G. (1974). The job diagnostic survey: An instrument for the diagnosis of jobs and the evaluation of job redesign projects. New Haven, CT: Yale University.

Hackman, J. and Oldham, G. (1975). Development of the job diagnostic survey. Journal of Applied Psychology, 60, 159-170.

Hackman, J. and Oldham, G. (1976). Motivation through the design of work: Test of a theory. Organizational Behavior and Human Performance, 16, 250-279.

Hart, S. (1992). An integrative framework for strategy-making processes. Academy of Management Review, 17, 327-351.

Harrison, D. and Shaffer, M. (2005). Mapping the criterion space for expatriate success: Task- and relationship-based performance, effort, and adaptation. International Journal of Human Resource Management, 16, 8, 1454-1474. 
Harvey, M. and Novicevic, M. (2004). The development of political skill and political capital by global leaders through global assignments. International Journal of Human Resource Management, 15, 7, 1173-1188.

Hechanova, R., Beehr, T. and Christiansen, N. (2003). Antecedents and consequences of employees' adjustment to overseas assignment: A meta-analytic review. Applied Psychology: An International Review, 52, 2, 213-236.

Hedlund, G. (1980). The role of foreign subsidiaries in strategic decision-making in Swedish multinational corporations. Strategic Management Journal, 1, 1, 23-26.

Hinds, P. and Kiesler, S. (1995). Communication across boundaries: Work, structure, and use of communication technologies in a large organization. Organization Science, $\underline{6}$, 4, 373-391.

Hoon-Halbauer, S. (1999). Managing relationships within sino-foreign joint ventures. Journal of World Business, 34, 4, 344-369.

House, R. (1971). A path-goal theory of leadership effectiveness. Administrative Science Quarterly, 16, 321-338.

House, R. and Rizzo, J. (1972). Role conflict and ambiguity as critical variables in a model of organizational behavior. Organizational Behavior and Human Performance, 7 , 467-505.

Ilgen, D. and Hollenbeck, J. (1991). The structure of work: Job design and roles. In M. Dunette and L. Hough (Eds.), Handbook of industrial and organizational psychology, $2^{\text {nd }}$ edition, volume 2. Consulting Psychologists Press: Palo Alta, CA, 165-207.

Ireland, R., Hitt, M., Bettis, R. and de Porras, D. (1987). Strategy formulation processes: Differences in perceptions of strength and weaknesses indicators and environmental uncertainty by managerial level. Strategic Management Journal, $\underline{8}$, 5, 469-485.

Jackson, S. and Schuler, S. (1985). A meta-analysis and conceptual critique of research on role ambiguity and role conflict in work settings. Organizational Behavior and Human Decision Processes, $\underline{36}, 16-78$.

Jemison, D. (1984). The importance of boundary spanning roles in strategic decision making. Journal of Management Studies, 21, 2, 131-151.

Johlke, M., Stamper, C., Shoemaker, M. (2001). Antecedents to boundary spanner perceived organizational support. Journal of Managerial Psychology, 17, 2, 116-128.

Kahn, R., Wolfe, D., Quinn, R., Snoek, J. and Rosenthal, R. (1964). Organizational stress: Studies in role conflict and ambiguity. New York: Wiley. 
Karasek R. and Theorell, T. (1990). Healthy work: Stress, productivity, and the reconstruction of working life. New York: Basic Books.

Katz, D. and Kahn, R. (1966). The social psychology of organizations. New York: Wiley.

Kealey, D., Protheroe, D., MacDonald, D. and Vulpe, T. (2005). Re-examining the role of training in contributing to international project success: A literature review and an outline of a new model training program. International Journal of Intercultural Relations, 29, 289-316.

Kerr, S., Schriesheim, C., Murphy, C. and Stogdill, R. (1974). Toward a contingency theory of leadership based on the consideration and initiating structure literature. Organizational Behavior and Human Performance, August, 62-82.

Kipnis, D., Schmidt, S. and Wilkinson, I. (1980). Intraorganizational influence tactics: explorations in getting one's way. Journal of Applied Psychology, 65, 440-452.

Kozlowski, S. and Klein, K. (2000). A multilevel approach to theory and research in organizations. In: K. Klein and S, Kozlowski, (Eds.), Multilevel theory, research and methods in organizations. San Francisco: Jossey-Bass, 3-90.

Kraimer, M. and Wayne, S. (2004). An examination of perceived organizational support as a multidimensional construct in the context of expatriate assignment. Journal of Management, $\underline{30}, 2,209-237$.

Lazarus, R. and Folkman, S. (1984). Stress, appraisal, and coping. Springer: New York.

Leifer, R. and Delbecq, A. (1976). Organizational/Environmental interchange: A model of boundary spanning activity. Academy of Management Review, $\underline{3}, 40-50$.

Leifer, R. and Huber, G. Relations among perceived environmental uncertainty, organizational structure, and boundary spanning behavior. Administrative Science Quarterly, 22, 235-247.

Levin, D. and Cross, R. (2004). The strength of weak ties you can trust: The mediating role of trust in effective knowledge transfer. Management Science, 50, 11, 1477-1490.

Light, D. (1997). Expatriate employees: Getting the most out of their experience. Harvard Business Review, November-December.

Lord, M. and Ranft, A. (2000). Organizational learning about new international markets: Exploring the internal transfer of local market knowledge. Journal of International Business Studies, $\underline{31}$, 4, 573-589. 
Lyonksi, S. (1985). A boundary theory investigation of the product manager's role. Journal of Marketing, $\underline{49}, 26-40$.

Manev, I. (2003). The managerial network in a multinational enterprise and the resource profiles of subsidiaries. Journal of International Management, 9 , 133-151.

Manev, I. and Stevenson, W. (2001a). Balancing ties: Boundary spanning and influence in the organization's extended network of communication. Journal of Business

Communication, $\underline{38}, 2,183-205$.

Manev, I. and Stevenson, W. (2001b). Nationality, cultural distance, and expatriate status: Effects on the managerial network in a multinational enterprise. Journal of International Business Studies, $\underline{32}$, 2, 285-303.

Maznevski, M. and Chudoba, K. (2000). Bridging space over time: Global virtual team dynamics and effectiveness. Organization Science, 11, 5, 473-492.

McGraw, P. (2004). Influences on HRM practices in MNCs: A qualitative study in the Australian context. International Journal of Manpower, 25, 6, 535-546.

McNulty, Y. and Tharenou, P. (2005). Expatriate return on investment. A definition and antecedents. International Studies of Management and Organization, 34, 3, 69-95.

Mendenhall, M., Kuhlmann, T., Stahl, G. and Osland, J. (2002). In: Gannon, M. and Newman, K. (Eds.), Blackwell handbook of cross-cultural management, 156-183. Oxford: Blackwell.

Mertens, D. (1998). Research methods in education and psychology. Thousand Oaks, CA: Sage.

Mercer Human Resource Consulting (2003). New survey of Canadian companies assesses expatriate services. News Release, September, 19; http://www. mercerhr.com.

Miles, R. (1976). Role requirements as sources of organizational stress. Journal of Applied Psychology, 61, 2, 172-179.

Miles, M. and Huberman, M. (1984). Qualitative data analysis. Beverly Hills, CA: Sage.

Miles, R. and Snow, C. (1978). Organizational strategy, structure and process. New York: McGraw Hill.

Mintzberg, H. (1973). The nature of managerial work. New York: Harper and Row.

Mitchell, J. (1969). The concept and use of social networks. In: J. Mitchell (Ed.), Social 
networks in urban situations. Manchester: University of Manchester Press.

Montoya-Weiss, M., Massey, A. and Song, M. (2001). Getting it together: Temporal coordination and conflict management in global virtual teams. Academy of Management Journal, 44, 6, 1251-1262.

O'Donnell, S. (2000). Managing foreign subsidiaries: Agents of headquarters, or an interdependent network? Strategic Management Journal, 21, 5, 525-548.

O'Sullivan, S. L. (1999). The distinction between stable and dynamic cross-cultural competencies: Implications for expatriate trainability. Journal of International Business Studies, $\underline{30}, 4$.

O'Driscoll, M. and Beehr, T. (1994). Supervisor behaviors, role stressors and uncertainty as predictors of personal outcomes for subordinates. Journal of Organizational Behavior, 15, 141-155.

Organ, D. (1971). Linking pins between organization and environment. Business Horizons, December, 73-80.

Pappas, J. (2004). Middle managers' strategic influence: Investigating network centrality and perceptual deviance. Academy of Management Proceedings. Best Conference Paper.

Patton, M. (2002). Qualitative research and evaluation methods. Thousand Oaks, CA: Sage.

Peppas, S. (2004). Making the most of international assignments: A training model for non-resident expatriates. Journal of American Academy of Business, September, 41-45.

Perrow, C. (1986). Complex organizations. New York: Random House.

Pinfield, L. (1986). A field evaluation of perspectives on organizational decision making. Administrative Science Quarterly, 31, 365-388.

Podsakoff, P., and MacKenzie, S. (1994). An examination of the psychometric properties and nomological validity of some revised and reduced substitutes for leadership scales. Journal of Applied Psychology, 79, 5, 702-713.

Porter, M. (1986). Competition in global industries: A conceptual framework. In: M. Porter (Ed.), Competition in global industries. Harvard Business School Press: Boston.

Pugh, D., Hickson, D., Hinings, K. and Turner, C. (1968). Dimensions of organizational structrue. Administrative Science Quarterly, 13, 65-105. 
Rangarajan, D., Chonko, L., Jones, E., and Roberts, J. (2004). Organizational variables, sales force perceptions of readiness for change, learning, and performance among boundary spanning teams: A conceptual framework and propositions for research. Industrial Marketing Management, 33, 289-305.

Rhoads, G., Singh, J., and Goodell, P. (1994). The multiple dimensions of role ambiguity and their impact upon psychological and behavioral outcomes of industrial salespeople. Journal of Personal Selling and Sales Management, 14, 3, 1-24.

Rizzo, J., House, R. and Lirtzman, S. (1970). Role conflict and ambiguity in complex organizations. Administrative Science Quarterly, 15, 150-163.

Rosner, J. (1990). Ways women lead. Harvard Business Review, November.

Sawyer, J. (1992). Goal and process clarity: Specification of multiple constructs of role ambiguity and a structural equation model of their antecedents and consequences.

Journal of Applied Psychology, 77, 2, 130-142.

Schilit, W. (1990). A comparative analysis of strategic decisions. Journal of Management Studies, 27, 5, 435-461.

Schuler, R., Aldag, R., and Brief, A. (1977). Role conflict and ambiguity: A scale analysis. Organizational Behavior and Human Performance, 20, 111-128.

Schwab, R., Ungson, G., and Brown, W. (1985). Redefining the boundary-spanning environment relationship. Journal of Management, $\underline{11}, 1,75-86$.

Shay, J. and Baack, S. (2004). Expatriate assignment, adjustment and effectiveness: An empirical examination of the big picture. Journal of International Business Studies, 35 , 216-232.

Siegall, M. (2000). Putting the stress back into role stress: Improving the measurement of role conflict and role ambiguity. Journal of Managerial Psychology, 15, 5, 427-439.

Simon, H. (1973). The organization of complex systems. In: H. Pattee (Ed.), Hierarchy theory. New York: Brazilier, 1-27.

Sinangil, H. and Ones, D. (2005). Expatriate management. In: N. Anderson, S. Ones, H. Sinangil, and C. Viswesvaran (Eds.). Handbook of industrial, work and organizational psychology, volume 1, 424-443. London: Sage.

Singh, J. (1993). Boundary role ambiguity: Facets, determinants and impacts. Journal of Marketing, 57, 11-31.

Stamper, C. and Johlke, M. (2003). The impact of perceived organizational support on 
the relationship between boundary spanner role stress and work outcomes. Journal of Management, 29, 4, 569-588.

Strauss, A. and Corbin, J. (1990). Basics of qualitative research: Grounded theory procedures and techniques. Newbury Park, CA: Sage.

Taylor, F. (1911). Scientific management. New York: Harper and Row.

Thomas, D. (1994). The boundary spanning role of expatriates in the multinational corporation. Advances in International Comparative Management, $\underline{9}, 145-170$.

Thompson, J. (1967). Organizations in action. New York: McGraw Hill.

Tichy, N., Tushman, M. and Fombrun, C. (1979). Social network analysis for organizations. Academy of Management Review, 4, 4, 507-519.

Tiegland, R. and Wasko, M. (2003). Integrating knowledge through information trading: Examining the relationship between boundary spanning communication and individual performance. Decision Sciences, 34, 2, 261-286.

Tsui, A., Ashford, S., St. Clair, L, and Xin, K. (1995). Dealing with discrepant expectations: Response strategies and managerial effectiveness. Academy of Management Journal, $\underline{38}, 8,1515-1543$.

Tubre, T. and Collins, J. (2000). Jackson and Schuler revisited: A meta-analysis of the relationships between role ambiguity, role conflict, and job performance. Journal of Management, 26, 1, 155-169.

Tung, R. (1981). Selecting and training personnel for overseas assignments. Columbia Journal of World Business, $\underline{19}, 68-78$.

Tushman, M. and Romanelli, E. (1983). Uncertainty, social location and influence in decision making: A sociometric analysis. Management Science, 29, 1, 12-23.

Tushman, M. and Scanlan, T. (1981a). Boundary spanning individuals: Their role in information transfer and their antecedents. Academy of Management Journal, 24, 2, 289-305.

Tushman, M. and Scanlan, T. (1981b). Characteristics and external orientations of boundary spanning individuals. Academy of Management Journal, 24, 1, 83-98.

von Bertalanffy, L. (1950). The theory of open systems in physics and biology. Science, $\underline{111}, 23-28$.

Watson, A. and Wooldridge, B. (2005). Business unit manager influence on corporate 
level strategy formulation. Journal of Managerial Issues, 27, 2, 147-161.

Werner, S. (2002). Recent developments in international management research: A review of 20 top management journals. Journal of Management, 28, 3, 277-305.

Westley, F. (1990). Middle managers and strategy: Microdynamics of inclusion. Strategic Management Journal, 11, 337-351.

Wooldridge, B. and Floyd, S. (1989). Strategic process effects on consensus. Strategic Management Journal, 10, 3, 295-301.

Wooldridge, B. and Floyd, S. (1990). The strategy process, middle management involvement, and organizational performance. Strategic Management Journal, $\underline{11}, \underline{3}$, 231-241.

Wooldridge, B. and Floyd, S. (1997). Middle management's strategic influence and organizational performance. Journal of Management Studies, 34, 3, 465-487.

Yin, R. (2003). Case study research: Design and methods. Thousand Oaks, CA:Sage Yip, G. (2003). Total global strategy II . Upper Saddle River, NJ: Pearson Education International.

Zeithaml, V., Berry, L., and Parsuraman, A. (1988). Communication and control processes in the delivery of service quality. Journal of Marketing, 52, 35-48. 


\section{Appendix A: Interview protocol ${ }^{13}$}

Intro: (Introduce self as student, working with ADM, Bilateral Relations Branch)

Preamble: Before we begin, I would like to tell you a bit about this research. I am interested in how a global organization manages a work force that is geographically dispersed. In particular, I am looking at what is referred to in management studies as the "boundary spanning role". By "boundary spanner", I mean an organizational member whose job it is to interface with people outside the organization. Boundary spanners are essentially the point of contact between an organization and its external environment. They represent their organization to the outside world, they procure resources, they gather local intelligence, they ensure the inward flow of information needed to inform and improve strategy. This boundary role is of great interest in the context of the global organization, and I am trying to understand how organizations can better support boundary spanners in their roles.

In order to understand this, I needed a group of professionals who were subject matter experts. That's why I am pleased you have agreed to participate. Heads of mission, professionals in the political stream at DFAIT are expert boundary spanners- representing Canada to the world, gathering local intelligence, garnering the support of partners and stakeholders- - that's what you do. So, I want to talk with you about your perceptions of this role.

Specifically, this interview will revolve around a model I am testing. I am thinking that a boundary spanner would need three things to perform their work effectively. They would need to know what their organization expects of them in their work abroad. They would need to be able to carry out these expectations locally. And then they would need to be able to feed back into the organization what they know and what they learn so that where these expectations are misaligned with local reality, the organization can adjust its course. So, these are the three "bubbles" in my model and the interview is organized around them. Does that make sense? (perception check respondent's understanding of model)

The interview should last about one hour. I don't have any questions that are personal, but I want to ensure you that your answers are confidential. I am using this information toward a Ph.D. thesis, so I will be writing up a summary of these interviews. But I have chosen the sample myself, I am speaking with nearly 90 people abroad, and I will be writing this up at an aggregate level, so no individual will be identifiable. If there are any questions you don't care to answer for any reason, though, just tell me and we'll skip them.

\footnotetext{
${ }^{13}$ Protocol items are grouped by research question as given in Chapter 6 . Lettered sections of the protocol correspond to lettered elements of the conceptual framework given in Figure 6.2. Following the protocol, Appendix Table A-1 provides a mapping of key interview items to their rationale as given in the relevant literature.
} 
The way I collect the data is to tape record the conversation. I then code the information from tape and destroy the tape. Questions before we start? OK to start tape?

\section{Work history/demographics}

I'll start with some background information:

W1. How long have you been at (post)?

W2 For how many years have you been in (foreign service)?

W3 How many years with DFAIT?

W4 And how many different countries have you been posted to previous to this?

W5 To whom do you report? What is this person's position in the organization? (verify front line vs. mid-management by finding folks directly reporting to HOM)

W6 Do you have people who report to you? How many direct reports? Indirect?

W7 (Age)

W8 (Gender)

W9 What is your job title?

\section{A. Organizational expectations}

Let's begin by discussing your experience within your own organization.

A1 You mentioned that you have been at post now for _ months/years. Can you tell me, what do you think DFAIT expects of you out there in the field? What do you sense is the organization's expectation for you in your role at (post)?

A2 How do you know this? In general, how do you know what the organization expects of you?

(Prompt: How do you find out about your responsibilities and what you need to do to meet them?)

(Prompt: Could be things you have in writing, could be conversations you have with others in the organization, could be something about the job itself, any cues that you think give you an idea of what you are expected to do) 
A3 Feedback is one way we come to gauge how well we are doing in a job, but it is not the only way. In general, how do you know when you have done a good job?

A4 Is there any one individual within the organization that you feel is extremely important to you in letting you know what is expected of you in your job?

A5 Who is this person (what position does this person hold, where is this person located)?

A6 How do you normally connect with this person?

A7 And how often would you connect with this person?

A8 How does this person let you know what they expect of you in your job?

(Prompt: I am looking for cues they might give you as to what they expect- - do they tell you directly, do they task you formally? Is it more subtle, do they debrief on information they have come across, that kind of thing)

A9 Does the way this individual expresses their expectations work for you? How might they do it better? How would you like this person to convey expectations to you?

\section{B. Expectations of local constituents}

We have talked about your organization, let's look at the other side of what we're calling the organizational boundary. The external contacts with whom you deal.

B1 How do you develop your contacts? How do you know which organizations or individuals will be important to you in doing your job?

B2 No doubt you have some sense of what people in these other organizations expect of you in your role as (HOM/political officer) as well. Can you tell me, in general, how do you know what people in these external organizations expect of you?

(Prompt: I am looking for cues again. You have told me some of the ways you have come to know what DFAIT expects of you. Now, I am looking at the same thing, but with outsiders. In general, how do you come to know what your external contacts want from you?)

(Prompt: Could be what they do or say, could be someone else told you what to expect, could be more formal sources of information that tell you what their agenda for you might be) 


\section{Boundary interactions at the micro level (dimensions of the construct: activity and purpose)}

C1 I have some more detailed questions about your interactions with your external contacts. So let's select one of them. Can you pick an outside contact that you deal with who you believe is extremely important to you right now in terms of doing your job?

So, let's talk about $\mathrm{X}$.

C2 You picked $\mathrm{X}$ because you believed him/her to be someone who is very important to you in terms of doing your job. Why this person?

(Prompt - -why is connecting with this person important to your job)

C3 How do you normally connect with $\mathrm{X}$ ? (Activity)

(Prompt - email, phone, chat room, DFAITe to face, club membership, social events- list all)

(Prompt - formal/informal)

C4 And how often would you connect with X?

C5 Think of a recent occasion on which you and X were in touch. Can you tell me a bit about that exchange? Describe briefly the project or task at hand, what work you were doing together.

C6 What was the purpose of your interaction with X? (Desired outcome/ Purpose of activity in context)

(Prompt: What were you trying to achieve through your contact with $\mathrm{X}$ ?)

\section{Reconciliation of external/internal expectations}

D1 Now, what do you think X expected from you over the course of this exchange? (Constituent expectations)

(If constituent expectations perceived to be the same as respondent's given in C6, go to E1)

(If expectations different from own...)

D2 So, X's expectations were somewhat at odds with yours. One of the challenges often mentioned by people in boundary roles is how to handle situations where 
there is a difference in perspective. I am very interested in your personal strategies for reconciling these kinds of situations. Can you recall how you handled this? What did you do? (Reconciliation strategies)

(Prompts: You were trying to achieve one thing and the person you were dealing with was coming from somewhere else on it. What thoughts went through your mind? What did you say/ do over the course of the interaction? Anything you did afterward to address it ?)

\section{E. Translation to local work objectives ${ }^{14}$}

We have spoken now about what the Department expects of you, what your local contacts expect of you... now I am interested in how you bring these multiple perspectives together, how you translate them into action at the level of your own job.

E1 First, the influence of the department's expectations on your day-to-day work. How do you take into account the interests and needs of the department in your day-to-day work?

(Prompt: Can you see the department's priorities played out in your in your own work or in your planning around your job? Do the objectives of the department affect who you connect with, how you connect, what you ask of them, etc.?)

E2 What about the expectations of your local constituents? How do you take into account the interests and needs of your local contacts in your day-to-day work?

(Prompt: Can you see the priorities of your local contacts playing out in your work or your planning around your job? Do you factor in the local realities, the interests of the people you deal with out in the field?)

E3 Who do you think has the greater influence over what you do on the job? Would it be your own organization, would it be your local contacts, or would their influence be about the same?

E4 Why do you say this?

F. Ability to influence

F1 I have a few questions now about how you might convey your local knowledge to

\footnotetext{
${ }^{14}$ This section was dropped from the interview protocol subsequent to time constraints identified in the pilot study. Data on the translation process were obtained through other means (see Chapter 9.)
} 
management. People at post are critical sources of insights about local issues. I am interested in how they make their insights known to the organization. I need an example if you can think of one. Have you ever tried to get management attention on an issue you personally felt might be of strategic value? By strategic, I mean something that you thought might affect the organization's performance. For example, a local trend or development that you viewed as having implications for the organization's performance. Have you ever tried to get management's attention on a strategic issue? (Ability to influence)

\section{(If yes)}

F2 Can you tell me about this occasion? (If several, pick one as target)

What was this issue and how did you go about conveying it to management? (Prompt, What did you do to move your idea forward/ What did you do to get your alternative or point of view on the table? Whose attention did you feel you needed to get? Who did you involve?)

F3 How did it turn out? (If successful, key factors. If not, how could you have done it better?)

(If no)

F4 Have you had ideas or issues that you, for whatever reason, did not bring forward?

Can you tell me about that?

(Prompt: What was the issue and what factors/considerations led you to decide against bringing it forward?)

F5 Overall, are you satisfied with the ways you have been able to provide ideas and issues to management? How would you like to convey information to them?

\section{G. Rewards and challenges of boundary spanning}

A couple of questions about your overall feelings about your role as a boundary spanner, as the interface between your organization and your local environment.

G1 What would you say is the most rewarding aspect of serving this "interface" role between your organization and the local environment?

G2 What is the most challenging aspect? 


\section{H. Sources of organizational support}

Finally, I am interested in ways that organizations can support employees in carrying out their duties as boundary spanners

H1 Is there anything DFAIT does that you find helps you perform more effectively in your role? (List all)

$\mathrm{H} 2$ Is there anything you would like from the organization in the way of support?

H3 What about your manager? Is there anything he or she does that you think helps you to perform more effectively in your role? (List all)

H4 Anything you would like from your manager in the way of support?

Close

Thank you, those are all the questions I have for you. Do you have anything you would like to add, or any questions for me?

(Offer to share summary of results) 
Appendix Table A-1: Mapping of selected interview items to rationale and supporting literature

\begin{tabular}{|c|c|c|}
\hline Interview Item & Rationale for Item & $\begin{array}{l}\text { Supporting } \\
\text { Literature/ } \\
\text { Parallel Wording }\end{array}$ \\
\hline \multicolumn{3}{|l|}{ A. Organizational expectations } \\
\hline $\begin{array}{l}\text { A2 How do you know what } \\
\text { the organization expects of } \\
\text { you? }\end{array}$ & $\begin{array}{l}\text { Taps multiple sources of role cues } \\
\text { within organization, including formal } \\
\text { cues and cues from individuals, as } \\
\text { given in literature }\end{array}$ & $\begin{array}{l}\text { Kahn et al., 1964; } \\
\text { Hackman and } \\
\text { Oldham, 1976; House, } \\
\text { 1971; Pugh et al., } \\
1968\end{array}$ \\
\hline $\begin{array}{l}\text { A3 Feedback is one way we } \\
\text { gauge how well we are doing } \\
\text { in a job, but it is not the only } \\
\text { way.... How do you know } \\
\text { when you have done a good } \\
\text { job? }\end{array}$ & $\begin{array}{l}\text { Elicits responses around the nature } \\
\text { of the job to access the constructs of } \\
\text { task identity, task feedback }\end{array}$ & $\begin{array}{l}\text { Hackman and } \\
\text { Oldham, 1976; llgen } \\
\text { and Hollenbeck, } 1991\end{array}$ \\
\hline $\begin{array}{l}\text { A4 to A9 Individual internal } \\
\text { to the organization who is } \\
\text { important in conveying } \\
\text { expectations for the job? }\end{array}$ & $\begin{array}{l}\text { Identifies internal role sender most } \\
\text { important to the boundary spanner in } \\
\text { conveying expectations, and } \\
\text { explores how this role sending might } \\
\text { be affected in an MNE context }\end{array}$ & $\begin{array}{l}\text { Birkinshaw, 1997; } \\
\text { Gupta, Govindarajan } \\
\text { and Malhotra, 1999; } \\
\text { McGraw, } 2004\end{array}$ \\
\hline \multicolumn{3}{|c|}{ B. Expectations of local constituents } \\
\hline $\begin{array}{l}\text { QB2 How do you know what } \\
\text { people in these organizations } \\
\text { expect from you? }\end{array}$ & $\begin{array}{l}\text { Taps specific role cues emanating } \\
\text { from outside the organization }\end{array}$ & Kahn et al., 1964 \\
\hline \multicolumn{3}{|c|}{ C. Boundary interactions (The dimensions of the boundary spanning construct) } \\
\hline $\begin{array}{l}\text { C1 Pick a contact who is } \\
\text { very important to you in terms } \\
\text { of doing your job }\end{array}$ & $\begin{array}{l}\text { Identifying a contact who is } \\
\text { important to the job locates a site } \\
\text { with high organizational-environment } \\
\text { dependencies }\end{array}$ & $\begin{array}{l}\text { Kahn et al., } 1964 \\
\text { Ancona et al., } 1988\end{array}$ \\
\hline $\begin{array}{l}\text { QC2 Why did you pick this } \\
\text { person? }\end{array}$ & $\begin{array}{l}\text { Specifies the nature of the } \\
\text { dependency at individual level }\end{array}$ & Kahn et al., 1964 \\
\hline $\begin{array}{l}\text { QC3 How do you normally } \\
\text { connect with X? }\end{array}$ & $\begin{array}{l}\text { Identifies boundary activity } \\
\text { (separates activity from purpose) }\end{array}$ & $\begin{array}{l}\text { Kahn et al., } 1964 \\
\text { Ancona et al., } 1988 \\
\text { Mintzberg, } 1973 \\
\end{array}$ \\
\hline
\end{tabular}




\begin{tabular}{|c|c|c|}
\hline $\begin{array}{l}\text { QC4 How often would you } \\
\text { normally connect with X? }\end{array}$ & $\begin{array}{l}\text { Early literature on boundary } \\
\text { spanning operationalized boundary } \\
\text { spanning intensity by frequency of } \\
\text { contact. Subsequent work indicated } \\
\text { that frequency of contact was not a } \\
\text { good indicator of the importance of a } \\
\text { contact. Managers are poor } \\
\text { estimators of their frequency of } \\
\text { contact and time allocation. The } \\
\text { important aspect in terms of } \\
\text { boundary relevance is the amount of } \\
\text { time spent on the boundary, not } \\
\text { frequency. Question is included to } \\
\text { identify any variability in the } \\
\text { frequency of interactions for highly } \\
\text { important contacts. }\end{array}$ & $\begin{array}{l}\text { Kahn et al., } 1964 \\
\text { Ancona et al., } 1988 \\
\text { Brass, } \\
\text { Mintzberg, } 1973\end{array}$ \\
\hline $\begin{array}{l}\text { QC6 What are you trying to } \\
\text { achieve through your } \\
\text { contact? }\end{array}$ & $\begin{array}{l}\text { Identifies purpose of activity in } \\
\text { context, separates purpose from } \\
\text { activity }\end{array}$ & $\begin{array}{l}\text { Kahn et al., } 1964 \\
\text { Ancona et al., } 1988 \\
\text { Mintzberg, } 1973\end{array}$ \\
\hline \multicolumn{3}{|c|}{ D. Reconciliation of external/internal expectations } \\
\hline $\begin{array}{l}\text { QD1 What did you do (when } \\
\text { expectations differed)? }\end{array}$ & Taps reconciliation strategies & Tsui et al., 1995 \\
\hline \multicolumn{3}{|l|}{ F. Ability to influence } \\
\hline $\begin{array}{l}\text { QF1 Ever tried to get } \\
\text { management's attention on a } \\
\text { strategic issue, "strategic" } \\
\text { defined as a "local event, } \\
\text { trend, or development with } \\
\text { implications for the } \\
\text { organization's performance" }\end{array}$ & $\begin{array}{l}\text { Question taken directly from Dutton } \\
\text { et al.'s (2001) approach to } \\
\text { identifying stories around "issue } \\
\text { selling" } \\
\text { Definition of a strategic issue (i.e., } \\
\text { "local event... with implications for... } \\
\text { performance") is given in terms of } \\
\text { environmental adaptability, and is } \\
\text { taken from Ansoff (1965), cited in } \\
\text { Dutton et al. (2001). }\end{array}$ & $\begin{array}{l}\text { Ansoff (1965) } \\
\text { Dutton et al. (2001) }\end{array}$ \\
\hline $\begin{array}{l}\text { QF3 If successful, why; if } \\
\text { not, why not? }\end{array}$ & $\begin{array}{l}\text { Designed to elicit responses as per } \\
\text { social network theory: to what does } \\
\text { the boundary spanner attribute } \\
\text { his/her success? (Did he or she } \\
\text { mediate a valued resource? Rely on } \\
\text { friendships/ use internal networks? } \\
\text { Know the relational/normative } \\
\text { context (timing, packaging, knowing } \\
\text { "how things work around here")? } \\
\text { ldentifies whether same factors } \\
\text { "show up" in accounts of both } \\
\text { successful and unsuccessful } \\
\text { episodes }\end{array}$ & $\begin{array}{l}\text { Brass (1984) } \\
\text { Dutton et al. (2001) } \\
\text { Eisenhardt and } \\
\text { Bourgeois (1988) }\end{array}$ \\
\hline
\end{tabular}




\section{G. Rewards and challenges}

G1-G4 Rewards and

"Back up" question allows for

Patton (2002) challenges of boundary role possibility that semi-structured questions have missed some aspect of boundary role. Recommended by Patton (2002) to complement any of the key research questions

Note: Citations in boldface reflect wording that was taken verbatim from the original source or slightly modified for the purpose of this study. 
APPENDIX B:

QUESTIONNAIRE 
1. A large part of the work of a political officer or manager at post involves interactions with local organizations and individuals outside of DFAIT. By organizations "outside of DFAIT", we refer to the local organizations who operate outside of the mission with whom you may have regular or occasional contact (e.g, local government, NGOs, academics, the private sector, local service providers).

Following is a list of activities you might engage in with people outside of DFAIT. To what degree do each of these activities represent an important part of your job?

\section{Not an important \\ important \\ part of my job}

\section{Somewhat \\ important}

1 Obtaining technical input from outsiders during development of policy, programs or services$$
1
$$

3

4

2 Gauging external support or opposition to DFAIT/ Government of Canada policy, programs or services

$$
1
$$

3

4

3 Persuading outsiders that DFAIT/Canada performs activities that are important to the local economy/ social well-being

12

4 Preventing outsiders from overloading

DFAIT with too much information or too many requests

1

5 Finding out what other organizations are doing in areas related to DFAIT policy, programs or services

6 Scanning the local environment

for emerging trends or developments

7 Gathering new ideas or expert opinion from individuals outside of DFAIT

8 Acquiring resources from outside agents (e.g., financial, physical, or human resources)

9 Negotiating with people outside of DFAIT about details surrounding special events

10 Promoting DFAIT/Canada's visibility or image

11 Monitoring the information and resources that outsiders request from DFAIT and determining how DFAIT will respond to these requests

12 Building working relationships and trust with individuals outside of the organization

2

3

2. Are there any other important aspects of your work with external contacts that are not mentioned in the list above? If so, please briefly describe these activities on the reverse of this page. 
3. The following items ask about various other aspects of your current job at post. Please indicate the degree to which you agree or disagree with the following statements.

Strongly
Disagree

The job I do gives me considerable opportunity

for independence and freedom in how I do the work

The job I do gives me considerable opportunity to use my personal initiative or judgment in carrying out the work

This job gives me almost complete responsibility

for deciding how and when the work is done

I know exactly what is expected of me in this job

I know that I have divided my time well

I feel certain about how much authority I have on the job

Explanation is clear of what has to be done in this job

I know what my responsibilities are

I have clear planned goals and objectives for my job

I feel I have a good deal of influence over

the important decisions made in this Department

I feel I have a good deal of influence over the important decisions made here at post

I feel I have a good deal of influence over decisions that affect my job

1

1

1

1

1

1

1

1

\section{Neutral Agree}
2

3

4
2

3

4

5

2

3

4

5

2

3

4

2

3

4

5

2

3

4

5

2

3

4

5

2

3

4

5

2

3

4

5

2

3

4

5

2

3

4

5

2

3

4

5

Thank you very much for taking the time to complete this questionnaire. If you have any questions or comments, please feel free to contact me at 
Table B-1 Mapping of preliminary classification of boundary role questionnaire items to revised classification as used in analysis

\begin{tabular}{|c|c|c|}
\hline Item & $\begin{array}{l}\text { Revised } \\
\text { (based on emergent } \\
\text { dimensions in this } \\
\text { research) }\end{array}$ & $\begin{array}{l}\text { Preliminary } \\
\text { (based on items } \\
\text { from Ancona and } \\
\text { Caldwell, 1988; } \\
\text { 1992; Au and } \\
\text { Fukuda, 2002) }\end{array}$ \\
\hline $\begin{array}{l}1 \text { Obtaining technical input from outsiders during } \\
\text { development of policy, programs or services }\end{array}$ & Coordinate/negotiate & Task coordinator \\
\hline $\begin{array}{l}2 \text { Gauging external support or opposition } \\
\text { to DFAIT/ Government of Canada } \\
\text { policy, programs or services }\end{array}$ & Not included & Ambassador \\
\hline $\begin{array}{l}3 \text { Persuading outsiders that DFAIT/Canada performs } \\
\text { activities that are important } \\
\text { to the local economy/ social well-being }\end{array}$ & Molding & Ambassador \\
\hline $\begin{array}{l}4 \text { Preventing outsiders from overloading } \\
\text { DFAIT with too much information or too many } \\
\text { requests }\end{array}$ & Not included & Ambassador \\
\hline $\begin{array}{l}5 \text { Finding out what other organizations are doing } \\
\text { in areas related to DFAIT policy, programs or services }\end{array}$ & Not included & Scout \\
\hline $\begin{array}{l}6 \text { Scanning the local environment } \\
\text { for emerging trends or developments }\end{array}$ & Not included & Scout \\
\hline $\begin{array}{l}7 \text { Gathering new ideas or expert opinion } \\
\text { from individuals outside of DFAIT }\end{array}$ & Not included & Scout \\
\hline $\begin{array}{l}8 \text { Acquiring resources from outside } \\
\text { agents (e.g., financial, physical, or human resources) }\end{array}$ & Not included & Ambassador \\
\hline $\begin{array}{l}9 \text { Negotiating with people outside of DFAIT } \\
\text { about details surrounding special events }\end{array}$ & Coordinate/ negotiate & Task coordinator \\
\hline 10 Promoting DFAIT/Canada's visibility or image & Represent & Ambassador \\
\hline $\begin{array}{l}11 \text { Monitoring the information and resources that } \\
\text { outsiders request from DFAIT and determining how } \\
\text { DFAIT will respond to these requests }\end{array}$ & Guard & Guard \\
\hline $\begin{array}{l}12 \text { Building working relationships and trust with } \\
\text { individuals } \\
\text { outside of the organization }\end{array}$ & Relationship & $\mathbf{N} / \mathbf{A}$ \\
\hline
\end{tabular}




\section{APPENDIX C: CODING SCHEME ${ }^{15}$}

ID

Job level

HOM 1

MID

2

(\#)

Mission

(specify)

Size

Asia-S.Pacific

$\mathrm{ME} / \mathrm{N}$ Africa

N/W Europe 5

2

Micro

(\#)Yrs DFAIT

(\#) Yrs FS

(\#) Countries

Manager? HOM 1 MID at post 2 Superembassy 3 DG HQ 4 ADM 5

Other 96 (Specify )

Levels to HOM 1 Report directly to HOM

$\begin{array}{ll}2 & \text { One level between me and HOM } \\ 3 & \text { Two levels between me and HOM } \\ 4 & \text { Three or more levels } \\ 5 & \text { N/A (Is the HOM) } \\ 99 & \text { Not asked }\end{array}$

Direct reports (\# Total )

99 Not asked

Age $\quad$ Sex $\quad$ M 1 $\quad$ F 2

Q1 What do you think DFAIT expects of you?

1 To represent/advocate (advance, transmit, project or model Canadian interests, values, image)

2 To report (strategic, analytic, interpretation of local events, implications for Canada)

3 Information and intelligence

4 Access/linkages to key individuals (in order to advocate Canada's position or garner intelligence)

5 Provide assistance to Canadians abroad and/or Canadian business

$6 \quad$ Manage visits and events

$7 \quad$ Program delivery or management

8 Mission management/ effective resource management, management of political or local staff

9 Difficult to answer, not always clear what is expected (code if mentioned at all)

96 Other

$98 \quad$ No response or not mentioned

$99 \quad$ Not asked

Q2 How do you know what is expected? (Sources of role cues and effectiveness)

Q2a Country strategy

1 Country strategy (unspecified, mentions as potential cue, but not elaborated)

2 I held the pen/contributed to it, parts of it

${ }^{15}$ Question numbers in coding scheme were modified to facilitate data entry, so do not correspond to question numbers in the interview protocol 
3 CS intent is welcome, step in right direction, needed effort to bring clarity and shared direction (no mention of effectiveness)

4 CS effective because clarifies high-level objectives, sets broad direction

5 CS effective because I can use it in helping my staff set objectives

6 CS effective because I have had objectives for my job derived from it

$7 \quad$ CS effective because I refer to it, have used it to position issues, report, etc.

8 CS effective because it opens up dialogue (with HQ, with manager, or others)

9. Other effective

10 CS ineffective b/c just another bureaucratic exercise, same as old planning (get it out of the inbox, won't be used again)

11 CS ineffective because all process or frustrating process (too many boxes, emphasis on template, too time consuming, unreasonable turnarounds)

12 CS ineffective because no real dialogue on real substantive issues

CS ineffective because objectives too vague, state the obvious, unable to link to my own job

14 CS ineffective because can't plan in a volatile environment (shifting government priorities, shifting local or international scene)

15 CS ineffective because unmeasurable, poor/no indicators

16 CS ineffective for me because I've never seen it, did not see final version

17 Other ineffective

18 Too new, don't know where it's going yet

96 Other

$98 \quad$ No response or not mentioned

\section{Q2b PMA/PMP}

1 PMA/PMP (unspecified, mentions, but not elaborated)

$2 \quad$ PMA effective because clarifies my job objectives

3 PMA effective because it enables discussions with $\mathrm{HQ}$, my manager, or others)

$4 \quad$ Other effective

$5 \quad$ PMA ineffective $b / c$ objectives too vague

6 PMA ineffective $b / c$ disconnect between it and the feedback you get all year, or the rewards/bonus you get at the end of the cycle

7 PMA ineffective $b / c$ done too late in the year, or after the fact

8 PMA ineffective $\mathrm{b} / \mathrm{c}$ it has not been used for discussions with my manager/discussions with my manager ineffective

9 PMA ineffective because I have no input into it, not collaborative

10 PMA ineffective because can't plan in a volatile environment (shifting government priorities, shifting local or international scene)

11 PMA ineffective because unmeasurable, poor/no indicators

12. Other ineffective

13 I don't have PMA/PMP/appraisal process

14 Too new, don't know where it's going yet

$96 \quad$ Other

98 No response or not mentioned

Q2c Mandate letter 
$1 \quad$ Mandate letter (unspecified, mentions as potential cue, but not elaborated)

2 Intent of ML welcome, step in right direction, needed effort to bring clarity (no mention of effectiveness)

3 ML effective because clarifies high-level objectives, sets broad direction

$4 \quad$ ML effective because I can use it in helping my staff set objectives

5 ML effective because I have objectives for my job derived from it

6 ML effective because it opens up dialogue with HQ, with manager, or others)

$7 \quad$ Other effective

$8 \quad \mathrm{ML}$ ineffective $\mathrm{b} / \mathrm{c}$ just another bureaucratic exercise

$9 \mathrm{ML}$ ineffective $\mathrm{b} / \mathrm{c}$ all process, frustrating process, too time consuming

$10 \quad$ ML ineffective $b / c$ no real dialogue on real substantive issues

11 ML ineffective $b / c$ objectives too vague, state the obvious

12 ML ineffective for me b/c I have never seen it, did not see response to it

13 ML ineffective because can't plan in a volatile environment (shifting government priorities, shifting local or international scene)

14 Other ineffective

15 My mission does not have a ML

16 Too new, don't know where it's going yet

96 Other

$98 \quad$ No response or not mentioned

\section{Q2d $\quad$ Reporting agreement}

1 Reporting agreement (unspecified, mentions as potential cue, but not elaborated)

2 I held the pen/contributed to it, parts of it

3 Intent of RA welcome, step in right direction, needed effort to bring clarity (no mention of effectiveness)

$4 \quad$ RA effective because clarifies target areas for reporting

5 RA effective because enables me to identify key local contacts to support reporting

6 RA effective because it opens dialogue with HQ, prompts HQ feedback (also code Q2k)

7 Other effective

8 RA ineffective because feedback is vague or acknowledges receipt only (also code Q2k)

9 RA ineffective because I have never seen it

10 RA ineffective because it doesn't guide my job, don't refer to it

11 Other ineffective

12 My mission does not have a RA

13 Too new, don't know where it's going yet

96 Other

98 No response or not mentioned

Q2e Other Formal (concluded)

1 "Suite" (unspecified, mentions as cue, not elaborated)

2 Suite welcome, step in right direction, in favour of formal tools, alignment, paper products, documentation, etc., (no mention of effectiveness)

3 Suite effective 
Other HQ products and documents (unspecified, not elaborated, e.g., sectoral, regional planning, regional implications, Q\&As, fact sheets, media packages) Docs welcome, step in right direction, in favour of formal tools, paper products, documentation, etc., (no mention of effectiveness)

7 Docs effective

8 Docs ineffective

$9 \quad$ High level policy statements (unspecified, mentions one or more, but not elaborated)

10 IPS

11 SFT, Budget, other speeches

12 Party platforms

14 Formal HOM/ PERPA meetings (not elaborated)

15 Opportunity for HQ to provide messaging and direction

16 Opportunity for HQ-Post dialogue

17 Opportunity for Post-Post dialogue

18 Opportunity for high-level govt and departmental leaders to provide messaging and direction (e.g., $\mathrm{DM}, \mathrm{ADM}, \mathrm{PCO}$, etc.)

19 Meetings ineffective (too infrequent, talking heads, etc.)

20 Job description/ job "package" (mentions, but not elaborated)

21 Job exists on paper and is well defined and useful

22 Job exists on paper but disconnect and not really useful (not current, not relevant, not reflective of what I am doing, or have not seen the paper)

23 "Discussions" of job package (b/f I left or upon arrival) useful (well explained, or natural outcrop of my expertise before posting; also code Q2g)

24 "Discussions" not very useful (vague or disconnect; also code Q2g)

96 Other job package related

\section{Q2f Supervisor}

$1 \quad$ Supervisor mentioned, discussions mentioned (unspecified, not elaborated)

2 Effective because provides direction and guidance (unspecified)

3 Effective because provides direction and guidance (high level for my interpretation, broad parameters)

4 Effective because provides direction and guidance (specific, at the level of my job, steps to follow)

$5 \quad$ Effective at feedback

6 Effective because provides context (unspecified)

7 Effective because provides mission context (history of files, local perspectives and developments)

8 Effective because provides $\mathrm{HQ}$ context (strategic, relational, current events)

9 Effective because is supportive (interpersonal, sounding board, someone is listening, good relationship)

10 Effective because is supportive (active, acts on my behalf, moves something for me)

11 Effective because is supportive (interactive, engages in substantive dialogue, one-on-one - - email, phone, or face-to-face, key is two-way discussions on real issues)

12 Effective because gives me autonomy

13 Other effective

14 Ineffective because provides little direction and guidance (unspecified)

15 Ineffective because does not provides high level direction and guidance I need 
16 Ineffective because does not provide specific direction and guidance

17 Ineffective at feedback

18 Ineffective in providing context (unspecified)

19 Ineffective in providing mission context

20 Ineffective in providing $\mathrm{HQ}$ context

21 Ineffective because is not supportive (interpersonal, poor relationship)

22 Ineffective because is not supportive (active, does not act on my behalf)

23 Ineffective because is not supportive (interactively, won't engage in substantive dialogue)

24 Ineffective because gives me too little autonomy

25 Other ineffective

26 Not supervisor's fault, just the reality, too busy, supervisor doesn't know priorities either (also code theories in use)

$98 \quad$ No response or not mentioned

Q2g Discussions with others (not my manager; could be either pre-posting or upon arrival)

1 Discussions (mentioned, not elaborated)

2 With colleagues (unspecified)

3 With colleagues at other posts

$4 \quad$ With colleagues at my post (unspecified)

5 With LES

6 With Canada-based staff (OGD or DFAIT)

$7 \quad$ With my HOM (if manager, code in Q2f)

8 Other senior manager(s) at post

9 With the HOM of the embassy to whom my embassy reports

10 With HQ (unspecified)

11 With ADM/DM

12 With DG (if manager, code in Q2f)

13 With Director

14 With Deputy Director

15 With Desk

16 With other division (not my line division)

17 With OGDs (Centre, OGDs in Ottawa who I work with, etc)

18 With diplomatic community (like-minded embassies)

19 With my network, peers, friends

96 Others

98 No response or not mentioned

Q2h $\quad$ Predecessor

Predecessor (unspecified, not elaborated)

Predecessor discussions (not elaborated as to effectiveness)

Discussions effective

Discussions ineffective

Predecessor handover notes or other written directions left behind

Notes effective

Notes ineffective

I initiated the contact with my predecessor

$\begin{array}{ll}8 & \text { I initiated the contact with } \\ 96 & \text { Other predecessor related }\end{array}$ 
Q2i Cues from tasking from/ reporting to HQ

1 I take my cues from the content of HQ's tasking/requests

2 Tasking/demarches come without context

3 Tasking can come from anywhere in $\mathrm{HQ}$

$4 \quad$ Everything is a priority

5 Unreasonable deadlines

6 They never close the loop, don't know what you have contributed to or how it turned out

$7 \quad$ I take my cues from whether or not my reporting triggers a response from HQ

$8 \quad$ No response means good reporting/good job

$9 \quad$ No response means bad reporting/bad job

10 No response means they didn't receive it or read it

11 I don't know what no response means

12 Asking you further questions is good (you have their attention, puts you on track)

13 Responses are often non-specific, so they tell you nothing ("thanks for the report")

14 No/little substantive discussion

15 You get feedback if you initiate it, if you ask questions, know what to ask

16 HQ cues adequate, good

17 I have a very good internal boundary spanner (Desk, Deputy Director, etc.)

18 Other HQ cues (favourable)

19 Other HQ cues (unfavourable)

88 BLACK HOLE

$98 \quad$ No response or not mentioned

Q3 How do you know you've done good job? (Task feedback and identity)

Discusses feedback from others (code also Q3)

"Internal sources", I am my own judge, sense of accomplishment, self assessment

Access and relationships, when doors open to me locally (task feedback)

Career opportunities, when doors open to me in assignments or promotions

Praise/comments from clients, partners, media attention (i.e., person feedback: clients impressed, comments from dignitaries following visit or event, could be OGD, DFAIT, media)

7 I can see for myself that a specific event has gone smoothly (task feedback)

8 Can see outcomes of work externally/locally (task identity: my contribution to a process, the conclusion of negotiation, treaties signed, buildings built, a business launched)

9 Can see outcomes of my work internally (task identity: contribution to a DFAIT policy or process or work is imitated, bestpractice)

10 Mission management related

11 Not easy to see, incremental only, distant results

12 Don't need feedback, don't need this kind of reminder

96 Other

97 DK

$98 \quad$ No response or not mentioned

$99 \quad$ Not asked

Q4a Any one individual who is important?

$1 \quad$ My supervisor 
2 A colleague at another post

3. A colleague at my post

$4 \quad$ HOM (if not manager, else code 1)

5 Other senior manager at post

6 HOM of the embassy to whom my embassy reports

$7 \quad \mathrm{ADM} / \mathrm{DM}$

8 DG (if not manager, else code 1)

9 Director

10 Deputy Director

11 Desk

12 A colleague in another division (not my line division)

13 Nobody is key to me (I define my own job and expectations, rely on self)

14 IT DEPENDS (on issue, who holds the lead, HQ for policy, mission boss for mission issues; also code all mentioned above)

15 Can't identify one, there are so many I rely on, artificial to think along this line; also code all mentioned above)

96 Other

$98 \quad$ No response or not mentioned

$99 \quad$ Not asked

Q4b How do you normally connect (i.e., on a directed exchange, not just copying)?

$0 \quad$ N/A no key person, or several, can't identify one

$1 \quad$ Email

2. Phone

3 Face to face

$4 \quad$ Hard to connect due to time differences (also code in Q24)

5 Hard to connect because this person is too busy (also code theory in use)

6 Not their fault, just the reality

98 No response or not mentioned

$99 \quad$ Not asked

Q4c How often?

$0 \quad$ N/A no key person

$1 \quad$ Less than every 3 months

2. Every two to three months

3 Once a month

4 Couple of times a month

5 Once a week

6 Twice a week

7 At least once a day

8 I try to be mindful of their time, and not approach them often

9 Hard to connect due to time differences (also code Q24)

10 Hard to connect because this person is too busy

11 Not their fault, just the reality

12 I normally initiate these exchanges

13 ."Pop my head in the door" relationship

98 No response or not mentioned

$99 \quad$ Not asked 
Q4d Does this work for you/what's your take-away?

$0 \quad$ N/A no key person

2 Effective because provides direction and guidance (unspecified)

3 Effective because provides direction and guidance (high level for my interpretation, broad parameters)

$4 \quad$ Effective because provides direction and guidance (pecific, at the level of my job, tasking, steps to follow)

5 Effective at feedback

6 Effective because provides mission context (history of files, local perspectives and developments)

7 Effective because provides $\mathrm{HQ}$ context (strategic, relational, current events)

8 Effective because is supportive (interpersonal, sounding board, someone is listening, good relationship)

9 Effective because is supportive (active, acts on my behalf, moves something for me)

10 Effective because is supportive (interactive, engages in substantive dialogue, one-on-one - - email, phone, or face-to-face, key is two-way discussions on real issues)

11 Effective because gives me autonomy

12 Other effective

13 Ineffective because provides little direction and guidance (unspecified)

14 Ineffective because does not provides high level direction and guidance I need

15 Ineffective because does not provide specific direction and guidance

16 Ineffective at feedback

17 Ineffective in providing context (unspecified)

18 Ineffective in providing mission context

19 Ineffective in providing $\underline{\text { HO context }}$

20 Ineffective because is not supportive (interpersonal, poor relationship)

21 Ineffective because is not supportive (active, does not act on my behalf)

22 Ineffective because is not supportive (interactively, won't engage in substantive dialogue)

23 Other ineffective

24 Not their fault, just the reality, too busy or also doesn't know priorities (also code theory in use)

$98 \quad$ No response or not mentioned

$99 \quad$ Not asked

Q5 How do you develop your contacts?

1 Given by institutional relationships (long-standing, well-defined, given in law, shared membership on certain files or issues, e.g., UN, NATO, and "expected" courtesy calls)

2 Objectives driven (driven by the issues you are responsible for, who are the best people to connect with for that?)

3 Support of mission/mission staff (unspecified)

4 Mission: Predecessor

$5 \quad$ Mission: Locally engaged staff

6 Mission: More experienced Canada-based staff

7 Mission: Supervisor

8 Mission: Formal system (influence mapping, strategic planning, shared drives, database)

9 They come to you (send invites, request funding, other requests)

Mapping (focused search): 
10 Consult like-minded embassies, diplomatic community

11 Watch the media, read, look for experts, if they're in the paper, they're willing to talk

12 Hold or attend events, meetings, ceremonies and functions (emphasis on search)

13 Attend meetings of other sectors, industry associations, parliament, conferences, and listen and watch, who's smart, who's respected, what are their platforms and issues?

14 Other mapping

Gaining access/ cultivation (personal contact):

15 Cold call (if courtesy call, code 1)

16 Ask mission staff to make initial contact (unspecified)

17 Ask mission staff to make initial contact (language: is normally LES)

18 Hold or attend events, introduce yourself (emphasis on establishing relationship)

19 Request meetings

20 Take them to lunch (never underestimate the power of food)

21 Give them something (look for opportunities for reciprocity)

22 Woo them, build rapport (invite to residence, etc.)

23 Other access/cultivation

Network extension (constant vigilance, opportunistic or fortuitous):

24 Gain introductions from existing contacts

25 Active networking, build core consultative network

26 Other extension

27 Not easy, doesn't come naturally, had to struggle with this, need more training on this

86 Importance of personal relationships, reciprocity, develop over time

87 Has to be face-to-face

90 Language critical

96 Other

97 DK

98 No response or not mentioned

$99 \quad$ Not asked

Q6 How do you know what they expect of you?

1 Given by organizational or institutional relationships (you know from their affiliation, history of that organization, known views and platforms)

2 Given by your professional role (I assume what they expect is what a diplomat offers: conduit to my government, information and intelligence, funding, consular services)

3 Given by training/briefing pre-departure or upon arrival

$4 \quad$ Mission staff does the groundwork

5 Consult with like-minded embassies

6 They tell you, direct, obvious from their correspondence, requests, etc.

7 They're not very direct in this culture, sometimes hard to tell

8 I ask them directly

9 I don't ask them directly, I probe or chat, wait for viewpoints to emerge

10 Body language

11 Not good at this, doesn't come naturally, had to struggle with this, need more training on this

12 Years of experience, intuition, etc.

13 They all want VISAs

86 Importance of personal relationships, reciprocity, develop over time

$87 \quad$ Has to be face-to-face 


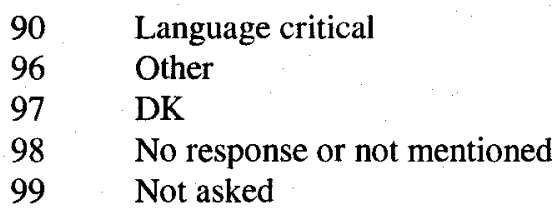

\section{Focal boundary transaction}

Q7a Target contact:

$1 \quad$ Host government interlocutor (official or officer)

2 Representative of multilateral international organization/forum (NATO, UN, etc.)

3 NGO

$4 \quad$ Academic /think tank experts

5 Private sector Canadian

6 Private sector local

7 Media

$8 \quad$ Culture/arts industry

9. Other embassy

10 Emergency/protective services

11 Canadians living or visiting abroad

12 Local citizen

13 Hypothetical discussion

96 Other

98 No response, no transaction recalled, hypothetical

$99 \quad$ Not asked

Q7b Target transaction:

$0 \quad$ N/A No transaction or was hypothetical

1 Face-to-face meeting (planned)

2 Face-to-face meeting (fortuitous, or impromptu pull-aside)

3 Telephone exchange

$4 \quad$ Email exchange

$5 \quad$ Snail mail exchange

6 Combination of above in a described "series" of transactions

96 Other

98 No response

99 Not asked

Q7c Why this person? (Site of dependency; Adaptive purpose of transaction in org terms)

$0 \quad$ N/A No transaction or was hypothetical

1 Necessary in order to achieve the Department's policy objectives or reporting priorities (link articulated to DFAIT"s priorities in areas of security, human rights, governance, etc.)

2 Necessary in order to achieve Department's program objectives (link articulated to DFAIT's program activities, approve funding, deliver funding, refer to appropriate funder, etc.)

3 Necessary in order to serve Department's role as mediator/ convenor

96 Other

98 No response

99 Not asked

Q7d Features of relationship

$0 \quad$ N/A No transaction or was hypothetical 


\section{First contact}

Known prior to this transaction

Travel in same circles, see frequently

Have made efforts to maintain this relationship, can't call only with demands

96 Other

97 No response

$99 \quad$ Not asked

Q7e Boundary dimensions observed

$0 \quad$ N/A No transaction

Representation (Opening boundary to outward flow of image):

1 Model, transmit, or project Canada's values, views, reputation or image

2 Showcase Canada as great place to work, live, visit, invest

3 Other representation

4 Molding (Opening boundary to outward flow of influence: Direct or indirect; deliberate efforts to modify task environment; to persuade agent to support the work of the organization; to influence external's agenda to suit Canada's interests; deliberate effort to inculcate Canada's values; e.g. human rights)

$5 \quad$ Intelligence (Opening boundary to inward flow of intelligence: Personal contact representing focused search for "privileged" or "insider" information not available through regular channels; flows from task demands, not general purpose scanning; identifies major interests at stake and unique perspectives of individuals)

6 Scouting (Opening boundary to inward flow of information: Personal contact representing focused search for information, clarification, ideas or best practices, but not privileged, "picking someone's brain", "fishing for ideas")

$7 \quad$ Relationship function (Opening boundary to outward flow of affect): Effort to build or maintain a relationship with external agent; laying foundation of trust; encouraging reciprocity; building rapport

8 Coordinating/Negotiating (Opening the boundary to two-way flow of influence, "permeable in both directions": communicating with externals in areas of workflow dependencies and shared projects or mandates; e.g., organizing visits and events, garnering and coordinating responses, consultations, or policy input)

14 Visit

15 Meetings, fora, consultations

16 Events (cultural, academic, Canada day, etc.)

17 Other coordination/negotiation on shared projects

Guarding (Closing the boundary: Refuse release of information; delay, avoid or ignore requests to protect image or work of the system)

18 Refusal to provide information, service, or resources in areas where request is misaligned with core work of the system (not DFAIT's area of responsibility, e.g., VISAs)

19 Refusal to provide information, service, or resources in areas where threatens DFAIT's or Canada's image, sends the wrong message, or "tarnishes through affiliation")

20 Delay, avoid or ignore requests in order to buy time to consider implications or get clearance or clarification from organization

21 Delay, avoid or ignore requests in order to discourage unwanted inquiries or task overload (may be aligned with work of system, but not a priority) 
22 Redirect and/or refer (to appropriate agency, or change the topic, redirect discussion)

24 Other guard

Delivery (Opening boundary to outward flow of goodwill, financial, human or information resources in response to external demands, "deliver the product")

25 Delivering program funds

26 Delivering information/intelligence requested by outside agent (if reciprocity, also code above)

27 Granting request for public appearance or attendance at an event

28 Delivering support or goodwill of department (e.g., casting a vote, signing a treaty, endorsing a resolution, offering/showing support; often, but not necessarily, in form of demarche) Other delivery

Intermediary (Opening boundary to outward flow of influence: indirectly modifies task environment by brokering introductions or meetings between externals, effort to modify task environment by bringing together parties who can then work independently of DFAIT in advancing interests or agendas aligned with Canada's) $30 \quad$ Providing introductions, referrals

31 Accompanying external visitors (GoC or other, not DFAIT) in meetings with local contacts

32 Other intermediary

$87 \quad$ Has to be face-to-face

$90 \quad$ Language critical

Q7f What contact expected from you?

$0 \quad$ N/A No transaction or was hypothetical

1 Wanted delivery of service, financial, human, or physical resources (funding, time investment, cosponsorship, work together, shared facilities, VISA)

2 Wanted delivery of support, goodwill, or to be seen to be associated with Canada

$5 \quad$ Wanted delivery of intelligence

$6 \quad$ Wanted delivery of general information, ideas

7 Wanted me to represent Canada, attend something, speak on DFAIT's/Canada's behalf on an issue

8 Wanted me to work together to get the job done, complete the task or negotiation in area of shared goals (to perform a coordination/negotiation function)

9 Wanted me to serve an intermediary role (introduce/refer to someone external to both of our organizations)

10 Just wanted me to hear his or her views, elevate the profile of his/her organization, enhance understanding of his/her interests, (they always want to talk to a diplomat; code also 12 if access suggested)

11 Wanted to control the interaction, manage my expectations, do it his or her way, wanted me to go away (contact driven by own guarding or molding goals)

12 Wanted to establish, nurture, or maintain the relationship (expectation for a return of affect in some form, i.e., access, cultivation, maintenance goals)

13 Wanted to make a deposit in the relationship bank (reciprocity)

14 Wanted to make a withdrawal from relationship bank (reciprocity)

15 They owed me one (reciprocity)

16 Perceived contact's expectations to be aligned with own

96 Other

97 DK, difficult to infer expectations, too soon to tell (code even if guesses expectations above)

$99 \quad$ Not asked

Q8 Strategies to deal with discrepant expectations

1 Coded from target transaction 
2 Coded from another example

3 Coded from hypothetical

Probe, listen, and learn (aimed at learning more about the contact's motivation or position, may be active and direct "20 questions"; passive "you're the expert, help me learn; "play dumb"; or both "active listening")

Trying to discern "where they're coming from" (what the problem is or what the motivation might be)

5 Looking for areas of overlapping interest/common ground

$6 \quad$ Looking for where hard and where soft for continued negotiation

7 Other probe/listen

Persuade (Aimed at changing the contact's point of view, rather than to accept, learn more, or retreat)

8 Acknowledge their position, multiple commitments, tough spot, etc.

9 "History lesson" (review for them their past actions and progress to date on this issue, often aimed at pointing out inconsistencies in their current position and/or reminding they have already committed to this)

10 Other persuade

11 Invoke the relationship (Stress how much they are needed on this issue, "I'd rather have you deal with this", give them something (reciprocity), or remind them of previous deposits you have made)

12 Reframe (to be more palatable, to better fit their position, to allow them to save face, or to give them the lines they need to justify going along with you)

13 Surface conflict (indicate clearly the point of departure, "come clean" there's an issue at hand)

Assert (direct, assertive, or forceful, often taken under conditions of power position or last resort)

14 Dogged politeness

15 Direct assertion that this request or approach is unacceptable or not within DFAIT's mandate (e.g., to Canadian values, spirit of fairness, visas)

16 Set game rules for this or future interaction (i.e., Itemizing responsibility areas, conditional involvement on projects, or emphasizing will not work with contact again on such projects)

17 Other assert

18 Explain DFAIT's point of view or your situation (not necessarily effort to persuade, may follow a guard transaction, just to increase understanding, may be aimed at preserving relationship when cannot persuade)

19 Agree to disagree (maintain cool, have to have a short memory, divergent views are based on different starting points, can't change that, let it go, often aimed at preserving the relationship)

\section{Retreat and/or regroup}

20 Indicate you have to go back to own organization for approval or further instruction

21 Break to buy time and/or reconsider strategy

22 Leave it with intention or agreement to revisit on future occasion

23 Other retreat

$97 \quad$ DK

98 Not mentioned or no response

$99 \quad$ Not asked 
Q9 Cultural considerations in boundary transactions (code from anywhere)

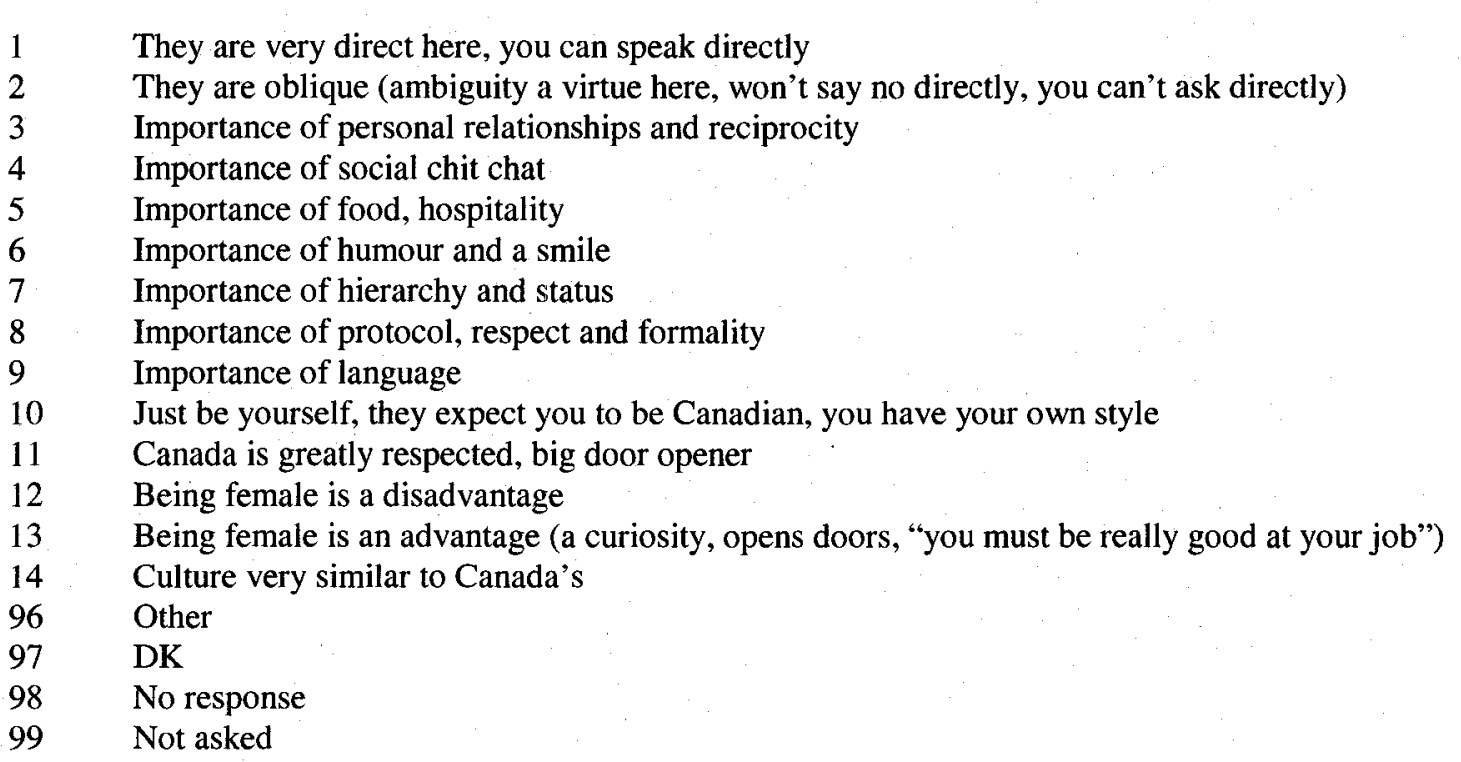

\section{Influence}

Q10a Ever tried to get management's attention or move an issue yourself?

$1 \quad$ Management attention

$2 \quad$ Moved it myself

$3 \quad$ Never tried (go to Q151...)

Q10b Coded from hypothetical/generic

$1 \quad \mathrm{Y}$

$2 \mathrm{~N}$

Q10c Nature of issue you tried to get attention on/ moved yourself

0 N/A Never tried or was hypothetical

1 Administrative or mission management (shifting financial or people resources to align with objectives or new objectives, building facilities)

2 To direct or change reporting priorities, to monitor and report on emerging local issues of interest or threat to key DFAIT policy areas (reporting related; also code 3 if mentioned)

3 To shift/ increase policy attention to an emerging issue, to encourage a policy stance or change an existing policy orientation in light of local realities (policy related)

4 To engage, to engage on a new issue, or to engage differently (with countries of accreditation, in multilateral fora, with locals or with partner departments)

5 To get a DFAIT/GoC official to speak on an issue, lobby, get it on the screen in bilateral or multilateral fora

6 To get a visit, to hold an event aligned with policy priorities

7 Other change aimed at changing reporting priorities, or influencing policy direction

8 Other change aimed at process, logistic, HQ-mission transactions, ways of working/engaging

9 Issue not identified (classified, still in progress, respondent would be identifiable)

96 Other

97 DK

$98 \quad$ No response

$99 \quad$ Not asked 


\section{Moves}

Q10d Packaging (if selling; if moving oneself, this is cited as justification for moving forward)

$0 \quad$ N/A (never tried or series not asked)

1 Positioning: Alignment with current policy directions, statements, priorities

2 Positioning: Coherence with existing programs, policy, or other priorities

3 Positioning: Tools, mechanisms, processes already in place to do it

4 Positioning: Bottom line, resource savings or efficiency

5 Positioning: Other countries doing it

6 Positioning: Threat/ implication for Canada's image, reputation, security, economy

7 Packaged within strong evidence base

8 Packaged with clear objectives and/or path to get there

9 Packaged succinctly, two-pagers, briefs, etc.

10 Hard to know how to package/position it when removed from HQ

96 Other

98 No response, not mentioned

Q10e Involvement (both sellers and movers: include all involved, whether consultative or instrumental; copied or targeted; may overlap with homework phase; Dutton, 2001, p. 725)

$0 \quad$ N/A (never tried or series not asked)

$1 \quad$ My manager

2 HQ regular reporting line (unspecified, also code targets if specified:)

3 DG (if not manager, else code 1)

4 Director

5 Deputy Director

6 Desk

7 Other HQ (unspecified, also code targets if specified:)

8 ADM (copied or targeted)

9. DM (copied or targeted)

10 Functionals or other divisions (not line division; copied or targeted)

11 Mission (unspecified, also code targets, if specified:)

12 HOM of the embassy to whom my embassy reports (if not manager, else code 1)

13. HOM (if not manager, else code 1)

14 Staff who report to me

15 Other employees at mission (DFAIT, OGD or LES)

16. Colleagues (unspecified)

17 Network (people trusted and known, DFAIT or other, located anywhere)

18 OGDs in Ottawa (Centre, OGDs in Ottawa I work with)

19 Other DFAIT missions

20 Local contacts (host government, private sector contacts)

21 Outside experts

22 Nobody, went it alone

23 "Coalition" - - deliberate mention of building allies 
24. "Champion": Sought or found champion, shooting for highest level attention possible (if also mentions internal BS is key, code 89 as well)

25 Hard to know who to involve when removed from HQ

88 BLACK HOLE

89 Needed my HQ connect to drive this (Internal BS code, code here if mentioned Internal BS needed, whether BS helpful or not; if also champion, code 21)

96 Other

$98 \quad$ Not mentioned

Q10f Process (steps in advancing issue; include involvement targets from Q10e if homework implied)

$0 \quad$ N/A (never tried or series not asked)

1 Homework: Collecting and/or documenting evidence

2 Homework: Consulting with colleagues (unspecified)

3 Homework: Consulting at post

4 Homework: Consulting at $\mathrm{HQ}$

5 Homework: Consulting with network (specifies trusted network, wherever located)

6 Homework: Consulting with manager (only as homework; if driver, code 17)

7 Homework: Consulting with HOM (not manager, else code 6)

8 Homework: Consulting with local contacts (host govt, private sector)

9 Homework: Consulting with outside experts

10 Homework: Other consulting

11 Other homework

12 Used regular reporting channels

13 Used existing processes or mechanisms (e.g., worked within the system, was asked for input on this topic, a task force was struck, responded in a consultative process, etc.)

14 Waited for an opportunity (Piggybacked on a visit or event, insinuated it in others' agendas when asked to do them, HOM meetings, perpa meetings, waited for an official to come to post and raised the issue then)

15 Created the opportunity (Created products to highlight issue, started email campaign, brought HQ to post, went to HQ to do this, brought local experts to HQ- - some mention that respondent had power to orchestrate this)

16 Readying the receivers (peppering- - subtle repeated messaging to everyone possible over time, e.g., identifying stakeholders and having sessions with them in advance)

17 Used my manager to drive it (had manager deliver it, more than involvement/ consulting)

18 Used HOM to drive it (not my manager, else code 17)

89 Needed my HQ connect to drive this ((Internal BS code, code here if mentioned Internal BS needed, whether BS helpful or not; If high level champion, also code Q10e)

96 Other

$98 \quad$ No response or not mentioned

Q10g Timing

$0 \quad$ N/A Never tried or series not asked

1 Piggybacking (waiting for opportunity, someone coming from HQ, $\mathrm{I} / \mathrm{my}$ boss was going to HQ; if meeting specified, also code 2)

2 Piggybacking: HOM meeting/ PERPA meeting

3 Struck while issue was hot (media, new government, $\mathrm{HQ}$ attention on this now, etc.)

96 Other

$98 \quad$ No response or not mentioned 
Q10h Channel to HQ (code all channels activated by players, not just respondent)

$0 \quad$ N/A Never tried or series not asked

1 email (unspecified whose)

2 email (mine)

3 email (my manager's or HOM's, prepared message for him/her)

$4 \quad$ Phone (unspecified)

$5 \quad$ Phone (my calls, I phoned DG)

6 Phone (my manager's or HOM's calls, got my HOM to phone DG, etc.)

$7 \quad$ Face to face (unspecified)

8 Face to face (personal: I went to Ottawa, spoke to HQ visitor at post

9 Face to face (my manager/ HOM went or spoke to HQ visitor)

10 Face to face (specifies HOM or PERPA meeting)

11 Secure channel

12 HQ not involved, acted at mission level

96 Other

98 No response or not mentioned

Q10i Success?

$0 \quad$ N/A Never tried

$1 \quad \mathrm{Y}$

$2 \quad \mathrm{Y}$, success using only regular reporting lines and no other moves

$3 \cdot \mathrm{N}$

4 DK, still in progress

88 DK, BLACK HOLE

98 No response

99. Not asked

Q10j If yes, CSF? (Code even if in progress if partial evidence of success, e.g., moved up a level)

$0 \quad$ N/A Never tried, not successful

1 Alignment of planets (contemporaneous event calls attention to issue, media picked it up, high level attention at $\mathrm{HQ}$, someone at Centre asked same question, etc.)

2 Good packaging (quality, packaged with priorities, with objectives, etc.)

3 "Readiness" of organization for this (aligned with existing processes or mechanisms, tools already in place)

My readying the receivers (peppering)

Involvement: My network

Involvement: My high level HQ champion

Involvement: My mission boss

Involvement: My HOM (if not boss, else code 7)

Involvement: My coalition

Involvement of externals

My timing

My channel

Worked within the system, used existing mechanisms or piggybacked

Autonomy, I had the power to do this

Personal characteristics (my perseverance, track record)

89 My HQ contact (Internal BS code; if was also champion, also code 6)

96 Other

97 DK

98 No response 
$99 \quad$ Not asked

Q10k If no, do different? (Also code any theories in use in Q10m)

$0 \quad$ Never tried, was successful, hypothetical

1 Better readying of the receivers

$2 \quad$ Get a network

3 Get a champion

4. Involve my manager

4 Get involvement of externals

$5 \quad$ Get coalition

6 Better packaging/positioning (quality report, packaged with priorities)

$7 \quad$ Better timing

$8 \quad$ Different channel

$9 \quad$ Work within system, use existing processes

10 No, org not ready for this (not aligned with existing processes or mechanisms, tools not in place, problem systemic, endemic, or cultural)

11 No, matter of luck, alignment of planets

12 No, can't do this from post, did my best

13 Should have piggybacked it on visit/event, more success if can insert in visit

$88 \quad$ No, BLACK HOLE

89 Need your HQ contact (internal BS code)

96 Other

97 DK

$98 \quad$ No response

99 Not asked

Q101 Why never tried? (also code any theories in use in Q101)

$0 \quad$ N/A Has tried

1 New to post, new to DFAIT, no ideas yet, etc.

2 Lack of trust in $\mathrm{HQ}$ / mission boss to move the issue

3 You can't move ideas from post

88. BLACK HOLE

96 Other reason

$98 \quad$ No response

99 : Not asked

Q10m Theories in use (code also in Q24 where applicable)

1 If you can show other countries are doing it, DFAIT will consider it

2 You can't be seen to be going native

3 You can't be seen as too pushy, have to pay your dues

4. You have to have your manager's support

5 You have to have your HOM's support

6 Only senior people can move ideas

$7 \quad$ Only high priority posts can move ideas

8 You can't move ideas from post (policy set in Ottawa, need HQ champion, etc.)

$9 \quad$ Better to ask for forgiveness

10 Nobody's fault, too busy, just the way it is at HQ, DFAIT underresouced, etc.

96 Other theory in use

98 None mentioned

Q11 Most rewarding aspect? 
The diplomatic/boundary role: Pride in representing Canada

The diplomatic/ boundary role: Prestige associated with diplomatic work, local influence and power Making a contribution, knowing I have made a difference (to org, to policy)

Making a contribution, knowing I have made a difference (to locals, seeing concrete progress locally, incremental progress locally)

Execution: Making it happen, doing the doing, not just policy, but execution of policy Access in intelligence sense: Effectively engaging locals, quality contacts

Access in opportunity sense: You meet the most amazing people, doors open

Feeding back something worthwhile, delivering key information for HQ

Intellectual stimulation, learning

Autonomy, independence, running your own show

Career related

Family related

Effective mission management (developing local staff, putting together my team, etc)

Other

DK or none

No response or not mentioned

Not asked

\section{Challenging aspect?}

The diplomatic/boundary role: hard to be "on" all the time

Org expectation related: working in a vacuum, can't represent, deliver, if you don't know context, where HQ is at on things, or what they want you to do (also code 88 if mentioned)

Org expectation related: work overload, low turnaround time, process, process

Org expectation related: unclear, shifting, or conflicting priorities

Other org expectation related

Local expectation related: language

Local expectation related: cultural

Local expectation related: mapping/access (identifying contacts, making contacts, need HQ, visits, to forge linkages)

Local expectation related: cultivating/maintaining relationships, trust difficult to establish, need time, uncomfortable, hard to meet people

Other local expectation related

Influence related: Lack of feedback, not knowing if anyone is hearing your suggestions, or where your issue has gone

Other influence related

Foot in two camps, bringing together disparate views, seeing both sides, saying no when resources limited

Translation: Not knowing if you are making a difference, hard to set goals, hard to link your work to objectives, measurables at job level

Other translation related

Challenges associated with particular posting: Hardship, seeing disasters

Mission management issues (HR problems, LES problems, facility problems)

Family issues

Career issues

Isolation or lonely at the top

BLACK HOLE

Other (not codable as $5,10,12,15$ )

DK or none

No response or not mentioned 
$99 \quad$ Not asked

Q13 How DFAIT is supportive

1 Setting objectives (alignment suite, etc.), generally heading in right direction

2 Providing high-level context and information for interpretation (e.g., policy docs, statements, position papers, Q\&As)

3 Providing specific context and interpretation in tasking

4 Outreach, interaction, contact and substantive discussions with $\mathrm{HQ}$

5 Coming to post (DG and other HQ people)

6 Bringing us to Ottawa

7 HOM meetings, PERPA meetings, bringing peers together

8 Autonomy

$9 \quad$ Training language

10 Training culture

11 Training management-related

12 Family support/relocation support/home and office accommodation/logistics

13 Tech support

14 Career planning, development, and advancement paths

15 Nothing needed

96 Other

97 DK or does nothing

$98 \quad$ No response

$99 \quad$ Not asked

Q14 Anything else DFAIT could do to support?

$1 \quad$ Setting clearer objectives, clearer direction

$2 \quad$ Less process, tasking, impatient turnaround, bureaucracy

3 More interaction, contact, and substantive discussions with peers (HOM meetings, perpa meetings)

4 More outreach, interaction, contact and substantive discussions with HQ

5 Deliberate mechanisms for connecting HQ to post more regularly

6 Provide more context and interpretation high level (e.g., policy docs, statements, position papers)

$7 \quad$ Provide more specific context and interpretation in tasking

8 Come to post (DG and other HQ people)

9. Bring us to Ottawa

10 Language training

11 Culture training

12 More attention to family issues/relocation support/accommodation/logistics

13 More attention to career issues

14 Better tech support

15 Mission management support (budgeting, LES management issues)

$16 \quad$ Nothing needed

88 Fix the BLACK HOLE

96 Other

97 DK

$98 \quad$ No response

99 Not asked

Q15 How manager is supportive?

$0 \quad$ N/A no perceived manager 
Interpersonal support

2 Strategic support, context, interpretation, substantive discussions

3 Access/contact support: introduces me to people locally, debriefs me on her/ his interactions

$4 \quad$ Clear direction and objectives for my job.

$5 \quad$ Clear feedback

6 Can trust to advance my issues within mission or within HQ

7 Team approach/collegial/inclusive/consultative

8 Provides me with autonomy

9 Not supportive

88 BLACK HOLE

96 Other

97 DK

98 No response, declines

$99 \quad$ Not asked

Q16 Anything else manager could do to support?

Interpersonal support

2 Strategic support, context, interpretation, substantive discussions

3 More support in accessing and building local contacts

$4 \quad$ Clearer direction and objectives for my job

5 Clearer feedback/more frequent feedback/faster feedback (also code 88 if mentioned)

6 Advance my issues within mission or within $\mathrm{HQ}$

7 Take more of a team approach/collegial/inclusive/consultative

8 Give me more autonomy

9 Nothing he or she can really do about it, too busy, out of her/his range of influence, just the way things are

10 Nothing, he/she is pretty great

88 Fix the BLACK HOLE

96 Other

97 DK

98 No response, declines

99 Not asked

Q 17 The "code anywheres"

$1 \quad$ Language is critical

2. Reciprocity is critical: importance of personal relationships in the field, develop over time, have to have something to give them

$3 \quad$ HQ boundary spanner is critical to providing me with priorities/ context (Not specified)

$4 \quad$ My DG is critical

5 The desk is critical

6 HQ boundary spanner is critical to communicating my messaging, or driving issues at HQ (Not specified)

$7 \quad$ My DG is critical

8 The desk is critical

88 BLACK HOLE

98 None of these mentioned

Q 18 The divides

1 Cultural divide (general comment about culture (HQ “doesn't get it") or unspecified): Differences $\mathrm{b} / \mathrm{w}$ HQ and post in terms of work context, task environment, performance drivers, exigencies and pressures, political realities, pacing, and rewards

2 Work context differences, different task environments, different "reality base" (monkeys on desk) 
Faster pace at $\mathrm{HQ}$, unrealistic deadlines and expectations for what you can turn around in this culture Political drivers at HQ and post are different, HQ is "serving the masters"

Localitis/going native (HQ questions your objectivity when you are at post and/or you forget what it is like to be at HQ)

Just the reality: shifting priorities, limited resources, short-termism are fact of life at HQ

Other cultural related

Cultural factors not an issue, (HQ understands/ tries hard, slower pace at post is welcome)

Strategic divide (general comment on not knowing/agreeing with $\mathrm{HO}$ strategy or unspecified):

Differences $b / w$ HQ and post, or lack of understanding/consensus b/w HQ and post, in terms of respective goals, plans, priorities, strategic interests and intentions HQ tasking/demarches come without context: why do they want this?

HQ never closes the loop: what did they do with this?

Everything is a priority with $\mathrm{HQ}$, or I don't know what their priorities are

Little substantive/strategic discussion

Limitations of technology for communicating strategy or tasking (e.g., important information should be targeted, not hidden in intranet or broadcast messaging)

15 Other strategic related

16 Strategic divide not an issue, good communication, HQ well aware of our goals, we're aware of theirs, etc.

Relational divide (general or unspecified): Lack of knowledge or understanding $\mathrm{b} / \mathrm{w}$ HQ and post regarding which individuals and which social relationships are important to their issues and/or lack of knowledge of what's "really going on" behind the scenes

18 Don't know who to call for advice/guidance

19 Don't know who is working on what, who has decision power, who is influential, who to involve, send messages to, copy in communications

20 Other relational

Relational divide not an issue, clarity around who to involve, responsibility areas, "who's who" lists, etc.

Interpersonal divide (general or unspecified): Hard feelings or inability to achieve work objectives due to lean media and/or lack of face-to-face contact

Can't walk across hall to ask or clarify, can't see reaction to my suggestion, gauge interest Hard feelings, misunderstandings, misinterpretation due to leanness of media (wording of written messages, lack of response misinterpreted when really they are just busy, etc) Can't have interactive, substantive dialogue/ sensitive issues through email/ writing Don't interact enough, don't want to "bother HQ"

Other interpersonal Interpersonal factors not an issue, my HQ connect is fabulous, I know people at HQ, took time to meet them before I left, we see each other often, talk often, etc.

Temporal divide (general or unspecified): Communication, logistical, and performance challenges arising from HQ and post being temporally out of phase (must mention time)

Unreasonable deadlines $b / c$ their day is our night

One hour windows to connect by phone

Energy level differences due to being out of phase in the beginning and end of our respective days HQ operating in 9 to 5 Ottawa mentality (issues are on fire here while Ottawa sleeps, 24 hours can make a big difference in Canada's international image and/ or effectiveness) Failure to recognize differences in operating hours (holidays, closures, can't get HQ their answers because our contacts aren't working here) sleeps, HQ's response is in the in-box when we get to work, lots of overlap in HQ-post business 
hours at this post etc.

Technological divide (general or unspecified): Communication, logistical and performance challenges arising from inadequacies in technological infrastructure Lack the set-up for videoconferencing or other communication media email goes down here, phones go down, power outages, etc. Other infrastructure problems

41 Distance technology is a good thing or not an issue- - email and/or blackberry great, you can do anything you ever did, faster, better in emergencies, engage everyone in one keystroke, pick up the phone for "real time"

Divides not mentioned

Q 19 How do you translate org expectations to individual objectives

1 Formal strategic planning processes at mission/would like such a process

2 Reporting agreement does this, or should do it

3 Your PMP does this, or should do this

4 Your expert local knowledge guides your objectives

$5 \quad$ High level objectives from HQ (IPS, etc)

6 Informal discussions/consultative (LES, manager, colleagues)

$7 \quad$ Manager formally discusses/sets objectives (if PMP, also code 3)

8 Professional orientation and knowledge

9 HQ's demands always win, you sacrifice time with local contacts for time on HQ requests

10 Not very good at this, need help or more work on this

96 Other

99 Not asked and/or not mentioned 